Portland State University

PDXScholar

Summer 7-26-2016

\title{
Do Forest Commons Contribute to International Environmental Initiatives? A Socio-Ecological Analysis of Nepalese Forest Commons in view of REDD+
}

Harisharan Luintel

Portland State University

Follow this and additional works at: https://pdxscholar.library.pdx.edu/open_access_etds

Part of the Environmental Sciences Commons, and the Forest Management Commons Let us know how access to this document benefits you.

\section{Recommended Citation}

Luintel, Harisharan, "Do Forest Commons Contribute to International Environmental Initiatives? A SocioEcological Analysis of Nepalese Forest Commons in view of REDD+" (2016). Dissertations and Theses. Paper 3087.

https://doi.org/10.15760/etd.3082

This Dissertation is brought to you for free and open access. It has been accepted for inclusion in Dissertations and Theses by an authorized administrator of PDXScholar. Please contact us if we can make this document more accessible: pdxscholar@pdx.edu. 
Do Forest Commons Contribute to International Environmental Initiatives?

A Socio-Ecological Analysis of Nepalese Forest Commons in view of REDD+

by

Harisharan Luintel

A dissertation submitted in partial fulfillment of the requirements for the degree of

Doctor of Philosophy

in

Earth, Environment and Society

Dissertation Committee:

Robert M. Scheller, Chair

Randall A. Bluffstone

Jeremy Spoon

Max Nielsen-Pincus

Veronica Dujon

Portland State University

2016 
(C) 2016 Harisharan Luintel 


\begin{abstract}
Forests in developing countries have the potential to contribute to global efforts to mitigate climate change, promote biodiversity and support the livelihoods of rural, local people. Approximately one-fourth of such forests are under the control of local communities, which primarily manage forests for subsistence and to meet their livelihood needs. The trend of bottom-up community control is increasing through the adoption of decentralization reforms over the last 40 years. In contrast, the United Nations has introduced the top-down program, Reducing Emissions from Deforestation and Forest Degradation (REDD+) for the conservation and enhancement of forest carbon and the sustainable management of forest in developing countries. REDD+ incentivizes forestmanaging communities to sequester carbon and reduce emissions. REDD+ has created hope for managing forests to mitigate climate change and has created fear that the new initiative may not be effective and may not ensure continuing forest-managing community benefits. However, little research has been conducted to answer these concerns. By taking nationally representative data from Nepalese community-managed forests ("forest commons"), I bring insights into whether and how these forests can contribute to REDD+ initiatives, particularly as they relate to carbon sequestration, biodiversity, equity in benefit sharing and collective action.
\end{abstract}

My results indicated the highly variable carbon and biodiversity in the forest plots across the country, depicting the availability of space for additional growth in carbon storage and biodiversity conservation. My results also reflect the complex and varied relationships of carbon with different indices of biodiversity at the national level, across 
geographic and topographic regions, and in forests with varying canopy covers. Weak positive relationships between carbon sequestration and biodiversity conservation indicate the possibility of synergies between carbon-forestry and biodiversity conservation. I also found that the formal community forestry program (CFP) has clearly positive impacts on biodiversity conservation and household-level equity in benefit sharing and a negative impact on carbon sequestration at the national level. However, disaggregated results of impacts of CFP on biodiversity, carbon and equity across geography, topography, forest quality and social groups display mixed results i.e., either positive or negative or neutral. I also identified that different drivers of collective action have different (i.e., positive, neutral, and negative) associations with carbon sequestration, which either supports or challenges established knowledge. In aggregate, my research indicates the potential of contribution by forest commons, and specially the CFP, to global environmental initiatives such as REDD+. It suggests that targeted, dedicated policies and programs to increase carbon sequestration, biodiversity conservation and foster equity and collective actions are critical. In addition, my results also contribute to the growing literature on socio-ecological implications of forest commons that demonstrated the need of interdisciplinary research to understand humannature relationships in the changing context. 


\section{Dedication}

I dedicate my dissertation to the forest-managing communities of Nepal, who are working relentlessly to conserve forests. In particular, I would like to devote my work to those who lost their lives while fighting forest fires in the year 2016 that have raged over several thousands of hectares of forest across the country. Their continuous, active engagement in forest management has inspired me to contribute to the forestry sector both academically and professionally. My engagement with forest-managing communities since 1992 has helped me refine my vision, mission, power, spirit and endurance continuously. 


\section{Acknowledgements}

Many individuals and institutions in the U.S.A. and in Nepal have supported me in completing this research. First and foremost, with deep appreciation and gratitude, I would like to recognize my supervisor, Dr. Robert Scheller, for his constant guidance, personal attention, encouragement, academic advice, and intellectual support during the last four years of my $\mathrm{PhD}$ program. I have been fortunate to have him as my supervisor, as he always gave priority to my work, responded to my queries, and provided prompt feedback and input into my research. I also appreciate his support in giving me an opportunity to be a member of Dynamic Ecosystems and Landscapes Lab, providing me office space and other support during my $\mathrm{PhD}$ journey. His moral and financial support toward presenting papers/posters at conferences was very helpful, allowing me to share my research ideas with a broad range of professionals and gain broader perspectives. I also appreciate his time, effort, and resources in visiting some of my research sites in Nepal and for providing on-site feedback to me.

Equally, I would like to express my sincere thanks to Prof. Randal Bluffstone, one of my committee members, for providing me space to be involved in the research led by him. Without his support, it would have not been possible for me to join the $\mathrm{PhD}$ program at the Portland State University (PSU). His constant guidance, encouragement and academic input helped me develop confidence, put in concentrated effort, and operationalize the research. His advice in conceptualizing my research questions and organizing my dissertation was very helpful. He always encouraged me to extend my professional network, which was crucial in accomplishing my $\mathrm{PhD}$. In addition, he also provided a 
feeling of home away from home for my family and me by organizing several family gatherings, including dinners, short trips and hikes around Portland. Being an international student, such informal gatherings and interactions helped a lot in my transition to the U.S.A. culturally and academically. I would like to thank his family as well for all the support they extended to my family and me during the course of my $\mathrm{PhD}$ at Portland.

Special thanks go to my dissertation committee members Dr. Jeremy Spoon, Dr. Max Nielsen-Pincus, and Prof. Veronica Dujon for their academic guidance, encouragement, and crucial input through the research process. Their ideas, suggestions and feedback have been absolutely invaluable in refining my research ideas, proposal and dissertation. In addition, their support in connecting me with other graduate students through informal networking, academic lab meetings, and family-friendly gatherings in their houses were vital for me to expand my professional network and share my research with other graduate students, faculty and professionals.

I am also indebted to Prof. Yangdong Pan, Prof. Kuan-Pin Lin and Dr. Rajan Lamichhane for their timely suggestions in figuring out the statistical methodology during my data analysis. Thanks is also due to the School of the Environment at PSU for giving me an institutional house to complete my academic degree requirements.

I would like to thank my lab colleagues at the Dynamic Ecosystems and Landscapes Lab, who gave me valuable feedback and insights at different stages of my research. I am very happy to be associated with such an active, talented and experienced colleagues with whom I learned many academic and cultural practices, which generally cannot be gained 
through formal academic processes. I especially acknowledge the contribution of Brooke Cassell, one of my labmates, for her support in copy-editing my dissertation.

I appreciate the role of ForestAction Nepal for encouraging me to join the $\mathrm{PhD}$ program at PSU. I also acknowledge ForestAction Nepal's role in conducting field work. Without ForestAction Nepal's hard work in data collection, this research would have not been possible. Particularly, I would like to express my gratitude to my colleagues at ForestAction including the entire project team. It is not possible to name them all, but I would especially like to thank: Dr. Naya Sharma Paudel, Dr. Hemant Ojha, Prakash Jha, Rajesh Bista, Laxman Ghimire, Dr. Krishna Paudel, Dr. Birendra Karna, Dr. Netra Timsina, Rahul Karki, Amrit Adhikari, Prabin Bhusal, Bikash Adhikari, Govind Paudel, Kamal Bhandari, Dil Khatri, Madan Basyal, Manita Chaudhary, Sanjeeb Bajracharya, Jailab Rai, Lalit Thapa, Laxmi Thapa and others for their support. Special thanks are due to members of forest-managing communities for their valuable time and effort in taking part in the research.

I would like to thank the World Bank for providing financial support for my research. In addition, I would like to thank Dr. Michael Toman at the Bank for his continuous support and professional input particularly at the beginning of the project. Interactions with him during the project inception workshop and field visit in Nepal were helpful in designing my research including data collection, and meeting in Portland was particularly encouraging in bringing the research outcomes to the public. I would also like to thank the Institute of Sustainability and the Edward D. and Olive C. Bushby scholarship, PSU, for providing financial resources for me to visit my research sites in Nepal with my 
supervisor and two other $\mathrm{PhD}$ students. The visit enormously helped me to augment my research through informal sharing of my preliminary findings with different forestry stakeholders including forest-managing communities. I am also grateful to the PSU Department of Environmental Science and Management for giving me an opportunity to work as a Teaching Assistant, which helped me to sustain financially and gave me an opportunity to learn and gain experience as a teacher and mentor.

Finally, I would like to express my gratitude to my family and friends who encouraged and supported me through my PhD process. Their continuous support and encouragement have been instrumental to arriving at this point of life. In particular, I would like to thank my wife, Gyanu, for her constant moral and psychological support. Her love, understanding and support provided me the energy and motivation to attain my study. Special thanks are due to my daughter Adhi for being such a loving, patient and cooperative child. She helped sustain my motivation to research particularly during the difficult times. Last but not least, I thank my parents, and my brother Bibek for their moral support and encouragement. 


\section{Table of Contents}

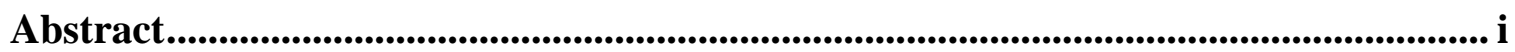

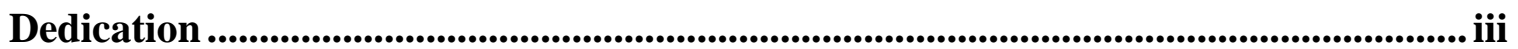

Acknowledgements ..................................................................................................................... iv

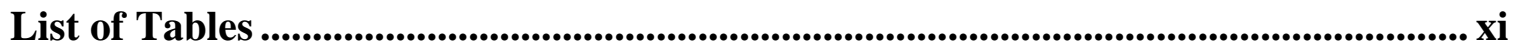

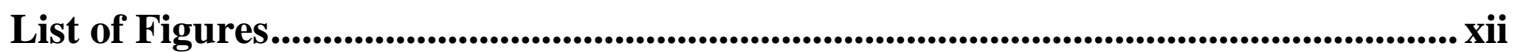

List of Abbreviations ...................................................................................................... xiii

Chapter 1: Introduction and Background.............................................................................. 1

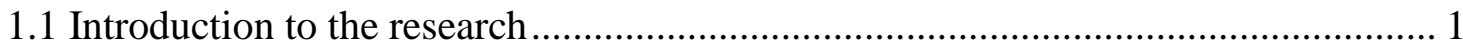

1.2 Climate change negotiation and issues.............................................................. 7

1.3 Climate change mitigation strategy and forest management ................................... 11

1.4 REDD+ features, opportunities and issues..................................................... 15

1.5 Forest commons features, outcomes and issues .................................................... 21

1.6 Forest commons and REDD+ in Nepal ......................................................... 26

1.7 Research approach and objectives.................................................................... 30

Chapter 2: Biodiversity and Carbon in the Nepalese Forest Commons: Implications for Global Environmental Initiatives ......................................................................... 34

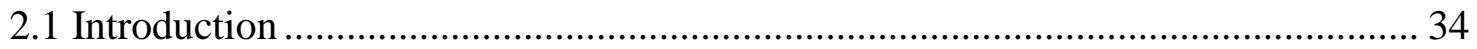

2.2 Research site, design and analytical model ......................................................... 37

2.2.1 Data sources and sampling methods ........................................................... 37

2.2.2 Description and preparation of data variables ................................................ 42

2.2.3 Specification of analytical models.................................................................. 45

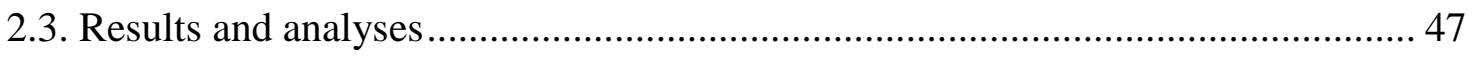

2.3.1 Current status of carbon and biodiversity ....................................................... 47

2.3.2 Relationships between biodiversity and carbon ………................................ 50

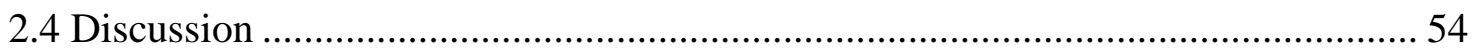

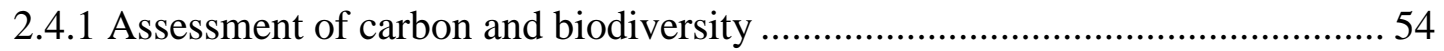

2.4.2 Relationships between carbon and biodiversity ............................................... 56 
2.4.3 Relevance of findings in global environmental initiatives and future research 57

2.5 Conclusion 59

Chapter 3: An Assessment of Causal Effects of Nepal's Community Forestry Program on Biodiversity Conservation and Carbon Storage.................................... 62

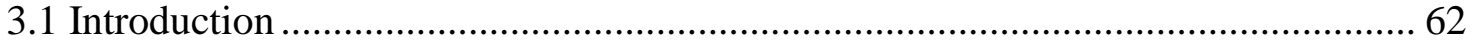

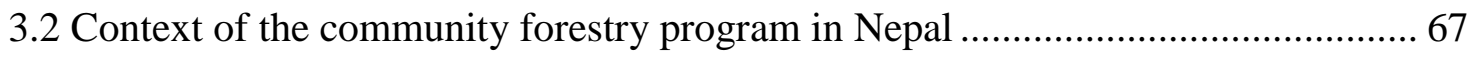

3.3 Research site, design and analytical model .................................................... 70

3.3.1 Sampling methods and research sites ................................................... 70

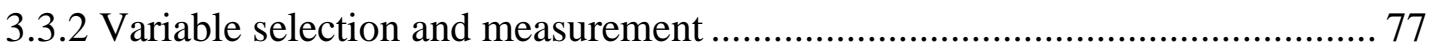

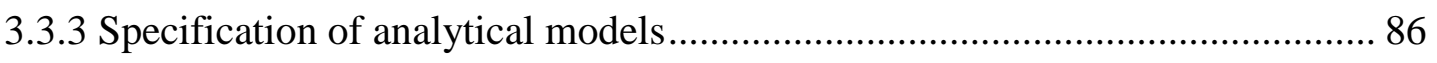

3.4 Effect of Community Forestry Program........................................................ 91

3.4.1 Effect of community forestry program in biodiversity conservation .............. 91

3.4.2 Effect of community forestry policy intervention in carbon .......................... 93

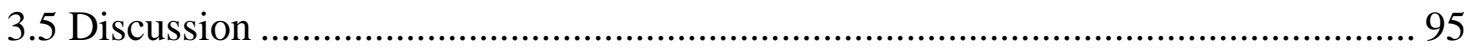

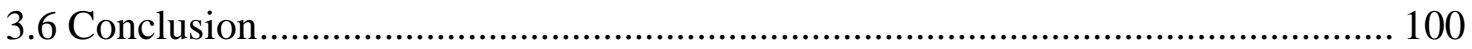

Chapter 4: An Assessment of Causal Effects of the Nepalese Community Forestry

Program on Equity in Benefit Sharing ................................................................................... 102

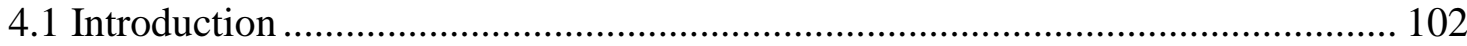

4.2 Research methods: site, design and analytical model .................................... 107

4.2.1 Sampling methods, sample sites and data collection .................................. 107

4.2.2 Variable selection and measurement ......................................................... 109

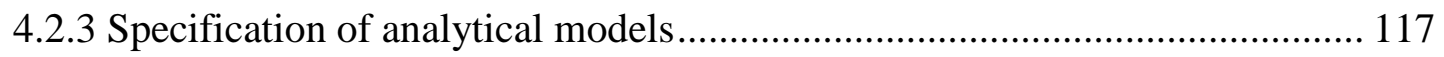

4.3 Effect of the Community Forestry Program on equity in benefit sharing ............ 122

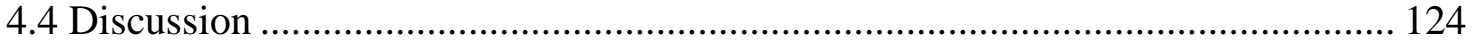

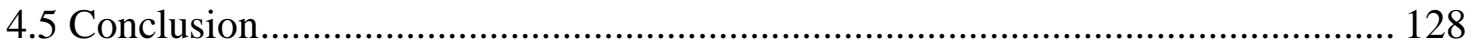

Chapter 5: An assessment of collective action drivers of carbon storage in Nepalese

forest commons.............................................................................................................. 130

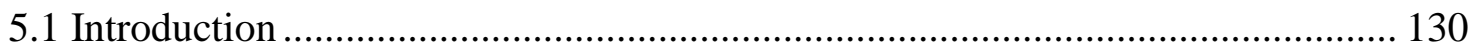

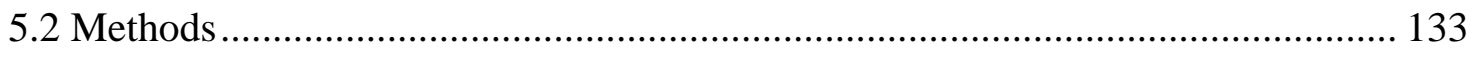

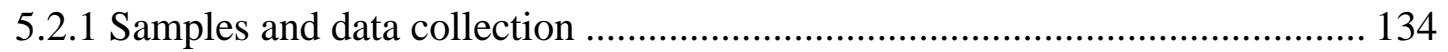


5.2.2 Analytical framework: variables, hypotheses and model specifications 139

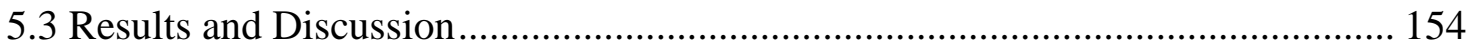

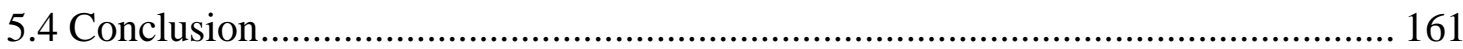

Chapter 6: A synthesis of the research .......................................................... 163

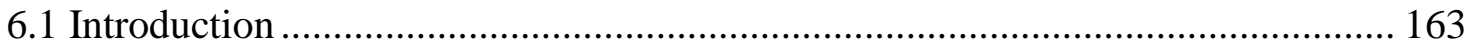

6.2 Contextualizing the research ................................................................... 164

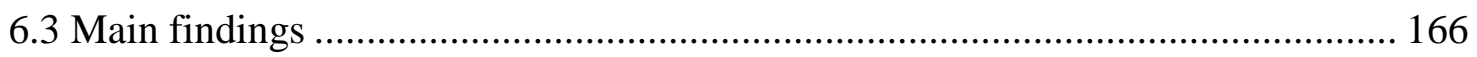

6.3.1 Relationships between carbon sequestration and biodiversity conservation.. 167

6.3.2 Effectiveness of formal forest decentralization on carbon sequestration and

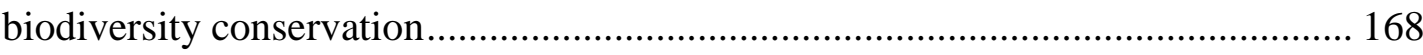

6.3.3 Effectiveness of formal forest decentralization on equity in benefit sharing 169

6.3.4 Examination of policy and institutional drivers of carbon sequestration ....... 170

6.4 Relevance, contributions and implications of findings ................................ 171

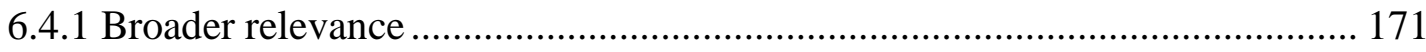

6.4.2 Theoretical and methodological contributions .......................................... 172

6.4.3 Policy and management implications .................................................... 174

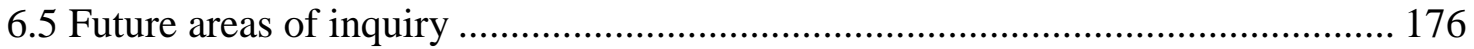

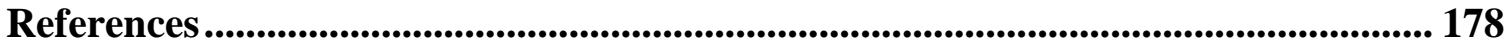

Appendix A. Covariate wise before and after matching standardized difference of

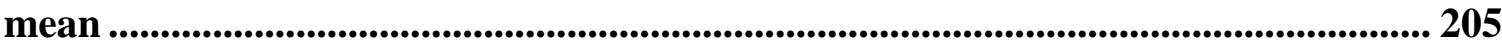

Appendix B. Covariate wise before and after matching standardized difference of

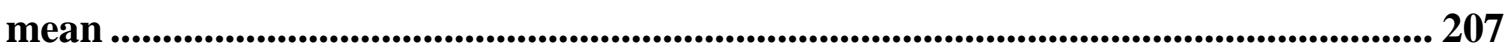

Appendix C. Exploratory regression of independent variables.................................. 208 


\section{List of Tables}

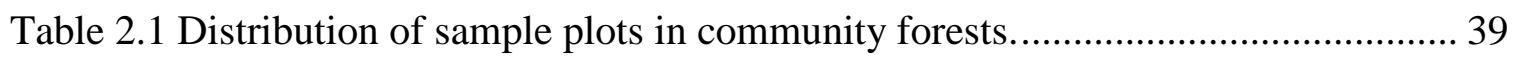

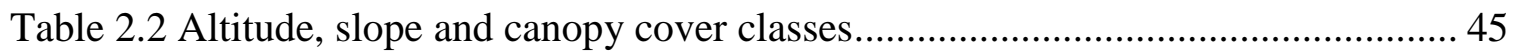

Table 2.3. The status of forest, tree, disturbance, management, AGTSC and species

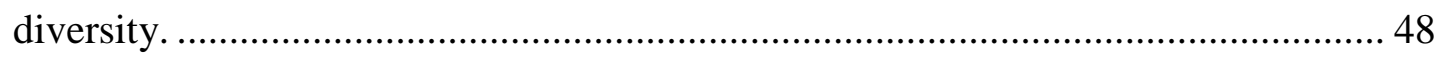

Table 2.4 Contribution of AGTSC in different forests by species. ............................... 50

Table 2.5 Correlations among different biodiversity indices..................................... 51

Table 2.6 Correlations of AGTSC with different biodiversity indices.......................... 52

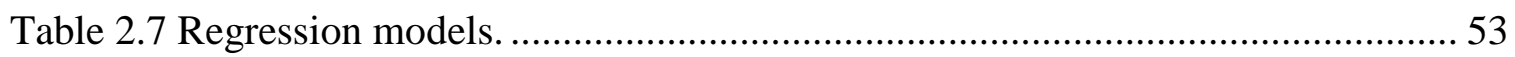

Table 3.1 Distribution of sample plots in community forests....................................... 72

Table 3.2 The status of forest, tree, disturbance and management of sampled forests.... 75

Table 3.3 Observed confounders and their relationships with CFP assignment.............. 82

Table 3.4 Average effect of CFP on $\mathrm{e}^{\mathrm{H}}$ and sensitivity analysis by forest category........ 92

Table 3.5 Average effect of CFP on AGTSC and sensitivity analysis by forest category.

Table 4.1 The description of indicators used to create the equity index and their measurement units.

Table 4.2 Eigenvalues of the reduced correlation matrix, factor pattern and weight factor.

Table 4.3 The descriptive statistics of equity index and the variables used to construct index.

Table 4.4 Observed confounders and their relationships with CFP assignment. 116

Table 4.5 Average effect of the CFP on equity at household level and the results of sensitivity analysis by social group and geographic region. 


\section{List of Figures}

Figure 2.1 Distribution of sample plots ................................................................. 40

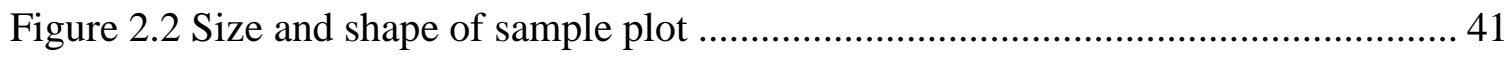

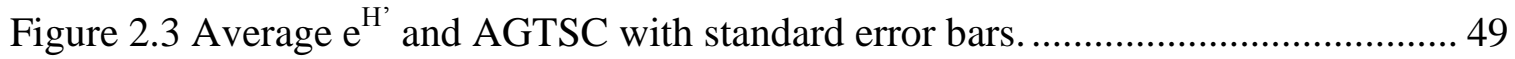

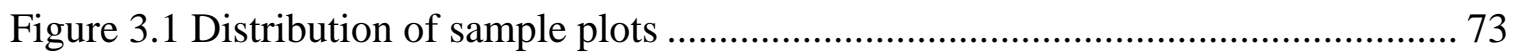

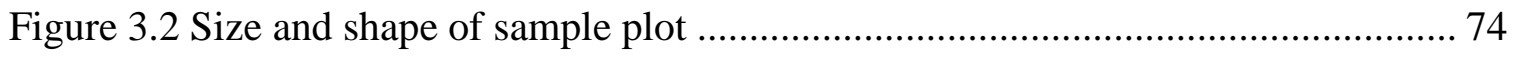

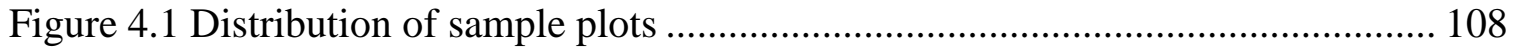

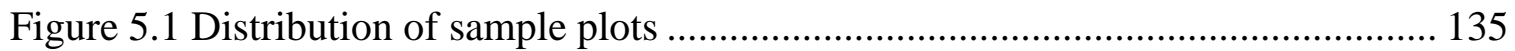

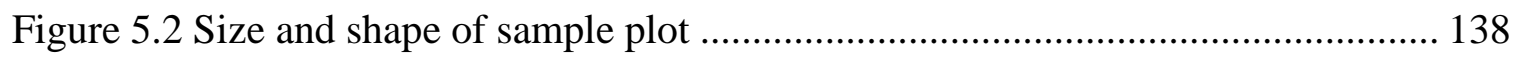




\section{List of Abbreviations}

AGB Above Ground Biomass

AGTSC Above Ground Tree and Sapling Carbon

AIC Akaike's Information Criterion

ATT Average Treatment Effect or Treated

$\mathrm{ATT}_{\mathrm{b}} \quad$ Average Effect of Community Forestry Program on Biodiversity

ATT $_{c} \quad$ Average Effect of Community Forestry Program on Carbon

$\mathrm{ATT}_{\mathrm{e}} \quad$ Average Effect of Community Forestry Program on Equity

C Carbon

CBD Convention of Biological Diversity

CF Community Forest

CFP Community Forestry Program

CFUG Community Forest User Group

CI Confidence Interval

$\mathrm{CO}_{2} \quad$ Carbon Dioxide

D \& D Deforestation and Forest Degradation

DBH Diameter at Breast Height

DFO District Forest Officer

DFO District Forest Office/Officer

DFRS Department of Forest Research and Survey

DoF Department of Forest

$\mathrm{e}^{\mathrm{H}^{\prime}} \quad$ Effective Number of Species

E $\quad$ Shannon Equitability Index

FAO Food and Agriculture Organization

FCPF Forest Carbon Partnership Facility

FPIC Free, Prior and Informed Consent

GHG Green House Gases

GPS Geographic Positioning System

H' Shannon Wienner Index 
IPCC Intergovernmental Penal on Climate Change

MoFSC Ministry of Forests and Soil Conservation

MoLJ Ministry of Law and Justice

MRV Measurement, Reporting and Verification

NCF Non Community Forest

NDVI Normalized Difference Vegetation Index

PCA Principal Component Analysis

PSU Portland State University

REDD Reducing Emissions from Deforestation and Forest Degradation in Developing Countries

REDD+ Reducing Emissions from Deforestation and Forest Degradation, Conservation and Enhancement of Forest Carbon and Sustainable Management of Forest in Developing Countries

REDD-IC Reducing Emissions from Deforestation and Forest Degradation Implementation Center

RPP Readiness Preparation Proposal

RRI Rights and Resources Initiatives

S Species Richness

SCBD Secretariat of Convention of Biological Diversity

SMD Standardized Mean Difference

UNFCCC United Nations Framework Convention on Climate Change

UN-REDD United Nations - Reducing Emissions from Deforestation and Forest Degradation 


\section{Chapter 1: Introduction and Background}

\subsection{Introduction to the research}

Climate change is one of the contemporary, pressing and serious threats to socio-cultural and economic wellbeing of people and environmental security of the earth. This is interlinked with another global challenge: biodiversity loss (Millennium Ecosystem Assessment, 2005). To address such environmental challenges and part of socioeconomic issues, the global community has put in place agreements such as the United Nations Framework Convention on Climate Change (UNFCCC) and the Convention on Biological Diversity (CBD). These initiatives clearly recognize the importance of tropical forests, a major terrestrial carbon sink and biodiversity hotspot, to sequester and store carbon and conserve biodiversity (Clark et al., 2001; Mittermeier et al., 2004; Pan et al. 2011; Parmentier et al. 2007; Philips et al. 1998).

Over a billion local forest users (those living within or in close proximity to forests) control approximately $15.5 \%$ of global forests, and the trend of community control is increasing as a result of decentralization reforms, particularly in tropical, developing countries (Charnley \& Poe, 2007; Larson \& Soto, 2008; Rights and Resource Initiative, 2014; Sunderlin et al., 2008). Both the UNFCCC and the CBD recognize the communitycontrolled forest ("forest commons") as a vehicle for effective forest management. In forest commons, equity in benefit sharing constitutes an important part of motivation for forest-managing communities, so as to manage forest commons in such a way that lead to reduced social conflict and environmental degradation (e.g., Andersson \& Agrawal, 
2011; Boyce, 1994) and increased economic and ecological outcomes (McDermott, 2009). Equity becomes more important when the international forestry programs incentivize local forest-managing communities. For instance, equity is critical in the United Nations Program on Reducing Emissions from Deforestation and Forest Degradation, conservation and enhancement of forest carbon and sustainable management of forest in developing countries (REDD+), as it is implemented at the community level. REDD+ values "forest" as an economic commodity i.e., carbon (Arsel $\&$ Buscher, 2012; Mcafee, 2012). It affects historical and contemporary forms of forest resource distribution and appropriation (e.g. Fairhead et al., 2012). Researchers and policy makers have identified poor forest policies and communities' institutional practices as the most pressing cause of deforestation and forest degradation (D\&D) in tropical, developing countries (Corbera et al., 2010; Woodwell \& Ullsten, 2001; World Bank, 2004;). Beyene et al. (2013) reported that the institutional practices of forestmanaging communities are one of the most important determinants of carbon sequestration.

Scientists, policy makers and practitioners have identified forest-based mitigation as one of the effective options to limit climate change. However, there is an acute shortage of empirical, evidence-based knowledge that informs practical policies, management plans and incentive mechanisms at national and local scales. For instance, inadequate empirical knowledge of the relationship between carbon sequestration and biodiversity conservation in tropical forests (Midgley et al., 2010; Szwagrzyk \& Gazda, 2007; Talbot, 2010; Thompson et al., 2011) raises questions about the potential contribution of 
biodiversity conservation to carbon sequestration and vice versa, particularly in the REDD+ agreement processes (Miles \& Dickson, 2010; Secretariat of the Convention on Biological Diversity [SCBD], 2011). Accurate and precise knowledge of the relationship between carbon sequestration and biodiversity conservation improves understanding of the effects of forest management activities on carbon storage and ecosystem functioning (Woodall et al., 2011) and promotes biodiversity conservation and carbon storage simultaneously (Gardner et al., 2012; Midgley et al., 2010; Miles \& Dickson, 2010; Sharma et al., 2010; Strassburg et al., 2010).

Chhatre and Agrawal (2009) suggested that the mere implementation of forest commons does not guarantee both carbon sequestration and biodiversity conservation; rather there could be either synergy and/or tradeoffs in achieving these two outcomes. Gautam et al. (2002), Pandey (2015) and Thapa-Magar \& Shrestha (2015) have reported the possibilities of carbon sequestration in Nepalese community forestry, a form of formal and popular forest commons. Acharya (2004) demonstrated the loss of biodiversity and Shrestha et al. (2010) reported the possibilities of biodiversity gain or loss in in Nepalese community forestry. Such inconclusive knowledge prevents forestry actors from knowing the effectiveness of the forest commons in storing carbon and conserving biodiversity and thereby limiting the possibility of innovative, productive management of forests.

Scientists, policy makers and practitioners are not able to resolve the issue of equity in the forest decentralization and REDD+ development process, primarily due to inadequate knowledge (e.g., Adhikari, 2005; Agarwal, 2001; Iversen et al., 2006; Lamichhane \& Parajuli, 2014; Mahanthy et al., 2009; Thoms, 2008). Different factors affect equity such 
as wider societal processes (Hobley, 2007), economic and cultural power relations (Bist, 1991), power of decision-making and resource access (Persha \& Anderson, 2014), and economic growth and commercialization processes (Beck \& Nesmith, 2001). However, empirical knowledge about the implications of such factors in equity is highly contextual and not sufficient.

Studies have identified inconclusive and conflicting results about the implications of decentralization policies and institutions on local socio-ecological systems, including collective actions and carbon sequestration. One challenge is due to different disciplinary understandings ${ }^{1}$ of institutional practices (e.g., Durkheim, 1995; Mauss, 1969; Pareto, 1935; Trent et al., 2003) that implant confusion and contradiction among scientists, hindering their ability to make adequate theoretical and empirical advances. The debates regarding the potential contribution of decentralized forestry in REDD+ indicates the need for interdisciplinary research. Empirical studies with better and smarter socioecological data combined with robust analytical techniques are needed to conclusively evaluate linkages of policies and institutions of forest commons with biodiversity conservation and carbon sequestration (e.g. Beyene et al., 2013). For instance, panel socio-ecological data and the analysis that controls the effects of confounding variables or endogeneity would be helpful in this regard.

\footnotetext{
${ }^{1}$ Different academic disciplines interpret institutional analysis differently such as (i) economists refer to it as ways of thinking that have a direct impact on behaviors (Pareto, 1935); (ii) sociologists refer to it as the laws or the family evolve over time (Durkheim, 1995); (iii) anthropologists refer to it as the identification of hidden forms of power that institute behaviors and organizational procedures (Mauss, 1969); and (iv) public governance experts refer to it as implementing policies (Trent et al., 2003).
} 
My research adds critical knowledge on how forest commons function to yield ecological and socio-economic outcomes and contribute to climate change mitigation. I assessed the ecological, socio-economic and institutional dynamics of Nepalese forest commons that are critical to make REDD+ effective. I used survey and perceptions data of nationally representative random samples of 130 forest commons (both forest and communities) and 1300 households (10 in each community) in Nepal. Nepalese forest commons offer a unique learning ground to bring wide ranges of socio-economic and ecological issues into the analysis, as Nepal hosts a wide range of geographic locations, climatic patterns, forest types, socio-cultural practices, economic statuses, and policy and institutional provisions. Also, Nepal provides a long history of forest commons including approximately 40 years of formal decentralization efforts, where $>42 \%$ of the country's population is directly engaged in the management of forest commons (Department of Forest [DoF], 2015). I assessed the relationship between carbon sequestration and biodiversity conservation in forest commons. Identifying this relationship helps increase understanding of the potential synergy and/or tradeoff between REDD+ and CDB initiatives, and therefore provides guidance to policy makers and forest commons managers. I also examined the effectiveness of formal community forestry on carbon sequestration and biodiversity conservation by using a robust analytical method - a quasi-experimental, matching method. I specifically answered the following questions: Does community forestry increase plant species diversity and carbon storage in the community forests, and if so, to what extent? I identified the answers for such questions for the national level and across geographic regions and forest qualities. 
I also examined the impact of formal community forestry on equity in benefit sharing at the household level using a robust matching method. I identified such impacts for the overall national level and across social groups and geographic regions. In addition, I examined the relationships between collective action drivers and carbon sequestration. By using a multivariate regression analysis, I identified the key collective action drivers and examined their potential associations with carbon sequestration. Finally, I discussed the results in view of scientific understanding of ecological and socio-economic aspects of forest commons and their potential implications for policies and programs, and in particular, the REDD+ initiative.

The dissertation is organized in 6 Chapters as follows: Chapter One provides a broader context for the research, particularly in relation to climate change negotiation, role of forests in climate change mitigation, REDD+ initiatives, forest commons, Nepal as research site, and the research objectives. Chapter Two investigates the relationship between carbon sequestration and biodiversity conservation (paper 1). Chapter Three examines the effectiveness of formal community forestry programs on carbon sequestration and biodiversity conservation (paper 2). Chapter Four examines the effectiveness of formal community forestry programs on household level equity in benefit sharing (paper 3). Chapter Five explores and examines the collective action drivers in relation to their association with carbon sequestration (paper 4). Finally, Chapter Six outlines the overall synthesis of the research. 


\subsection{Climate change negotiation and issues}

Climate change has been one of the most complex, uncertain, pressing and serious contemporary threats to the socio-cultural and economic wellbeing of people and environmental security of the earth. A rapid and dramatic change in the world's climatic parameters, temperature and precipitation, has occurred since the industrial revolution. Recent decades have been the hottest throughout history, and precipitation has become more unpredictable. A range of human activities such as the use of fossil fuels, change in land use, increase in industrialization, and modernization in agriculture and livestock farming that emit greenhouse gases (GHGs) have caused increased global warming, resulting into unprecedented climate change (UNFCCC, 2007a).

The global community has promoted climate change negotiation as the top, mainstream political agenda at the international level, particularly through the United Nations Framework Convention on Climate Change (UNFCCC) process. The UNFCCC has recently agreed to the stabilization of the global atmospheric carbon dioxide $\left(\mathrm{CO}_{2}\right)$ level at 450 parts per million and limiting temperature increases, relative to the pre-industrial period, to below $2^{0} \mathrm{C}$ as guiding targets to reduce climate change risks, impacts and damages (Mein-shausen et al., 2009; Pachauri, 2007; UNFCCC, 2015). It has agreed on a range of major strategic and cross-national collaborative actions on mitigation, adaptation, financing, technology development and capacity building to combat climate change.

Reducing climate change risks through cross-national collaborations demands consideration of crucial social processes, in which different actors with often diverse and 
conflicting interests interact and coordinate at different levels (UNFCCC, 2007a). Actors' interests diverge and conflict partly due to the inequalities in carbon footprints and longterm differential impacts of climate change across countries. Divergent and conflicting interests result in challenges to framing climate change and to devising ways to address it. The debates about causes, consequences, timing, trajectory and remedies of climate change continue at different levels (Cammack, 2007). There are inadequate effective public discussions about climate change remedies (Giddens, 2008) and the outcomes of negotiations have rather slowly been trickling down to national and local levels. As yet there are no adequate substantive policy and action frameworks to offer a coherent and consistent path to cope with the long-term challenges of climate change. Climate change remains one of the most difficult issues to manage (Dessler \& Parson, 2006), despite [isolated] efforts of different actors (Cammack, 2007).

One of the major challenges in finding appropriate solutions to climate change is knowledge gaps in understanding the dynamic relationships among science, economy, society, culture and practices at global, national and local scales. To fill such knowledge gaps, actors such as scholars, policy makers, planners, technologists, financial experts, and development specialists have chosen science to be the important agenda setter for climate change negotiations. Consequently, climate sciences and global discourses have become key in rendering climate governable (Tanner \& Allouche, 2011; Webb, 2011) i.e., recognizing climate as a domain of problem and turning it into a coherent, technical and manageable object of governance that is amenable for regulation and interventions through technical expertise and management (Lovbrand \& Stripple, 2011). 
The roles of scientific expertise in climate change negotiations are being contested (Lovbrand, 2014). A distinct and independent international body, the Intergovernmental Panel on Climate Change (IPCC) emerged to contribute to climate negotiations through the UNFCCC processes. The IPCC consists of internationally accepted principles, norms and decision-making procedures and engages a large network of scientists, experts and governments for assessing, producing, synthesizing, evaluating and legitimizing expert knowledge on climate change (Biermann, 2002). However, some actors have raised concerns of legitimacy and credibility of the IPCC, particularly relating to developing countries' distrust in the cognitive and normative homogeneity of dominant epistemic communities, $^{2}$ (Lahsen, 2004) and have raised questions about whether the processes it follows are fair, inclusive and unpartisan (Mitchell et al., 2006). Considering the welldocumented disparity in the production of science among developed countries (Karlsson et al., 2007), IPCC has been criticized for feeding northern research agendas and norms into global decision-making while neglecting the environmental concerns of the developing countries (Jasanoff \& Martello, 2004). The preference of, and reliance on, scientific knowledge limits the role of indigenous knowledge (Hiraldo \& Tanner, 2011) within developing countries in the climate negotiation process. The experts' ability to deliver available information in a useful format has also been debated as the facts, theories, models and causal beliefs they share are questioned. The concerns related to legitimacy and credibility of the IPCC may create gaps leading to impractical policies

\footnotetext{
${ }^{2}$ Epistemic community is a network of knowledge-based experts with recognized expertise and competence in a particular domain and an authoritative claim to policy-relevant knowledge within that domain or issue-area.
} 
such as resource and technology transfer to developing countries without proper understanding of their resource base, governance, and socio-cultural values and practices. The dominant voices in the international climate negotiations and debates are coming from the industrialized countries, particularly those of scientists, international policymakers, intellectual elites and influential international [environmental] organizations. This is particularly true as international and domestic playing fields and players are not even (Kakonen et al., 2014). The lack of economic power and international political influence of developing countries significantly constrains their opportunities and capacities to contribute to shaping global climate governance (Dryzek \& Stevenson, 2011). Developing countries are not able to bring innovations to international deliberations due to their limited capacity and differences in socio-cultural values in relation to the more formal institutional culture of international negotiation processes. Rather, developing countries adopt donor-driven climate change policy narratives, draw on science-dominated expert knowledge to which they have limited access, and interpret climate change as an easily governable issue (Kakonen et al., 2014).

International environmental negotiations continue to be riddled with controversies regarding the fair distribution of costs, resources and responsibilities (Prost \& Camprubi, 2012). The efforts to address climate change could be a threat multiplier if less attention is given to the issue of discriminatory and exploitative power relations and social inequalities that exist at international, national and local scales. This is particularly true in 
the context of elite capture ${ }^{3}$ of resources, resource constraints, conflicts and poor governance that exacerbate existing inequalities and drive those with poor adaptive capacity into deeper conditions of vulnerability to shocks and stresses (Polack, 2008).

\subsection{Climate change mitigation strategy and forest management}

Climate change mitigation primarily identifies and adopts sustainable paths of emissions, which can be achieved through switching to low-carbon energy sources (e.g., renewable and nuclear energy) and expanding carbon sinks (e.g., forests and others) (UNFCCC, 2007b). A wide range of actions that reduce or prevent GHG emissions have been identified such as using new technologies and renewable energies, making older equipment more energy efficient, changing management practices or consumer behavior, conserving and managing forests, reducing waste and inefficiency, and adopting laborintensive activities (UNFCCC, 2007a). Some of these mitigation actions, including forest-based actions, possess the "public good"4 nature and demand collective actions for proper management (UNFCCC, 2007b). Reforms in regulatory, economic, and technological aspects and capacity building can facilitate collective action. Regulatory reform includes formation and enforcement of policies and institutions. Economic measures create incentives, and technological innovations offer more efficient and

\footnotetext{
${ }^{3}$ Elite capture is a situation when resources (e.g., economic, political, educational) transferred for the benefit of the larger population are usurped by a few individuals of superior status.

${ }^{4}$ A public good is non-excludable and non-rivalrous. They are subject to excessive use resulting in negative externalities. Such externalities are often closely related to the "free-rider" problem. Therefore, such goods may be under-produced, overused or degraded. However, they can be better managed by converting them into other types of goods such as club good, private good and/or common good by introducing proper policy, institution and/or incentive.
} 
effective means of production. Capacity building offers knowledge and skill in adopting climate-friendly actions.

Forests can be both carbon sinks and sources (Dixon et al., 1994) and therefore have implications for climate change mitigation. They reduce ambient $\mathrm{CO}_{2}$ levels by sequestering atmospheric carbon into biomass through photosynthesis. Forest management measures may sequester atmospheric carbon and improve forest ecosystem productivity. Forests also sequester soil organic carbon (Brown \& Pearce, 1994) through the process of biomass decomposition and therefore reduce emissions. An estimated total of 638 Gigaton of carbon is stored in global forests in 2005 (UNFCCC, 2011). About $80 \%$ of carbon is stored above ground (Kirschbaum, 1996; Saatchi et al., 2011), despite the effects of fragmentation, deforestation and forest degradation (D\&D) (Scheller \& Mladenoff, 2008). Old growth forests can continue to be a net sink of carbon (Luyssaert et al., 2008). Most forests have the potential to become old growth and store carbon (Harmon, 2001). Due to active management and recovery from past disturbances, temperate and boreal forests are net sinks of carbon (Dixon et al., 1994a).

Land-use change contributes $17.4 \%$ of global anthropogenic emissions, particularly $\mathrm{CO}_{2}$ - the most abundant GHG (IPCC, 2007). The emissions from land use change continue to escalate and its global dynamics and regulations are inadequately understood (Houghton et al., 1992). The dynamics of terrestrial carbon flux is influenced by several factors such as vegetation succession (Harmon, 2001), photosynthesis (Collatz et al., 1991), ecosystem respiration (Parton et al., 1993; Ryan, 1991), disturbances (Crutzen \& Andreae, 1990), erosion (Stallard, 1998), herbivory (McNaughton et al., 1989) and 
biomass removal (Houngton \& Hackler, 2000). Land use change usually results from a combination of proximate factors, underlying causes and other factors involving individuals, community groups, corporations, government agencies and development projects (Geist \& Lambin, 2002). Proximate causes include land-use change for agriculture, logging and infrastructure development that directly remove forest cover. Underlying causes include economic, policy, institutional, technological, cultural and demographic factors that influence land-use decisions (Trexler \& Haugen, 1995) but are beyond the control of deforestation agents. Other factors include environmental factors, biophysical drivers and social trigger events.

Almost all forest-based emissions are reported either from burning or from decomposition of above-ground biomass in tropical countries where $\mathrm{D} \& \mathrm{D}$ is prevalent. Much of the deforested area is converted into low carbon intensive new agriculture or pasture lands, which often replace degraded agricultural lands that may or may not be capable of supporting tree cover for carbon sequestration (Brown, 1993; Dale et al., 1993). Forest degradation that occurs through damage to residual trees and soil from poor logging practices, log poaching, fuelwood collection, overgrazing, and anthropogenic fire also results in a significant loss of biomass carbon (Brown et al., 1991; Food and Agriculture Organization [FAO], 1993; Flint \& Richards, 1994; Goldammer, 1990). Scientists and environmental organizations have put forward several arguments with empirical and/or logical supports either to include or to exclude forest in the climate change mitigation program. Including forest in a mitigation program can be advantageous from both environmental and socio-economic perspectives. Forests can significantly 
reduce emissions, remove $\mathrm{CO}_{2}$ from the atmosphere, improve soil quality and increase biodiversity (Batjes \& Sombroek, 1997). Several studies have indicated that D\&D is marginally profitable, therefore the forest-based mitigation program could be one of the cheapest options in climate policy (Kindermann et al., 2008; McKinsey \& Company, 2009; Stern, 2006). Forest management has the potential to reduce emissions quickly with policy and institutional reform as shown in the case of forest decentralization, and it may not require expensive and time-taking technological innovations (Angelsen \& Atmadja, 2008). Forests are equally important to achieve socio-economic co-benefits (e.g., McDowell, 2002; Sombroek et al., 1993), including conservation of ecosystem services and biodiversity, and reduction of poverty.

Future forest carbon cycling trends could be attributable to uncertain losses and regrowth associated with global climate and land-use change. Management of forests merits consideration in climate change mitigation strategies. If managed properly, forests have the potential to: (i) lessen carbon emissions by protecting and conserving the carbon pools in existing forests; (ii) create carbon sinks by expanding carbon storage capacities, increasing the area and/or carbon density of native forests, plantations and agroforests, and by increasing the total pool of wood products; and (iii) substitute fossil fuels with fuelwood from sustainably managed forests, short-lived wood products with long-lived wood products, and energy-expensive materials with wood (Dixon et al., 1991; Grainger, 1988; IPCC, 1992; Nilsson \& Schopfhauser, 1995; Trexler \& Haugen 1995; Winjum et al., 1992a, 1992b). 
Global efforts to stabilize the concentration of GHGs $<450 \mathrm{ppm}$ in the atmosphere could practically be impossible without including forests in mitigation strategies. Therefore, after long deliberations on potential pros and cons, the UNFCCC decided to include forest management in its climate change mitigation program. Consequently, the UNFCCC developed the REDD+ program. REDD+ placed forests squarely within climate change mitigation options and made forests governable in a new way by framing them as crucial carbon stocks. An increasing number of tropical countries now perceive REDD+ as a potential solution and source of funding to fight against the persistent problems of D\&D, biodiversity loss and poverty, and they are therefore engaged in REDD+.

\subsection{REDD+ features, opportunities and issues}

The UNFCCC developed the REDD+ program to incentivize the contributions of tropical, developing countries to reducing emissions from D\&D and conservation and enhancement of carbon through sustainable management of forests. The idea behind REDD+ is to encourage forest management by financing forestry activities to maintain existing, and/or generate additional, carbon stocks (Kanowski et al., 2011). It would involve billions of dollars, perhaps significantly greater than that currently available for biodiversity conservation, to improve forest management (Eliasch, 2008). Such finances are available to carry out different activities that reduce $\mathrm{D} \& \mathrm{D}$, conserve and enhance forest carbon, and manage forests sustainably.

Several globally-developed, sophisticated and science-based requirements and standards such as ensuring additionality, controlling leakages, maintaining permanence, and 
ensuring social and environmental safeguards are introduced to make REDD+ a successful program at national and local levels. The concept of additionality emphasizes crediting only real emission reductions caused due to the REDD+ program. Controlling leakage means trees saved within the REDD+ project area or country do not lead to more trees being harvested elsewhere. The idea of permanence demonstrates that any tree saved now and credited for carbon sequestration will not be felled for a specified number of years. Social safeguards are primarily introduced to respect national sovereignty of participating countries in governing and managing forest resources and to ensure the forest rights of, and distribute the payments equitably to, forest dependent poor, vulnerable, marginalized, and/or indigenous peoples. Environmental safeguards demand maintaining ecological integrity and conserving forest biodiversity in line with the Convention on Biological Diversity (CBD) and other national policies. Several transparent, scientific and reliable monitoring, reporting and verification (MRV) systems are visualized to help monitor the extent and level of REDD+ achievements by estimating accurate forest carbon stocks (Maniatis et al., 2011; Miles \& Dickson, 2010) and assessing the status of safeguards.

REDD+ is accepted as a cheaper, quicker, significant and win-win strategy to halt landuse changes, reduce D\&D and increase carbon sequestration (Angelsen \& Atmadja 2008; Toni 2011). It would include significantly larger forest area than the area currently receiving conservation efforts (Harvey et al., 2010). It has potential to deliver enormous benefits for carbon sequestration and biodiversity conservation through the protection of species-diverse forests (Gardner et al., 2012; Harvey et al., 2010). 
REDD+ is seen as a unique opportunity to foster collaboration between developed and developing countries to address global challenges such as climate change, biodiversity loss and poverty, simultaneously. It allows developed countries opportunity and flexibility to adopt emission offset options. It increases unconventional forestry investment in developing countries (Eliasch, 2008). Such investments may bring myriad opportunities to improve forest governance and bolster global conservation efforts (Wollenberg \& Springate-Baginski, 2010), promote low carbon paths to development, generate livelihoods, and fight against persistent problems of poverty. REDD+ may provide an opportunity for local communities to revisit existing policies, institutions and practices of forest commons, so as to make them more effective, efficient and equitable. It also provides developing countries an opportunity to contribute to climate change mitigation, which otherwise, particularly in the Kyoto protocol, was not visualized.

Social and environmental safeguards of REDD+ have generated considerable hope in the UNFCCC and CBD processes (CBD, 2011), and among conservation science communities (e.g. Busch et al., 2011; Harvey et al., 2010; Stickler et al., 2009; Strassburg et al., 2009). The UNFCCC considered three principles, including "do no harm" to natural forests, maintain long-term ecological integrity of forests, and secure net-positive impacts for biodiversity, in the environmental safeguards development process (CBD, 2010). "Do no harm" intends to reduce the risk of conversion of natural forests and the displacement (leakage) of D\&D to areas of lower carbon but high biodiversity value. Ecological integrity, by taking lessons from landscape ecology and the ecosystem approach (Gardner et al., 2009), aim to ensure the permanence of forest carbon stocks 
and functional significance of biodiversity (Diaz et al., 2009; Thompson et al., 2009). Positive biodiversity aims for achieving economies of scale and delivering additional benefits for biodiversity (Miles \& Kapos, 2008).

REDD+ may add to the tensions related to the climate finance (e.g. Gupta, 2009;

Stadelmann et al., 2010). Several design-related issues such as fitting REDD+ within the overall UNFCCC processes, developing financing approaches (e.g., voluntary market, compliance market or fund-based) and choosing crediting baselines for financing (e.g., input-based approach or performance-based approach) are still unresolved. Concerns may be raised that if forest-based offset becomes cheaper and fungible with clean technology, carbon markets may be distorted negatively affecting the development of clean technology. For example, Bosetti et al., (2011) showed that REDD+ may reduce investments in cleaner energy technologies over the next four decades by a maximum of $10 \%$.

Scholars have pointed out that REDD+ may undermine the overall value of the forest. For instance, REDD+ tends to overemphasize forests as "carbon sinks," and that can lead to adverse effects to existing multi-purpose forest management practices of communities (Caplow et al., 2011). It may overlook livelihood-related outcomes for local communities (Campbell 2009; Coomes et al., 2008; Putz \& Redford, 2009) and gradually alienate local people from resource access in the future (Phelps et al., 2010b). However, Karsenty \& Ongolo (2012) argued that concern about the marginalization of forest communities appears to be unjustified in many countries where the capacity of the state is limited by 
various crisis-linked situations (e.g., post-conflict, institutional instability and ethnic tensions).

Different scholars have explicitly indicated that REDD+ may not be beneficial or rather may be harmful in certain ways. The trade-offs between local livelihoods, biodiversity conservation and carbon sequestration caused by REDD+ are highly uncertain (Corbera \& Brown, 2010; Hiraldo \& Tanner, 2011). REDD+ is not going to necessarily help local community-managed forests (Ostrom, 2010). For instance, REDD+ has now created the notion of "global forests," moving local forests away from their local physical and cultural contexts and integrating them with global carbon markets and strong governance (Eliasch, 2008).

On the basis of knowledge drawn from historical forest management practices, particularly the creation of protected areas that alienate local people from resources (Cernea \& Schmidt-Soltau, 2006), different challenges and issues are brought into attention while developing the REDD+ program. Some of these issues are related to (i) defining and meeting requirements and standards of REDD+ at the local level; (ii) defining and ensuring ownership and tenure security of forestland, forest resources and carbon; (iii) enhancing capacity of the forestry actors; (iv) transforming and balancing de jure and de facto power relations of actors; (v) maximizing carbon sequestration while meeting immediate forest product needs; and (vi) maintaining equity and justice in benefit sharing. Reflecting from different REDD+ pilot projects, scholars have indicated issues related to the governance of forests. For instance, Peskett et al. (2011) and Thompson et al. (2011) indicated that REDD+ does not fully acknowledge the links 
among political, economic, technical, ecological, and social issues in governing tropical forests. Rather, it would destabilize forest governance (Bluffstone et al., 2013) and exacerbate the persistent efforts of governments and corporations to exert increasing control over forests, leading to reverses in recent trends of forest devolution, thereby reducing community autonomy and wellbeing (Lovera, 2009; Phelps et al., 2010b). Khatri (2012) and Ratsimbazafy et al. (2011) indicated the possibility of subtle recentralization of forest governance power by the state forest authority and negative implication for forest-dependent poor from REDD+.

Taking the case of a REDD+ pilot project in Nepal, Paudel et al. (2011) and Upreti et al. (2011) showed that REDD+ may either reinforce existing conflicts or induce new ones in the management of forest commons. They also reported concerns related to implementing REDD+ standards and monitoring carbon sequestration and emissions from the forest commons. Particularly, the emergence of new functions and agencies in carbon monitoring may affect motivation, commitment, action and power dynamics of communities in forest management. Compounding these issues with the social heterogeneity and discriminatory power relations among community members may result in inequity in benefit sharing. These dynamics affect the overall processes and outcomes on forest commons and REDD+ in the long run.

REDD+ involves contextualization, complexity and uncertainty that may lead to both tradeoffs and synergies in the outcomes. Major parts of complexities and uncertainty are contingent on several factors, including viewing the forest as different resources (e.g., carbon reservoir, natural resource and home for different species and/or people), 
designing REDD+ features, and formulating policies and institutions at local, national and international levels. Scholars have further identified a range of factors to make REDD+ a successful program. For instance, Luintel et al. (2013) identified that availability of capable human resources at national and grassroots levels is crucial; Cotula and Mayers (2009) highlighted that effective governance, clear property rights and secure tenure of forests are pre-requisites; and Agrawal et al. (2011) recommended the collaborative efforts and use of lessons from past forestry, agriculture, biodiversity and development policies. In addition, robust forest and emission databases, proper policy framework and institutional set up, and co-benefits are crucial factors for the success of REDD+. Allowing flexibility in designing REDD+ projects at different levels (e.g., national, project and nested levels) is crucial for effective, efficient and equitable outcomes. Effectiveness demonstrates the level of emissions reductions against the plan. Efficiency shows the cost of emission reductions. Equity highlights whether benefits and costs are distributed fairly among forest managing communities.

\subsection{Forest commons features, outcomes and issues}

Ostrom (1990) reviewed age-old customary practices and local institutions, and theoretically and empirically demonstrated the great potential of local communities to manage forest commons sustainably. Over a billion people are using approximately $18 \%$ of forests globally (Chhatre \& Agrawal, 2009; Dietz \& Henry, 2008; White \& Martin 2002), among which approximately $15.5 \%$ are under the control of communities (Rights and Resources Initiatives [RRI], 2014; Sunderlin et al., 2008). Community-controlled forests ("forest commons") have a wide range of crucial features that make them unique 
and successful in achieving developmental goals, at least at the local level. They represent forests that are held in common and owned collectively or by the state or a legal entity but not privately. They are physically accessible to all members of a community and therefore likely to be under the most pressure from land use change. Ranges of legal and customary forest commons with locally acceptable access, use and management practices are present worldwide. Such forest commons are variously named community forestry, collaborative forest management, joint forest management, leasehold forestry, participatory forestry, buffer zone forestry, social forestry, and village forestry. Despite the difference in name, they primarily embrace the basic idea of engaging local communities in the management of forest resources, albeit different forms and degrees. These models of forest commons translate into the practice based on either legal or customary rules.

Forest commons primarily builds on traditional ecological knowledge (TEK) and bottomup planning approach. As TEK is derived from socially different groups of people based on age, sex, caste, ethnicity, education, regions of settlement and occupation (Spoon, 2011), forest commons may benefit from wide range of knowledge held in common. Environmental problems, such as tragedy of commons, may not be avoided through conventional approaches such as by state/external control or by market but could be addressed by developing local common property institutions in certain conditions (Ostrom, 1990), indicating the importance of TEK in conservation. Even simple TEK about plant and animal include knowledge about their habitats and therefore provide clue to understand overall ecosystem and to address complex conservation problems (Lee, 
1993). TEK is helpful to increase the diversity of ecological and cultural capitals upon which local people can draw environmental resources for their livelihoods even in the time of unanticipated change (Berkes \& Folke 1994; Turner et al., 2003). It is extremely important in managing ecological systems while improving productivity through semidomestication, domestication, cultivation, controlled firing, mulch preparation and reforestation (Posey, 2008 [1985]). It has also been important for understanding ecological hazards, reducing disaster risk, mitigating vulnerability (Lauer, 2012).

The objective of forest commons management is to supply tangible products and functional services needed for consumptive and non-consumptive uses at the local scale. The local communities are the primary stakeholders for the management and use of forest commons. They are better suited to, and therefore do, develop the forest management plan and locally-suitable criteria, indicators and standards for assessing ecological and socio-economic impacts of forest management. They use national forest management and biodiversity conservation frameworks as references to design and execute forest management plans and monitor activities at the local scale. They possess rights to govern, manage and use forest resources and to access management services as and when needed. The role of government forestry institutions is primarily confined to policy formulation, technical support, capacity building, and monitoring. The communities enjoy all or part of benefits derived from forests on the basis of legal and/or customary arrangements. Resource and cost sharing mechanisms and processes are normally prepared considering several factors such as legal provisions, community needs, resource condition and availability, and historical practices. 
The formal decentralization of forest commons is becoming a more popular, dominant strategy for conservation of biodiversity, reduction of $D \& D$, enhancement of local livelihoods and democratization of the forestry sector in developing countries (Brown et al., 2002; Johannes, 2002; Mansuri \& Rao, 2004; Nurse \& Malla, 2006). The trend of forest decentralization is increasing (RRI, 2014; Sunderlin et al., 2008). Governments transfer forest rights to forest-managing communities through decentralization policy reforms in tropical, developing countries (Charnley \& Poe, 2007; Larson \& Soto, 2008; Schlager \& Ostrom, 1992). Forest rights can be differentiated into access, withdrawal, management, exclusion and alienation rights (Schlager \& Ostrom, 1992). Often these rights are defined nationally and locally considering the forest conditions, national forest management priorities and community needs. The formal forest commons are associated with democratization of resource access, poverty alleviation, and forest resource sustainability (Pulhin, 2000). They also attract funding support from international nongovernmental organizations (FAO, 1993; Sharma \& Rowe, 1992).

Forest commons have been instrumental to gaining multiple outcomes from forests (Chazdon, 2008; Nepstad et al., 2006; Ranganathan et al., 2008). They provide key forest products to well over a billion people (Chhatre \& Agrawal, 2009; Dietz \& Henry, 2008) and livelihood benefits to more than half a billion poor people in the world (Eliasch, 2008; World Bank, 2004). They offer the best prospect for environmental sustainability, particularly through revitalization of degraded forest ecosystems, sustainable management of forest resources, poverty reduction, inclusion of poor and marginalized people, promotion of community development and institutional strengthening in rural 
areas (Chapagain \& Banjade, 2009; Gautam et al., 2002; Kanel, 2004; Luintel et al., 2009; Luintel, 2006; Mahat, 2009; Pokharel et al., 2007; Yadav et al., 2003). They spread over large areas and offer opportunities to support carbon sequestration and biodiversity conservation beyond the remotely located conventional conservation areas. They provide space to improve the relationships between different groups of people in the community. For instance, local communities organized in community forestry in Nepal have been able to transform the hegemonic, discriminatory and unjust forest-based social relations to some extent (Luintel et al., 2009; Pokharel et al., 2007). Such communities have been largely practicing good forest governance (Pokharel et al., 2007).

Forest commons conserve, manage and sequester carbon by slowing D\&D, increasing forest area and/or carbon density, promoting plantations and agroforestry, and increasing the transfer of biomass carbon into products (e.g., long-lived wood products and biofuels that can be used instead of fossil-fuel). Their governance frameworks, time-tested institutional practices, and abilities of forest management could be effective institutional vehicles for REDD+ implementation that sequesters carbon and achieves co-benefits at the local level. Through the management of forest commons, local communities could be mobilized effectively in creating awareness in adopting energy efficient technology and expanding tree-plantations in agricultural land so as to reduce emissions and sequester carbon. Such communities could devise locally suitable, practical methods to support forest-dependent poor with required resources (e.g., Pokharel et al., 2006).

Different issues exist in the management of forest commons. For instance, Nepalese community forests are managed passively (Yadav et al., 2003). Inequity, gender 
discrimination and elite capture of resources and decision-making processes are prevalent in forest-managing communities (Agarwal, 2001; Banjade et al., 2004; Luintel \& Timsina 2007; Luintel 2006; Malla et al., 2003; Persha \& Anderson, 2014). Conflicts between different actors are increased due to ambiguity in forest property rights. The forest property rights in Nepal are shaped by discriminatory, exploitative and unjust historical social relations of power (Luintel \& Chhetri, 2008). Bribery has been a driving factor for forest product trade (Paudel et al., 2006). The weak enterprising capacity of forestmanaging communities compounded with inadequate policy, financial and technical supports limits better utilization of economic opportunities derived from forest commons (Kunwar et al., 2009). Forest-managing communities may reduce biological diversity by favoring and/or clearing particular species (Huettner, 2012). These issues may hinder the environmental sustainability and social harmony in the long run.

Primary objectives of forest commons and REDD+ may not be matched perfectly. They may either conflict and/or complement each other. Therefore, the REDD+ outcomes in forest commons may imply trade-offs and/or synergies depending on the resource, policy and institutional contexts (Chhatre \& Agrawal, 2009). There are not adequate studies to understand such potential synergy and tradeoff between both initiatives.

\subsection{Forest commons and REDD+ in Nepal}

Nepal covers a total of 147,148 square kilometers and is broadly divided into three geographic regions: the high Himalaya (16\%) to the north, the middle hills (68\%) and the plain land, Terai, (17\%) to the south. The altitudinal range varies from $73-4848 \mathrm{~m}$ from the mean sea level, providing an opportunity for diverse geo-climatic zones from tropical 
to alpine regions. Legally, 40.36\% (5.96 million hectares) of land is categorized as forest in Nepal (Department of Forest Research and Survey [DFRS], 2015). While Nepal occupies $0.1 \%$ of the Earth's land, it harbors $>3 \%$ and $>1 \%$ of the world's known flora and fauna, respectively (Ministry of Forest and Soil Conservation [MoFSC], 2014). It hosts about 118 ecosystems and 35 forest types (Stainton, 1972). More than two-thirds of the population live in the rural areas and have subsistence agricultural economies where forest constitutes an integral part of their livelihoods. Approximately $77 \%$ of energy in the country is supplied as fuelwood majority of which come from the forest and contribute to one of the major sources of emissions in Nepal (Water and Energy Commission Secretariat, 2010).

Nepal has a long history of customary and formal forest commons management. It was an early leader in initiating formal community forestry, an innovative program involving local communities in forest management (Agrawal \& Ostrom, 2001). The Nepalese government started experimenting with community forestry from the mid-1970s and fully developed and implemented a concrete program in the early 1990s. The Nepalese government and international environmental organizations started providing support to local communities for the protection and management of forests. Now, community forestry has been one of the most prioritized, popular and extensive forestry programs to revitalize the degraded forests in the hills and fulfill the demand of subsistence forest products in the rural areas. The hill region of the country was prioritized for community forestry due to communities' dependence on, and willingness to protect, forests; existence of traditional management practices; inability of government forestry staff to 
protect and manage forests; deteriorating forest conditions; little value for commercial use and public revenues; and financial and technical support of international development communities (Gilmour \& Fisher, 1991; World Bank, 2001). Nepalese community forestry have been contributing to the environmental sustainability, particularly through revitalization of degraded forest ecosystems, sustainable management of forest resources, poverty reduction, inclusion of poor and marginalized people, promotion of community development and institutional strengthening in rural areas (e.g., Chapagain \& Banjade, 2009; Gautam et al., 2002; Kanel, 2004; Luintel et al., 2009; Luintel, 2006; Mahat, 2009; Pokharel et al., 2007; Yadav et al., 2003).

Community forestry directly engages $\sim 12$ million people ( $42 \%$ of the population) in the management and consumptive uses of $>1.8$ million hectares ( 1/3) of forest (Department of Forest [DoF], 2015). In addition, many communities are traditionally, informally engaged in the management of forests. The community forestry policy legally recognized local forest-managing communities by forming and registering the community forest user groups (CFUG). The CFUG is an autonomous and self-organizing public body having perpetual succession for forest management that can acquire, possess, transfer or manage property (Ministry of Law and Justice [MoLJ] 1995, 1993). The communities managing forests are formally or legally entitled to own, access, manage, use and sell (including setting pricing) all the resources of community forests (except wildlife and minerals) as per the self-prepared and DFO-approved forest management plan. Such legal, institutional arrangements made community forestry an indispensable strategy for any international environmental initiatives managing local forests such as REDD+. The 
diversities in terms of characteristics of forests and communities have created opportunities to carry out varieties of research related to environmental and socioeconomic outcomes of forest commons management.

The Nepalese government is a party to the UNFCCC and has been officially taking part in REDD+ readiness activities to capacitate itself to implement forest carbon projects. It prepared a Readiness Preparation Proposal (RPP), a roadmap for developing and implementing regulatory and programmatic strategies for REDD+ in a participatory way involving governmental and non-governmental organizations, civil society, communities and donors (MoFSC, 2010b). The Nepalese government has now been developing REDD+-sensitive forest policies, programs, institutions, databases, and capacity. The new forest sector strategy 2015 has made provisions for payment of ecosystem services and paved the way for REDD+ projects. The Ministry of Forest and Soil Conservation (MoFSC) has created a "REDD Implementation Centre (REDD-IC)" to organize REDD+ initiatives in the country. The REDD IC is taking the lead in formulating REDD+ strategy including clarifying carbon ownership, strengthening institutional mechanisms, creating mechanisms for efficient MRV of carbon sequestration and safeguard systems, equitable benefit sharing and practical safeguards. Recently, the MoFSC decided to carry out a REDD+ pilot project in the western and central Terai of the country.

Different organizations such as civil societies, national and international nongovernmental organizations, donors and development partners have been supporting the REDD+ initiative in Nepal. For instance, the World Bank's Forest Carbon Partnership Facility (FCPF) is supporting the country's overall REDD+ readiness. The United 
Nations-REDD (UN-REDD) is providing capacity-building support in policy development. The government of Finland has been assisting in the Forest Resource Assessment. The governments of Finland, Norway, Switzerland, the United Kingdom, and the United States of America have been assisting in a range of forestry development projects and REDD+ initiatives. Local development partners and national civil societies are closely working with international environmental organizations to create awareness and build capacity of forest-managing communities. Luintel et al. (2013) demonstrated the need and possibility of partnership and collaboration between actors to build capacity for REDD+ at the local level so that the forest-managing communities are able to manage the forest to increase carbon storage and co-benefits.

A range of challenges have appeared to meeting REDD+ standards in Nepal. Such challenges include the lack of adequate and dedicated policy framework, limited competency of stakeholders, inadequate attention to the local ecological conditions and communities' socio-economic requirements in the planning process, and lack of provision for local people's free, prior and informed consent (FPIC). Also, national forestry professionals voice the concern that REDD+ incentives may perhaps be too weak to address the drivers of D\&D. The drivers of D\&D in Nepal, particularly in the plainland Terai region, are historical, cultural and socio-political in nature and therefore complex to address (Paudel et al., 2014).

\subsection{Research approach and objectives}

I took an interdisciplinary and cross-scale approach to accomplish my research. This interdisciplinary approach helps better elucidate the linkages between local ecological 
and socio-economic systems (Berkes \& Folke, 1998). Understanding socio-ecological linkages are crucial to help manage forest resources, particularly in the context of a changing climate. I used contemporary, cross-scale information and their linkages to accomplish this research. Specifically, I took data from the forest commons, forestmanaging communities and households, and discussed the findings in relation to national policies and programs that are often guided by international environmental initiatives. Such an approach helps bring local perspectives into national and global climate change policy initiatives and vice versa.

My research is located on the fundamental premise of human-forest interactions in the context of emerging global environmental challenges. The central focus of my research is to examine the conditions of forest commons and communities' practices, so as to develop a better understanding of how they are likely to respond to REDD+ in Nepal. My aim is to examine how local ecological conditions and communities' institutional practices affect outcomes of forest commons management in view of REDD+. More specifically, I addressed the following four objectives.

Objective \# 1: Examine the relationship between carbon sequestration and biodiversity conservation in forest commons

To achieve objective \# 1, I assessed forest carbon stocks, biodiversity and their relationships. Such assessments are important to understand the current forest conditions and the possible future-forest scenario in relation to carbon and biodiversity. I used standard allometric equations to estimate carbon and biodiversity. I applied statistical tools, correlations and regressions, to estimate the strength and 
direction of relationships and the unbiased coefficients, respectively. I carried out such assessments at the national level and across management regimes, geographic regions, topographic regions and forest qualities, so as to gain disaggregated and comparative pictures. I critically discussed the empirical results in relation to theoretical expectations, other studies, and potential implications in policy and management in view of REDD+.

Objective \# 2: Examine the effectiveness of formal community forestry on carbon sequestration and biodiversity conservation

To achieve objective \# 2, I examined the effects of formal community forestry on carbon sequestration and biodiversity conservation. I used a robust analytical quasiexperimental method i.e., the matching method to estimate the effect of community forestry against non-community forestry. I carried out analyses at the national level and across geographic regions, topographic regions and forest qualities. I critically discussed the empirical results in relation to theoretical expectations, other studies, and potential implications in policy and management in view of REDD+.

Objective \# 3: Examine the effectiveness of formal community forestry on equity in benefit sharing at the household level.

To achieve objective \# 3, I used a robust matching method to estimate the effect of community forestry on equity against that of non-community forestry. I carried out analyses at the national level and across geographic regions and social groups. I critically discussed the empirical results in relation to theoretical expectations, other studies, and potential implications for policy and management in view of REDD+. 
Objective \# 4: Examine the relationships between collective action drivers and carbon sequestration.

To achieve objective \#4, I examined relationships between collective action drivers and carbon sequestration. I examined such relationships by identifying key collective actions drivers and using a multivariate regression analysis to estimate their contribution to carbon sequestration. Finally, I discuss the results of the study in the context of scientific contributions and implications for the REDD+ initiative.

Achieving these objectives helps understand critical dimensions of linkage between forest commons and REDD+. While carbon constitutes the core interest of REDD+ program, biodiversity is the major, unavoidable co-benefit. Similarly, equity constitutes one of the critical components of incentive structure, which is the key of REDD+ mechanism. The impacts of formal community forestry program on biodiversity, carbon and equity provide crucial knowledge on what modality of forest commons are effective and therefore should be promoted. The understanding of collective action drivers in relation to carbon storage would signal the areas for specific attention in view of REDD+ in view of REDD+. 


\section{Chapter 2: Biodiversity and Carbon in the Nepalese Forest Commons: Implications for Global Environmental Initiatives}

\subsection{Introduction}

Climate change and biodiversity loss are two interlinked, contemporary environmental crises of global magnitude, each posing serious risks to human wellbeing and ecosystem function (Metz et al., 2007; Millennium Ecosystem Assessment, 2005). To address climate change and biodiversity loss, the global community has put in place agreements such as the United Nations Framework Convention on Climate Change (UNFCCC) and the Convention on Biological Diversity (CBD). These initiatives recognize the importance of forests, particularly as they contribute to carbon storage and biodiversity conservation, as ecosystem services. They highlight the importance of forest management and forest health monitoring at the national scale. They also prioritize the management of tropical forests, which are both major terrestrial carbon sinks and biodiversity hotspots (Clark et al., 2001; Mittermeier et al., 2004; Pan et al., 2011; Parmentier et al., 2007; Philips et al., 1998).

Balvanera et al. (2006), Hooper et al. (2005) and Tilman (2001) reported the positive correlation between biodiversity and ecosystem performance, including carbon sequestration. Greater biodiversity provides more functional variations of biotic communities, buffers against environmental fluctuations, and fosters the stabilization of ecosystem processes (Schlapfer et al., 1999; Schwartz et al., 2000). Biodiversity also provides insurance against the loss or poor performance of some species (Folke et al., 1996). Biodiversity generally includes species with higher growth rates and adaptive 
capacity to withstand diverse environmental conditions (Fridley, 2001) and accumulates higher carbon (Caspersen \& Pacala, 2001). The relationships between biodiversity and carbon depend on the nature of ecological processes in the particular ecosystem. For instance, complementarity in utilizing different resources such as through niche partitioning and facilitation may allow different species to increase overall productivity in less stressful habitats, while dominant species may competitively exclude other species in more productive habitats (Loreau \& Hector, 2001; Paquette \& Messier, 2011; Warren et al., 2009). Such relationships vary across time and space due to spatial heterogeneity and disturbance regimes (Cardinale et al., 2000).

There is inadequate empirical knowledge regarding the relationships between biodiversity and carbon, particularly in tropical forests (Midgley et al., 2010; Szwagrzyk \& Gazda, 2007; Talbot, 2010; Thompson et al., 2011). Such gap of empirical knowledge hinders environmental scientists' ability to inform policy makers regarding the potential contributions of biodiversity conservation to carbon sequestration and vice versa. Such hindrance has appeared in the international environmental agreement processes such as the United Nations program on Reducing Emissions from Deforestation and Forest Degradation, conservation and enhancement of forest carbon and sustainable management of forests in developing countries (REDD+). For example, the Secretariat of the Convention on Biological Diversity [SCBD] (2011) and Miles and Dickson (2010) raised concerns that REDD+ would displace deforestation of diverse forests and convert natural forests into less diverse plantations, respectively. 
Assessment of the relationships between biodiversity and carbon supports efforts to better understand the effects of various forest management activities on carbon storage and ecosystem functioning (Woodall et al., 2011). Accurate and precise knowledge of the relationships between biodiversity and carbon in different forest types at national and regional scales is a prerequisite to promoting biodiversity conservation and carbon storage simultaneously (Gardner et al., 2012; Midgley et al., 2010; Miles \& Dickson, 2010; Sharma et al., 2010; Strassburg et al., 2010).

I assessed biodiversity and carbon relationships using data from 620 nationally representative random sample plots in Nepalese forest commons (e.g., both formally decentralized community forest $(\mathrm{CF})$ and open access forests protected by the government but used by the local communities (NCF)). Nepal harbors over three percent and one percent of the world's known flora and fauna, respectively, despite a $0.1 \%$ share of the Earth's land (Ministry of Forest and Soil Conservation [MoFSC], 2014). High biodiversity is attributed to its location at the crossroads of the Indo-Malayan and Palearctic biogeographic regions and the wide range of geographic and climatic diversities (Stainton, 1972). It is topographically divided into three regions: the high altitude Himalaya (16\%), the middle hills (68\%) and the lowland plains referred to as Terai (17\%). Approximately 23 million people depend on 5.8 million ha of forest for ecosystem services such as forest products and watershed services. More than 12 million people are directly engaged in the management and consumptive uses of forests, which poses challenges and creates opportunities for biodiversity conservation and carbon storage. 
I estimated the tree and shrub biodiversity (hereafter called biodiversity) and Above Ground Tree and Sapling Carbon (AGTSC) for forests overall and across altitudes, slopes and canopy covers. I also identified species in which most of the AGTSC are concentrated. Further, I clarified how and under what circumstances biodiversity can serve as a useful indicator for AGTSC. I tested three hypotheses: (i) Plot-level biodiversity and AGTSC were strongly, positively correlated at national scales and across altitudes, slopes and canopy covers; (ii) Plot-level biodiversity and AGTSC were more strongly correlated in highly productive forests (i.e., lower altitudes, lower slopes and closed canopies) than less productive forests (i.e., higher altitudes, higher slopes and open canopies). Finally, I discussed the study results in relation to emerging global environmental policy, particularly carbon forestry (i.e., REDD+.)

\subsection{Research site, design and analytical model}

The data presented are part of an ongoing multi-disciplinary research project funded by the World Bank and jointly implemented by Portland State University and ForestAction Nepal (Bluffstone et al., 2015). The primary aim of the project was to assess the potential synergies and/or tradeoffs between Nepalese forest commons and REDD+.

\subsubsection{Data sources and sampling methods}

ForestAction researchers and I jointly conducted a pilot survey in 2012 to estimate the required number of sample plots. We selected 45 sample plots from nine community forests $(\mathrm{CFs})$ across physiographic regions to capture the most heterogeneity possible in plot basal area, a proxy of forest biomass. We deployed a field team to measure the diameter at breast height (DBH) of trees and saplings and estimated the basal area for 
each plot. Considering variance of basal area, we calculated the number of required sample plots for 10\% error and 95\% confidence level using the standard formula (2.1) (Saxena \& Singh, 1987).

$$
\begin{aligned}
& \mathrm{N}=\mathrm{C}_{\mathrm{v}}{ }^{2} \mathrm{t}^{2} / \mathrm{E}^{2} \ldots \ldots \ldots \ldots \ldots \ldots \ldots \ldots \ldots \ldots \ldots \ldots \\
& \text { Where } \mathrm{N}=\text { Required number of sample plots; } \\
& \mathrm{C}_{\mathrm{v}}=\text { Coefficient of variation, } \mathrm{s} / \mu \text { (s= standard deviation and } \mu=\text { sample mean); } \\
& \mathrm{E}=\text { Standard error, } \mathrm{s} / \sqrt{ } \mathrm{n} \text { ( } \mathrm{n}=\text { sample number); } \\
& \mathrm{t}=\text { Value of student- } \mathrm{t} \text { distribution for }(\mathrm{n}-1) \text { degrees of freedom and } 95 \% \\
& \text { confidence level }
\end{aligned}
$$

We estimated that a total of 325 plots were required for sampling in the CF. Sample plots were distributed in $65 \mathrm{CFs}$, which were selected from the random samples chosen for a national CF impact study conducted by the Nepalese government during 2010-2012. ForestAction recruited a team of 25 Nepalese field researchers with whom I closely worked to collect the data. Each of the field researchers had undergraduate degrees in forestry (12) and graduate degrees in social science (13), and ForestAction trained them to conduct forest surveys, forest inventories and household surveys.

As the size of CF varies, we allocated between 3-7 sample plots in each forest based on the quintile distribution of forest size. As forest size in the hills and Terai markedly differ, we considered different quintile ranges for the hills and Terai (Table 2.1). 
Table 2.1 Distribution of sample plots in community forests.

\begin{tabular}{|c|c|c|c|c|c|}
\hline \multirow{2}{*}{$\begin{array}{l}\text { Quintile } \\
\text { distribution }\end{array}$} & \multicolumn{2}{|c|}{ Forest size (ha) } & \multirow{2}{*}{$\begin{array}{l}\text { Sample } \\
\text { plots/forests }\end{array}$} & \multirow{2}{*}{$\begin{array}{l}\text { No. of } \\
\text { forests }\end{array}$} & \multirow{2}{*}{$\begin{array}{l}\text { No. of } \\
\text { plots }\end{array}$} \\
\hline & Hill & Terai & & & \\
\hline $1^{\text {st }}$ quintile & $<18$ & $<113$ & 3 & 13 & 39 \\
\hline $2^{\text {nd }}$ quintile & $18-64$ & $113-154$ & 4 & 13 & 52 \\
\hline $3^{\text {rd }}$ quintile & $64-91$ & $154-335$ & 5 & 13 & 65 \\
\hline $4^{\text {th }}$ quintile & $91-183$ & $335-526$ & 6 & 13 & 78 \\
\hline $5^{\text {th }}$ quintile & $\geq 183$ & $\geq 526$ & 7 & 13 & 91 \\
\hline
\end{tabular}

The field team selected 65 non-CFs in such a way that they were as similar as the CFs in a variety of characteristics. Such plots were close but not next to CFs to avoid being used simultaneously by the same people. The field team carried out forest boundary surveys using Geographic Positioning System (GPS), prepared forest maps on graph paper and estimated forest area. The maps of CF that were in the forest operational plan were also copied on the graph paper so as to divide areas into smaller grid cells. To identify the sample plot, the cells were selected randomly, and X and Y coordinates of the center of selected cells were identified. The coordinates were then fed into a GPS unit to locate the plots in the forests. Due to differences in non-CF size, it was possible to allocate 295 plots following forest size criteria and standards given in Table 2.1. The distribution of sample plots is given in Figure 2.1. 


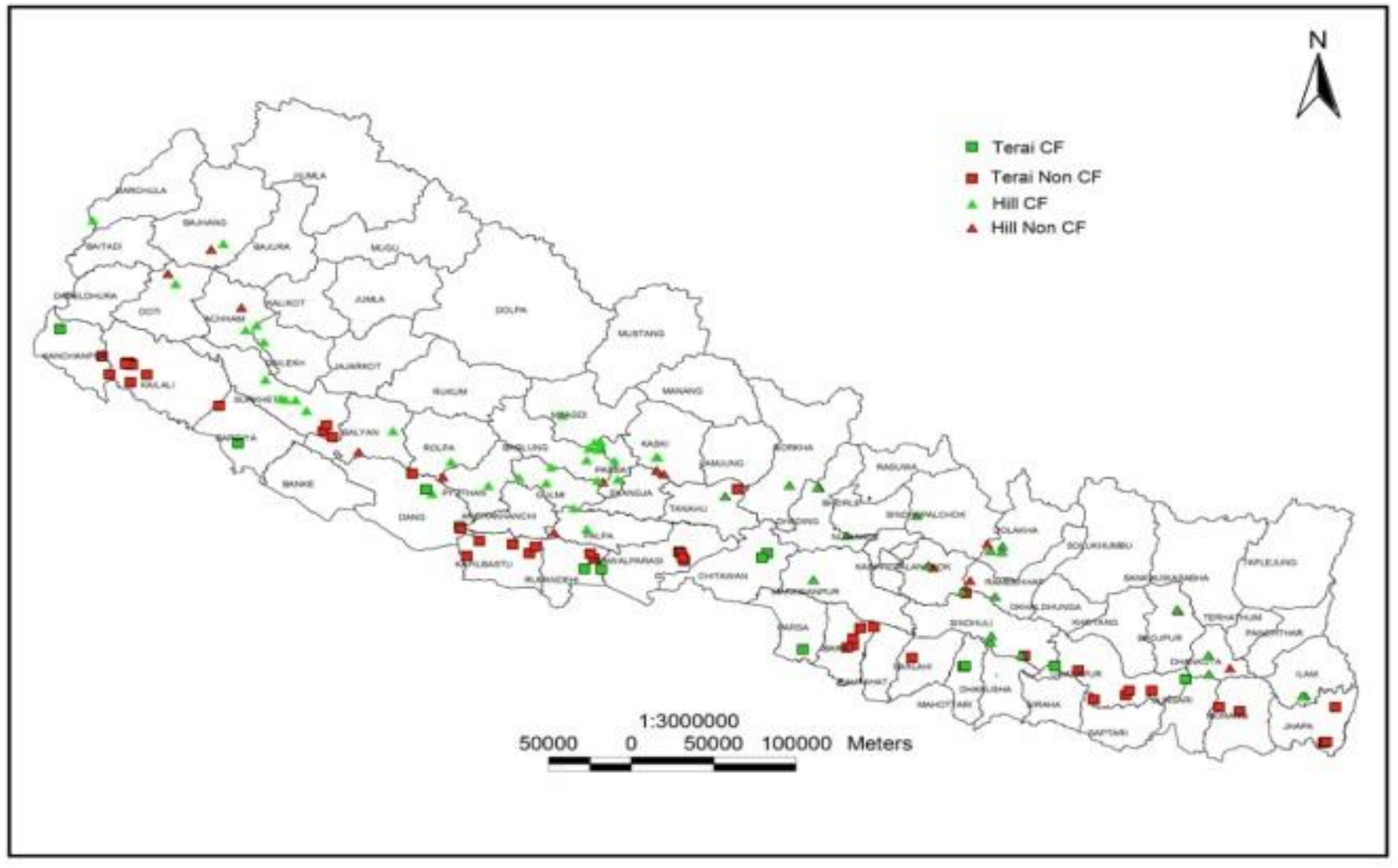

Figure 2.1 Distribution of sample plots 
A circular plot with a radius of $8.92 \mathrm{~m}$ was selected for collecting environmental data and measuring trees $(>5 \mathrm{~cm}$ diameter at breast height $[\mathrm{DBH}])$, which is suitable for moderate to dense vegetation and is widely used (MacDicken, 1997). Using the same center, second and third plots with radiuses of $5.64 \mathrm{~m}$ and $1 \mathrm{~m}$ were established to measure saplings (1-5cm DBH) and count seedlings (Figure 2.2).

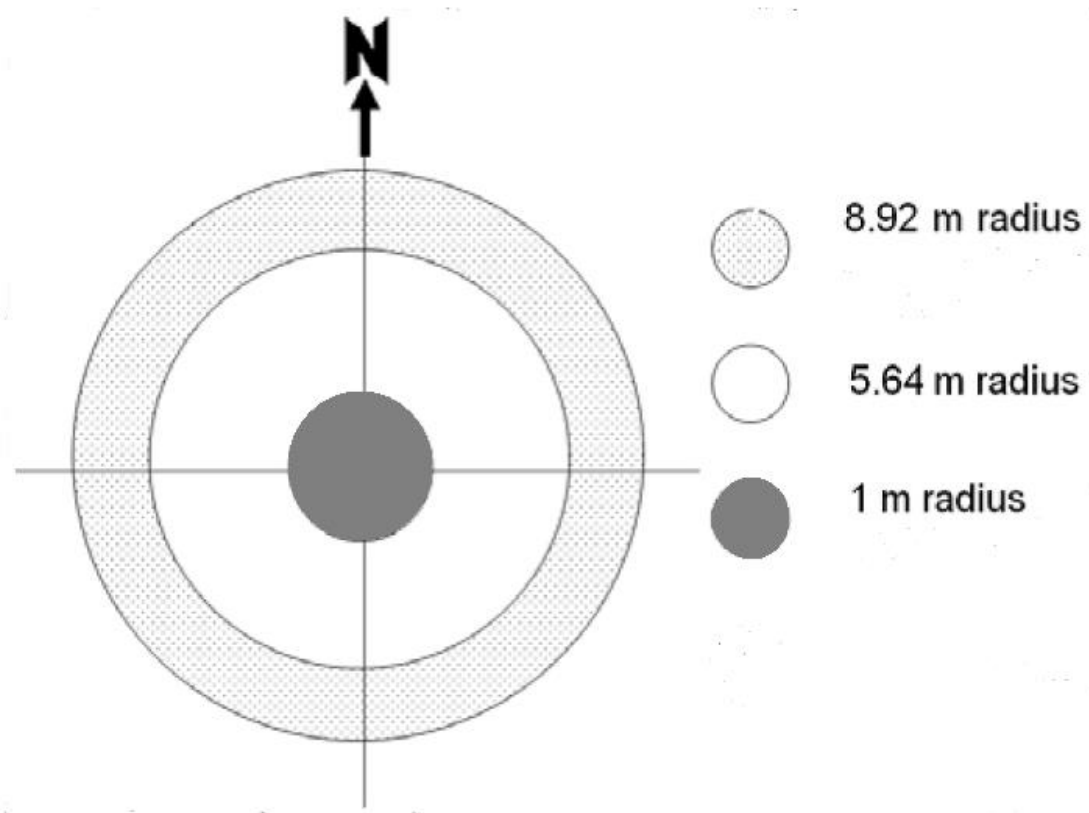

Figure 2.2 Size and shape of sample plot

The team measured height and circumference of each tree and sapling using a clinometer and linear tape, respectively. Vernacular names of species were recorded and the data on canopy, slope, altitude, aspect, soil color, soil depth, fire occurrence, forest encroachment, forest product collection, soil erosion and grazing were also collected. In addition, forest area and management regime, households using the forest, and distance of forest from the road and district headquarters were collected. All the information was collected from February to May 2013. Some data such as households in the CF user 
group was used from the CF impact study conducted by the Nepalese government in 2010, for which I trained field enumerators and conducted preliminary data analysis.

\subsubsection{Description and preparation of data variables}

I focus on AGTSC, because it provides information about the location of carbon sources and sinks and allows partial estimation of carbon storage and emissions from deforestation and forest degradation (Houghton, 2005; Ketterings et al., 2001). Recent studies using estimates of AGTSC have indicated a growing potential for tropical forests to serve as carbon sinks (Baker et al., 2004; Lewis et al., 2009; Pan et al., 2011; Philips et al., 1998).

I used equations (2.2) and (2.3) proposed by Chave et al. (2005) to estimate Above Ground Biomass (AGB), which is prepared using a large global dataset of trees across different climatic conditions. Equations (2.2) and (2.3) are used to estimate AGB in dry $(<1500 \mathrm{~mm}$ average annual rainfall) and moist forests $(1500-4000 \mathrm{~mm}$ average annual rainfall), respectively. These equations are used by several researchers and are recommended by the Nepalese government (MoFSC, 2010a). Approximately 5\% of my sample plots were in dry forests.

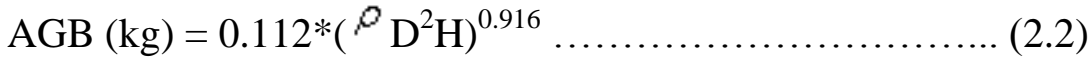

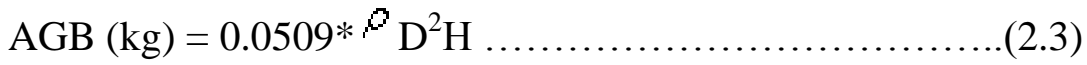

$$
\begin{aligned}
& \text { where, } \\
& \rho=\text { Specific gravity of wood }\left(\mathrm{g} \mathrm{cm}^{-3}\right) \text {; } \\
& \mathrm{D}=\mathrm{DBH}
\end{aligned}
$$




$$
\mathrm{H}=\text { Tree height }
$$

I used species-based wood specific gravity recommended by Jackson (1994) to calculate biomass. Where such information was unavailable, I used general values derived from average specific gravity of associated species (same genus and family) within a forest type (Baker et al., 2004; MoFSC, 1988; Ngugi et al., 2011).

I used Nepal-specific biomass equations developed by Tamrakar (2000) to estimate the green biomass of individual saplings. I converted the green biomass into dry biomass multiplying by species-wise fractions or the average of associated species identified in the literature. I used the fractions $0.627,0.613,0.58,0.57,0.545,0.517,0.5$ and 0.45 for Quercus species, Lyonia ovalifolia, Pinus roxburghii, Alnus nepalensis, Schima wallichii, Shorea robusta, Terminalia tomentosa and Pinus wallichiana, respectively (Bhatt \& Tomar, 2002; Jain \& Singh, 1999; Kataki \& Konwer, 2002; Shrestha et al., 2006; Wihersaari, 2005). For unidentified species, or where wood density information was not available for the species, genus or family, I used the overall mean wood density obtained from the database of species compiled for this study (Baker et al., 2004). Finally, I converted AGB into carbon stock multiplying by 0.50 (International Panel on Climate Change [IPCC], 2007).

I checked the names of all tree and shrub species for orthography and synonymy. I calculated plot-wise biodiversity indices to reflect different salient features: species richness $(\mathrm{S})$ to account for the number of species present, Shannon Wiener index $\left(H^{\prime}\right)$ to account for $\mathrm{S}$ and abundance of species, effective number of species $\left(\mathrm{e}^{\mathrm{H}}\right)$ to account for $\mathrm{S}$ 
and $H^{\prime}$ in an unbiased and easily interpretable form, and Shannon equitability index $\left(\mathrm{E}_{\mathrm{SW}}\right)$ to account for the evenness of species.

I calculated S by simply counting the number of species present in a plot. Using equation (2.4), I calculated $H^{\prime}$, which positively correlates with the number and evenness of species and takes a value of zero when there is only one species and a maximum value when all species are present in equal abundance (Mohan et al., 2007).

$$
H^{\prime}=-\Sigma_{i=1}^{S} p_{i} \ln p_{i}
$$

where, $S=$ Species richness;

$i=$ Individual species;

$p_{i}=$ Individuals of one species (n) divided by the total number of individuals of all species in the plot $(\mathrm{N})$;

$\Sigma=$ Sum of the calculations

By using equation (2.5), I transformed $\mathrm{H}^{\prime}$ to $\mathrm{e}^{\mathrm{H}^{\prime}}$, which is the number of species present if all species were equal in abundance. This transformation is an unbiased estimate of diversity (Beck \& Schwanghart, 2010) that reduces inaccuracies when comparing diversity among plots (Jost, 2006). It measures the diversity in units of number of species making it relatively easy to interpret.

$$
\mathrm{e}^{\mathrm{H}^{\prime}}=\mathrm{e}^{\mathrm{H}^{\prime}}
$$

where, e $=$ natural log 
I calculated the $\mathrm{E}_{\mathrm{SW}}$, which normalizes $\mathrm{H}^{\prime}$ to a value between 0 and 1 ( $1=$ evenness) for each plot by using equation (2.6):

$$
\mathrm{E}_{\mathrm{SW}}=\mathrm{e}^{\mathrm{H}^{\prime} / \ln \mathrm{S}}
$$

where, $\quad \ln =$ Natural $\log$

\subsubsection{Specification of analytical models}

\subsubsection{Assessment of forest carbon and biodiversity}

I assessed the current forest and tree characteristics, including AGTSC and biodiversity, using descriptive statistics. I disaggregated biodiversity and AGTSC on the basis of altitude, slope and canopy, as they are important aspects to account for forest health and management decisions (Table 2.2). Looking at the overall altitudinal distribution of sample-plots i.e., from $75 \mathrm{~m}$ to $2775 \mathrm{~m}$ from mean sea level and the general change in vegetation with altitude, I disaggregated altitudes into 6 categories by $500 \mathrm{~m}$ class. Similarly, as the sample plots fall from $0-60^{0}$ slopes, which has implications for forest type, structure and composition, I categorized forests into 5 groups of $10^{0}$ classes. As there were few plots $>40^{\circ}$, these very steeply-sloped plots are all in one class. For canopy, I followed the general practice of using 4 categories.

Table 2.2 Altitude, slope and canopy cover classes

\begin{tabular}{rrrr}
\hline Class & Altitude $(\mathbf{m})$ & Slope (degree) & Canopy (\%) \\
\hline 1 & $<500$ & $<10$ & $0-<25 \%$ \\
2 & $500-<1000$ & $10-20$ & $25-<50 \%$ \\
3 & $1000-<1500$ & $20-30$ & $50-<75 \%$ \\
4 & $1500-<2000$ & $30-40$ & $75-100 \%$ \\
5 & $2000-<2500$ & $>40$ & \\
6 & $2500-<3000$ & & \\
\hline
\end{tabular}


I also identified the high AGTSC contributing species and analyzed their share.

\subsubsection{Relationships between carbon and species diversity}

I estimated the Pearson correlation between different biodiversity indices (i.e., $\mathrm{S}, \mathrm{H}^{\prime}, \mathrm{e}^{\mathrm{H}^{\prime}}$ and $\left.\mathrm{E}_{\mathrm{sw}}\right)$ to assess the strength of their relationships. I also estimated the Pearson correlation between biodiversity indices and AGTSC to assess the direction and strength of their relationships. These relationships were analyzed for overall forests and forests across altitudes, slopes and canopies. I divided forests into lower $(<1000 \mathrm{~m})$ and higher $(\geq 1000 \mathrm{~m})$ altitudes, lower $\left(<15^{0}\right)$ and higher $\left(\geq 15^{0}\right)$ slopes, and open $(<50 \%)$ and closed ( $\geq 50 \%$ ) canopies. I also developed regression models using AGTSC as the dependent variable and different biodiversity indices as independent variables controlling average tree $\mathrm{DBH}$, average tree height, tree density, forest area, altitude, slope and canopy to assess the significance of biodiversity indices (i.e., to estimate the unbiased coefficient.) The models were selected on the basis of Akaike's Information Criterion (AIC). Finally, I checked diagnostics for each model by looking at residual plots and confirmed that the assumptions of the model were not violated. A relatively flat line of residual versus fitted values indicated the linearity of residuals. Most of the residuals look normal except at the upper end. I calculated Cook's Distance, which confirmed that no observations showed a strong influence in the model and no outliers were detected. A relatively flat line of standardized residuals versus fitted values showed a constant variance, indicating homoscedasticity (i.e., the variance of residuals does not change as a 
function of X.) Finally, the values of Variance Inflation Factors for each variable were between $1.05-4.23$, indicating a lack of multicollinearity.

\subsection{Results and analyses}

\subsubsection{Current status of carbon and biodiversity}

The current status of different forest attributes related to forest location, management, disturbances and trees are presented (Table 2.3). A total of 264 (57.4\%) plots were in the Terai region. The mean time required for two-way travel from the forest to the nearest roadhead was shorter than to the district headquarters, indicating easier access to transportation than to the management support from district forest offices (DFOs) that are usually located at the district headquarters.

Altogether, 324 species were recorded. The mean plot $\mathrm{S}, \mathrm{H}^{\prime}, \mathrm{e}^{\mathrm{H}^{\prime}}, \mathrm{E}_{\mathrm{sw}^{-}}$were $4.54 \pm 0.11$, $3.67 \pm 0.09,0.99 \pm 0.02$, and $0.32 \pm 0.01$, respectively. Given the small plot size, S, H' and $\mathrm{e}^{\mathrm{H}}$ 'seemed to be moderately diverse while $\mathrm{E}_{\mathrm{sw}}$ was relatively low. The 155 plots within the upper quartile of $\mathrm{e}^{\mathrm{H}^{\prime}}$ estimates had five times higher mean $\mathrm{e}^{\mathrm{H}^{\prime}}(6.89 \pm 0.30 \mathrm{Mg}$ $\left.\mathrm{ha}^{-1}\right)$ compared to the 155 plots within lower quartile of $\mathrm{e}^{\mathrm{H}^{\prime}}$ estimates $(1.21 \pm 0.08 \mathrm{Mg}$ ha${ }^{1}$ ), indicating a high degree of variation in biodiversity among plots.

A total of $98.34 \pm 4.19 \mathrm{Mg} \mathrm{ha}^{-1}$ AGTSC was recorded. The 155 plots within the upper quartile of AGTSC estimates had 18 times higher mean carbon $\left(244.19 \pm 16.45 \mathrm{Mg} \mathrm{ha}^{-1}\right)$ compared to the 155 plots in the lower quartile of the AGTSC estimates (11.09 \pm 1.25 $\mathrm{Mg} \mathrm{ha}^{-1}$ ), indicating high AGTSC variation across plots. Those plots had a higher mean $\mathrm{e}^{\mathrm{H}^{\prime}}(4.15 \pm 0.37)$ compared to the plots in the lower quartile of the AGTSC estimates 
$(2.81 \pm 0.33)$, indicating a difference of $\mathrm{e}^{\mathrm{H}^{\prime}}$ between plots with higher and lower AGTSC. Only 45 plots in the upper quartile of $\mathrm{e}^{\mathrm{H}^{\prime}}$ fell in the upper quartile of AGTSC estimates, indicating not all biodiverse forests have higher levels of AGTSC.

Table 2.3. The status of forest, tree, disturbance, management, AGTSC and species diversity. Continuous and ordinal variables are presented as means \pm standard errors (95\% confidence interval) of the mean; dichotomous variables are presented as percentages.

\begin{tabular}{|c|c|c|c|}
\hline Variables (units) & $\begin{array}{l}\text { Overall forest } \\
(\mathrm{N}=620)\end{array}$ & Variables (units) & $\begin{array}{l}\text { Overall forest } \\
(\mathrm{N}=620)\end{array}$ \\
\hline Forests exist in the hill (yes/no) & $264(42.5 \%)$ & Tree density $\left(\right.$ no. ha $\left.^{-1}\right)$ & $570.11 \pm 18.14$ \\
\hline Forests exist in Terai (yes/no) & $356(57.5 \%)$ & Sapling density (no. ha ${ }^{-1}$ ) & $491.73 \pm 22.04$ \\
\hline Altitude (m) & $748.20 \pm 25.20$ & $\begin{array}{l}\text { Regeneration density (no. } \\
\mathrm{ha}^{-1} \text { ) }\end{array}$ & $323164 \pm 13692$ \\
\hline Slope (degree) & $15.40 \pm 0.53$ & Total biomass $\left(\mathrm{Mg} \mathrm{ha}^{-1}\right)$ & $196.67 \pm 8.37$ \\
\hline Forest area (ha) & $127.70 \pm 27.92$ & $\operatorname{AGTSC}\left(\mathrm{Mg} \mathrm{ha}^{-1}\right)$ & $98.34 \pm 4.19$ \\
\hline $\begin{array}{l}\text { Moisture gradient }(1-5=\text { low- } \\
\text { high })\end{array}$ & $3.38 \pm 0.05$ & $\mathrm{~S}$ & $4.54 \pm 0.11$ \\
\hline Forest fire (yes/no) & $179(28.9 \%)$ & $\mathrm{H}^{\prime}$ & $0.99 \pm 0.02$ \\
\hline Average tree height (m) & $11.60 \pm 0.22$ & $\mathrm{e}^{\mathrm{H}^{\prime}}$ & $3.67 \pm 0.09$ \\
\hline Average tree DBH (cm) & $21.11 \pm 0.47$ & $\mathrm{E}_{\mathrm{sw}}$ & $0.32 \pm 0.01$ \\
\hline Canopy cover (\%) & $49.70 \pm 0.93$ & & \\
\hline
\end{tabular}

A disaggregated $\mathrm{e}^{\mathrm{H}^{\prime}}$ and AGTSC across altitudes, slopes and canopies is given in Figure 2.2 (a-i). A decreasing trend in mean AGTSC was observed with increasing altitude or slope and with a decline in canopy. Standard errors (SE) and percent SE of mean AGTSC also increased as the altitude or slope increased albeit in different rates. 

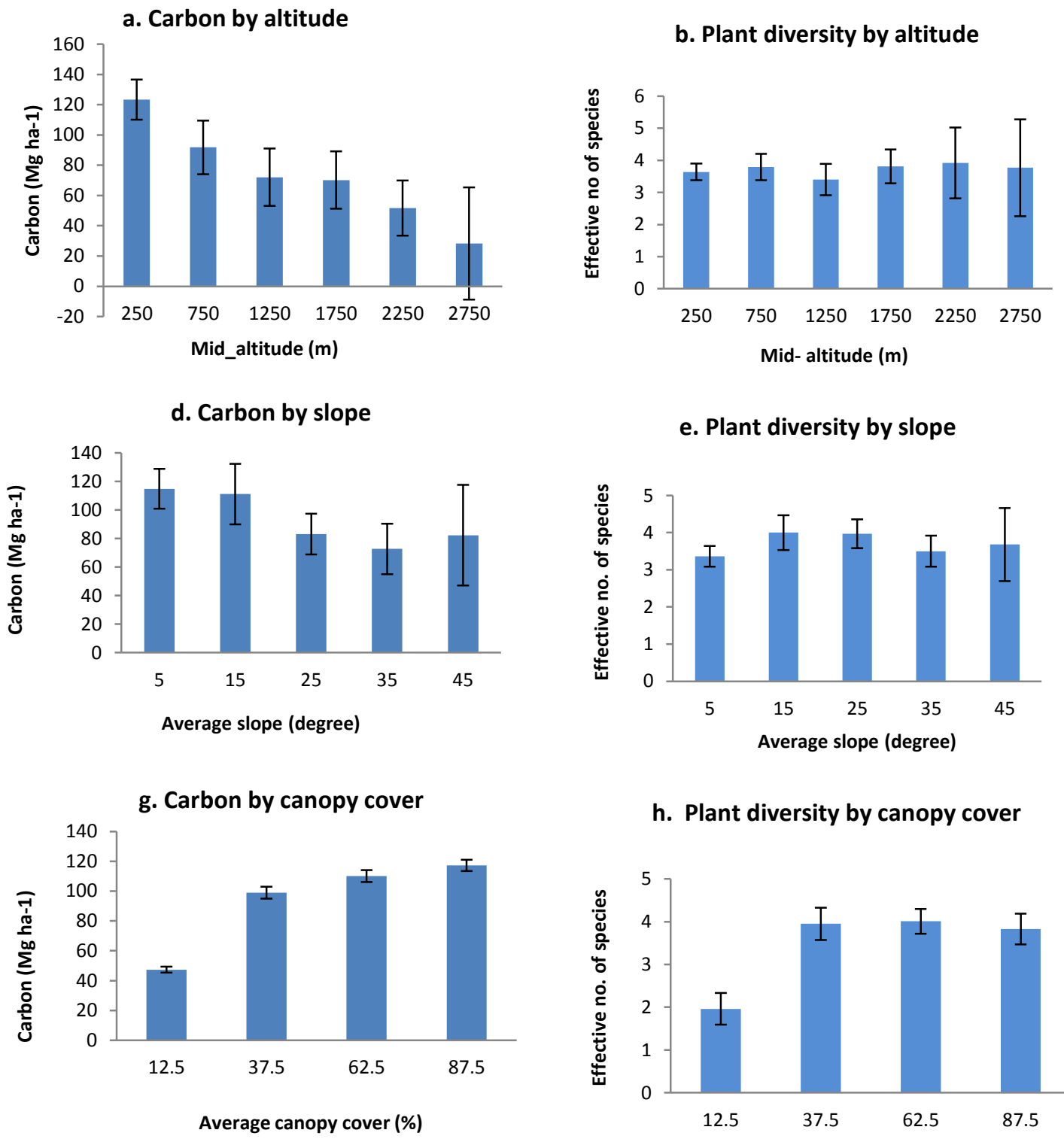

e. Plant diversity by slope

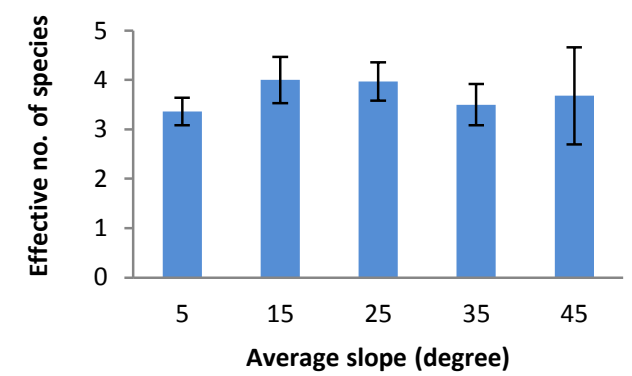

h. Plant diversity by canopy cover

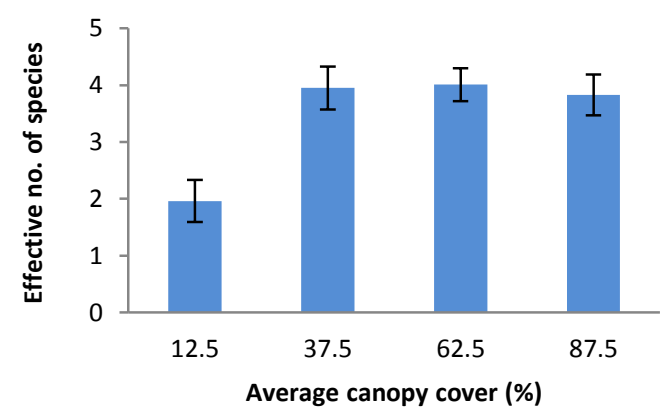

Figure 2.3 Average $\mathrm{e}^{\mathrm{H}^{\prime}}$ and AGTSC with standard error bars.

Standard bars represent uncertainties at 95\% confidence interval for each altitude, slope and canopy classes as shown in the $\mathrm{x}$-axes by their corresponding mid-points.

The $95 \%$ confidence intervals of the mean $\mathrm{e}^{\mathrm{H}^{\prime}}$ across altitudes and slopes overlap, indicating statistical plausibility of having the same mean values of $\mathrm{e}^{\mathrm{H}^{\prime}}$. Sizes of SE increase with altitudes or slopes, except in the1500-2000m altitude class and in the 20$30^{0}$ slope class, indicating increased uncertainty in higher altitudes and slopes. The $95 \%$ 
confidence intervals of $\mathrm{e}^{\mathrm{H}^{\prime}}$ overlap in $25-<50 \%, 50-<75 \%$ and $75-100 \%$ canopy classes (except 0 - < 25\% canopy class), indicating the statistical plausibility of having same mean $\mathrm{e}^{\mathrm{H}^{\prime}}$.

I found that $84 \%$ of AGTSC is available in $10(3 \%)$ dominant species, indicating a highly skewed AGTSC distribution across species (Table 2.4). Each species in Table 2.4 contributed $>1 \%$ of total AGTSC. Shorea robusta, Terminalia tomentosa and Pinus roxburghii jointly contributed the most: $>74 \%,>80 \%$ and $>51 \%$ in overall and lower and higher altitudes respectively. While Shorea robusta and Terminalia tomentosa are major contributors to AGTSC in lower altitudes, Pinus roxburghii, Shorea robusta and Schima wallichii contributed the most in higher altitudes.

Table 2.4 Contribution of AGTSC in different forests by species. All the values are given in the percentage.

\begin{tabular}{llccr}
\hline SN & Species & National & $\begin{array}{r}<\mathbf{1 0 0 0 m} \\
\text { altitude }\end{array}$ & $\begin{array}{r}\mathbf{1 0 0 0 m} \\
\text { altitude }\end{array}$ \\
\hline 1 & Sal (Shorea robusta) & 57.01 & 69.25 & 16.48 \\
2 & Saj (Terminalia tomentosa) & 9.12 & 11.08 & 2.65 \\
3 & Jamun (Syzigium cumini) & 1.10 & 1.36 & 0.24 \\
4 & Sissoo (Dalbergia sissoo) & 0.88 & 1.09 & 0.19 \\
5 & Bot dhangero (Lagestroemia parviflora) & 1.36 & 1.50 & 0.90 \\
6 & Pinus roxburghii & 8.39 & 1.19 & 32.21 \\
7 & Chilaune (Schima wallichii) & 3.66 & 1.55 & 10.67 \\
8 & Katus (Castanopsis indica) & 0.89 & 0.19 & 3.22 \\
9 & Gurans (Rhododendrom arboretum) & 0.50 & 0.00 & 2.14 \\
10 & Utis (Alnus nepalensis) & 0.99 & 0.01 & 4.22 \\
\hline
\end{tabular}

\subsubsection{Relationships between biodiversity and carbon}

The relationships between $\mathrm{S}, \mathrm{H}^{\prime}, \mathrm{e}^{\mathrm{H}^{\prime}}$ and $\mathrm{E}_{\mathrm{sw}}$ were examined by analyzing the Spearman correlation coefficients (Table 2.5). Most of these biodiversity indices are strongly, 
positively correlated with each other. However, the strength of correlation varies. A general trend was observed that the $\mathrm{E}_{\mathrm{sw}}$ is moderately correlated with $\mathrm{S}$ and $\mathrm{e}^{\mathrm{H}}$.

Table 2.5 Correlations among different biodiversity indices.

All correlation coefficients have p-values $<0.001$.

\begin{tabular}{cllll}
\hline Biodiversity indices & $\mathbf{S}$ & $\mathbf{H}^{\prime}$ & $\mathbf{e}^{\mathbf{H}^{\prime}}$ & $\mathbf{E}_{\mathbf{s w}}$ \\
\hline $\mathrm{S}$ & 1 & & & \\
$\mathrm{H}^{\prime}$ & 0.83 & 1 & & \\
$\mathrm{e}^{\mathrm{H}}$ & 0.96 & 0.78 & 1 & 1 \\
$\mathrm{E}_{\mathrm{sw}}$ & 0.60 & 0.87 & 0.63 & 1
\end{tabular}

Spearman correlations between biodiversity and AGTSC were complex and variable. The correlations of $\mathrm{S}, \mathrm{H}^{\prime}$ and $\mathrm{e}^{\mathrm{H} \text { ' }}$ with AGTSC were weakly positive or insignificant (Table 2.6) and the correlations varied in strength across altitudes, slopes, canopies and biodiversity indices. For instance, the correlations between AGTSC and S or $\mathrm{e}^{\mathrm{H}}$ are significant at all categories of forests. Such correlations at open canopy forests are relatively higher followed by lower altitude, higher slope, overall forest, lower slope, higher altitude and closed canopy. correlations are insignificant at higher altitudes. The correlations between AGTSC and H' are relatively lower than the correlations between AGTSC and $\mathrm{S}$ or $\mathrm{e}^{\mathrm{H}}$, being insignificant in case of higher altitude and open and closed canopies. Similarly, AGTSC is insignificantly correlated with $\mathrm{E}_{\mathrm{sw}}$. 
Table 2.6 Correlations of AGTSC with different biodiversity indices.

P-values of coefficients are given in the parentheses. Bolded correlation coefficients are significant at a 0.05 level of significance. The sign "-" denotes an inverse relationship.

\begin{tabular}{lllll}
\hline Forest type & $\mathbf{S}$ & $\mathbf{H}^{\prime}$ & $\mathbf{e}^{\mathbf{H}}$ & $\mathbf{E}_{\mathbf{s w}}$ \\
\hline Overall forest & $\mathbf{0 . 2 2}(0.000)$ & $\mathbf{0 . 1 0}(0.009)$ & $\mathbf{0 . 2 6}(0.000)$ & $-0.03(0.447)$ \\
Lower altitude $(<1000 \mathrm{~m})$ & $\mathbf{0 . 2 6}(0.000)$ & $\mathbf{0 . 1 1}(0.028)$ & $\mathbf{0 . 2 9}(0.000)$ & $-0.03(0.598)$ \\
Higher altitude $(\geq 1000 \mathrm{~m})$ & $\mathbf{0 . 1 8}(0.011)$ & $0.13(0.057)$ & $\mathbf{0 . 2 0}(0.005)$ & $-0.01(0.884)$ \\
Lower slope $(<15$ degree $)$ & $\mathbf{0 . 2 1}(0.000)$ & $0.10(0.089)$ & $\mathbf{0 . 2 6}(0.000)$ & $-0.01(0.852)$ \\
Higher slope $(\geq 15$ degree $)$ & $\mathbf{0 . 2 6}(0.000)$ & $\mathbf{0 . 1 5}(0.006)$ & $\mathbf{0 . 2 8}(0.000)$ & $-0.02(0.659)$ \\
Closed canopy $(\geq 50 \%)$ & $\mathbf{0 . 1 3}(0.018)$ & $0.03(0.584)$ & $\mathbf{0 . 1 8}(0.001)$ & $-0.06(0.289)$ \\
Open canopy $(<50 \%)$ & $\mathbf{0 . 3 0}(0.000)$ & $\mathbf{0 . 1 5}(0.013)$ & $\mathbf{0 . 3 3}(0.000)$ & $0.02(0.777)$ \\
\hline
\end{tabular}

The regression models using AGTSC as a dependent variable and $\mathrm{S}, \mathrm{H}^{\prime}, \mathrm{e}^{\mathrm{H}^{\prime}}$ and $\mathrm{E}_{\mathrm{sw}}$ as independent variables controlling average tree $\mathrm{DBH}$, average tree height, tree density, forest area, altitude, slope and canopy depicted the significance of such indices. S has positive, unbiased, significant coefficients in the overall forest (6.76) and $\mathrm{e}^{\mathrm{H} \text { ' }}$ has positive, unbiased, significant coefficients in lower altitudes (9.49), lower slopes (9.55) and closed canopies (9.50) (Table 2.7). $\mathrm{E}_{\mathrm{sw}}$ has negative, unbiased, significant coefficients in overall forest (-58.30) and forests in lower altitudes (-49.81), lower slopes (-54.48) and higher slopes (-264.64). No biodiversity indices were significant in explaining AGTSC in high altitudes and open canopies, indicating no relationship existed. The H', slope and canopy cover were not significant in explaining variations in AGTSC in overall forest and forests across altitudes, slopes and canopies. 
Table 2.7 Regression models.

I used the AGTSC as dependent variable. I presented standard errors in the parentheses along with coefficients. Only significant coefficients are reported. All models have p-value $<0.001$.

\begin{tabular}{|c|c|c|c|c|c|c|c|}
\hline $\begin{array}{l}\text { Model } \\
\text { attributes }\end{array}$ & Overall forest & $\begin{array}{l}\text { Lower altitude } \\
(<1000 \mathrm{~m})\end{array}$ & $\begin{array}{l}\text { Higher altitude } \\
(>1000 \mathrm{~m})\end{array}$ & $\begin{array}{l}\text { Lower slope } \\
(<15 \text { degree })\end{array}$ & $\begin{array}{l}\text { Higher slope } \\
\geq 15 \text { degree })\end{array}$ & $\begin{array}{l}\text { Closed canopy } \\
(\geq 50 \%)\end{array}$ & $\begin{array}{l}\text { Open canopy } \\
(<50 \%)\end{array}$ \\
\hline Intercept & $\begin{array}{l}-79.03 * * * \\
(11.38)\end{array}$ & $\begin{array}{l}-93.45 * * * \\
(14.31)\end{array}$ & $\begin{array}{l}-92.19 * * * \\
(13.75)\end{array}$ & $\begin{array}{l}-86.55 * * * \\
(17.39)\end{array}$ & $-49.94 * * *(12.74)$ & $\begin{array}{l}-191.6^{* * * *} \\
(17.94)\end{array}$ & $\begin{array}{l}-43.80 * * * \\
(12.80)\end{array}$ \\
\hline S & $6.76^{* * *}(1.59)$ & $\cdots$ & $\cdots$ & $\cdots$ & $\ldots$ & $\cdots$ & $\cdots$ \\
\hline $\mathrm{H}^{\prime}$ & $\cdots$ & $\cdots$ & $\cdots$ & $\cdots$ & $\ldots$ & $\cdots$ & $\cdots$ \\
\hline $\mathrm{e}^{\mathrm{H}^{\prime}}$ & $\ldots$ & $9.49 * * *(2.41)$ & $\ldots$ & $9.55 * *(3.01)$ & $\ldots$ & $9.50 * * *(1.87)$ & $\ldots$ \\
\hline $\mathrm{E}_{\mathrm{sw}}$ & $-58.30 * *(21.52)$ & $-49.81 \cdot(25.69)$ & $\cdots$ & $-54.48 \cdot(29.91)$ & $-264.64 * * *(45.14)$ & $\ldots$ & $\cdots$ \\
\hline Average DBH & $3.15 * * *(0.43)$ & $2.52 * * *(0.58)$ & $4.57 * * *(0.68)$ & $2.24 * *(0.68)$ & $4.48 * * *(0.65)$ & $5.00 * * *(0.56)$ & $1.56 *(0.61)$ \\
\hline Average height & $4.93 * * *(0.91)$ & $6.43 * * *(1.30)$ & $2.96 * * \quad(1.13)$ & $6.12 * * *(1.53)$ & $4.48^{* * *}(1.21)$ & $7.81 * * *(1.21)$ & $4.66 * *(1.30)$ \\
\hline Tree density & $0.06 * * *(0.01)$ & $0.06 * * *(0.01)$ & $0.07 * * *(0.01)$ & $0.06 * * *(0.02)$ & $\ldots$ & $0.09 * * *(0.01)$ & $0.08 * * *(0.01)$ \\
\hline Forest area & $0.11 * * *(0.02)$ & $0.11 * * * \quad(0.02)$ & $\cdots$ & $0.12 * * *(0.02)$ & $\ldots$ & $0.07 * * *(0.02)$ & $0.14 * * *(0.03)$ \\
\hline Altitude & $-0.01 *(0.005)$ & $\ldots$ & $\ldots$ & $\cdots$ & $\ldots$ & $-0.02 * *(0.01)$ & $-0.01^{\bullet}(0.008)$ \\
\hline Slope & $\cdots$ & $\cdots$ & $\cdots$ & $\cdots$ & $\cdots$ & $\cdots$ & $\cdots$ \\
\hline Canopy cover & $\cdots$ & $\ldots$ & $\cdots$ & $\ldots$ & $\ldots$ & $\ldots$ & $\ldots$ \\
\hline $\begin{array}{l}\text { Degree of } \\
\text { freedom }\end{array}$ & 612 & 406 & 203 & 270 & 338 & 337 & 270 \\
\hline Adjusted $\mathrm{R}^{2}$ & 0.4780 & 0.4784 & 0.4223 & 0.4682 & 0.3722 & 0.5772 & 0.4381 \\
\hline $\mathrm{p}$ value & 0.000 & 0.000 & 0.000 & 0.000 & 0.000 & 0.000 & 0.000 \\
\hline
\end{tabular}

Note: “***”=0.001; “**”=0.01, “*”=0.05 and “"”" $=0.1$ level of significance. 


\subsection{Discussion}

\subsubsection{Assessment of carbon and biodiversity}

The AGTSC estimate is comparable with Nepal's recent field-based regional studies (e.g., Baral et al., 2009; Gurung et al., 2015; Pandey et al., 2014) and a secondary databased national study (Oli \& Shrestha, 2009). As expected, the AGTSC is higher than the IPCC default value of biome average $\left(90 \mathrm{Mg} \mathrm{ha}^{-1}\right)$ and some studies of similar Indian forests (e.g., Chaturvedi et al., 2011; Haripriya, 2000). On the contrary, the AGTSC is markedly less than the secondary data-based estimates of Asian moist forests (e.g., 264 $\mathrm{Mg} \mathrm{ha}^{-1}$ ) (Houghton, 2005).

Differential AGTSC estimates across altitudes, slopes and canopy covers reflect the variation in site quality, climatic factors, topographic conditions, and past disturbances. As altitude and slope increases, soil erosion increases, retarding tree growth rate; average temperature drops for longer periods resulting in a shorter growing season; and incidence of past disturbances such as forest fire and loss of forest cover (Eckholm, 1975) lowered the base AGTSC. The increased AGTSC as the canopy cover increases is a reflection of forest productivity where both vertical and horizontal spaces of forest are better utilized.

The variations in the plot level AGTSC indicate the potential to increase carbon storage in Nepal's forest through appropriate management interventions. This indication is supported also by Thapa-Magar and Shrestha (2015), who demonstrated that the forest carbon stock in mid-hill Shorea robusta forest proportionally increased with management duration at the rate of 2.6 $\mathrm{Mg} \mathrm{ha}^{-1} \mathrm{yr}^{-1}$ and by Pandey et al. (2014), who report that forest carbon stock positively changed by $25 \%$ from 2010 to 2012 in $104 \mathrm{CF}$. Well-managed 
forests provide better site, space and nutrients for remaining trees and saplings for their enhanced growth that compensates for the removed biomass (Lung \& Espira, 2015; Taylor et al., 2008).

Plot level variations of biodiversity estimates across altitude, slope and canopy cover indicate the existence of a wide range of variables simultaneously affecting the distribution of biodiversity. Higher variances on $\mathrm{e}^{\mathrm{H}^{\prime}}$ in higher altitudes and higher slopes may be due to greater uncertainties and more variation in local factors (e.g., microclimate or diverse edaphic conditions.) The lower level of variation across altitudes does not follow an earlier study that indicated species diversity in natural growth varied with altitude, with higher diversity in lower altitudes compared to higher altitude forests (Swamy et al., 2000). Increased mean $\mathrm{e}^{\mathrm{H}}$ with increases in canopy cover reflects the existence of multi-layer canopies and better utilization of vertical and horizontal spaces in the forest. The higher percentage of variance in $\mathrm{e}^{\mathrm{H}}$ in the open canopy is due to the higher level of anthropogenic disturbances and the availability of gaps in the forest floor, which provide space for more species to regenerate (Sapkota et al., 2009).

A highly skewed AGTSC, with most carbon in a few species, lowered the influence of biodiversity on AGTSC. In the case of carbon forestry, forest management could apply silvicultural activities in such a way that keep only high carbon-yielding species, putting other ecologically important species at risk. Such a forest management approach may result in a less resilient ecosystem and reduce livelihood and economic opportunities for forest-managing communities. Forest-managing communities prefer economically viable species at the expense of other species (e.g., Acharya, 2004; Harrison \& Paoli, 2012; 
Venter et al., 2009) that provide a conducive environment by facilitating nutrient cycling and conserving moisture for economically viable or high carbon sequestrating species. Eventually, many species could be disturbed through either ecological processes or management interventions, and the forest or particular species could be threatened.

\subsubsection{Relationships between carbon and biodiversity}

The biodiversity indices have shown varied relationships with AGTSC. For instance, the

$\mathrm{S}$ and $\mathrm{e}^{\mathrm{H}^{\prime}}$ showed a clear positive but weak relationship with AGTSC in overall forest and forests in lower altitudes, lower and higher slopes, and closed and open canopies based on correlation and/or regression coefficients. This finding resembles earlier studies showing weak positive correlations between biodiversity and carbon (e.g., Nadrowski et al., 2010; Potvin et al., 2011; Thompson et al., 2009). This finding also indicates the possibility of dominant interspecific complementarity rather than interspecific competitive exclusions in such forests. A clear positive relationship of $\mathrm{S}$ and $\mathrm{e}^{\mathrm{H}^{\prime}}$ with AGTSC indicates the possibility of increasing the carbon stock by maintaining or increasing the number and abundance of species.

$\mathrm{E}_{\mathrm{sw}}$ showed an insignificant correlation with all categories of forests. However, clear significant negative regression coefficients of $\mathrm{E}_{\mathrm{sw}}$ with AGTSC in overall forest and forests in lower altitudes and lower and higher slopes indicate the increased evenness of species could imply decrease in the carbon in these forests. However, no relationship between $\mathrm{E}_{\mathrm{sw}}$ and AGTSC in higher altitudes and closed and open canopy forests indicate the possibility of no impact of evenness of species on carbon forestry. 
These variations in the relationships between different indices of biodiversity and carbon in forests across altitudes, slopes and canopies reflect the existence of a complex network of interactions between wide ranges of co-varying abiotic and biotic environmental factors. Such factors affect different dimensions of biodiversity and AGTSC. For instance, soil quality, drainage and topography strongly influence the relationships between biodiversity and carbon (Healy et al., 2008).

\subsubsection{Relevance of findings in global environmental initiatives and future research}

The possibility to increase carbon storage reveals a forest's potential to contribute to emerging global environmental initiatives that aim to mitigate climate change such as REDD+. This potential can best be harnessed using field-based methods of carbon measurement, which may estimate higher carbon than the IPCC default value and thereby better incentivize communities that engage in forest management.

The skewness of carbon towards a few species indicates a critical need for an effective biodiversity safeguard approach in carbon forestry. The positive relationships between AGTSC and biodiversity, particularly $\mathrm{S}$ and $\mathrm{e}^{\mathrm{H}}$ in overall forest and forests in lower altitudes, lower slopes and closed canopies, indicate the possibility of synergy between biodiversity conservation and carbon forestry. These indicate the relevance of number and abundance of species to climate change policies. In light of the studies by Gibson et al. (2011) and SCBD (2009) that show that the conservation of primary and mature forests maintains higher levels of AGTSC and biodiversity simultaneously, my findings indicate that bringing more natural and mature forests under a REDD+ regime may 
contribute to both biodiversity conservation and carbon storage in overall forest and forests in lower altitudes, lower slopes and closed canopies.

Insignificant correlations of $\mathrm{S}$ and $\mathrm{e}^{\mathrm{H}}$ with AGTSC in higher altitude forests indicate the lack of synergy between biodiversity conservation and carbon forestry. This finding warrants that carbon forestry neglecting biodiversity conservation may lead to neither tradeoff nor synergy with the number and abundance of species. The negative and/or neutral associations of $\mathrm{E}_{\mathrm{sw}}$ with AGTSC clearly indicate the need to target both biodiversity and carbon in forest management for their conservation and storage, respectively.

These findings clearly indicate that policy makers, planners and managers may need to clarify which of their interests in biodiversity (i.e., components of biodiversity such as species richness, abundance or evenness) are of prime importance. If the interest is species richness and abundance, carbon forestry may not be a challenge but of minimal support. However, if species evenness is also a target of biodiversity conservation, then carbon forestry may need to accommodate the interest of biodiversity evenness exclusively. In such a case, efficient tradeoffs between biodiversity conservation and carbon sequestration could be the better target for future forest management, which can partly be achieved by incorporating both carbon and biodiversity in a spatial planning process (Thomas et al., 2013). Strassburg et al. (2009) also indicate that additional gains in biodiversity conservation are possible, without compromising the effectiveness of carbon sequestration, if carbon forestry takes biodiversity distribution into account. 
The high variabilities of biodiversity, AGTSC and their relationships warrant further indepth studies to understand their dynamics (e.g., Day et al., 2013; Thompson et al., 2012). There is a need to analyze the changes in biodiversity and carbon over time at different scales and management regimes to gain better knowledge about biodiversity and carbon dynamics. Novel biodiversity indices such as functional and evolutionary diversities may help refine understanding of relationships between biodiversity and AGTSC. Studies on adaptive capacity of forest and impacts of management modalities on species composition, forest structure and growth are also crucial in enhancing understanding of biodiversity and carbon relationships.

The AGTSC and biodiversity estimates are conservative as I used only the trees and saplings that were $\geq 5 \mathrm{~cm}$ DBH for AGTSC and only tree and shrub species for biodiversity. These estimates of carbon may need to be revised for the purpose of incentivizing forest-managing communities under REDD+. However, because these underestimations are expected to impact all plots in equal proportion, the analysis of the relationship between AGTSC and biodiversity is consistently affected. Estimates of both biodiversity indices and AGTSC captured the uncertainties derived from plot variation. Within-plot variation, errors associated with the allometric equations, and uncertainties arising from sampling design and inferences to large landscapes might have influenced estimates.

\subsection{Conclusion}

In the context of mounting concerns about sustainable environmental health, my assessments of forest biodiversity, carbon and their relationships bring critical insights for 
researchers, policy makers and practitioners at global, national and local levels. Nepal's forests have potential for carbon storage and biodiversity conservation, and REDD+ is critical for fighting climate change and promoting biodiversity as envisioned by the UNFCCC and CBD, respectively. As carbon and biodiversity fluctuate across altitude, slope and canopy cover, they are critical factors for planning and implementing forestry projects. The comparable carbon with other local and regional field studies and the higher carbon than the IPCC biome average demonstrate possibilities of greater incentives for forest-managing communities through carbon forestry if field-based methods are used for carbon measurement.

As the dynamics of biodiversity, carbon and their relationships are complex, calculating accurate and fully reliable estimates are challenging when using one-time cross-sectional data. However, my study indicates the possibility of weak synergies between carbonforestry and biodiversity conservation in Nepal's forests, although there could be neutral relations and/or tradeoffs in some cases. These possibilities indicate that policy makers and forest managers need to adapt their forest management decisions in light of local environmental factors to make the REDD+ and CBD effective. Particularly, planning and implementation of REDD+ need especial attention in the provisioning and implementation of effective biodiversity safeguards. Dedicated policy and institutional arrangements, careful and site-specific planning of silvicultural activities, and proper implementation and periodic monitoring of forestry projects are required to ensure synergy between carbon and biodiversity outcomes and thereby promote climate mitigation, biodiversity conservation and other ecosystem services in the long run. A 
national forest inventory system may need to be established to periodically collect required information that helps promote future studies and planning. 


\section{Chapter 3: An Assessment of Causal Effects of Nepal's Community Forestry Program on Biodiversity Conservation and Carbon Storage}

\subsection{Introduction}

Over a billion local people control $\sim 15.5 \%$ of global forests and the trend of community control is increasing (Rights and Resource Initiative [RRI], 2014; Sunderlin et al., 2008). Most of such local control of forests is in tropical, developing countries. Tropical forests host 34 global biodiversity hot spots, constitute $40 \%$ of terrestrial biomass carbon and emit 17\% of global anthropogenic emissions (Mittermeier et al., 2004; Pan et al., 2011), and therefore the role of local communities in proper management of tropical forests for biodiversity conservation and carbon storage is imperative. By recognizing the role of local communities, governments in most tropical countries have been transferring various forest rights (e.g., access, use, management, alienation, governance, and due process and compensation) to the local communities through decentralization policy reforms over the last 40 years (Charnley \& Poe, 2007; Larson \& Soto, 2008). These governments and other forestry actors expect that this decentralized forestry has a positive impact on forest health and communities' livelihood.

Considering these facts, global environmental initiatives of biodiversity conservation and carbon storage such as the Convention on Biological Diversity (CBD) and Reducing Emissions from Deforestation and Forest Degradation, Conservation and enhancement of forest carbon and sustainable management of forest in developing countries (REDD+) recognized the community-controlled forest as a vehicle for effective forest management. The National Biodiversity Strategies and Action Plans, which the Parties need to prepare to fulfill the commitment of CBD, recognize the inevitable role of local communities in 
conservation. For instance, Nepalese biodiversity strategies recognize the need for full and effective participation, knowledge and innovations, and cooperation and collaboration of indigenous and local communities in the management of biodiversity (Ministry of Forest and Soil Conservation [MoFSC], 2014). REDD+ initiatives also prioritize the need for indigenous and local communities' full and effective participation in managing local forests through the provisioning of safeguards. Free, prior and informed consent of local communities are imperative for the effective implementation of REDD+.

One popular form of decentralized community-controlled forest management, the community forestry program (CFP), legally provides opportunities to local communities for the management and use of forest resources to support local livelihood, environment and economy (Brown et al., 2002; Nurse \& Malla, 2006). It is recognized as a major accomplishment in natural resource management and credited with successfully curbing deforestation and protecting forests while supporting local livelihoods (Agrawal \& Ostrom, 2008; Gautam et al., 2002; Pokharel et al., 2007). However, naive implementation of CFP does not guarantee biodiversity conservation and carbon sequestration, as past studies show potential for both synergy and tradeoffs in achieving these two outcomes depending on contexts and management interventions. For instance, Nepal's CFP revitalized the degraded forests in the hills (Chapagain \& Banjade, 2009; Gautam et al., 2002), which might have led to increased biodiversity conservation and carbon sequestration, However, communities' use of biomass might have decreased biodiversity and carbon (Shrestha et al., 2010). By taking the case of two community 
forests in Nepal, Acharya (2004) found that communities often carry out speciespreferred silvicultural practices leading to reduction in plant species diversity. By conducting a study of 11 community forest user groups for three years, Yadav et al. (2003) argued that communities manage the forest "passively" i.e., prioritizing conservation rather than carrying out appropriate silvicultural practices to increase the productivity of forests. Bhattarai (2006) indicated that Nepal's Forest Policy 2000 discriminated in the implementation of CFP between the hill and plain-land, (i.e., Terai), discouraging Terai communities in managing forests sustainably. In contrast to these studies, by taking cases of landscape-level community forests, Pandey (2015) and ThapaMagar and Shrestha (2015) recently collected the carbon data and demonstrated the evidence that Nepal's CFP has potential to increase carbon sequestration over time. Increasing and/or maintaining credibility, legitimacy and acceptability of CFP necessitates rigorous empirical evaluations of its impacts. Evaluations of CFP in biodiversity conservation and carbon storage are now particularly important to empirically examine the contribution of the CFP in the CBD and REDD+. So far, despite small-scale, localized studies showing positive impacts of CFP on communities' livelihoods and revitalization of degraded forests (e.g., Luintel et al., 2009; Pokharel et al., 2007), there are not adequate empirical studies at larger scales evaluating its environmental impacts, particularly on biodiversity conservation and carbon sequestration (Chhatre \& Agrawal, 2009). This knowledge gap prevents stakeholders from predicting the effectiveness of the program and therefore limits the possibility of innovative, productive management of forests that help address the new, global 
environmental concerns of biodiversity loss and carbon emissions. Beyene et al. (2013) indicated the need for empirical studies with better and smarter data (e.g., more variables and observations at multiple points of time) combined with robust analytical techniques to conclusively evaluate linkages of $\mathrm{CFP}$ with biodiversity conservation and carbon sequestration. It is critical to analyze empirical evidence of CFP effects in biodiversity conservation and carbon sequestration in order to inform future research, policies and management.

Nepal has a long history of CFP that offers a unique, suitable ground to carry out research about the effects of CFP in biodiversity conservation and carbon storage (Agrawal \& Ostrom, 2008; Pokharel et al., 2007). Specifically, I addressed the following research questions: 1. Did the CFP increase plant species diversity? and 2. Did the CFP enhance carbon storage in community forests? To answer these questions, I used cross-sectional data collected in the year 2013 from nationally representative random samples of community forest $(\mathrm{CF})$ and corresponding non-CF (NCF) and followed rigorous analytical processes. One challenge in evaluating CFP was to derive an appropriate counterfactual condition such as: What would have happened in the absence of the program? As the CFP areas were seldom distributed randomly across the country, overcoming potential selection bias was critical. I addressed this problem by use of a quasi-experimental, matching method. I identified confounding variables (“confounders") affecting the assignment of forest into the CFP and controlled those confounders through a matching process, which is a trusted and satisfactory technique that helps mimic randomized experiments (Hansen, 2004). The matching method helped develop a 
counterfactual control group allowing me to use existing data from NCF and providing information on what would have happened to biodiversity conservation and carbon storage in the absence of CFP (Pattanayak, 2009).

By using only matched samples, I estimated the average treatment effect on treated (ATT) i.e., the average effect of CFP on biodiversity $\left(\mathrm{ATT}_{\mathrm{b}}\right)$ and average effect of CFP on carbon $\left(\mathrm{ATT}_{\mathrm{c}}\right)$. As national-level estimates may mask a great deal of variation in the effectiveness of CFP across the country, I estimated $\mathrm{ATT}_{\mathrm{b}}$ and $\mathrm{ATT}_{\mathrm{c}}$ across geographic, topographic and geo-political regions and forest qualities. The identification of CFP effects across regions and forest qualities provides critical and specific information to policy makers, planners, managers and researchers to design their future courses of action so as to balance the local cost of CFP with local and global benefits. I also explored whether, where, and to what extent the $\mathrm{ATT}_{\mathrm{b}}$ and $\mathrm{ATT}_{\mathrm{c}}$ persist by testing their sensitivity to bias as driven by unobserved covariates.

This research makes several contributions in the context of the acute shortage of empirical knowledge regarding the effects of CFP on biodiversity conservation and carbon sequestration. By providing the first rigorous evidence, it adds to the scarce literature to broaden and deepen scientific understanding of the effects of CFP (e.g., Bluffstone et al., 2015; Chapagain \& Banjade, 2009; Gautam et al., 2002). It may inform researchers, policy makers and practitioners for future research design, policy formulation and action-plan preparation in Nepal and beyond, which are particularly important as many tropical countries have already decided, and are now preparing, to adopt carbon-focused forestry (e.g., REDD+). In such forestry practices, biodiversity 
conservation has also been one of the critical objectives, as depicted in the safeguard provisions, which is in line with the provisions made in the Convention on Biological Diversity (CBD). My research found heterogeneous effects of CFP across regions and forest qualities in carbon sequestration and biodiversity conservation. These results provide critical information to governments to design targeted, appropriate plans across regions and forest qualities and improve CFP outcomes.

\subsection{Context of the community forestry program in Nepal}

Nepal covers a total of 147,148 square kilometers and is broadly divided into three geographic regions: the high Himalaya (16\%) to the north, the middle hills (68\%), and the Terai (plain lands; 17\%) to the south. The altitudinal range varies from $73-4,848 \mathrm{~m}$ from the mean sea level, providing an opportunity for diverse geo-climatic zones from tropical to alpine regions. Legally, 39.6\% (5.8 million ha) of land in Nepal is forested (Department of Forest Research and Survey [DFRS], 1999). While Nepal occupies 0.1\% of the Earth's land, it harbors $>3 \%$ and $>1 \%$ of the world's known flora and fauna, respectively (MoFSC, 2014). It hosts about 118 ecosystems and 35 forest types (Stainton, 1972). More than two-thirds of the population live in rural areas and have subsistence agricultural economies where forest constitutes an integral part of their livelihoods. More than three-fourths of energy in the country is supplied from the forest, which contributes to one of the major sources of emissions in Nepal.

The Nepalese government nationalized all the Nepalese forests, particularly those distributed to elites by earlier governments, through the enactment of the Private Forest Nationalization Act 1957, to control environmental degradation and increase national 
revenue. The state's monopoly on national forests was further reinforced by necessary legal and institutional arrangements. However, the government was not able to slow deforestation and forest degradation, and most of the forest remained as open access commons where a phenomenon known as the "tragedy of the commonss ${ }^{5}$ (Hardin, 1968) appeared. Consequently, conservationists, scientists, and administrators expressed growing alarm about the rapid deterioration of the Himalayan environment in the late 1960s and 70s (e.g., Eckhholm, 1975). Gradually, local communities became interested in the protection and management of local forests so as to sustain their subsistence forest product needs (Gilmour \& Fisher, 1991), and the Nepalese government and international environmental organizations, where possible, started providing support to local communities for the protection and management of forests.

Nepal was an early leader in initiating CFP as an innovative program involving local communities in forest management (Agrawal \& Ostrom, 2001). Building on local communities' traditional practices of forest management, the Nepalese government started experimenting with CFP in the mid-1970s and fully developed and implemented a concrete program in the early 1990s. The formal CFP has been one of the most prioritized, popular and extensive forestry programs in Nepal to revitalize the degraded forests in the hills and fulfill the demand of subsistence forest products in the rural areas. Thus far, local communities have been managing forests for timber, fuelwood, nontimber forest products, medicine and soil conservation. Yadav et al. (2003) reported that

\footnotetext{
${ }^{5}$ Tragedy of the commons represent a deteriorating situation of a shared-resource system, where individual users act independently and rationally to maximize their own benefits without considering the sustainability of the resource.
} 
the CF in Nepal are primarily managed "passively" i.e., focusing on the protection and conservation of forests and restricting the harvest of forest products. Bhattarai (2001) reported the existence of different innovative practices of forest protection at the community level (e.g., fencing, fines, rotational patrolling, and cash and/or in-kind contributions), which are intended primarily to strengthen collective action and reduce deviant behavior of members.

Nepal's CFP provides unique, complex and dynamic environments that both create opportunities and pose challenges for biodiversity conservation and carbon storage by directly engaging $\sim 12$ million $(\sim 40 \%)$ of the population in the management and consumptive uses of $\sim 1.8$ million ha ( one-third) of forests (Department of Forest [DoF], 2015). The CFP legally recognized local forest-managing communities, community forest user groups (CFUG), as an autonomous public body having perpetual succession for forest management that can acquire, possess, transfer or manage property (Ministry of Law and Justice [MoLJ], 1993). The CFUG is entitled to own, access, manage, use and sell (including setting pricing) all the resources of CF (except wildlife and minerals) as per the self-prepared and DFO-approved forest management plan. Such legal institutional arrangements made CFP an indispensable strategy for any international environmental initiatives that need local forest management such as CBD and REDD+.

The Nepalese government prioritized the hill region of the country for the CFP due to communities' dependence on and willingness to protect forests; existence of traditional management practices; inability of government forestry staff to protect and manage forests; deteriorating forest conditions; little value for commercial use and public 
revenues; and financial and technical support of international development communities

(Gilmour \& Fisher, 1991; World Bank, 2001). The government has maintained its control and has been reluctant to hand over forests to communities in the Terai due to high commercial value and revenue potential of forests in the region (Bhattarai, 2006; Gilmour \& Fisher, 1991). Rather, the government delineated, gazetted and managed the large contiguous forests in the Terai as national forests (MoFSC, 2000). The focus of the government in Terai forest management was on timber production from the often dominant natural Shorea robusta forest (Banjade et al., 2011). The illegal logging and cross-border smuggling of Shorea robusta timber has long been an informal source of income for forest bureaucracy (Paudel et al., 2006). Only small to medium sized, barren forests in the vicinity of the settlement were handed over to communities in the Terai.

\subsection{Research site, design and analytical model}

The data presented are part of an on-going multi-disciplinary research project funded by the World Bank and jointly implemented by Portland State University and ForestAction Nepal (Bluffstone et al., 2015). The primary aim of the project is to assess potential synergies and/or tradeoffs between Nepalese forest commons and REDD+.

\subsubsection{Sampling methods and research sites}

A pilot survey was conducted in 2012 to estimate the required number of sample plots. I selected 45 sample plots from nine community forests (CFs) across physiographic regions to capture the greatest possible heterogeneity in plot basal area, a proxy of forest biomass. I deployed a field team to measure the diameter at breast height (DBH) of trees and saplings and estimated the basal area for each plot. Considering variance of basal 
area, I calculated the number of required sample plots for $10 \%$ error and $95 \%$ confidence level using the standard formula (3.1) (Saxena \& Singh, 1987).

$$
\begin{aligned}
& \mathrm{N}=\mathrm{C}_{\mathrm{v}}{ }^{2} \mathrm{t}^{2} / \mathrm{E}^{2} \ldots \ldots \ldots \ldots \ldots \ldots \ldots \ldots \ldots \ldots \ldots \\
& \text { Where, } \\
& \mathrm{N}=\text { Required number of sample plots; } \\
& \mathrm{C}_{\mathrm{v}}=\text { Coefficient of variation, } \mathrm{s} / \mu(\mathrm{s}=\text { standard deviation and } \mu=\text { sample mean); } \\
& \mathrm{E}=\text { Standard error, } \mathrm{s} / \sqrt{ } \mathrm{n}(\mathrm{n}=\text { sample number); } \\
& \mathrm{t}=\text { Value of student-t distribution for }(\mathrm{n}-1) \text { degree of freedom and } 95 \% \\
& \text { confidence level. }
\end{aligned}
$$

A total of 325 plots were estimated to be required for sampling in the CFs. Sample plots were distributed among the $65 \mathrm{CFs}$, which were selected from the random samples chosen for a national CF impact study conducted by the Nepalese government during 2010 - 2012. ForestAction Nepal recruited a team of 25 Nepalese field researchers with whom I closely worked to collect the data. Each of the field researchers had undergraduate degrees in forestry (12) and graduate degrees in social science (13), and ForestAction Nepal trained them to conduct forest surveys, forest inventories and household surveys

As the size of CF varies, we allocated between 3-7 sample plots in each forest based on the quintile distribution of forest size. As the forest size in the hill and Terai markedly differ, we considered different quintile ranges for hill and Terai (Table 3.1). 
Table 3.1 Distribution of sample plots in community forests.

\begin{tabular}{|c|c|c|c|c|c|}
\hline \multirow{2}{*}{$\begin{array}{l}\text { Quintile } \\
\text { distribution }\end{array}$} & \multicolumn{2}{|c|}{ Forest size (ha) } & \multirow{2}{*}{$\begin{array}{l}\text { Sample } \\
\text { plots/forest }\end{array}$} & \multirow{2}{*}{$\begin{array}{l}\text { Number } \\
\text { of forests }\end{array}$} & \multirow{2}{*}{$\begin{array}{l}\text { No. of } \\
\text { plots }\end{array}$} \\
\hline & Hill & Terai & & & \\
\hline $1^{\text {st }}$ quintile & $<18$ & $<113$ & 3 & 13 & 39 \\
\hline $2^{\text {nd }}$ quintile & $18-64$ & $113-154$ & 4 & 13 & 52 \\
\hline $3^{\text {rd }}$ quintile & 64-91 & $154-335$ & 5 & 13 & 65 \\
\hline $4^{\text {th }}$ quintile & $91-183$ & $335-526$ & 6 & 13 & 78 \\
\hline $5^{\text {th }}$ quintile & $\geq 183$ & $\geq 526$ & 7 & 13 & 91 \\
\hline
\end{tabular}

The field team selected 65 non-CFs in such a way that they were similar to the CFs in a variety of characteristics. Such plots were close but not next to CFs to avoid being used simultaneously by the same people. The field team carried out forest boundary surveys using Geographic Positioning System (GPS), prepared forest maps on graph paper and estimated forest area. The maps of $\mathrm{CF}$ that were in the forest operational plan were also copied on the graph paper so as to divide areas into smaller grid cells. To identify the sample plot, the cells were selected randomly, and X and Y coordinates of the center of selected cells were identified. The coordinates were then fed into a GPS unit to locate the plots in the forests. Due to differences in non-CF size, it was possible to allocate 295 plots following forest size criteria and standards given in Table 3.1. The distribution of sample plots is given in Figure 3.1. 


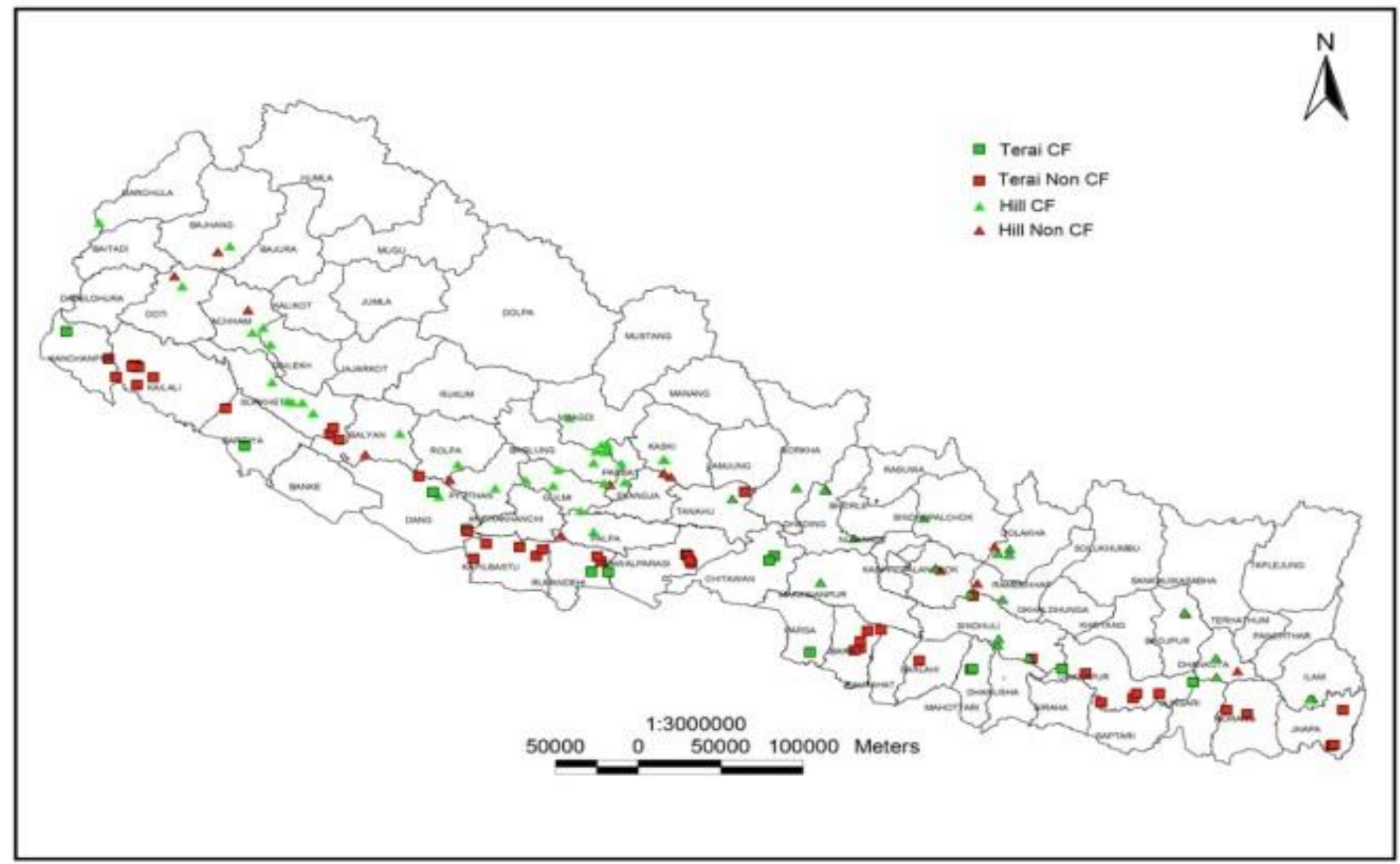

Figure 3.1 Distribution of sample plots 
A circular plot with a radius of $8.92 \mathrm{~m}$ was selected for collecting environmental data and measuring trees $(>5 \mathrm{~cm}$ diameter at breast height $[\mathrm{DBH}])$, which is suitable for moderate to dense vegetation and used widely (MacDicken, 1997). Using same center, second and third plots with radiuses of $5.64 \mathrm{~m}$ and $1 \mathrm{~m}$ were established to measure saplings $(1-5 \mathrm{~cm}$ DBH) and count seedlings, respectively (Figure 3.2).

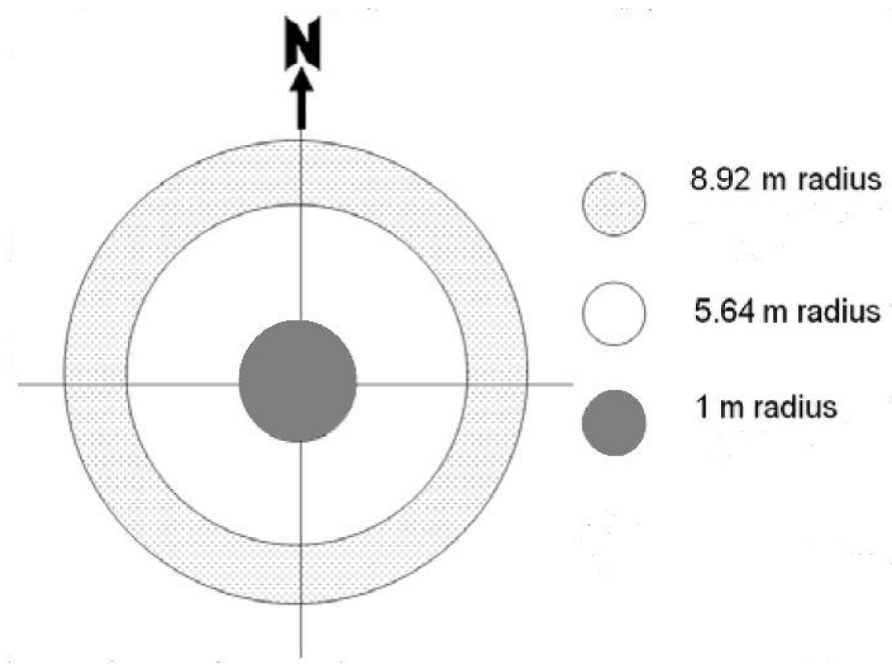

Figure 3.2 Size and shape of sample plot

The team measured height and circumference of each tree and sapling by using clinometer and linear tape, respectively. Vernacular name of each species were recorded and the data on canopy, slope, altitude, aspect, soil color, soil depth, fire occurrence, forest encroachment, forest product collection, soil erosion and grazing were collected for each plot. Data on forest area and management regime, number of households using the forest and distances of forest from the nearest roads and district headquarters were also collected. Data was collected from February to May 2013. Some data such as households in the CF user group was used from the CF impact study conducted by the Nepalese 
government in 2010 for which I trained field enumerators and conducted preliminary data analysis.

Sample plots were distributed in the tropical, sub-tropical and temperate climatic zones of 42 (out of 75) districts across the country. The majority of studied CFs (63\%) are in the hills. This reflects the higher number and area of CFs in the hills i.e., 87\% CFs covering $\sim 80 \% \mathrm{CF}$ area are in the hills (DoF, 2015). A range of different types of natural as well as plantation forests, ranging from approximately $80 \mathrm{~m}$ to $2800 \mathrm{~m}$ altitude (average $748.20 \pm 25.20 \mathrm{~m}$ ) from the mean sea level and 0 - 60 degree slope (average $15.40 \pm 0.53$ degree) were sampled. The mean time required traveling to and from the forest to the nearest road-head (i.e., less than half day) is shorter than traveling to the districtheadquarters (i.e., more than half-day), indicating easier access to transportation than to the management support from district forest offices (DFOs) that are usually located at the district head-quarters.

The average moisture gradient, reflected primarily by aspect, is modest. While the average size of overall forest is $127.70 \pm 27.92 \mathrm{ha}$, average size of forest per household is $0.82 \pm 0.30$ ha. More detailed statistics are given in Table 3.2.

Table 3.2 The status of forest, tree, disturbance and management of sampled forests.

Continuous and ordinal variables are presented as means \pm standard errors of the mean; dichotomous variables are presented as $\mathrm{N}(\%)$. Mann-Whitney test for continuous variables and proportion test for dichotomous variables were carried out to test the difference between CF and NCF. Bolded p-values $(\mathrm{p}<0.05)$ indicate significant differences between CF and NCF.

\begin{tabular}{lccrr}
\hline Variables and their measurement units & $\begin{array}{c}\text { Overall forest } \\
(\mathbf{N = 6 2 0})\end{array}$ & $\begin{array}{c}\text { CF } \\
(\mathbf{N = 3 2 5})\end{array}$ & $\begin{array}{c}\text { NCF } \\
(\mathbf{n = 2 9 5})\end{array}$ & $\begin{array}{r}\text { P- } \\
\text { values }\end{array}$ \\
\hline Forest location and area & & & & \\
Forests exist in the hills (yes/no) & $264(42.5 \%)$ & $205(33.1 \%)$ & $59(9.6 \%)$ & $<\mathbf{0 . 0 0 1}$ \\
Forests exist in Terai (yes/no) & $356(57.5 \%)$ & $120(19.4 \%)$ & $236(38.1 \%)$ & $\mathbf{0 . 0 0 4}$
\end{tabular}




\begin{tabular}{|c|c|c|c|c|}
\hline Variables and their measurement units & $\begin{array}{c}\text { Overall forest } \\
(\mathrm{N}=620)\end{array}$ & $\begin{array}{c}\mathbf{C F} \\
(\mathrm{N}=325)\end{array}$ & $\begin{array}{c}\text { NCF } \\
(n=295)\end{array}$ & $\begin{array}{c}\text { P- } \\
\text { values }\end{array}$ \\
\hline $\begin{array}{l}\text { Time required for } 2 \text {-way travel to and } \\
\text { from road }(1-3=<2 \text { hours to a day) }\end{array}$ & $1.41 \pm 0.03$ & $1.48 \pm 0.05$ & $1.33 \pm 0.04$ & 0.058 \\
\hline $\begin{array}{l}\text { Time required for } 2 \text {-way travel to and } \\
\text { from district headquarters }(1-3=<2 \text { hours } \\
\text { to full day) }\end{array}$ & $2.45 \pm 0.05$ & $2.59 \pm 0.07$ & $2.28 \pm 0.06$ & 0.002 \\
\hline Altitude (m) & $748.20 \pm 25.20$ & $981.67 \pm 33.77$ & $485.13 \pm 31.69$ & $<0.001$ \\
\hline Slope (degree) & $15.40 \pm 0.53$ & $20.37 \pm 0.68$ & $9.87 \pm 0.71$ & $<0.001$ \\
\hline Forest area (ha) & $127.70 \pm 27.92$ & $148.96 \pm 44.17$ & $106.44 \pm 33.71$ & $<0.001$ \\
\hline Per household forest area (ha) & $0.82 \pm 0.30$ & $0.90 \pm 0.27$ & $0.47 \pm 0.32$ & $<0.001$ \\
\hline $\begin{array}{l}\text { Moisture gradient }(1-5=\text { low-high based } \\
\text { on aspect) }\end{array}$ & $3.38 \pm 0.05$ & $3.14 \pm 0.07$ & $3.65 \pm 0.07$ & $<0.001$ \\
\hline \multicolumn{5}{|l|}{ Forest disturbances } \\
\hline Presence of forest fire (yes/no) & $179(28.9 \%)$ & $75(23.1 \%)$ & $104(35.3 \%)$ & 0.058 \\
\hline Presence of fodder collection (yes/no) & $379(61.1 \%)$ & $165(50.8 \%)$ & $214(72.5 \%)$ & 0.002 \\
\hline Presence of grazing (yes/no) & $309(49.8 \%)$ & $126(38.8 \%)$ & $183(62.0 \%)$ & 0.001 \\
\hline Presence of fuelwood harvesting (yes/no) & $430(69.4 \%)$ & $208(64.0 \%)$ & $222(75.3 \%)$ & 0.082 \\
\hline Presence of timber harvesting (yes/no) & $266(42.9 \%)$ & $135(41.5 \%)$ & $131(44.4 \%)$ & 0.679 \\
\hline Presence of encroachment (yes/no) & $40(6.5 \%)$ & $19(5.8 \%)$ & $21(7.1 \%)$ & 0.708 \\
\hline Presence of soil erosion (yes/no) & $158(25.5 \%)$ & $78(24.0 \%)$ & $80(27.1 \%)$ & 0.615 \\
\hline Presence of wildlife herbivory (yes/no) & $408(65.8 \%)$ & $210(64.6 \%)$ & $198(67.1 \%)$ & 0.709 \\
\hline \multicolumn{5}{|l|}{ Forest management } \\
\hline Years of forest user group formation (no.) & $11.2 \pm 0.20$ & $10.10 \pm 0.26$ & $12.43 \pm 0.28$ & $<0.001$ \\
\hline Households of forest users (no.) & $295.82 \pm 101.09$ & $295.80 \pm 182.70$ & $295.85 \pm 88.44$ & 0.496 \\
\hline $\begin{array}{l}\text { Existence of forest operational plan } \\
\text { (yes/no) }\end{array}$ & $388(62.6 \%)$ & $325(100.0 \%)$ & $63(21.4 \%)$ & $<0.001$ \\
\hline $\begin{array}{l}\text { Existence of forest management rules } \\
\text { (yes/no) }\end{array}$ & $516(83.2 \%)$ & $325(100.0 \%)$ & $192(65.1 \%)$ & $<0.001$ \\
\hline $\begin{array}{l}\text { Existence of community protection of } \\
\text { forest (yes/no) }\end{array}$ & $549(88.5 \%)$ & $325(100.0 \%)$ & $224(75.9 \%)$ & $<0.001$ \\
\hline $\begin{array}{l}\text { Existence of provisions of penalties for } \\
\text { culprits (yes/no) }\end{array}$ & $542(87.4 \%)$ & $325(100.0 \%)$ & $217(73.6 \%)$ & $<0.001$ \\
\hline \multicolumn{5}{|l|}{ Tree attributes } \\
\hline Average tree height $(\mathrm{m})$ & $11.60 \pm 0.22$ & $11.17 \pm 0.29$ & $12.13 \pm 0.34$ & 0.047 \\
\hline Average tree $\mathrm{DBH}(\mathrm{cm})$ & $21.11 \pm 0.47$ & $19.62 \pm 0.57$ & $22.84 \pm 0.77$ & 0.009 \\
\hline \multicolumn{5}{|l|}{ Forest attributes } \\
\hline Canopy cover $(\%)$ & $49.70 \pm 0.93$ & $48.66 \pm 1.21$ & $51.09 \pm 1.43$ & 0.105 \\
\hline Tree density $\left(\right.$ no. ha $^{-1}$ ) & $570.11 \pm 18.14$ & $629.17 \pm 27.75$ & $503.46 \pm 22.40$ & 0.002 \\
\hline Sapling density (no. ha ${ }^{-1}$ ) & $491.73 \pm 22.04$ & $512.92 \pm 35.67$ & $471.19 \pm 25.07$ & 0.640 \\
\hline Regeneration density (no. ha ${ }^{-1}$ ) & $\begin{array}{r}32316.84 \pm \\
1369.32\end{array}$ & $\begin{array}{r}29661.93 \pm \\
1965.02\end{array}$ & $\begin{array}{r}35420.49 \pm \\
1896.97\end{array}$ & $<0.001$ \\
\hline Presence of Shorea robusta (yes/no) & $350(56.5 \%)$ & $145(44.6 \%)$ & $205(69.5 \%)$ & $<0.001$ \\
\hline $\begin{array}{l}\text { Broadleaved-conifer forest gradient } \\
(1=\text { broadleaved, } 2=\text { mixed, } 3=\text { conifer })\end{array}$ & $1.39 \pm 0.02$ & $1.53 \pm 0.03$ & $1.22 \pm 0.03$ & $<0.001$ \\
\hline
\end{tabular}




\begin{tabular}{lccrc}
\hline Variables and their measurement units & $\begin{array}{c}\text { Overall forest } \\
(\mathbf{N = 6 2 0})\end{array}$ & $\begin{array}{c}\mathbf{C F} \\
(\mathbf{N = 3 2 5})\end{array}$ & $\begin{array}{c}\text { NCF } \\
(\mathbf{n = 2 9 5})\end{array}$ & $\begin{array}{c}\text { P- } \\
\text { values }\end{array}$ \\
\hline Normalized Difference Vegetation Index- & $0.2942 \pm 0.0022$ & $0.2945 \pm 0.0030$ & $0.2938 \pm$ & 0.388 \\
NDVI $^{1}, 1989$ (0=bare, $1=$ green) & & & 0.0032 & \\
Proportion of households living in the & & & & \\
village for at least 2 generations & $0.748 \pm 0.011$ & $0.821 \pm 0.014$ & $0.668 \pm 0.017$ & $<\mathbf{0 . 0 0 1}$ \\
Proportion of ethnic population & $0.416 \pm 0.012$ & $0.437 \pm 0.019$ & $0.394 \pm 0.015$ & 0.107 \\
Proportion of poor population & $0.376 \pm 0.009$ & $0.372 \pm 0.012$ & $0.382 \pm 0.014$ & 0.600 \\
\hline
\end{tabular}

${ }^{1} \mathrm{NDVI}$ is a widely used and important tool that measures "greenness" of vegetative cover based on remotely sensed data. It is directly related to energy (visible light in the red band) absorption by plant canopies (chlorophyll) for use in photosynthesis, which correlates to denser vegetation (Myneni et al., 1995; Sellers, 1985). A cloud free Landsat 5 image of November 1989 was used to calculate NDVI, as it gives information about the quality of forests just before the CFP was begun, crucial information to estimate the unbiased effect of CFP on carbon and biodiversity. The equation: NDVI $=(\mathrm{NIR}-\mathrm{Red}) /(\mathrm{NIR}+$ Red) was used to calculate the NDVI, where NIR= near-infrared (band 4) and Red= visible red light (band 3). (Charles Maxwell, PhD student at The School of the Environment, PSU calculated NDVI).

\subsubsection{Variable selection and measurement}

\subsubsection{Treatment and control variables}

The implementation of a formal CFP is the treatment variable. Local communities and/or government opt into CF status, and therefore the data are observational and non-random. On the other hand, the non-implementation of CFP, specifically the NCFs, are the control variable. The resources of the NCFs are formally owned by, and management responsibilities are vested on, the government. However, they remain open access, and local communities may protect and use forest resources, particularly non-timber forest products, for fulfilling subsistence needs.

\subsubsection{Outcome variables}

The effective number of species $\left(\mathrm{e}^{\mathrm{H}^{\prime}}\right)$ and the Above-Ground Tree and Sapling Carbon (AGTSC) are two outcome variables. I used the $\mathrm{e}^{\mathrm{H} \text { ' }}$ (i.e., the numbers of species present if 
all species were equal in abundance) to assess biodiversity, as it is an unbiased estimate of diversity that reduces inaccuracies when comparing diversity among plots (Jost, 2006). It measures biodiversity, considering both species richness (S) and abundance, in units of the number of species making it relatively easy to interpret.

I checked names of all tree and shrub species for orthography and synonymy. I calculated $\mathrm{S}$ by simply counting the number of species present in a plot. To estimate $\mathrm{e}^{\mathrm{H}}$, I calculated the Shannon-Weiner Index $\left(H^{\prime}\right)$ using equation (3.2) and transformed it using equation (3.3). H' is positively correlated with the number and evenness of species and takes a value of zero when there is only one species and a maximum value when all species are present in equal abundance (Mohan et al., 2007).

$H^{\prime}=-\Sigma_{i=1}^{S} p_{i} \ln p_{i}$

Where, $S=$ Species richness;

$i=$ Iindividual species;

$p_{i}=$ Individuals of one species (n) divided by the total number of individuals of all species in the plot $(\mathrm{N})$;

$\Sigma=$ Sum of the calculations.

$\mathrm{e}^{\mathrm{H}^{\prime}}=\mathrm{e}^{\mathrm{H}^{\prime}}$

Where, e $=$ Natural log

The AGTSC provides information about the location of carbon sources and sinks, particularly providing an estimation of major carbon storage in forests and potential 
emissions from deforestation and forest degradation (Houghton, 2005; Ketterings et al., 2001). Recent studies, using estimates of AGTSC, have indicated the growing potentials of tropical forests to serve as a carbon sink (Lewis et al., 2009; Pan et al., 2011).

I used equations (3.2) and (3.3) proposed by Chave et al. (2005) to estimate AboveGround Biomass (AGB), which is prepared by using a large dataset of trees across different climatic conditions of global sites. Equations (3.2) and (3.3) are used to estimate AGB in dry $(<1500 \mathrm{~mm}$ average annual rainfall $)$ and moist forests $(1500-4000 \mathrm{~mm}$ average annual rainfall), respectively. These equations are used by several researchers and recommended by the Nepalese government (MoFSC, 2010a). Approximately 95\% and 5\% sample plots in my study were classified as moist and dry forests, respectively.

$$
\begin{aligned}
& \operatorname{AGB}(\mathrm{kg})=0.112 *\left(\mathrm{D}^{2} \mathrm{H}\right)^{0.916} \ldots \ldots \ldots \ldots \\
& \operatorname{AGB}(\mathrm{kg})=0.0509 * \mathrm{D}^{2} \mathrm{H} \ldots \ldots \ldots \ldots \ldots \\
& \text { Where, } \\
& \rho=\text { Specific gravity of wood }\left(\mathrm{g} \mathrm{cm}^{-3}\right) ; \\
& \mathrm{D}=\text { DBH; } \\
& \mathrm{H}=\text { Tree height. }
\end{aligned}
$$

I used species-based wood specific gravity recommended by Jackson (1994) to calculate biomass. Where such information is unavailable, I used a general value derived from average specific gravity of associated species (same genus and family) within a forest type (Baker et al., 2004; Ngugi et al., 2011). I used Nepal-specific biomass equations developed by Tamrakar (2000) to estimate the green biomass of individual saplings, 
which is converted into dry biomass by multiplying by species-wise fractions or calculating an average of the associated species identified in the literatures. I used the fractions $0.627,0.613,0.58,0.57,0.545,0.517,0.5$ and 0.45 for Quercus species, Lyonia ovalifolia, Pinus roxburghii, Alnus nepalensis, Schima wallichii, Shorea robusta, Terminalia tomentosa and Pinus wallichiana, respectively (Bhatt \& Tomar, 2002; Jain \& Singh, 1999; Kataki \& Konwer, 2002; Shrestha et al., 2006; Wihersaari, 2005). For unidentified species, or where wood density information was not available for the species, genus or family, I used the overall mean wood density obtained from the database of species compiled for this study (Baker et al., 2004). I converted AGB into carbon stock by multiplying by 0.50 (Intergovernmental Panel on Climate Change [IPCC], 2006).

\subsubsection{Confounding variables}

Because communities opted into CFP, or the government persuaded communities to participate, there are a number of confounding variables, or confounders, that affected treatment status and/or outcomes. Confounders may inflate errors in $\mathrm{ATT}_{\mathrm{b}}$ or $\mathrm{ATT}_{\mathrm{c}}$ estimates (Heinrich et al., 2010). I controlled the confounders in the matching process that helps identify the best matches between $\mathrm{CF}$ and NCF plots so as to minimize error. Matching helped me develop a counterfactual control group, which allowed me to use select existing data from NCF plots and provided information on what would have happened to biodiversity conservation and carbon storage in the absence of CFP (Pattanayak, 2009). 
On the basis of the literature (see Section 3.2) and consultation with experts and community members, I identified 16 observable confounders determined by nature and communities. On the basis of my data, the identified confounders and their relationships with the CFP assignment is analyzed for overall forest and forests across altitudes, slopes, geo-political regions (i.e., hill and Terai) and canopies (Table 3.3) and briefly discussed below. If the treatments were randomly assigned, the coefficients should be statistically insignificant. 
Table 3.3 Observed confounders and their relationships with CFP assignment.

The model of relationship is generated using the probit model considering probability of forest selected under CFP as the dependent variable and confounders as independent variables. The coefficients and the $\mathrm{p}$-values in parentheses are reported. A blank space indicates that the concerned confounder is not used in the model to achieve matching in the particular forest category.

\begin{tabular}{|c|c|c|c|c|c|c|c|c|c|}
\hline Confounders & $\begin{array}{l}\text { Overall } \\
\text { forest }\end{array}$ & $\begin{array}{l}\begin{array}{l}\text { Lower } \\
\text { altitude } \\
(<1000 \mathrm{~m})\end{array} \\
\end{array}$ & $\begin{array}{l}\text { Higher } \\
\text { altitude } \\
(\geq 1000 \mathrm{~m}) \\
\end{array}$ & $\begin{array}{l}\text { Lower } \\
\text { slope } \\
\left(<15^{0}\right) \\
\end{array}$ & $\begin{array}{l}\text { Higher } \\
\text { slope } \\
\left(\geq 15^{0}\right) \\
\end{array}$ & Terai & Hill & $\begin{array}{l}\begin{array}{l}\text { Open } \\
\text { canopy } \\
(<\mathbf{5 0 \%})\end{array} \\
\end{array}$ & $\begin{array}{l}\text { Closed } \\
\text { canopy } \\
(\geq \mathbf{5 0 \%}) \\
\end{array}$ \\
\hline Intercept & $\begin{array}{l}-0.1051 \\
(0.127)\end{array}$ & $\begin{array}{l}-0.3224 \\
(0.000)\end{array}$ & $\begin{array}{l}-0.2165 \\
(0.536)\end{array}$ & $\begin{array}{l}-0.3526 \\
(0.013)\end{array}$ & $\begin{array}{l}0.218 \\
(0.009)\end{array}$ & $\begin{array}{l}-0.3522 \\
(0.001)\end{array}$ & $\begin{array}{l}0.9589 \\
(0.000)\end{array}$ & $\begin{array}{l}-0.2128 \\
(0.086)\end{array}$ & $\begin{array}{l}-0.0704 \\
(0.520)\end{array}$ \\
\hline Forest area & $\begin{array}{l}0.0000 \\
(0.951)\end{array}$ & $\begin{array}{l}0.0000 \\
(0.946)\end{array}$ & $\ldots$ & $\begin{array}{l}0.0005 \\
(0.005)\end{array}$ & $\begin{array}{l}0.0000 \\
(1.000)\end{array}$ & $\begin{array}{l}0.0000 \\
(0.948)\end{array}$ & $\ldots$ & $\ldots$ & $\begin{array}{l}0.0008 \\
(0.000)\end{array}$ \\
\hline Forest size per household & $\ldots$ & $\ldots$ & $\begin{array}{l}-0.0228 \\
(0.630)\end{array}$ & $\ldots$ & $\ldots$ & $\ldots$ & $\begin{array}{l}0.0333 \\
(0.223)\end{array}$ & $\begin{array}{l}0.0559 \\
(0.010)\end{array}$ & $\ldots$ \\
\hline Travel time to nearest road & $\begin{array}{l}0.0036 \\
(0.889)\end{array}$ & $\ldots$ & $\begin{array}{l}-0.0156 \\
(0.653)\end{array}$ & $\begin{array}{l}0.1442 \\
(0.015)\end{array}$ & $\begin{array}{l}-0.0683 \\
(0.069)\end{array}$ & $\begin{array}{l}0.1295 \\
(0.005)\end{array}$ & $\ldots$ & $\begin{array}{l}0.0074 \\
(0.835)\end{array}$ & $\begin{array}{l}0.0155 \\
(0.653)\end{array}$ \\
\hline $\begin{array}{l}\text { Travel time to district } \\
\text { headquarters }\end{array}$ & $\ldots$ & $\begin{array}{l}0.0725 \\
(0.001)\end{array}$ & $\ldots$ & $\ldots$ & $\ldots$ & $\ldots$ & $\begin{array}{l}-0.0130 \\
(0.602)\end{array}$ & $\ldots$ & $\ldots$ \\
\hline Slope & $\begin{array}{l}-0.0000 \\
(0.999)\end{array}$ & $\begin{array}{l}-0.0000 \\
(0.989)\end{array}$ & $\begin{array}{l}-0.000 \\
(1.000)\end{array}$ & $\begin{array}{l}0.0000 \\
(1.000)\end{array}$ & $\begin{array}{l}0.0000 \\
(1.000)\end{array}$ & $\begin{array}{l}-0.0000 \\
(0.989)\end{array}$ & $\begin{array}{l}0.0000 \\
(1.000)\end{array}$ & $\begin{array}{l}0.0000 \\
(1.000)\end{array}$ & $\begin{array}{l}0.0000 \\
(1.000)\end{array}$ \\
\hline Altitude & $\begin{array}{l}0.0000 \\
(0.997)\end{array}$ & $\begin{array}{l}0.0000 \\
(0.996)\end{array}$ & $\begin{array}{l}0.0000 \\
(1.000)\end{array}$ & $\begin{array}{l}0.0000 \\
(0.998)\end{array}$ & $\begin{array}{l}0.0000 \\
(1.000)\end{array}$ & $\begin{array}{l}0.0000 \\
(0.997)\end{array}$ & $\begin{array}{l}0.0000 \\
(1.000)\end{array}$ & $\begin{array}{l}0.0000 \\
(1.000)\end{array}$ & $\begin{array}{l}0.0000 \\
(1.000)\end{array}$ \\
\hline Moisture gradient & $\begin{array}{l}0.0000 \\
(0.992)\end{array}$ & $\begin{array}{l}0.0000 \\
(0.982)\end{array}$ & $\begin{array}{l}0.0000 \\
(1.000)\end{array}$ & $\begin{array}{l}0.0000 \\
(1.000)\end{array}$ & $\begin{array}{l}0.0000 \\
(1.000)\end{array}$ & $\begin{array}{l}0.0000 \\
(0.984)\end{array}$ & $\begin{array}{l}0.0000 \\
(1.000)\end{array}$ & $\begin{array}{l}0.0000 \\
(1.000)\end{array}$ & $\begin{array}{l}-0.0000 \\
(1.000)\end{array}$ \\
\hline Broadleaved-conifer gradient & $\begin{array}{l}0.1515 \\
(0.000)\end{array}$ & $\ldots$ & $\begin{array}{l}-0.0949 \\
(0.074)\end{array}$ & $\ldots$ & $\begin{array}{l}0.0910 \\
(0.066)\end{array}$ & $\ldots$ & $\begin{array}{l}-0.0742 \\
(0.106)\end{array}$ & $\begin{array}{l}0.1848 \\
(0.000)\end{array}$ & $\begin{array}{l}0.2209 \\
(0.000)\end{array}$ \\
\hline Presence of Shorea robusta & $\begin{array}{l}0.0000 \\
(0.985)\end{array}$ & $\begin{array}{l}0.0000 \\
(0.979)\end{array}$ & $\ldots$ & $\begin{array}{l}0.0000 \\
(1.000)\end{array}$ & $\begin{array}{l}-0.0000 \\
(1.000)\end{array}$ & $\begin{array}{l}0.0000 \\
(0.978)\end{array}$ & $\begin{array}{l}0.0000 \\
(1.000)\end{array}$ & $\begin{array}{l}0.0000 \\
(1.000)\end{array}$ & $\begin{array}{c}-0.0000 \\
(1.000)\end{array}$ \\
\hline
\end{tabular}




\begin{tabular}{|c|c|c|c|c|c|c|c|c|c|}
\hline Confounders & $\begin{array}{l}\text { Overall } \\
\text { forest }\end{array}$ & $\begin{array}{l}\text { Lower } \\
\text { altitude } \\
(<1000 \mathrm{~m})\end{array}$ & $\begin{array}{l}\text { Higher } \\
\text { altitude } \\
(\geq 1000 \mathrm{~m})\end{array}$ & $\begin{array}{l}\text { Lower } \\
\text { slope } \\
\left(<15^{0}\right)\end{array}$ & $\begin{array}{l}\text { Higher } \\
\text { slope } \\
\left(\geq 15^{0}\right)\end{array}$ & Terai & Hill & $\begin{array}{l}\text { Open } \\
\text { canopy } \\
(<50 \%)\end{array}$ & $\begin{array}{l}\text { Closed } \\
\text { canopy } \\
(\geq \mathbf{5 0 \%})\end{array}$ \\
\hline Presence of soil erosion & $\begin{array}{l}0.0000 \\
(0.918)\end{array}$ & $\begin{array}{l}0.0000 \\
(0.883)\end{array}$ & $\ldots$ & $\begin{array}{l}0.0000 \\
(1.000)\end{array}$ & $\begin{array}{l}0.0000 \\
(1.000)\end{array}$ & $\begin{array}{l}0.0000 \\
(0.869)\end{array}$ & $\begin{array}{l}-0.0000 \\
(1.000)\end{array}$ & $\begin{array}{l}-0.0000 \\
(1.000)\end{array}$ & $\begin{array}{l}-0.0000 \\
(1.000)\end{array}$ \\
\hline NDVI 1989 & $\begin{array}{l}-0.0127 \\
(0.270)\end{array}$ & $\begin{array}{l}-0.0148 \\
(0.214)\end{array}$ & $\begin{array}{l}0.3724 \\
(0.375)\end{array}$ & $\begin{array}{l}-0.1936 \\
(0.001)\end{array}$ & $\begin{array}{r}-0.2388 \\
(0.012)\end{array}$ & $\begin{array}{l}-0.0065 \\
(0.312)\end{array}$ & $\begin{array}{l}-0.4148 \\
(0.221)\end{array}$ & $\begin{array}{l}0.2112 \\
(0.010)\end{array}$ & $\begin{array}{l}-0.3927 \\
(0.020)\end{array}$ \\
\hline $\begin{array}{l}\text { Years of communities } \\
\text { conserving forest }\end{array}$ & $\begin{array}{l}0.0000 \\
(0.985)\end{array}$ & $\begin{array}{l}0.0165 \\
(0.000)\end{array}$ & $\ldots$ & $\begin{array}{l}0.0210 \\
(0.000)\end{array}$ & $\begin{array}{l}0.0000 \\
(1.000)\end{array}$ & $\begin{array}{l}0.0192 \\
(0.000)\end{array}$ & $\ldots$ & $\ldots$ & $\cdots$ \\
\hline $\begin{array}{l}\text { Number of forest user } \\
\text { households }\end{array}$ & $\begin{array}{l}0.0000 \\
(0.270)\end{array}$ & $\begin{array}{l}0.0000 \\
(0.214)\end{array}$ & $\ldots$ & $\begin{array}{l}0.0001 \\
(0.145)\end{array}$ & $\begin{array}{l}0.0004 \\
(0.012)\end{array}$ & $\begin{array}{l}0.0000 \\
(0.312)\end{array}$ & $\ldots$ & $\ldots$ & $\begin{array}{l}0.0000 \\
(0.510)\end{array}$ \\
\hline $\begin{array}{l}\text { Proportion of households living } \\
\text { in the village for at least } 2 \\
\text { generations }\end{array}$ & $\begin{array}{l}0.5127 \\
(0.000)\end{array}$ & $\begin{array}{l}0.3224 \\
(0.000)\end{array}$ & $\begin{array}{l}1.1900 \\
(0.000)\end{array}$ & $\begin{array}{l}0.4654 \\
(0.000)\end{array}$ & $\begin{array}{l}0.4785 \\
(0.000)\end{array}$ & $\begin{array}{l}0.2126 \\
(0.014)\end{array}$ & $\ldots$ & $\begin{array}{l}0.5333 \\
(0.000)\end{array}$ & $\begin{array}{l}0.3881 \\
(0.000)\end{array}$ \\
\hline Proportion of ethnic population & $\begin{array}{l}0.0000 \\
(0.999)\end{array}$ & $\begin{array}{l}0.3002 \\
(0.000)\end{array}$ & $\begin{array}{l}0.0000 \\
(1.000)\end{array}$ & $\begin{array}{l}-0.0257 \\
(0.128)\end{array}$ & $\begin{array}{l}0.0000 \\
(1.000)\end{array}$ & $\begin{array}{l}0.2804 \\
(0.005)\end{array}$ & $\begin{array}{l}0.0000 \\
(1.000)\end{array}$ & $\begin{array}{l}0.1064 \\
(0.241)\end{array}$ & $\begin{array}{l}-0.0000 \\
(1.000)\end{array}$ \\
\hline Proportion of poor population & $\begin{array}{l}0.0000 \\
(0.996)\end{array}$ & $\begin{array}{l}0.0000 \\
(0.993)\end{array}$ & $\begin{array}{l}-0.2708 \\
(0.066)\end{array}$ & $\ldots$ & $\begin{array}{l}0.0000 \\
(1.000)\end{array}$ & $\begin{array}{l}0.0000 \\
(0.993)\end{array}$ & $\begin{array}{l}0.1870 \\
(0.150)\end{array}$ & $\begin{array}{l}-0.3284 \\
(0.009)\end{array}$ & $\begin{array}{l}-0.0000 \\
(1.000)\end{array}$ \\
\hline
\end{tabular}


Forest area: Forest area had significant positive effect on the expected log odd of a forest to be selected under CFP; each additional hectare of forest adds to expected log odds of 0.0005 in lower slopes and 0.0008 in closed canopies. Similarly, the expected log odd of a forest being selected under CFP is increased by 0.0559 in open canopies if the size of forest per household is increased by one hectare. This is reasonable as the local communities prefer larger-sized (and larger per household) forest for provision of more resources, and also the government has a policy of designating forests according to the communities' willingness and capacity to manage (MoLJ, 1995).

Distance from road and district headquarters: As two-way travel time from forest to nearest road increases by 2-2.5 hours, the expected log odds of a forest to be selected under CFP increases by 0.1442 in lower slopes and 0.1295 in Terai. Similarly, a 2-2.5 hours increase for two-way travel from forests to district head-quarters increases the expected log odds of a forest to be selected under CFP in lower altitudes by 0.0725 . These results indicate that the government prioritized inaccessible forests for CFP as they were less connected with markets and had less revenue potential (Gilmour \& Fisher, 1991).

Forest composition and quality: As forest composition shifts from broadleaved to mixed or mixed to conifer-dominated, the expected log odd of forest to be selected under CFP increases by 0.1515 in overall, and by 0.1848 and 0.2209 in open and closed canopies, respectively. These data reflects that most of the plantations that were handed over to communities were dominated by Pinus roxburghii (Campbell \& Bhattarai, 1983; Gilmour et al., 1990; MoFSC, 1988). The greenness of the forest as measured by NDVI 1989 has a 
significantly negative effect on the expected log odd of forest being selected under CFP. Each additional unit of index reduces the expected log odd of forest to be selected under CFP by $0.1936,0.2367$ and 0.3947 in lower slopes, higher slopes and closed canopies, respectively. This reflects the preference of the government to hand over degraded forests to communities (Kanel \& Shrestha, 2001). However, the result of 0.2112 positive expected $\log$ odd in open canopies may be due to the handover of relatively good quality forests that perhaps became degraded. Some good quality forests were handed over to the communities due to communities' willingness and ability to manage as well as political pressure and willingness of DFO. Initially, DFOs were interested in gaining trust from local communities by demonstrating that they were willing to hand over good quality forests.

Management history: Each additional year that communities managed/protected a forest before the commencement of CFP raises the expected log odds of participating in the CFP in lower altitudes, lower slopes and Terai by $0.0165,0.0210$ and 0.0192 , respectively. The government prioritized traditionally managed forests for CFP, as they increase the probability of the success of the program. Forest-dependent communities in the vicinity of forests that were cohesive in nature were prioritized for CFP (Gilmour \& Fisher, 1991).

Community attributes: Each proportion of household living for $\geq 2$ generations in a community has 0.2126 to1.19 positive effects on the expected log odds of participation in the CFP in all categories of forest except hill. Non-migrated communities likely follow traditional subsistence livelihood strategies based on agriculture and forest resources and 
therefore are interested in CFP participation. In lower altitudes, each additional proportion of ethnic household in a community has a 0.3002 positive effect on the expected log odd of participation in the CFP. Ethnic homogeneity increases the cohesiveness of communities and therefore is positively associated with better collective actions in managing forests (Tachibana et al., 2001). Nepalese ethnic communities have their own, locally suitable forest governance and management (e.g., protection, harvesting and use) practices that have been proven effective. Each additional proportion of poor households in a community has a 0.1708 and 0.3284 negative effect on the expected log odds of participation in the CFP in higher altitudes and open canopies, respectively. This could be due to the communities' limited awareness and capacity to bear organizing and management costs.

According to my data, some of the confounders such as altitude, slope, moisture, soil erosion, presence of Shorea robusta and number of forest users' households are insignificantly related to the assignment into the CFP. However, these confounders are important criteria for decision making during the initial years of CFP, and therefore I kept them in the analytical models.

\subsubsection{Specification of analytical models}

\subsubsection{Addressing confounding through matching}

Because my study is observational, the principal problems in the estimation of $\mathrm{ATT}_{\mathrm{b}}$ and $\mathrm{ATT}_{\mathrm{c}}$ are identifying counterfactual conditionals and dealing with confounding, particularly due to selection bias. Selection bias arises when the location of CFP is not 
randomly selected, and CF plots differ from NCF plots for reasons other than their status as CF or NCF per se. Differences of CF and NCF confounders depict their effects on $\mathrm{e}^{\mathrm{H}^{\prime}}$ and AGTSC even if the CFP had no effect. Therefore, confounders need to be controlled to identify counterfactuals so as to make matched plots as good as random or statistically equivalent. Matched $\mathrm{CF}$ and NCF plots allow comparing to achieve unbiased measures of $\mathrm{ATT}_{\mathrm{b}}$ and $\mathrm{ATT}_{\mathrm{c}}$.

I used a two-step method, nonparametric matching and analysis, for identification of counterfactuals and estimation of the $\mathrm{ATT}_{\mathrm{b}}$ and $\mathrm{ATT}_{\mathrm{c}}$. Matching, an ex post identification technique, reduces selection bias and generates a comparable set of NCF observations by controlling observed confounders (Ho et al., 2007; Imben, 2004; Rosenbaum \& Rubin, 1983; Sekhon, 2011). Appropriate matching asymptotically balances observed confounders by removing bias (Rosenbaum \& Rubin, 1983). However, there is no consensus on exactly how matching ought to be done, how to measure the success of the matching procedure, and whether matching estimators are sufficiently robust to misspecification (Heckman et al., 1998).

Matching reduces selection bias only if assumptions of 'conditional independence or unconfoundedness' and 'common support' are met (Rosenbaum \& Rubin, 1983). Conditional independence means that CFP status is independent of the confounders. Matching techniques control the selection bias fully if all confounders determining CFP assignment are used, which is rare in practice as there are likely to be unobservable confounders. This is a strong assumption as it makes CF and NCF plots comparable and has to be justified by the data at hand. The "common support condition" refers to two 
important conditions: positive probability (i.e., existence of positive probability of being both $\mathrm{CF}$ and $\mathrm{NCF}$ for each value of covariate) and overlap condition (i.e., finding adequate comparable matches that help reduce model dependence).

I developed matching and propensity score models by including 10 to 14 observed confounders that affect the assignment into CFP, $\mathrm{e}^{\mathrm{H}}$ and AGTSC (Table 3.3). As the confounders were measured at both plot and forest levels, I applied a mixed-effect probit model to estimate propensity scores and fed these into the matching model. I found almost all variances (>99\%) of random effects were attributed to forest level effects. The fixed effects of confounders are discussed in section 3.3.2.3.

I used $\leq 0.25$ standardized mean difference (SMD) as a cut-off point, a common numerical balance diagnostic criterion to check whether the matching is satisfactory and acceptable, for matching adjustment (Rubin, 2001). The SMD expresses the standardized bias and is similar to an effect size relative to the variability observed and estimated by dividing difference in mean outcomes between CF and NCF plots by standard deviation of outcome among CF plots. Reducing SMD minimizes overt bias due to measured covariates in the $\mathrm{ATT}_{\mathrm{b}}$ and $\mathrm{ATT}_{\mathrm{c}}$ estimates (Imai et al., 2008; Rubin \& Thomas, 1996). I matched CF and NCF plots based on observed confounders by using the MatchIt package of R 3.2.2 (Ho et al., 2007). I used the matching with replacement approach, allowing each selected NCF plot to be matched to $\geq 1 \mathrm{CF}$ plots, as it is a good option for the highest degree of balance and the lowest conditional bias (Abadie \& Imbens, 2006; Dehejia \& Wahba, 1999). I used genetic matching, a multivariate matching that optimizes the confounding balance between $\mathrm{CF}$ and NCF plots by automating the process of finding 
good matches using an evolutionary search algorithm (Diamond \& Sekhon, 2013). This is a generalization of propensity score and Mahalanobis distance matching (Rosenbaum \& Rubin, 1985), which minimizes balance measures by using $\mathrm{p}$-values. The Mahalanobis metric is considered a useful tool for determining similarities between CF and NCF plots even when there are several, correlated confounders (Mahalanobis, 1936; Rubin, 1980).

In my dataset, I found that genetic matching was the best-suited algorithm to balance the maximum number of confounders bringing the SMD below the acceptable limit (Appendix A). As the post-matching SMD for confounders is less than 0.25 standard deviations and the average SMD across all covariates range from $0.08-0.17$. I was able to find a sufficient number of NCF plots that are similar to CF plots based on the covariates included in the matching process. In some cases, it was not possible to bring SMD down to $\leq 0.25$ for some confounders while keeping as many covariates as possible. However, I included some of those confounders in the matching models, as they contributed positively in achieving overall balance. A total of 18 - 52\% of NCF plots are matched with CF plots in overall forest and across altitudes, slopes, geo-political regions and forest canopies. The average ratios of matched NCF to CF plots ranges from 1:2.8 to 1:4.6 across forest categories.

\subsubsection{Comparing biodiversity and carbon}

The $\mathrm{ATT}_{\mathrm{b}}$ and $\mathrm{ATT}_{\mathrm{c}}$ are estimated based on the average difference of $\mathrm{e}^{\mathrm{H}^{\prime}}$ and AGTSC between matched CF and NCF plots. As tests of average difference rely on the distributions of such differences, I checked whether the distributions are normal by using graphical plots (e.g., histogram and qq plot) and the Shapiro-Wilk test. I found that 
differences were not normally distributed and therefore a t-test was not possible. However, because data were independently collected and randomized through the matching process, I used a pairwise Wilcoxon signed rank sum test to identify the [median] $\mathrm{ATT}_{\mathrm{b}}$ and $\mathrm{ATT}_{\mathrm{c}}$ by deducting $\mathrm{NCF}$ values from $\mathrm{CF}$ values.

\subsubsection{Sensitivity analysis}

Matching methods are not robust against "hidden bias" arising from the existence of unobserved confounders that simultaneously affect assignment to CFP and outcomes. The legitimacy of matching is based on the assumption that the assignment to CFP is ignorable only when all the confounding covariates are employed in the analysis (Thoemmes \& Kim, 2011). Testing this assumption is empirically impossible as measuring all confounders is practically not possible. Therefore, sensitivity analysis is essential to help understand the robustness of research findings to potential hidden bias.

Following the model of sensitivity analysis approach proposed by Rosenbaum (2002, ch. 4) and using the sensitivitymv package in R 1.3, I explored how sustainable my $\mathrm{ATT}_{\mathrm{b}}$ and $\mathrm{ATT}_{\mathrm{c}}$ estimates are in view of potential effects of unobserved confounders. I quantified the degree to which a key model assumption, that CFP assignment is effectively random conditional on the matches, must be violated in order for my results to be reversed. I estimated how strong the effects of unobserved confounders on the CFP would have to be to change the probability of assignment to CFP that significantly change my $\mathrm{ATT}_{\mathrm{b}}$ and $\mathrm{ATT}_{\mathrm{c}}$ estimates. I used a sensitivity parameter, gamma $(\Gamma)$, that shows critical levels of hidden bias as a quantity of difference in the odds of CFP assignment for two individuals with the same observed confounders but that diverge on 
unobserved confounders. A higher $\Gamma$ implies that the estimated $\mathrm{ATT}_{\mathrm{b}}$ and $\mathrm{ATT}_{\mathrm{c}}$ results are robust against a greater potential selection bias, while a low $\Gamma$ implies that even a mild selection bias could make the estimate insignificant (where $\Gamma=1$ indicates that no hidden bias exists). I determined the smallest value of $\Gamma$ that will change the p-value of the "true" $\mathrm{ATT}_{\mathrm{b}}$ or $\mathrm{ATT}_{\mathrm{c}}$ to a non-significant level $(>0.05)$. When the p-value exceeds 0.05, the $\Gamma$ value indicates the $\mathrm{CF}$ to $\mathrm{NCF}$ odds ratio at which $\mathrm{ATT}_{\mathrm{b}}$ or $\mathrm{ATT}_{\mathrm{c}}$ estimates are sensitive to hidden bias. Since the sensitivity analysis for insignificant $\mathrm{ATT}_{\mathrm{b}}$ and $\mathrm{ATT}_{\mathrm{c}}$ is not meaningful, I computed critical level of hidden bias only for the significant CFP effects (Hujer et al., 2004).

\subsection{Effect of Community Forestry Program}

\subsubsection{Effect of community forestry program in biodiversity conservation}

The $\mathrm{ATT}_{\mathrm{b}}$ depicted the varied estimates and levels of sensitivity of the effect of the CFP on $\mathrm{e}^{\mathrm{H}^{\prime}}$ across forest categories (Table 3.4). CF and NCF plots in the overall forest, lower and higher slopes, open canopies and Terai are significantly non-identical $(\mathrm{p}<0.05)$. The positive differences in the $\mathrm{ATT}_{\mathrm{b}}$ in those forests indicate significant positive effects of the

CFP on $\mathrm{e}^{\mathrm{H}^{\prime}}$. The estimated $\mathrm{ATT}_{\mathrm{b}}$ in the overall forest, lower slopes, higher slopes, open canopies and Terai are $0.65,0.60,0.67,0.88$ and 0.73 , respectively. The sensitivity analyses showed that these results can be nullified by the influence of unobserved confounders if the odds ratios of CF to NCF are changed by 1.24, 1.18, 1.36, 1.45 and 1.26 in overall forest, lower slopes, higher slopes, open canopies and Terai, respectively. In lower altitudes, the result showed that $\mathrm{CF}$ and NCF plots are identical and therefore the $\mathrm{ATT}_{\mathrm{b}}$ is insignificant $(\mathrm{p}>0.05)$. 
Results showed CF and NCF plots in higher slopes are non-identical $(\mathrm{p}<0.05)$. The negative $\mathrm{ATT}_{\mathrm{b}}$ in those forests indicate a significant negative effect of the CFP on $\mathrm{e}^{\mathrm{H}}$. The estimated $\mathrm{ATT}_{\mathrm{b}}$ in higher slopes is -0.51 . Sensitivity analysis showed that results can be nullified by the influence of unobserved confounders even if forest plots are fully randomized. Results in lower altitudes, closed canopies and hills showed that CF and $\mathrm{NCF}$ plots are identical and therefore $\mathrm{ATT}_{\mathrm{b}}$ is insignificant $(\mathrm{p}>0.05)$.

Table 3.4 Average effect of CFP on $\mathrm{e}^{\mathrm{H}}$ and sensitivity analysis by forest category. Columns 2 and 3 depict the number of CF/NCF plots and average SMD of confounders before and after match across forest categories. Columns 4, 5-6 and 7 depict the ATTb, lower and upper confidence levels of ATTb and p-values, respectively. The last 2 columns provide information about the sensitivities of estimated results to the unobserved confounders. For sensitivity estimation, trimming was carried out at 2.5 times the median of the absolute matched difference, which is analogous to a trimmed mean that trims 5\% of outliers from each tail. As there is no need, I did not calculate the hidden bias for insignificant CFP effects.

\begin{tabular}{|c|c|c|c|c|c|c|c|c|}
\hline \multirow{2}{*}{$\begin{array}{l}\text { Forest } \\
\text { category }\end{array}$} & \multirow{2}{*}{$\begin{array}{l}\text { No. of } \\
\text { CF/ } \\
\text { NCF }\end{array}$} & \multirow[b]{2}{*}{$\begin{array}{l}\text { Average } \\
\text { SMD of } \\
\text { observed } \\
\text { confounders } \\
\text { (before/afte } \\
\text { r match) }\end{array}$} & \multicolumn{4}{|c|}{$\mathbf{A T T}_{\mathbf{b}}$} & \multicolumn{2}{|c|}{ Hidden bias } \\
\hline & & & $\begin{array}{l}\text { Point } \\
\text { estimate }\end{array}$ & $\begin{array}{l}\text { Lower } \\
\text { confid } \\
\text { ence } \\
\text { limit- } \\
95 \%\end{array}$ & $\begin{array}{l}\text { Upper } \\
\text { confid } \\
\text { ence } \\
\text { limit- } \\
95 \%\end{array}$ & $\begin{array}{l}p- \\
\text { value }\end{array}$ & $\begin{array}{l}\text { Critical } \\
\text { level of } \\
\text { bias }(\Gamma)\end{array}$ & $\begin{array}{l}\text { P- } \\
\text { value }\end{array}$ \\
\hline Overall forest & $325 / 70$ & $0.40 / 0.11$ & 0.65 & 0.31 & 1.00 & 0.000 & 1.24 & 0.052 \\
\hline $\begin{array}{l}\text { Lower } \\
\text { altitude }\end{array}$ & $170 / 60$ & $0.37 / 0.21$ & 0.38 & -0.14 & 0.90 & 0.151 & & \\
\hline $\begin{array}{l}\text { Higher } \\
\text { altitude }\end{array}$ & $155 / 28$ & $0.24 / 0.08$ & -0.51 & -0.98 & -0.04 & 0.031 & 1 & 0.998 \\
\hline Lower slope & $89 / 28$ & $0.39 / 0.11$ & 0.60 & 0.08 & 1.14 & 0.024 & 1.18 & 0.052 \\
\hline Higher slope & $236 / 56$ & $0.26 / 0.17$ & 0.67 & 0.27 & 1.07 & 0.001 & 1.36 & 0.052 \\
\hline Terai & $120 / 43$ & $0.36 / 0.13$ & 0.73 & 0.20 & 1.22 & 0.008 & 1.26 & 0.052 \\
\hline Hill & $205 / 41$ & $0.16 / 0.10$ & -0.29 & -0.71 & 0.17 & 0.201 & & \\
\hline Open canopy & $149 / 41$ & $0.42 / 0.09$ & 0.88 & 0.39 & 1.36 & 0.001 & 1.45 & 0.053 \\
\hline $\begin{array}{l}\text { Closed } \\
\text { canopy }\end{array}$ & $176 / 53$ & $0.39 / 0.13$ & 0.33 & -0.04 & 0.07 & 0.072 & & \\
\hline
\end{tabular}


These $\mathrm{ATT}_{\mathrm{b}}$ estimates mask variations in the effectiveness of effects of CFP on $\mathrm{e}^{\mathrm{H}}$ across forest categories. The $95 \%$ confidence interval (CI) across forest categories indicates that there is no difference in the $\mathrm{ATT}_{\mathrm{b}}$ in overall forest, lower slopes, higher slopes, open canopies and Terai. Open canopies have higher CF to NCF odds ratios, narrower CI and lowest SMD (average $=0.09$, range $=0.02-0.24$ ), indicating $\mathrm{ATT}_{\mathrm{b}}$ that is less sensitive to hidden bias, with the more precise $\mathrm{ATT}_{\mathrm{b}}$ estimate and the better match between $\mathrm{CF}$ and NCF plots reflecting a more robust $\mathrm{ATT}_{\mathrm{b}}$ estimate.

\subsubsection{Effect of community forestry policy intervention in carbon}

The $\mathrm{ATT}_{\mathrm{c}}$ depicted varied estimates and levels of sensitivity of the effect of CFP on AGTSC across forest categories (Table 3.5). CF and NCF populations in lower slopes and open canopies are non-identical $(\mathrm{p}<0.05)$. The positive $\mathrm{ATT}_{\mathrm{c}}$ in those forests indicate significant positive effects of CFP on AGTSC. The estimated $\mathrm{ATT}_{\mathrm{c}}$ is $25.51 \mathrm{t} \mathrm{ha}^{-1}$ in lower slopes and $25.84 \mathrm{t} \mathrm{ha}^{-1}$ in open canopies. The sensitivity analysis showed that these results can be nullified by the influence of unobserved confounders if odds ratios of CF to NCF are changed by 1.10 and 1.66 in lower slopes and open canopies, respectively. 
Table 3.5 Average effect of CFP on AGTSC and sensitivity analysis by forest category.

Columns 2 and 3 depict the number of CF/NCF plots and average SMD of confounders before and after match across forest categories. Columns 4, 5-6 and 7 depict the ATTc, lower and upper CI of ATTc and pvalues, respectively. The last 2 columns provide information about the sensitivities of estimated results to the unobserved confounders. For sensitivity estimation, trimming was carried out at 2.5 times the median of the absolute matched difference, which is analogous to a trimmed mean that trims $5 \%$ of outliers from each tails. As there is no need, I did not calculate the hidden bias for insignificant CFP effects.

\begin{tabular}{|c|c|c|c|c|c|c|c|c|}
\hline \multirow{2}{*}{$\begin{array}{l}\text { Forest } \\
\text { category }\end{array}$} & \multirow{2}{*}{$\begin{array}{l}\text { No. of } \\
\text { CF/ } \\
\text { NCF }\end{array}$} & \multirow{2}{*}{$\begin{array}{l}\text { Average } \\
\text { SMD of } \\
\text { observed } \\
\text { confounders } \\
\text { (before/after } \\
\text { match) }\end{array}$} & \multicolumn{4}{|l|}{$\mathbf{A T T}_{\mathbf{c}}$} & \multicolumn{2}{|c|}{ Hidden bias } \\
\hline & & & $\begin{array}{l}\text { Point } \\
\text { estimate }\end{array}$ & $\begin{array}{l}\text { Lower } \\
\text { confid } \\
\text { ence } \\
\text { limit- } \\
95 \%\end{array}$ & $\begin{array}{l}\text { Upper } \\
\text { confid } \\
\text { ence } \\
\text { limit- } \\
95 \%\end{array}$ & $\begin{array}{l}\text { p- } \\
\text { value }\end{array}$ & $\begin{array}{l}\text { Critical } \\
\text { level of } \\
\text { bias }(\Gamma)\end{array}$ & $\begin{array}{l}P \\
\text { value }\end{array}$ \\
\hline Overall forest & $325 / 70$ & $0.40 / 0.11$ & -15.11 & -26.35 & -3.49 & 0.012 & 1 & 0.982 \\
\hline Lower altitude & $170 / 60$ & $0.37 / 0.21$ & 11.21 & -7.42 & 31.02 & 0.243 & & \\
\hline Higher altitude & $155 / 28$ & $0.24 / 0.08$ & -22.81 & -37.41 & -9.39 & 0.001 & 1 & 0.999 \\
\hline Lower slope & $89 / 28$ & $0.39 / 0.11$ & 25.51 & 0.98 & 55.14 & 0.041 & 1.10 & 0.053 \\
\hline Higher slope & $236 / 56$ & $0.26 / 0.17$ & -17.72 & -30.93 & -4.22 & 0.010 & 1 & 0.989 \\
\hline Terai & $120 / 43$ & $0.36 / 0.13$ & 5.87 & -15.88 & 32.80 & 0.585 & & \\
\hline Hill & $205 / 41$ & $0.16 / 0.10$ & 9.76 & -1.48 & 22.04 & 0.089 & & \\
\hline Open canopy & $149 / 41$ & $0.42 / 0.09$ & 25.84 & 12.22 & 41.36 & 0.000 & 1.66 & 0.051 \\
\hline Closed canopy & $176 / 53$ & $0.39 / 0.13$ & -2.93 & -18.06 & 12.11 & 0.694 & & \\
\hline
\end{tabular}

Results showed CF and NCF plots in the overall forest and higher slopes are nonidentical $(\mathrm{p}<0.05)$. The negative $\mathrm{ATT}_{\mathrm{c}}$ in those forests indicate a significant negative effect of the CFP on AGTSC. The estimated $\mathrm{ATT}_{\mathrm{c}}$ in overall forest is $-15.11 \mathrm{t} \mathrm{ha}^{-1}$ and in higher slopes is $-17.72 \mathrm{tha}^{-1}$. Sensitivity analysis showed that results can be nullified by the influence of unobserved covariates even if forest plots are fully randomized. In lower altitudes and Terai, results showed that CF and NCF plots are identical and therefore $\mathrm{ATT}_{\mathrm{c}}$ are insignificant $(\mathrm{p}>0.05)$.

These $\mathrm{ATT}_{\mathrm{c}}$ estimates mask variations in the effectiveness of effects of CFP on AGTSC across forest categories. The 95\% CI across forest categories indicates that the $\mathrm{ATT}_{\mathrm{c}}$ in 
the overall forest is lower than in lower slopes, open canopies and Terai. Also, the $\mathrm{ATT}_{\mathrm{c}}$ in the overall forest is not different from higher slope forest within a 95\% CI. Similarly, $\mathrm{ATT}_{\mathrm{c}}$ in lower slopes and open canopies do not differ within a 95\% CI. However, open canopies have higher $\mathrm{CF}$ to $\mathrm{NCF}$ odds ratio, narrower CI than lower slopes and lowest SMD (average $=0.09$, range $=0.02-0.24$ ), indicating that the less sensitive $\mathrm{ATT}_{\mathrm{c}}$ is to hidden bias, the more precise the $\mathrm{ATT}_{\mathrm{c}}$ estimate and the better match between $\mathrm{CF}$ and $\mathrm{NCF}$ plots reflecting a more robust $\mathrm{ATT}_{\mathrm{c}}$ estimate.

\subsection{Discussion}

At the national level, my results clearly illustrate that the CFP has a positive effect on $\mathrm{e}^{\mathrm{H}^{\prime}}$ and a negative effect on AGTSC. However, the CFP has mixed and differential (positive, negative and no) net effects on $\mathrm{e}^{\mathrm{H}}$ and AGTSC across altitudes, slopes, geographic regions and canopy covers. For instance, the CFP has a significantly positive effect on biodiversity conservation in overall forest and forests in higher and lower slopes, Terai and open canopies while it has a significantly negative effect in higher altitudes and no significant effects in lower altitudes, hills and closed canopies. In terms of carbon stocks, the CFP has significantly positive effects in lower slopes and open canopies while it has significantly negative effects in overall forest and forests in higher altitudes and higher slopes and no significant effects in lower altitudes, Terai, hill and closed canopy. These variations in $\mathrm{ATT}_{\mathrm{b}}$ and $\mathrm{ATT}_{\mathrm{c}}$ might reflect different forest management and silvicultural practices of communities across the country. Different forest management practices are, principally, encouraged by the CFP to suit local context. Under the broader management 
guidelines, local forestry technicians prepare and the district forest officers approve the forest operational plan for each community forests separately.

My $\mathrm{ATT}_{\mathrm{b}}$ estimates reflect findings from earlier studies. While significant positive $\mathrm{ATT}_{\mathrm{b}}$ reflects the contribution of CFP in revitalizing degraded forestlands (Gautam et al., 2002; Luintel et al., 2009), significant negative $\mathrm{ATT}_{\mathrm{b}}$ indicates the reduction of biodiversity in CF likely due to the communities' preference for valuable species and selective harvesting (Acharya, 2004) and higher pressure in the CFs. The biodiversity of CF depends on context and communities' efforts in conservation and their use of biomass (Shrestha et al., 2010). Because communities manage forests for subsistence goods and services of which choice of species constitutes a major part, the results reflect a wide variety of locally targeted, specific forest management and conservation actions carried out by individual communities. It also reflects that the policy and programmatic frameworks for biodiversity conservation that were in place may have been too broad, failing to provide locally suitable, practical guidelines to the communities and DFO staff. For instance, Nepalese biodiversity strategy plans have provided space to local governments and other line agencies (e.g., agriculture offices, national park and wildlife reserve authorities, soil conservation offices, non-governmental organizations, etc.) for decision-making. However, such line agencies might not have comprehensive knowledge and/or appropriate human resources for decision making and planning for biodiversity conservation.

My ATT ${ }_{c}$ estimates reflect unexpected and complex results that confirm and also contradict the earlier findings of Bluffstone et al. (2015), which concluded that the CFP 
effect on carbon is not significant. The result of $\mathrm{ATT}_{\mathrm{c}}$ may need to be viewed in the context of basic objectives and management practices in $\mathrm{CF}$, disturbance regime, base carbon stock and spillover effect of CFP on NCF, all of which might not have been well captured in the observed confounders. As degraded forests were handed over to the communities, they primarily managed forest "passively" i.e., focusing on conservation and conservative use of forest products (Yadav et al.; 2003), limiting the productivity and carbon stock potential of forests. As extraction of timber and other woody forest products from CFs is legal, the carbon stored in CFs reflects only that retained after harvesting. Base-carbon affects biological and physical potential of forest to sequester carbon. For instance, low carbon may constrain the biological potential of carbon sequestration but provides physical space to store additional future carbon. Also, NCFs in the vicinity of communities could have mimicked CFP with an aim to demonstrate their commitment to forest management and persuade DFOs to designate those forests as CFs in the future. Community and household surveys carried out as part of this research reflect that $80 \%$ of communities have written rules and $>60 \%$ of households engage in forest management in NCFs.

The possibilities of positive, negative or no contributions of CFP to both $\mathrm{ATT}_{\mathrm{b}}$ and $\mathrm{ATT}_{\mathrm{c}}$ demonstrate the need for a review of CFP particularly in view of the CBD and REDD+. While the positive effects on $\mathrm{ATT}_{\mathrm{b}}$ and $\mathrm{ATT}_{\mathrm{c}}$ indicate the worthiness of continuation of the program, the neutral and negative $\mathrm{ATT}_{\mathrm{c}}$ in some CFs signals the need for greater policy, management, monitoring and motivational support to communities managing forests under CFP. 
Differential $\mathrm{ATT}_{\mathrm{b}}$ and $\mathrm{ATT}_{\mathrm{c}}$ in different categories of CFs clearly indicate the inadequacy of evaluating the effect of CFP at a national scale to identify local effects. Different results across geographical regions suggest that rather than a "cookie-cutter approach" or "one size fits all approach" to forest management, adaptive and areaspecific policies and programs are critical for promoting biodiversity conservation and sequestering greater amounts of carbon. Such policies and programs need to provide communities with practical guidance for adopting locally suitable management options. This finding challenges the government's current efforts toward CFP that promote homogenous policy and program irrespective of geographic and topographic regions and forest qualities. For instance, the same CFP is applicable for natural and plantation forests, large and small-sized forests, forests in high-hill, mid-hill and Terai and opencanopy and closed canopy forests.

It is less clear whether estimated $\mathrm{ATT}_{\mathrm{b}}$ and $\mathrm{ATT}_{\mathrm{c}}$ in different categories of forests are driven by different factors and/or differing degrees of bias. These results point to the need for future research that helps explore why CFP is effective in some areas but ineffective in others, how communities interpret and apply CFP, and what motivational and capacity building supports to communities are needed. Such research would contribute to amending current the CFP to make it more compatible with the CBD and REDD+. In the context of inadequacy of systematic database systems instituted in Nepal (and perhaps in many tropical countries), creating national and landscape level databases is critical to advance future studies. 
My research adds to the slowly growing literature of impact evaluations of communitybased conservation policy (e.g., Bluffstone et al.; 2015; Pandey et al. 2014; Thapa-Magar \& Shrestha; 2015). First, my study employs a robust method to reduce bias in estimates and strengthens the claim that I have measured the causal effects of Nepal's CFP. Second, this is one of the pioneer studies of its kind investigating the impact of CFP on biodiversity and carbon. Finally, in contrast to the more common focus on aggregate deforestation and poverty outcomes of conservation programs, I responded to recent calls emerged due to introduction of REDD+ (UNFCCC, 2007b; UNFCCC, 2015) to better tailor impact evaluations by examining outcomes on biodiversity conservation and carbon storage.

The estimation of $\mathrm{ATT}_{\mathrm{b}}$ and $\mathrm{ATT}_{\mathrm{c}}$ is invariably difficult although matching based on a large number of confounders helps overcome difficulties. Certain levels of imbalance in the observed confounders still exists, although SMD is brought below an acceptable cutoff point, resulting in increased variations in $\mathrm{ATT}_{\mathrm{b}}$ and $\mathrm{ATT}_{\mathrm{c}}$ estimates. As there are multiple, applicable matching algorithms with certain pros and cons, and tradeoffs need to be made in choosing matching techniques, there is room for questions on the quality of matching. The use of only SMD as a criterion to check the acceptability of the match balance may also be considered a limitation of my analysis. Also, despite the execution of sensitivity analysis, analytical and communicative complexities are prevalent in my results as they are sensitive to the possibility of spurious variation driven by the effect of unobservable confounders. Unobservable confounders may include the existence of strong leaders and communities' motivation affecting the probability of assignment to the 
CFP, carbon sequestration and/or biodiversity conservation. Also, the estimated results do not reflect the bias induced by biological (e.g., life form, species, growth rate, wood density and stage of life cycle), and ecological (e.g., successional stage, species composition, disturbance regime) factors.

\subsection{Conclusion}

Using cross-sectional data and robust analytical methods for evaluating $\mathrm{ATT}_{\mathrm{b}}$ and $\mathrm{ATT}_{\mathrm{c}}$ estimates, I demonstrate the existence of positive, neutral and negative effects of CFP nationally, across geographic, topographic, and geo-political regions and in different forest qualities. Specifically, the CFP in lower slopes and open canopies perform positively and at higher altitudes performed negatively in both biodiversity conservation and carbon storage. The CFP at lower altitudes, closed canopies and hills do not reflect a unique path to contribute to biodiversity and carbon stock. My findings provide critical methodological and substantive information in evaluating the communities' contributions to global environmental initiatives such as CBD and REDD+ by providing impacts on biodiversity conservation and carbon sequestration. In aggregate, evidence demonstrates that the CFP has the potential to conserve biodiversity and sequester carbon in forests, albeit differently across geography, topography and canopies. This indicates the possibility of CFP to support global environmental initiatives such as CBD and REDD+. However, dedicated, appropriate policies that motivate and capacitate communities to implement active forest management and enhance performance of forests in conserving more biodiversity and stocking more carbon is critical to realize this potential. 
As the CFP is a viable approach towards incentivizing communities that spur effects in $\mathrm{NCF}$ as well, attempts to promote CFP are crucial for obtaining local communities' real and authentic contributions for promoting biodiversity conservation and carbon sequestration. Equally important is to create awareness of global environmental issues and build capacity to contribute to addressing those issues at the local level.

Given that average effects of CFP at the national level may be misleading, heterogeneous effects of CFP across forest categories provide useful insights for regional or landscapelevel planning. Regional analyses provide critical insights about the factors responsible for different levels of effectiveness of CFP. A locally specific cautious approach to exploring key drivers of heterogeneity is crucial to help make policy and management plans of biodiversity- and carbon- focused forestry effective. Landscape-level assessments of CFP effectiveness may add value in informing locally suitable planning and management of forest resources. 


\section{Chapter 4: An Assessment of Causal Effects of the Nepalese Community Forestry Program on Equity in Benefit Sharing}

\subsection{Introduction}

Equity reflects justice in day-to-day interactions primarily in relation to the distribution of social, political and economic goods and bads (Rawls, 1971). Equity implies "fair treatment or due reward" (Schroeder \& Pisupati, 2013:13) and involves getting a "fair share" which is not biased by any personal stake and varies according to different situations and cultures (Fisher, 1989). Equity ideally refers a fair opportunity i.e., free from bias to everyone to participate in decision making processes and thus access resources with their full potential as they need (Luintel, 2006). However, the concept of equity is founded on the equality of liberty, opportunity, rights, welfare, utility and income (Sen, 1992:ix).

In the context of environmental management, equity is related to resource access, livelihood security and social dignity of resource-managing communities. Equity motivates resource-managing communities and leads to economic and ecological gains (McDermott, 2009). Equity is increasingly considered to be a legitimate basis for the management of forest commons (e.g., Li, 1996); it affects credibility, acceptability and social and environmental outcomes of any environmental management initiative, and particularly those that emerge at the global level and trickle down to the local level. For instance, one such contemporary environmental initiative is the United Nations Program on Reducing Emissions from Deforestation and Forest Degradation, conservation and enhancement of forest carbon and sustainable management of forest in developing countries (REDD+), in which equity is a paramount concern. REDD+ values "forest" as 
an economic commodity (Arsel \& Buscher, 2012; Mcafee, 2012), which affects historical and contemporary forms of resource distribution and appropriation (e.g. Fairhead et al., 2012), leading to change in power and economic relations between different forestry actors. Researchers, policy makers and practitioners have raised concerns that REDD+ may lead to social conflict and environmental degradation if equity at the grassroots level is not addressed properly (e.g., Boyce et al., 2007; Patel et al., 2013; Paudel et al., 2015). Focusing on equity rather than on participation would allow more effective implementation of conservation initiatives (Smith \& McDonough, 2001). However, equity remains a largely unresolved issue in the REDD+ development process.

Many governments in tropical countries promote decentralized forestry to engage forestdependent communities and households in the conservation and management of local forests. Decentralized forestry formally provides forest rights and incentives to forestmanaging communities (Charnley \& Poe, 2007; Larson \& Soto, 2008). However, studies have shown both positive and negative results of decentralized forestry on equity and thereby have invited debates. Advocates pitch decentralized forestry as an effective approach to increasing access to forest benefits and improving rural wellbeing. For instance, the Right and Resource Initiative (2014) indicates that decentralized forestry may reduce rural poverty and halt environmental degradation; it provides vital resources and safety nets to the rural poor for subsistence livelihoods, particularly when other sources of production and income are not available (Beck \& Nesmith, 2001). Decentralized forestry devolves power to local communities fostering the evolution of equitable, fair and inclusive processes and outcomes (e.g., Luintel, 2006) and reduces 
inequity by generating positive change at community and higher levels (e.g., McDermott \& Schreckenberg, 2009). Persha and Anderson (2014) and Luintel (2006) argue that equity in decentralized forestry has improved primarily due to the support of forestry projects and civil society organizations. The World Bank (2001) also noted that legally recognized community forest user groups (CFUGs) receive required supports from a range of state and non-state actors to improve institutional practices and forest management.

Agrawal and Ostrom (2001) point out that the equity outcome of forest commons, including decentralized forestry, may not necessarily meet this expectation. In line with this view, Adhikari (2005), Agarwal (2001), Iversen et al. (2006) and Thoms (2008) demonstrated that even much acclaimed decentralized forestry in South Asia is associated with communities' unequal forest access. Because of the inequitable distribution of forest products, the gap between the rich and poor forest users is widening and the involvement of poor and marginalized communities in forest management activities has been decreasing in the hills of Nepal (Lamichhane \& Parajuli, 2014). Mahanthy et al. (2009) demonstrated that inequity in benefit sharing is common due to differential power, assets and capacity among forest-managing community members. Inequities are reinforced by local as well as wider societal processes (Hobley, 2007) including unequal economic and cultural power relations (Bist, 1991), elite capture ${ }^{6}$ in decision-making and resources

\footnotetext{
${ }^{6}$ Elite capture refers to the process by which local elites - individuals with superior political status due to economic, educational, ethnic or other social characteristics - take advantage of their positions to amass a disproportionately large share of resources or a flow of benefits, curtaining the benefits of the larger population (Bardhan, 2002).
} 
(Persha \& Anderson, 2014) and exclusion of the poor in economic growth and commercialization processes (Beck \& Nesmith, 2001).

Robust empirical evaluations of the effectiveness of decentralized forestry on equity are lacking. This knowledge gap not only limits the credibility and legitimacy of the program but also constrains the contributions of forestry actors in implementing innovative, productive forest management systems in the context of newly emerging global environmental concerns: biodiversity loss and carbon emissions. Therefore, empirical research using robust analytical methods to conclusively evaluate the linkages between decentralized forestry and equity is critical.

The Nepalese community forestry program (CFP), a form of decentralized forestry, is one of the most popular and extensive forestry programs to revitalize degraded forests in Nepal and fulfill the demand of subsistence forest products in rural areas. The CFP offers a unique opportunity for research to examine causal effects of CFP on equity; it has 40 years of history of managing $\sim 1.8$ million hectares of forest engaging $\sim 42 \%$ of people from a wide range of socio-economic backgrounds (Department of Forest [DoF], 2015). The CFP legally recognized $\sim 19,000$ CFUGs, as autonomous public bodies having perpetual succession that can acquire, possess, transfer or manage property (Ministry of Law and Justice [MoLJ], 1993). The sizes and compositions of forests and CFUGs vary across Nepal based on the distribution of forests and households. Diverse sizes and compositions of forests and households create opportunities to understand, and pose challenges to achieve, equity in forest-managing communities. In addition, many 
communities across the country are traditionally informally engaged in forest management and bring a range of age-old benefit sharing practices.

In this research, I specifically examined whether and how much the Nepalese CFP increases equity at the household level across the country, social groups (i.e., poor, dalit, indigenous peoples and women-headed households) and geographic regions (i.e., hill and Terai). I used cross-sectional data collected in 2013 from nationally representative random samples of community forest $(\mathrm{CF})$ and corresponding non-CF (NCF). I used both survey data from 130 forests and perceptions of 1300 forest-managing households. I followed a quasi-experimental, matching method - a method that mimics randomized experiments - to analyze the data. The most prominent challenge in this research is to deduce an appropriate counterfactual i.e., estimating equity in the absence of the program (e.g., Hendrickson, 2008).

By using only matched samples, I estimated the average treatment effect on the treated (ATT) i.e., the average effect of CFP on equity $\left(\mathrm{ATT}_{\mathrm{e}}\right)$. As national-level estimates may mask a great deal of variation in the effectiveness of CFP across social groups and geographic regions, I estimated the $\mathrm{ATT}_{\mathrm{e}}$ across social groups and geographic regions. I also estimated whether, where and to what extent my $\mathrm{ATT}_{\mathrm{e}}$ can be affected by hidden bias caused by unobserved confounders by testing the sensitivity. My research broadens and deepens the scientific understanding on the effects of CFP on equity. The CFP effect on equity across social groups and geographic regions will provide crucial insights and evidence to researchers, policy makers and managers to plan future courses of action targeting different social groups and/or geographic regions. My results and methods are 
applicable beyond Nepal to include countries that are practicing decentralized forestry. My results provide critical insight to assist REDD+ policy makers and planners in making REDD+ and CFP more compatible.

\subsection{Research methods: site, design and analytical model}

The data presented are part of an on-going multi-disciplinary research project funded by the World Bank and jointly implemented by Portland State University and ForestAction Nepal (Bluffstone et al., 2015). The primary aim of the project was to assess the potential synergies and/or tradeoffs between Nepalese forest commons and REDD+.

\subsubsection{Sampling methods, sample sites and data collection}

The researchers at ForestAction Nepal and I randomly selected 65 CFUGs from a pool of 137 national random samples of CF impact from a study conducted by the Nepalese government during 2010-2012. We then randomly selected ten households from each CFUG to survey. The field team selected 65 non-CFs in such a way that they were analogous to CFs in a variety of characteristics. Such non-CFs were close, but not next to, CFs to avoid being used simultaneously by the same people. The selected CFs and nonCFs were distributed in the tropical, sub-tropical and temperate climatic zones of 42 (out of 75) districts across the country (Figure 4.1). A total of 1300 households (i.e., 10 households from each group) were surveyed. 


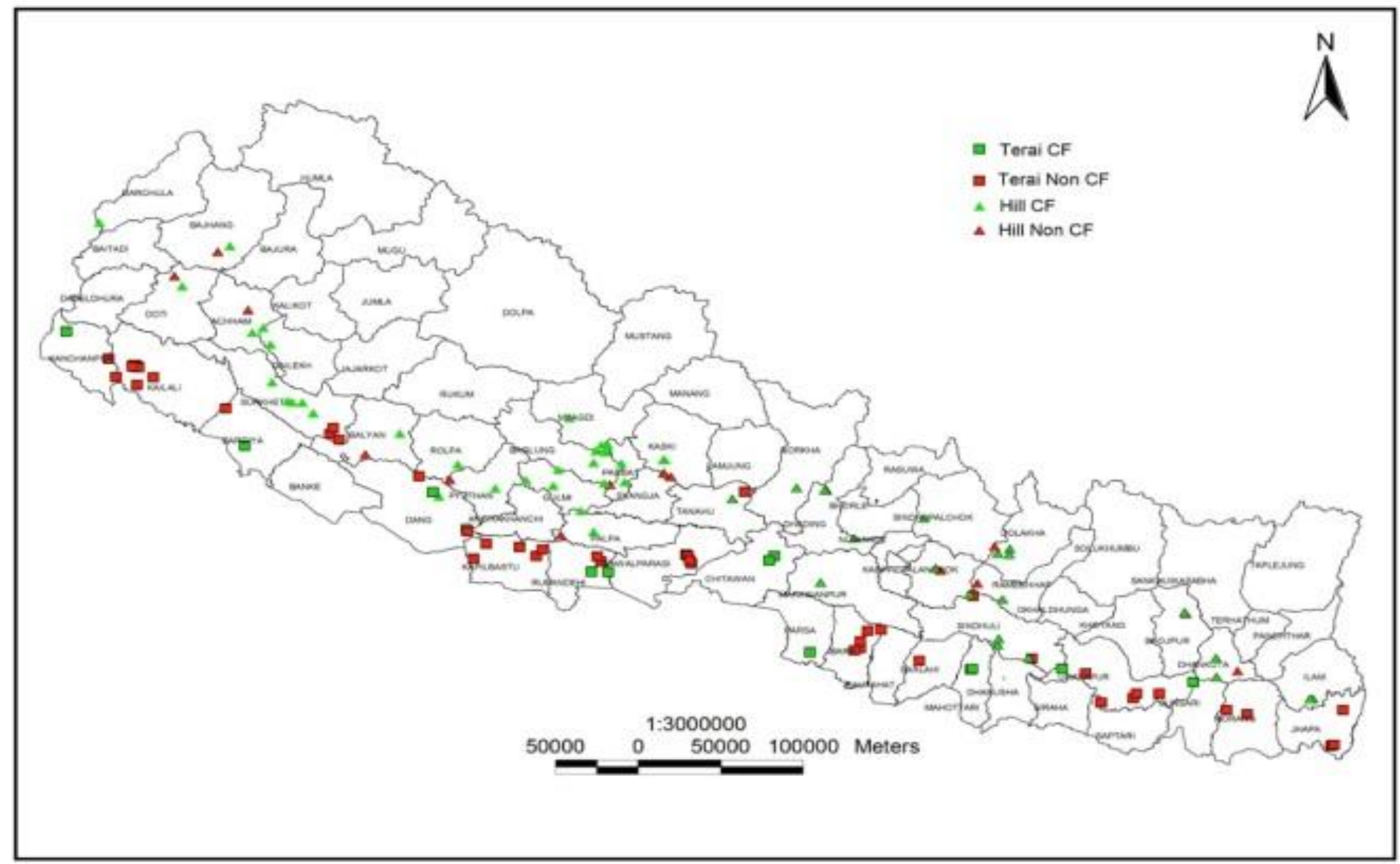

Figure 4.1 Distribution of sample plots 
By considering research objectives, a set of structured questions were developed for household surveys. Questions were tested in two CFUGs for their appropriateness and finalized before conducting the survey. Both quantitative (e.g., resource availability, socio-economic profile) and qualitative (e.g., perspectives and experience) data were collected from the survey. The data were collected from March to May 2013.

ForestAction recruited a team of 25 Nepalese field researchers with whom I closely worked to collect the data. Each of the field researchers had undergraduate degrees in forestry (12) and graduate degrees in social science (13), and ForestAction trained them to conduct forest surveys, forest inventories and household surveys.

The training helped field researchers develop a common understanding of the research and use the questionnaires effectively and efficiently during the survey. Field surveyors were closely monitored and constantly supported by the ForestAction researchers to ensure effectiveness of the survey and quality of the data.

\subsubsection{Variable selection and measurement}

\subsubsection{Treatment and control variable}

The treatment variable is the implementation of a formal CFP. Local communities and/or the Nepalese government opt into CF status and therefore the data are observational and non-random. On the other hand, the non-implementation of CFP, specifically the NCFs, are the control variable. The resources of the NCFs are formally owned by, and management responsibilities are vested on, the Nepalese government. However, they remain open access (i.e., depletable, rivalrous and non-excludable resources), and local 
communities may protect and use the resources available in NCFs, particularly nontimber forest products, for fulfilling subsistence needs.

\subsubsection{Outcome variable: the equity index}

Equity constitutes contextual, procedural and distributional dimensions (McDermott et al. 2013). While contextual dimension refers to the overall capacity of different actors to participate and capture benefits; procedural dimension focuses on the equity in decisionmaking processes; and the distributional dimension focuses on how costs, benefits and risks are distributed among actors across time and space (McDermott et al. 2013). All these dimensions are important to understand the dynamics of equity in forest commons. Households may use different substantive, context-specific criteria and indicators to view, and have different experience and perspectives on, these dimensions. Household perceptions on these dimensions help create a complete picture of the equity.

Considering these dimensions, I constructed a composite measure of equity, equity index. Equity index here means an accumulation of scores from a variety of individual items that reflect above-mentioned three dimensions that together form households' perceptions of equity. Such an index is intended to capture most of the underlying ethics and assumptions of ongoing processes of forest governance and management in relation to benefit sharing. I used four different variables that reflect fairness at different stages of benefit-sharing systems to construct equity index (Table 4.1). First, I used the fairness in benefit sharing rules that exist in the community. Such rules are normally prepared considering the socio-cultural and economic practices and resource condition of the community, which primarily reflect the contextual dimension of equity. Second, I used 
the fairness in the processes of benefit sharing, which is generally guided by certain governance principles. Such principles construct the foundation of procedural dimension of equity that affect the level of acceptance of benefit sharing practice. Third, I used the fairness of benefit sharing practice, which reflects the distributive aspect of equity in benefit sharing. At last, I also used the existence of conflict related to benefit sharing. It is important indicator that captures the satisfaction of forest users at the post benefit sharing situation.

Table 4.1 The description of indicators used to create the equity index and their measurement units.

\begin{tabular}{lll}
\hline Variables & Definition of variables & Measurement unit \\
\hline Fair rule & $\begin{array}{l}\text { Existence of fair system of benefit sharing } \\
\text { (e.g., selecting forest beneficiaries) }\end{array}$ & $\begin{array}{l}1-5=\text { Strongly disagree to } \\
\text { strongly agree }\end{array}$ \\
Fair process & $\begin{array}{l}\text { Existence of fair and acceptable system of } \\
\text { accessing and distributing forest benefits. }\end{array}$ & $\begin{array}{l}1-5=\text { Strongly disagree to } \\
\text { strongly agree }\end{array}$ \\
Fair practice & Existence of fair benefits distribution. & $\begin{array}{l}1-5=\text { Strongly disagree to } \\
\text { strongly agree }\end{array}$ \\
& & Yes=1, Neutral=3, No=5 \\
$\begin{array}{l}\text { Existence of } \\
\text { conflicts }\end{array}$ & $\begin{array}{l}\text { Existence of conflicts and problems in } \\
\text { benefit distribution. }\end{array}$ & \\
\hline
\end{tabular}

The four variables had different weights depending on the data structure. I identified the weights of these variables considering variations explained by each variable through employing a principal component analysis (PCA) ${ }^{7}$ as described in Organization for the

\footnotetext{
${ }^{7}$ PCA is a simple and non-parametric method of extracting relevant information from confusing data sets that helps extenuate the problem of multicollinearity and identifies the weights for each factor in constructing an index. It reduces dimensionality of a data set by performing a covariance analysis between factors and maximizes the correlation between the original variables and new uncorrelated factors that are mutually orthogonal. Then the eigen technique, which transforms the original set of inter-correlated variables into a new set with an equal number of independent uncorrelated factors, is used for factor analysis. The principal factors are then classified in decreasing order according to the percentage of the variance they account for so that most of the variation in the data can be described by the first few factors that can be used to represent the original observations.
} 
Economic Cooperation and Development (2008). In order to prevent any single variable having undue influence on the composite index, I standardized the variables by creating a correlation matrix, so as to have zero means and unit variance at the start of the analysis. Diagnostic checks of the data showed that the assumptions for PCA were met; specifically, all the variables were correlated or internally consistent with the principal components $($ Cronbach alpha $=0.71(95 \% \mathrm{CI}=0.66-0.75))$; sampling adequacy scored as "middling" to "meritorious" (Kaiser-Meyer-Olkin Measure = $0.64-0.85$ ); and the data had different variance (Bartlett test of sphericity $=211.14, \mathrm{df}=3$, $\mathrm{p}$-value $=<0.000$ ). As my interest is to determine the weights for each variable to construct an equity index (as opposed to minimizing the number of variables), I selected the principal components that have at least one of the following attributes: (i) factors that have associated eigen values larger than one commonly known as the Kaiser criteria (Lise, 2007; Manly, 2005), (ii) factors that contribute cumulatively to the explanation of the overall variance by $>60 \%$, and (iii) factors that contribute at least $10 \%$ to the overall variance explanation. On these bases, I selected all four principal components for further analysis, which explain $100 \%$ of total variance (Table 4.2). Then I performed a varimax rotation of the original variables associated with each of the selected principal components and ensured that each variable is maximally correlated with one principal component (Jolliffe, 2002). The rotation provided component loadings for each variable. Components that have a greater than 0.5 loading were identified as important for further analysis. 
Table 4.2 Eigenvalues of the reduced correlation matrix, factor pattern and weight factor.

\begin{tabular}{|c|c|c|c|c|c|c|}
\hline \multirow{2}{*}{$\begin{array}{l}\begin{array}{l}\text { Principal } \\
\text { components }\end{array} \\
1\end{array}$} & \multirow{2}{*}{$\begin{array}{c}\begin{array}{c}\text { Eigen } \\
\text { values }\end{array} \\
1.60\end{array}$} & \multirow{2}{*}{$\begin{array}{c}\begin{array}{c}\text { Proportion } \\
\text { of variance }\end{array} \\
0.40\end{array}$} & \multicolumn{4}{|c|}{ Cumulative proportion of variance } \\
\hline & & & & & .40 & \\
\hline 2 & 1.06 & 0.27 & & & .67 & \\
\hline 3 & 0.77 & 0.19 & & & .86 & \\
\hline 4 & 0.57 & 0.14 & & & 1 & \\
\hline \multicolumn{7}{|l|}{ Cronbach alpha $=0.71$} \\
\hline $\begin{array}{l}\text { Variables/ } \\
\text { components }\end{array}$ & $\begin{array}{l}\text { Compo } \\
\text { nent } 1\end{array}$ & $\begin{array}{c}\text { Compo } \\
\text { nent } 2\end{array}$ & $\begin{array}{l}\text { Compo } \\
\text { nent } 3\end{array}$ & $\begin{array}{l}\text { Compo } \\
\text { nent } 4\end{array}$ & $\begin{array}{c}\text { Component } \\
\text { scores* }\end{array}$ & $\begin{array}{c}\text { Variable } \\
\text { weights* } \\
*\end{array}$ \\
\hline Fair rule & -0.47 & 0.43 & -0.32 & 0.71 & 0.071 & 0.1080 \\
\hline Fair process & -0.50 & 0.44 & -0.25 & -0.71 & 0.100 & 0.1518 \\
\hline Practice & -0.33 & 0.23 & 0.92 & 0.05 & 0.161 & 0.2450 \\
\hline Existence of conflict & -0.66 & -0.75 & -0.04 & 0.01 & 0.327 & 0.4970 \\
\hline Explained variance & 1.60 & 1.06 & 0.77 & 0.57 & 0.659 & 1 \\
\hline $\begin{array}{l}\text { Proportion of } \\
\text { explained variance }\end{array}$ & 0.40 & 0.27 & 0.19 & 0.14 & & \\
\hline
\end{tabular}

Note: Numbers in bold face denote a dominating indicator (factor loading $\geq 0.5$ or $\leq-0.5$ ).

* Factor scores: square the significant loading factor $(>0.5)$ and multiply by the proportion of explained variance.

** Variable weights: Factor scores scaled to 1.

Component 1 accounted for $40 \%$ of the common variance and received moderately negative loadings from process (-0.50) and conflict (-0.66). Component 2 explained $27 \%$ of the common variance and received moderately negative loadings from conflict $(-0.75)$. Component 3 accounted for $19 \%$ of total variance and largely depended on the actual practice of benefit distribution (0.92). Component 4 accounted for $14 \%$ of the common variance and received positive leadings from rule (0.71) and negative leadings from conflict (-0.71). By using the factor loadings and the proportion of variance explained by principal factors, I calculated the weight for each indicator (Table 4.2). The weights for rule, process, practice and conflict-related indicators of equity are $0.1080,0.1518,0.2450$ 
and 0.4970 , respectively. I used these weights to construct the equity index for each household. The equity index ranges from $0-1$, where 0 means no equity at all and 1 means full equity. The descriptive statistics of equity index and the variables used are given in the Table 4.3 below.

Table 4.3 The descriptive statistics of equity index and the variables used to construct index.

\begin{tabular}{lrrrr}
\hline Variables & Mean & Standard deviation & Minimum & Maximum \\
\hline Equity index & 0.75 & 0.16 & 0.2 & 1 \\
Fair rule & 3.57 & 1.00 & 1 & 5 \\
Fair process & 3.49 & 1.03 & 1 & 5 \\
Fair practice & 3.62 & 0.91 & 1 & 5 \\
Existence of conflicts & 4.27 & 1.32 & 1 & 5 \\
\hline
\end{tabular}

\subsubsection{Confounding variables}

As communities opted into CFP or were persuaded by the Nepalese government to join, there were a number of confounders that affected treatment status and/or outcomes. Confounders may inflate bias in $\mathrm{ATT}_{\mathrm{e}}$ estimates (Heinrich et al., 2010). I controlled the confounding variables ("confounders") through a matching process so as to minimize error and identify the optimum matches between CF and NCF households. Matching allowed me to develop a counterfactual control group from NCF households that provided information about what would have happened in regards to equity in the absence of CFP (Pattanayak, 2009).

On the basis of the literature and focus group discussions with 10 different forestmanaging communities and one consultation meeting with experts at Kathmandu in the year 2012, I identified 14 observable confounders determined by forest/topographical 
characteristics and communities. I analyzed the relationships between confounders and CFP assignment for social groups and geographic regions (Table 4.4). If treatments were randomly assigned, the coefficients should be statistically insignificant.

Forest area: Forest area had a significant positive effect on the probability of a forest being selected under CFP; each additional hectare of forest adds to the expected log odds of selection by $0.0136,0.0150$ and 0.0260 in poor, indigenous people and women-headed households, respectively. This is reasonable as the local communities prefer to obtain larger-sized forests, which provide more resources. Also, the Nepalese government has a policy of handing over forest according to the community's willingness and capacity to manage (MoLJ, 1995).

Forest topography: Forest slope had a significant positive effect on the probability of a forest to be selected under CFP; each additional degree of slope adds to the expected log odds of selection by 0.2889 in poor communities and 0.3871 in indigenous populations. This is reasonable as the Nepalese government prioritized CFP in the hills.

According to my data, some of the confounders such as the number of forest user households, travel time to the nearest road-head from the forest, altitude, moisture, soil erosion, presence of Shorea robusta, years of communities conserving the forest, broadleaf-conifer gradient, NDVI 1989, proportion of households living in the village for at least 2 generations, proportion of ethnic population and proportion of poor are not significantly related with the assignment into the CFP. However, these confounders are important decision criteria during the initial years of CFP and therefore I kept them in the analytical models (see Section 3.3.2.3). 
Table 4.4 Observed confounders and their relationships with CFP assignment.

The model of relationship is generated using the probit model considering probability of forest selected under CFP as the dependent variable and confounders as independent variables. The coefficients and the pvalues in parentheses are reported. A blank space indicates that the concerned confounder is not used in the model to achieve matching in the particular forest category.

\begin{tabular}{|c|c|c|c|c|c|c|c|}
\hline Confounders & Overall & Poor & Dalit & $\begin{array}{l}\text { Indigen } \\
\text { ous } \\
\text { people } \\
\end{array}$ & $\begin{array}{l}\text { Women- } \\
\text { headed } \\
\text { household }\end{array}$ & Hill & Terai \\
\hline Intercept & $\begin{array}{l}-4.7807 \\
(0.821)\end{array}$ & $\begin{array}{l}-6.3900 \\
(0.5966)\end{array}$ & $\begin{array}{l}-5.3460 \\
(0.563)\end{array}$ & $\begin{array}{l}-3.2570 \\
(0.794)\end{array}$ & $\begin{array}{l}-4.6678 \\
(0.641)\end{array}$ & $\begin{array}{l}-9.3334 \\
(0.843)\end{array}$ & $\begin{array}{l}-8.6736 \\
(0.782)\end{array}$ \\
\hline Forest area & $\begin{array}{l}0.0229 \\
(0.201)\end{array}$ & $\begin{array}{l}0.0136 \\
(0.004)\end{array}$ & $\begin{array}{l}0.0125 \\
(0.177)\end{array}$ & $\begin{array}{l}0.0150 \\
(0.0427)\end{array}$ & $\begin{array}{l}0.0260 \\
(0.0454)\end{array}$ & & $\begin{array}{l}0.0185 \\
(0.225)\end{array}$ \\
\hline $\begin{array}{l}\text { Number of forest } \\
\text { user households }\end{array}$ & $\begin{array}{l}-0.0003 \\
(0.921)\end{array}$ & $\begin{array}{l}0.0005 \\
(0.802)\end{array}$ & $\begin{array}{l}-0.0023 \\
(0.687)\end{array}$ & $\begin{array}{l}0.0003 \\
(0.879)\end{array}$ & $\begin{array}{l}0.0013 \\
(0.626)\end{array}$ & $\begin{array}{l}0.0874 \\
(0.129)\end{array}$ & $\begin{array}{l}-0.0008 \\
(0.799)\end{array}$ \\
\hline $\begin{array}{l}\text { Travel time to } \\
\text { nearest road }\end{array}$ & $\begin{array}{l}-0.1290 \\
(0.965)\end{array}$ & $\begin{array}{l}0.0036 \\
(0.998)\end{array}$ & $\begin{array}{l}-0.9081 \\
(0.529)\end{array}$ & $\begin{array}{l}-0.9320 \\
(0.618)\end{array}$ & $\begin{array}{l}-0.1298 \\
(0.915)\end{array}$ & $\begin{array}{l}-0.5000 \\
(0.906)\end{array}$ & $\begin{array}{l}1.4275 \\
(0.761)\end{array}$ \\
\hline Altitude & $\begin{array}{l}0.0043 \\
(0.552)\end{array}$ & $\begin{array}{l}0.0019 \\
(0.521)\end{array}$ & $\begin{array}{l}0.0028 \\
(0.435)\end{array}$ & $\begin{array}{r}0.0010 \\
(0.774)\end{array}$ & $\begin{array}{l}0.0018 \\
(0.520)\end{array}$ & $\begin{array}{l}-0.0017 \\
(0.889)\end{array}$ & $\begin{array}{l}0.0024 \\
(0.834)\end{array}$ \\
\hline Slope & $\begin{array}{l}0.4287 \\
(0.191)\end{array}$ & $\begin{array}{l}0.2889 \\
(0.041)\end{array}$ & $\begin{array}{l}0.2136 \\
(0.175)\end{array}$ & $\begin{array}{l}0.3871 \\
(0.000)\end{array}$ & $\begin{array}{l}0.1936 \\
(0.173)\end{array}$ & $\begin{array}{l}0.077 \\
(0.902)\end{array}$ & $\begin{array}{l}0.2785 \\
(0.581)\end{array}$ \\
\hline $\begin{array}{l}\text { Years of } \\
\text { communities } \\
\text { conserving forest }\end{array}$ & $\begin{array}{l}-0.0185 \\
(0.850)\end{array}$ & $\begin{array}{l}0.0095 \\
(0.875)\end{array}$ & $\ldots$ & $\begin{array}{l}-0.0076 \\
(0.904)\end{array}$ & $\begin{array}{l}0.0698 \\
(0.533)\end{array}$ & $\begin{array}{l}0.0411 \\
(0.765)\end{array}$ & $\begin{array}{l}-0.0533 \\
(0.693)\end{array}$ \\
\hline Moisture gradient & $\begin{array}{l}-0.5303 \\
(0.849)\end{array}$ & $\begin{array}{l}-0.1289 \\
(0.930)\end{array}$ & $\ldots$ & $\begin{array}{l}0.0171 \\
(0.991)\end{array}$ & $\begin{array}{l}-0.0897 \\
(0.939)\end{array}$ & $\begin{array}{l}1.1895 \\
(0.845)\end{array}$ & $\begin{array}{l}-0.2624 \\
(0.946)\end{array}$ \\
\hline $\begin{array}{l}\text { Broadleaf-conifer } \\
\text { gradient }\end{array}$ & $\begin{array}{l}-0.0152 \\
(0.997)\end{array}$ & $\begin{array}{l}0.1528 \\
(0.951)\end{array}$ & $\begin{array}{l}1.2342 \\
(0.638)\end{array}$ & $\begin{array}{l}0.0857 \\
(0.979)\end{array}$ & $\begin{array}{l}-0.5451 \\
(0.799)\end{array}$ & $\begin{array}{l}-0.3970 \\
(0.961)\end{array}$ & - \\
\hline $\begin{array}{l}\text { Presence of Shorea } \\
\text { robusta }\end{array}$ & $\begin{array}{l}-2.4642 \\
(0.736)\end{array}$ & $\begin{array}{l}-2.1250 \\
(0.537)\end{array}$ & $\begin{array}{l}-1.4444 \\
(0.672)\end{array}$ & $\begin{array}{l}-2.4325 \\
(0.570)\end{array}$ & $\begin{array}{l}-2.2193 \\
(0.482)\end{array}$ & $\begin{array}{l}0.0166 \\
(0.999)\end{array}$ & $\begin{array}{l}-6.5473 \\
(0.541)\end{array}$ \\
\hline $\begin{array}{l}\text { Presence of soil } \\
\text { erosion }\end{array}$ & $\begin{array}{l}-2.3708 \\
(0.703)\end{array}$ & $\begin{array}{l}-1.6544 \\
(0.6157)\end{array}$ & $\begin{array}{l}-1.1956 \\
(0.714)\end{array}$ & $\begin{array}{l}-2.3963 \\
(0.544)\end{array}$ & $\begin{array}{l}-1.0150 \\
(0.703)\end{array}$ & $\begin{array}{l}0.5564 \\
(0.962)\end{array}$ & $\begin{array}{l}-0.3563 \\
(0.969)\end{array}$ \\
\hline NDVI 1989 & $\begin{array}{l}-5.0557 \\
(0.863)\end{array}$ & $\begin{array}{l}-3.2999 \\
(0.817)\end{array}$ & $\begin{array}{l}-4.6764 \\
(0.756)\end{array}$ & $\begin{array}{l}-3.7593 \\
(0.833)\end{array}$ & $\begin{array}{l}-5.8121 \\
(0.648)\end{array}$ & $\begin{array}{l}-0.8161 \\
(0.989)\end{array}$ & $\begin{array}{l}7.0555 \\
(0.875)\end{array}$ \\
\hline $\begin{array}{l}\text { Proportion of } \\
\text { ancestral household } \\
\text { ( } \geq 2 \text { generations) }\end{array}$ & $\begin{array}{l}2.8127 \\
(0.775)\end{array}$ & $\begin{array}{l}3.8418 \\
(0.464)\end{array}$ & $\begin{array}{l}3.3199 \\
(0.578)\end{array}$ & $\begin{array}{l}2.1773 \\
(0.738)\end{array}$ & $\begin{array}{l}3.8504 \\
(0.464)\end{array}$ & $\begin{array}{l}3.8518 \\
(0.894)\end{array}$ & $\begin{array}{l}2.4360 \\
(0.855)\end{array}$ \\
\hline $\begin{array}{l}\text { Proportion of } \\
\text { ethnic population }\end{array}$ & $\begin{array}{l}0.6005 \\
(0.937)\end{array}$ & $\begin{array}{l}0.6275 \\
(0.838)\end{array}$ & $\begin{array}{l}0.0622 \\
(0.988)\end{array}$ & $\begin{array}{l}1.7862 \\
(0.267)\end{array}$ & $\begin{array}{l}-0.2088 \\
(0.941)\end{array}$ & $\begin{array}{l}1.1531 \\
(0.915)\end{array}$ & $\begin{array}{l}2.5174 \\
(0.817)\end{array}$ \\
\hline $\begin{array}{l}\text { Proportion of poor } \\
\text { population }\end{array}$ & $\begin{array}{l}-2.8359 \\
(0.749)\end{array}$ & $\ldots$ & $\begin{array}{l}-2.6501 \\
(0.603)\end{array}$ & $\begin{array}{l}-3.5630 \\
(0.528)\end{array}$ & $\begin{array}{l}-1.9762 \\
(0.627)\end{array}$ & $\begin{array}{l}5.5278 \\
(0.791)\end{array}$ & $\begin{array}{l}-8.1204 \\
(0.509)\end{array}$ \\
\hline
\end{tabular}




\subsubsection{Specification of analytical models}

\subsubsection{Addressing confounding through matching}

Because my study is observational, the principal problem in the estimation of $\mathrm{ATT}_{\mathrm{e}}$ is identifying counterfactuals and dealing with confounders particularly due to selection bias. Selection bias arises when the household of a CFP is not randomly selected, and CF households differ from NCF households for reasons other than their status as CF or NCF per se. Differences of CF and NCF confounders can effect equity in benefit sharing even if the CFP had no effect. Therefore, confounders need to be controlled and counterfactuals need to be identified so as to make matched households as good as random or statistically equivalent. Matched CF and NCF households allow comparisons to achieve unbiased measures of $\mathrm{ATT}_{\mathrm{e}}$.

I used a two-step method -nonparametric matching and analysis- for identification of counterfactuals and estimation of $\mathrm{ATT}_{\mathrm{e}}$. Matching, an ex post identification technique, reduces selection bias and generates a comparable set of NCF observations by controlling observed confounders (Ho et al., 2007; Imben, 2004; Rosenbaum \& Rubin, 1983; Sekhon, 2011). Appropriate matching asymptotically balances observed confounders by removing bias (Rosenbaum \& Rubin, 1983). However, there is no consensus on how exactly matching ought to be done, how to measure the success of the matching procedure, and whether matching estimators are sufficiently robust to misspecification (Heckman et al., 1998). 
Matching reduces selection bias only if assumptions of "conditional independence or unconfoundedness' and 'common support' are met (Rosenbaum \& Rubin, 1983). Conditional independence means that CFP status is independent of the confounders. Matching techniques control selection bias fully if all confounders determining CFP assignment are used, which is rare in practice as there could also be unobservable confounders. This is a strong assumption as it makes CF and NCF households comparable and must be justified by the data at hand. The "common support condition" refers to two important conditions - positive probability (i.e., existence of the positive probability of being both $\mathrm{CF}$ and $\mathrm{NCF}$ for values of each covariate) and overlap condition (i.e., finding adequate comparable matches that help reduce model dependence).

I developed matching and propensity score models by including 10 to 14 observed confounders that affect the assignment into CFP and equity in benefit sharing (Table 4.4). As the confounders were measured at community and forest level, I applied a mixedeffects probit model to estimate propensity scores at household level and fed the scores into the matching model. I found almost all variances (> 99\%) of random effects were attributed to the community or forest level effect and the fixed effects of confounders are discussed in Section 3.3.2.3.

I used $\leq 0.25$ standardized mean difference (SMD), a common numerical balance diagnostic criterion to check whether matching is satisfactory and acceptable, as the cutoff point for matching adjustment (Rubin, 2001). The SMD expresses the "standardized bias" and is similar to an effect size relative to the variability observed and estimated by dividing 'difference in mean outcomes between CF and NCF households' by "standard 
deviation of outcome among CF households". Reducing SMD minimizes the overt bias due to measured covariates in the ATTe estimates (Imai et al., 2008; Rubin \& Thomas, 1996).

I matched $\mathrm{CF}$ and NCF households based on observed confounders by using the MatchIt package of R 3.2.2 (Ho et al., 2007). I used the matching with replacement approach, allowing each selected NCF household to be matched to $\geq 1 \mathrm{CF}$ households, as this option provides the highest degree of balance and the lowest conditional bias (Abadie \& Imbens, 2006; Dehejia \& Wahba, 1999). I used genetic matching, a multivariate matching method that optimizes the confounding balance between $\mathrm{CF}$ and NCF households by automating the process of finding good matches using an evolutionary search algorithm (Diamond \& Sekhon, 2013). It is a generalization of propensity score and Mahalanobis distance matching (Rosenbaum \& Rubin, 1985), which minimizes balance measures by using pvalues. Mahalanobis metric is considered a useful tool to determine similarities between CF and NCF households even when there are several correlated confounders (Mahalanobis, 1936; Rubin, 1980).

In my dataset, I found that genetic matching was the best suited algorithm to balance the maximum number of confounders bringing the SMD below the acceptable limit (Appendix B). As the post-matching SMD for confounders is less than 0.25 standard deviations and the average SMD across all covariates are 0.11, 0.16, 0.14, 0.14, 0.12, 0.09 and 0.15 for the overall CFUG and across poor, dalit, indigenous and womenheaded households, and households across hills and Terai respectively, I was able to find a sufficient number of NCF households that are similar to CF households based on the 
covariates included in the matching process. It was not possible to bring SMD down to $\leq 0.25$ for travel time to the nearest road-head in poor and women-headed households and presence of Shorea robusta in the Terai while keeping as many covariates as possible in the matching models. However, I included those confounders in the matching models, as they contributed positively to achieving overall balance. A total of $20-63 \% \mathrm{NCF}$ households are matched with CF households in overall CFUGs and across different social and geographic categories. The average ratios of matched NCF to CF households range from 1:2.43 to 1:4.69 across social and geographic categories.

\subsubsection{Comparing equity}

The $\mathrm{ATT}_{\mathrm{e}}$ is estimated on the basis of average difference of equity in benefit sharing between matched $\mathrm{CF}$ and NCF households. As the test of average difference relies on the distributions of such differences, I checked whether the distributions are normal by using graphical plots (e.g., histogram and qq-plot) and the Shapiro-Wilk test. I found that such differences were not normally distributed and therefore using a t-test was not possible. However, data were independently collected and randomized through the matching process, so I used the pairwise Wilcoxon signed rank sum test to identify the [median] $\mathrm{ATT}_{\mathrm{e}}$ by deducting NCF values from CF values. I compared equity at different levels and categories such as for overall national level and across poor, dalit, ingigenous people and women-headed households and households across hills and Terai regions. Such results are crucial to identify the disaggregated local impact of CFP on the basis of recipients of benefit sharing. 


\subsubsection{Sensitivity analysis}

Matching methods are not robust against "hidden bias" arising from the existence of unobserved confounders that simultaneously affect assignment to CFP and outcomes. The legitimacy of matching is based on the assumption that the assignment to CFP is ignorable only when all the confounding covariates are employed in the analysis (Thoemmes \& Kim, 2011). Testing this assumption is empirically impossible as measuring all confounders is practically not possible. Therefore, sensitivity analysis is essential in helping us understand the robustness of research findings to potential hidden bias.

Following the model of sensitivity analysis approach proposed by Rosenbaum (2002, ch. 4) and using the sensitivitymv package in R 1.3, I explored how sustainable my $\mathrm{ATT}_{\mathrm{e}}$ estimates are in view of the potential effects of unobserved confounders. I quantified the degree to which a key model assumption - CFP assignment is effectively random conditional on the matches - must be violated in order for my results to be reversed. I estimated how strong the effects of unobserved confounders on the CFP would have to be to change the probability of assignment to CFP that significantly change my $\mathrm{ATT}_{\mathrm{e}}$ estimates. I used a sensitivity parameter, gamma $-\Gamma$, that shows critical levels of hidden bias as a quantity of difference in the odds of CFP assignment for two individuals with the same observed confounders but who diverge on unobserved confounders. A higher $\Gamma$ implies that the estimated $\mathrm{ATT}_{\mathrm{e}}$ results are robust against a greater potential selection bias, while a low $\Gamma$ implies that even a mild selection bias could make the estimate insignificant (where $\Gamma=1$ indicates that no hidden bias exists). I determined the smallest 
value of $\Gamma$ that will change the $p$-value of the "true" $\mathrm{ATT}_{\mathrm{e}}$ to a non-significant level (>0.05). When the p-value exceeds 0.05 , the $\Gamma$ value indicates the $\mathrm{CF}$ to $\mathrm{NCF}$ odds ratio at which $\mathrm{ATT}_{\mathrm{e}}$ estimates are sensitive to hidden bias. Since the sensitivity analysis for insignificant $\mathrm{ATT}_{\mathrm{e}}$ is not meaningful, I computed the critical level of hidden bias only for the significant CFP effects (Hujer et al., 2004).

\subsection{Effect of the Community Forestry Program on equity in benefit sharing}

Table 4.3 depicts that the absolute value of average equity at the household level is consistently higher in $\mathrm{CF}$ than NCF in all social and geographic categories. In $\mathrm{CF}$, the highest average equity is in the hill households (0.6591) and the lowest is in the dalit households (0.6044). In NCF, highest average equity is in the women-headed households (0.6032) and the lowest is in the indigenous households (0.5228).

The $\mathrm{ATT}_{\mathrm{e}}$ depicted the varied estimates and levels of sensitivity of the effect of the CFP on equity across social groups and geographic regions (Table 4.5). Equity in CF and NCF households in the overall, hills, poor, dalit and indigenous households is significantly non-identical $(\mathrm{p}<0.05)$, indicating the significant positive effects of the CFP on equity. The estimated $\mathrm{ATT}_{\mathrm{e}}$ in overall CFUGs, hills, poor, dalit, and indigenous households are $0.0937,0.0921,0.0505,0.1391$ and 0.0794 , respectively. The sensitivity analysis showed that these results can be nullified by the influence of unobserved confounders if the odds ratio of $\mathrm{CF}$ to $\mathrm{NCF}$ is changed by $2.01,1.74,1.91,1.14$ and 2.61 in overall, hill, poor, dalit, and indigenous households, respectively. In women-headed households (WHH) and households in the Terai, the results showed that $\mathrm{CF}$ and NCF households are identical and therefore the $\mathrm{ATT}_{\mathrm{e}}$ are insignificant $(\mathrm{p}>0.05)$. 
My national level $\mathrm{ATT}_{\mathrm{e}}$ estimates may mask variations in the effectiveness of the CFP on equity at household level across social categories and geographic locations. Therefore, I estimated $\mathrm{ATT}_{\mathrm{e}}$ separately for each social category. I found that $\mathrm{ATT}_{\mathrm{e}}$ estimates are overlapped within a $95 \%$ confidence interval in the overall, hill, poor, dalit and indigenous households. The higher CF to NCF odds ratio, narrower confidence interval and lowest SMD after matching indicate the less sensitive $\mathrm{ATT}_{\mathrm{e}}$ to unobserved confounders, the more precise $\mathrm{ATT}_{\mathrm{e}}$ estimate and the better match between $\mathrm{CF}$ and $\mathrm{NCF}$ households. These statistics reflect the more robust $\mathrm{ATT}_{\mathrm{e}}$ estimates.

Table 4.5 Average effect of the CFP on equity at household level and the results of sensitivity analysis by social group and geographic region.

Column 1 is the social and geographic categories of households. Columns 2 and 3 contain the number of $\mathrm{CF} / \mathrm{NCF}$ plots and average SMD of confounders before and after matching across social and geographic categories. Columns 4 and 5 present the mean equity of CF and NCF, respectively. Columns 6, 7-8 and 9 depict the $\mathrm{ATT}_{\mathrm{e}}$, lower and upper confidence levels of $\mathrm{ATT}_{\mathrm{e}}$ and p-values, respectively. The last two columns provide information about the sensitivities of estimated $\mathrm{ATT}_{\mathrm{e}}$ to the unobserved confounders. For sensitivity estimation, trimming was carried out at 2.5 times the median of the absolute matched difference, which is analogous to a trimmed mean that trims $5 \%$ outliers from each tails. I computed the critical level of hidden bias only for the significant CFP effects at a 5\% level of significance.

\begin{tabular}{|c|c|c|c|c|c|c|c|c|}
\hline \multirow{2}{*}{$\begin{array}{l}\text { Social } \\
\text { category/geo } \\
\text { graphic } \\
\text { regions }\end{array}$} & \multirow{2}{*}{$\begin{array}{l}\text { No. of } \\
\mathrm{CF} / \\
\mathrm{NCF}\end{array}$} & \multirow{2}{*}{$\begin{array}{l}\text { Mean SMD } \\
\text { of observed } \\
\text { confounders } \\
\text { (before/ after } \\
\text { matching) }\end{array}$} & \multicolumn{4}{|c|}{$\mathrm{ATT}_{\mathrm{e}}$} & \multicolumn{2}{|c|}{ Hidden bias } \\
\hline & & & $\begin{array}{l}\text { Point } \\
\text { estimate }\end{array}$ & $\begin{array}{l}\text { Lower } \\
\text { confiden } \\
\text { ce limit- } \\
95 \%\end{array}$ & $\begin{array}{l}\text { Upper } \\
\text { confiden } \\
\text { ce limit- } \\
95 \%\end{array}$ & $\begin{array}{l}\mathrm{p}- \\
\text { value }\end{array}$ & $\begin{array}{l}\text { Critical } \\
\text { level of } \\
\text { bias }(\Gamma)\end{array}$ & $P$ value \\
\hline Overall & $650 / 199$ & $0.40 / 0.11$ & 0.0937 & 0.0705 & 0.1103 & 0.000 & 2.01 & 0.055 \\
\hline Poor & $253 / 73$ & $0.41 / 0.16$ & 0.0921 & 0.0577 & 0.1226 & 0.000 & 1.91 & 0.053 \\
\hline Dalit & $94 / 33$ & $0.70 / 0.14$ & 0.0505 & 0.0108 & 0.0974 & 0.017 & 1.14 & 0.054 \\
\hline $\begin{array}{l}\text { Indigenous } \\
\text { people }\end{array}$ & $284 / 114$ & $0.33 / 0.14$ & 0.1391 & 0.1102 & 0.1699 & 0.000 & 2.61 & 0.051 \\
\hline WHH & $122 / 26$ & $0.47 / 0.12$ & 0.0324 & -0.0000 & 0.0705 & 0.062 & - & - \\
\hline Hill & $410 / 101$ & $0.20 / 0.09$ & 0.0794 & 0.0505 & 0.1066 & 0.000 & 1.74 & 0.051 \\
\hline Terai & 240/99 & $0.40 / 0.15$ & 0.0215 & -0.0108 & 0.0597 & 0.268 & - & - \\
\hline
\end{tabular}




\subsection{Discussion}

My analysis contributes to the recently emerging literature on the impact of formal forestry decentralization on equity (e.g., Adhikari \& Lovett, 2006; Luintel, 2006; Naidu, 2009; Thoms, 2008). By using nationally representative samples from formal community forest user groups and informal forest commons, and by utilizing robust analytical methods that reduced bias, I demonstrated the effect of CFP on equity. At the national level, different social groups such as poor, dalit, indigenous and women-headed households, and households in the hills, my results clearly demonstrated that the CFP has a positive effect on equity. However, the CFP has no statistically significant effects on equity at the household level in Terai region. My results showed the variations in $\mathrm{ATT}_{\mathrm{e}}$ across social and geographical groups of households. Such variations reflect the implementation of locally-suitable, equitable benefit sharing mechanisms in community forest user groups as provisioned by the Forest Act 1993, Forest Regulations 1995 and Community Forestry Directives 2008.

My $\mathrm{ATT}_{\mathrm{e}}$ estimates reflect findings of earlier studies. My results are in line with a recent study by Khanal Chhetri et al. (2016), who demonstrated, by taking Gini decomposition approach in five community forest user groups, that the community forests have an equalizing effect on household income distribution in the Nepalese hills. Significant positive $\mathrm{ATT}_{\mathrm{e}}$ reflects the contribution of CFP in institutionalizing rules and practices of benefit sharing in an equitable way as provisioned by the Community Forestry Directives (Ministry of Forest and Soil Conservation [MoFSC], 2008). The CFUGs receive support from a range of state and non-state actors (World Bank, 2001) that help reduce elite 
capture of resources and promote more equitable benefit sharing (Luintel, 2006; Persha \& Anderson, 2014). Larson et al. (2010) argued that the forest management regime is an important factor in determining the access and distribution of benefits from resources. Formal forest decentralization, e.g., CFP, delegates certain levels of forest rights to the CFUGs, resulting in increased opportunities to participate in forestry activities thereby increasing their ownership in decision making and equitable access to forest resources (Adhikari et al., 2014; Ribot \& Peluso, 2003). The households participating in forestry activities are more likely to benefit from the forest's resources because of their better access to information and ability to voice concerns (Agrawal \& Gupta, 2005). Community and household surveys carried out as part of this research reflect that $80 \%$ of communities have written rules and $>60 \%$ of households engage in forest management in NCF. Utilizing both traditional and scientific knowledge on forest ecosystem and sociocultural practices, local communities might have made and implemented locally appropriate forest management plans that increased forest productivity. Increased forest productivity generally increases the ability of communities to access higher quantities of products from the forest commons as indicated by Naidu (2011) in case of the Western Himalayas. The formally registered CFUGs regulate the extraction and distribution of forest products (Meynen \& Dornboos, 2005), control the free-riding problem or control unauthorized resource extraction and establish equitable benefit sharing systems.

The insignificant $\mathrm{ATT}_{\mathrm{e}}$ across Terai regions indicates a lack of dedicated institutional rules and practices on the part of communities and supporting agencies including government forest bureaucracy, civil society organizations, and donor funded projects. 
The Nepalese government had (and still has) low priority in promoting community forestry in the Terai region (Bhattarai, 2006; MoFSC, 2000; World Bank, 2001). The local communities also have a tendency to sell forest products to increase their CFUG funds, which they generally spend in community development activities ignoring specific needs of households (Lamichhane \& Parajuli, 2014). Elites generally dominate the CFP's decision-making process in the Terai, which reinforces inequity in the communities. These elites often develop clandestine relations with timber traders and corrupt forest officials and misuse forest resources for their own benefits. They tend to homogenize the community and ignore socio-economic and cultural diversity, while trying to develop groupthink and reduce the freedom of members to make choices. At times, the elites and decision-makers do not make the CFUG transactions transparent but rather make them complex and ambiguous, so as to justify their exercise of discretionary power.

Differential $\mathrm{ATT}_{\mathrm{e}}$ across households in social and geographic categories clearly indicates the inadequacy of evaluating the effect of CFP at the national scale to identify local effects. Such $\mathrm{ATT}_{\mathrm{e}}$ further indicate the need of flexible and social group- and areaspecific policies for promoting equitable benefit sharing. While the positive $\mathrm{ATT}_{\mathrm{e}}$ indicates the need to continue the existing CFP practices, the neutral $\mathrm{ATT}_{\mathrm{e}}$ signals the need of greater, targeted support at policy, monitoring and motivational levels for the forest-managing communities so as to ensure equitable benefit sharing. Neutral effects of CFP in the Terai indicate a clear need to review the current community practices on benefit sharing. As the population structure, socio-cultural diversities, and services and 
input provided by government and non-government institutions vary across geographic area, reviewers need to carefully account such variables.

It is less clear whether my $\mathrm{ATT}_{\mathrm{e}}$ estimates are driven by different factors and/or differing degrees of bias. These results point to the need for further research exploring why CFP is effective in promoting equity in different social groups and hills, but not in the Terai, how communities interpret and implement benefit-sharing provisions made in CFP, and what motivational and capacity building supports to forest-managing communities could be useful to ensure and strengthen equitable benefit sharing. Such research would contribute to amending the current $\mathrm{CFP}$ to improve intended outcomes of $\mathrm{CBD}$ and REDD+.

My research indicates that the Nepalese CFP may provide groundworks and lessons for promoting equity in REDD+. However, a closer look at different factors affecting equity at national to local levels is crucial. Scientists may be required to empirically answer the questions regarding who should get REDD+ benefits, how, why, when and where. Equally important is the examination of broader political and economic forces at regional, national and international levels to understand the dynamics of equity at local level. Such forces influence the shaping of household perceptions about equity in benefit sharing and influence the quantity and flow of REDD+ benefits.

My research is the first of its kind to take the case of Nepalese community forestry and bring insights into the less studied and complex issue of equity. The estimation of $\mathrm{ATT}_{\mathrm{e}}$ is challenging, particularly using cross-sectional data. However, by matching based on a large number of confounders I was able to overcome difficulties associated with non- 
random sampling. However, a certain level of imbalance in the observed confounders still exists, which might have added variation to my $\mathrm{ATT}_{\mathrm{e}}$ estimates. As there are competing multiple, applicable matching methods available, each of which has certain advantages and disadvantages, the methods I used may be debated. The use of SMD to check the match balance may capture only certain dimensions of balance. Challenges may remain in terms of understanding and communicating the results of the sensitivity analysis.

\subsection{Conclusion}

With the commencement of incentive-based forest management, including decentralized forestry and REDD+, equity has been one of the critical outcomes of concern and is therefore gaining momentum for examination and promotion. Equity has been crucial in motivating forest-managing communities and in gaining their support for effective management of forest commons. Using cross-sectional data and robust analytical methods for evaluating $\mathrm{ATT}_{\mathrm{e}}$ estimates, I demonstrated the unique path and positive causal effect of Nepalese CFP on household level equity except in the Terai. My results indicated the need for review of benefit sharing practices in the Terai and continue (or further improve or strengthen) such practices at the national level and across households in the hills, and poor, dalit, indigenous and women-headed households.

My findings demonstrated the CFP's potential to support CBD and REDD+ initiatives. However, dedicated, appropriate policies promoting equity in the Terai are critical for motivating communities in managing forests. A cautious approach in exploring key drivers of heterogeneity in equity is important to helping policies and institutions contribute to the objectives of CBD and REDD+. One policy initiative may be the 
promotion of CFP in non-CFP areas so as to promote equitable benefit sharing and therefore incentivizing those communities. My research indicates that government in tropical countries may need to devote more attention to decentralization policies to make the CBD and REDD+ initiatives more equitable, legitimate, credible, acceptable and effective in the long run. By addressing equity, CBD and REDD+ may be better positioned to achieve their conservation, carbon sequestration and poverty reduction goals. 


\section{Chapter 5: An assessment of collective action drivers of carbon storage in Nepalese forest commons}

\subsection{Introduction}

The institutional practices governing conservation and management of forests in tropical countries are defined by national and/or sub-national policies and regulations (Constance et al., 2010). Over the last four decades, governments in many tropical countries have put significant efforts into promoting "collective action" deforestation and manage forests sustainably by recognizing traditional forest management practices and introducing formal decentralization reforms (Charnley \& Poe, 2007; Larson \& Soto, 2008). Approximately $15.5 \%$ of global forests (and $25 \%$ of developing country forests) are under the control of communities ("forest commons") and the trend of community control through decentralization reforms is increasing (Rights and Resources Initiatives [RRI], 2014; Sunderlin et al., 2008; World Bank, 2009). Local communities' primary objective in the management of forest commons is to access essential subsistence forest products such as fuelwood, timber and grass (e.g., MoFSC, 1988).

Understanding the role of forest commons in mitigating climate change is important due to their potential roles as both sinks and sources of carbon (Dixon et al., 1994) and contributions to both rural livelihoods and biodiversity conservation. These roles are now even more valued following the emergence of the Reducing Emissions from

\footnotetext{
${ }^{8}$ Collective actions are activities carried out together or jointly by a specified community or a group of people that share the same or similar objectives so that all individuals enhance their socio-economic, cultural or political status as a group or community.
} 
Deforestation and Forest Degradation, Conservation and enhancement of forest carbon and sustainable management of forest in developing countries (REDD+) program. Past studies show potentially mixed results from communities' conservation efforts in relation to carbon storage and emissions. For instance, Nepalese forest commons have contributed to reducing deforestation and forest degradation and restoring degraded forest ecological systems (Chapagain \& Banjade, 2009; Department of Forest Research and Survey [DFRS], 2015; Gautam et al., 2002). On the other hand, local communities' practices of harvest and use of forest products (e.g., timber, fuelwood, and fodder), grazing and burning can result in a significant loss of biomass carbon (Brown et al., 1991; Flint \& Richards, 1994; Food and Agriculture Organization [FAO], 1993; Goldammer, 1990). This paradox results from the diverse array of communities, and their actions governing the management and use of local forests.

The REDD+ program should incentivize forest-dependent communities (Phelps et al., 2010a) and follow common property design principles or collective action drivers (Agrawal \& Angelsen, 2009) to achieve its objectives, particularly in the forest commons. Using a worldwide data set, Chhatre and Agrawal (2009) demonstrated the possibility of both tradeoffs and/or synergies between climate and livelihood benefits of forest commons. Other scholars have also indicated both the opportunities and challenges of REDD+ to forest commons management. For instance, REDD+ brings unconventional forestry investment to developing countries (Eliasch, 2008), which can improve forest governance and bolster global conservation efforts (Wollenberg \& Springate-Baginski, 2010), promote low carbon paths to development, generate livelihoods and reduce 
poverty. On the contrary, it may overlook livelihood related outcomes for local communities (Campbell, 2009; Coomes et al., 2008; Putz \& Redford, 2009; Ratsimbazafy et al., 2011) and gradually alienate local people from accessing resource in the future (Khatri, 2012; Phelps et al., 2010b). REDD+ will not necessarily serve to help local community-managed forests (Ostrom, 2010). Dyer and Counsel (2010) warned that the local people in developing countries may need to shoulder the cost of emissions reduction instead of benefiting from REDD+.

Shyamsundar (2008) demonstrated that effective forest commons contribute to better forest management particularly through promoting fairness in rules and sanctions and in participation and monitoring (Ostrom, 1990; Agrawal, 2000, 2001). Beyene et al. (2013) indicated that the collective action of forest-managing communities is one of the most important determinants of carbon storage within forest commons. However, there is limited empirical evidence that indicates whether better collective action practices lead forests to sequester more carbon (Beyene et al., 2013; Chazdon, 2008; Jodha, 2008; Ranganathan et al., 2008). Without empirical evidence of such relationships, it is difficult to decide whether and how to implement REDD+ in forest commons effectively i.e., by synergizing carbon and livelihood outcomes.

To understand the relationship between collective action drivers and carbon storage, I conducted research on Nepalese forest commons. I took empirical data collected in the year 2013 from a nationally representative random sample of 130 forest commons (both forests and communities) and 1300 households. Nepal is one of the pioneer countries into the practice of different legally supported models of forest commons over the last 40 
years. Approximately $42 \%$ of the population from a wide range of socio-economic groups are formally organized in $~ 19,000$ Community Forest User Groups (CFUGs), which are engaged in managing $~ 1.8$ million hectares of forests (Department of Forest, 2015). The high level of diversity of forests and communities in Nepal has posed challenges, and created opportunities, to understanding the varied relationships between collective action drivers and carbon storage.

Using a multivariate regression analysis, I analyzed the relationship between different collective action drivers of Nepalese forest commons and forest carbon. Specifically, I considered the communities' (i) forest conservation history, (ii) engagement in forest management, (iii) ability to modify rules, (iv) ability to enforce sanctions, (v) social capital and (vi) transparency of forestry affairs as part of collective action drivers, as they constitute critical elements of common property design principles (Agrawal \& Chhatre, 2006; Agrawal, 2001, 2000; Anderson \& Agrawal, 2011; Cox et al., 2010; Ostrom, 2009, 2000, 1990; Shyamsundar, 2008). Reflecting most findings of the collective action literature, I hypothesize that these drivers are positively associated with more carbon storage in forest commons. I discuss the research findings in view of literature and emerging REDD+ program. Finally, I suggest analytical areas for consideration while designing and implementing REDD+ at the local level so as to increase carbon storage in forest commons.

\subsection{Methods}

The data presented are part of an on-going multi-disciplinary research project funded by the World Bank and jointly implemented by Portland State University (PSU) and 
ForestAction Nepal (Bluffstone et al., 2015), a non-governmental, non-profit organization that works on issues related to forestry, agriculture and climate change in Nepal. The primary aim of the project was to assess the potential synergies and/or tradeoffs between Nepalese forest commons and REDD+.

\subsubsection{Samples and data collection}

We (ForestAction researcher and I) selected a total of 130 forests and forest user groups (FUGs), both CFUGs and non-CFUGs, for data collection (Figure 5.1). We randomly selected 65 CFUGs from a pool of 137 national random samples from the CF impact study conducted by the Nepalese government during 2010-2012. We randomly selected ten households from each CFUG to be surveyed. The field team selected 65 non-CFUGs in such a way that they shared a variety of characteristics with the CFUGs. Such nonCFUGs were close, but not next to CFUGs to avoid being used simultaneously by the same people. The field researchers randomly selected 10 households in each non-CFUG to be surveyed following same methods to those used in selecting CFUGs. Data were collected by the field team from February to May 2013. 


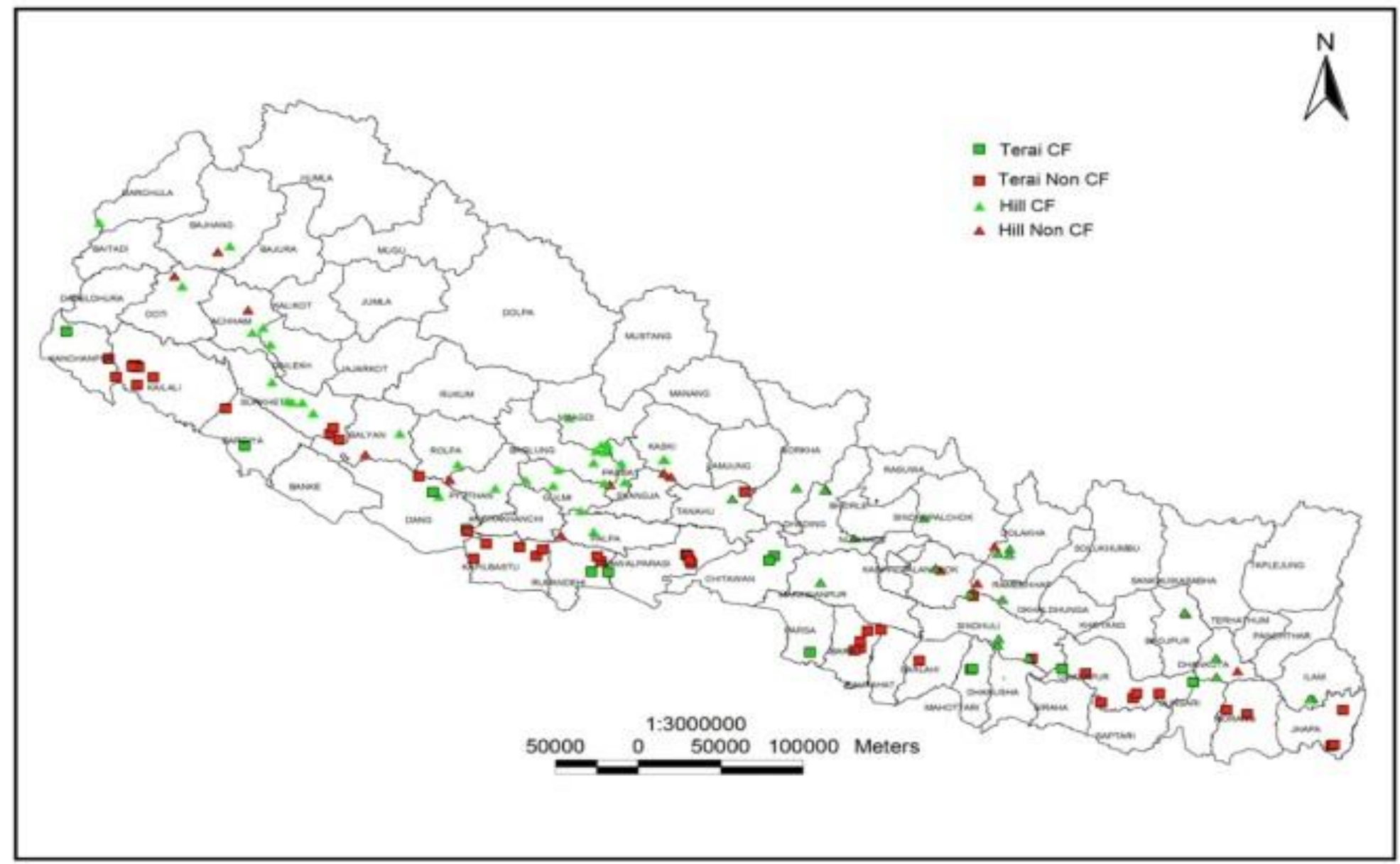

Figure 5.1 Distribution of sample plots 


\subsubsection{Forest data collection}

We conducted a pilot survey in 2012 to estimate the required number of sample plots for forest data collection. We selected 45 sample plots from nine community forests (CFs) across physiographic regions to capture the greatest possible heterogeneity in plot basal area, a proxy of forest biomass. We deployed a field team to measure the diameter at breast height $(\mathrm{DBH})$ of trees and saplings and estimated the basal area for each plot. Considering variance of basal area, we calculated the number of required sample plots to obtain results within $10 \%$ error and $95 \%$ confidence level using the standard formula (1) (Saxena \& Singh, 1987).

$$
\begin{aligned}
& \mathrm{N}=\mathrm{C}_{\mathrm{v}}{ }^{2} \mathrm{t}^{2} / \mathrm{E}^{2} \\
& \text { Where, } \\
& \mathrm{N}=\text { Required number of sample plots; } \\
& \mathrm{C}_{\mathrm{v}}=\text { Coefficient of variation, } \mathrm{s} / \mu(\mathrm{s}=\text { standard deviation and } \mu=\text { sample mean }) \text {; } \\
& \mathrm{E}=\text { Standard error, } \mathrm{s} / \sqrt{ } \mathrm{n}(\mathrm{n}=\text { sample number }) \\
& \mathrm{t}=\text { Value of student- } \mathrm{t} \text { distribution for }(\mathrm{n}-1) \text { degree of freedom and } 95 \% \\
& \text { confidence level. }
\end{aligned}
$$

A total of 325 plots were estimated to be required for sampling in the CFs. Sample plots were distributed among the $65 \mathrm{CFs}$, which were selected from the random samples chosen for the national community forestry impact study conducted by the Nepalese government during 2010-2012. ForestAction recruited a team of field researchers, with whom I closely worked to collect the data. Each of the field researchers had 
undergraduate degrees in forestry, and ForestAction trained them to conduct forest surveys and inventories.

As the size of CF varies, we allocated 3-7 sample plots in each forest based on the quintile distribution of forest size. As the forest size in the hill and Terai markedly differ, we considered different quintile ranges for hill and Terai (Table 5.1).

Table 5.1 Distribution of sample plots in community forests.

\begin{tabular}{|c|c|c|c|c|c|}
\hline \multirow{2}{*}{$\begin{array}{l}\text { Quintile } \\
\text { distribution }\end{array}$} & \multicolumn{2}{|c|}{ Forest size (ha) } & \multirow{2}{*}{$\begin{array}{l}\text { Sample } \\
\text { plots/forest }\end{array}$} & \multirow{2}{*}{$\begin{array}{l}\text { No. of } \\
\text { forest }\end{array}$} & \multirow{2}{*}{$\begin{array}{l}\text { No. of } \\
\text { plots }\end{array}$} \\
\hline & Hill & Terai & & & \\
\hline $1^{\text {st }}$ quintile & $<18$ & $<113$ & 3 & 13 & 39 \\
\hline $2^{\text {nd }}$ quintile & $18-64$ & $113-154$ & 4 & 13 & 52 \\
\hline $3^{\text {rd }}$ quintile & $64-91$ & $154-335$ & 5 & 13 & 65 \\
\hline $4^{\text {th }}$ quintile & $91-183$ & $335-526$ & 6 & 13 & 78 \\
\hline $5^{\text {th }}$ quintile & $\geq 183$ & $\geq 526$ & 7 & 13 & 91 \\
\hline
\end{tabular}

The field team carried out forest boundary surveys using a geographic positioning system (GPS), prepared forest maps on graph paper and estimated forest areas. The maps of CFs from the forest operational plans were copied onto the graph paper, so as to divide areas into smaller grid cells. To identify the sample plots, the cells were selected randomly and $\mathrm{X}$ and $\mathrm{Y}$ coordinates of the center of selected cells were identified. The coordinates were then fed into the GPS unit to locate the plots in the forests. Due to differences in non-CF size, it was possible to allocate 295 plots following forest size criteria and standards given in Table 5.1. The distribution of sample plots is also given in Figure 5.1.

A circular plot with a radius of $8.92 \mathrm{~m}$ was selected for collecting environmental data and measuring trees $(>5 \mathrm{~cm} \mathrm{DBH})$, which is suitable for moderate to dense vegetation and has been used widely (MacDicken, 1997). Using the same center, second and third plots with 
radii of $5.64 \mathrm{~m}$ and $1 \mathrm{~m}$ were established to measure saplings $(1-5 \mathrm{~cm} \mathrm{DBH})$ and count seedlings, respectively (Figure 5.2).

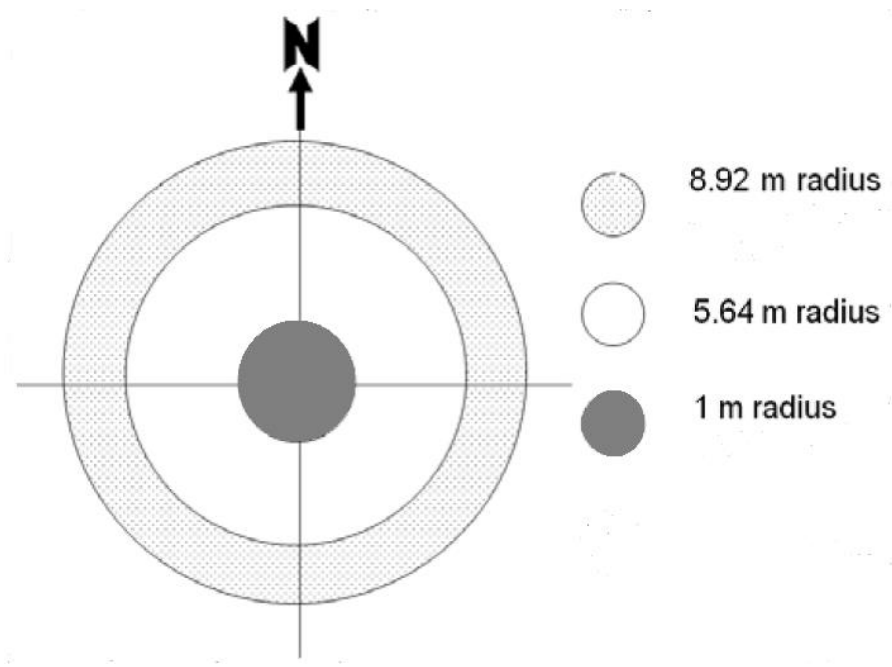

Figure 5.2 Size and shape of sample plot

The team measured height and circumference of each tree and sapling by using a clinometer and linear tape, respectively. The team also recorded the vernacular name of each species and collected data on canopy, slope, altitude, aspect, soil color, soil depth, fire occurrence, forest encroachment, forest product collection, soil erosion and grazing for each plot. Other data include forest area and management regime, number of households using the forest and distances of forest from the nearest road and district headquarters. Some data such as households in the CFUG were obtained from the CF impact study conducted by the Nepalese government in 2010 (in which I trained field enumerators and conducted preliminary data analysis).

\subsubsection{Institutional data collection}

The PSU and ForestAction researchers (including myself) developed a set of structured 
questions for community and household surveys by considering research objectives, and input from focus group discussions with CFUG members, and consultations with national level experts. We then tested the questionnaires in two CFUGs for their appropriateness and finalized them before conducting the survey. We collected both quantitative (e.g., resource availability, socio-economic profile) and qualitative (e.g., perspectives and experience) data from the survey.

I closely worked with the ForestAction-recruited team of field researchers to conduct the household surveys. ForestAction recruited 12 field researchers having masters degrees in social sciences and trained them to develop a common understanding of the research and to use the questionnaires effectively and efficiently during the survey. We closely and constantly monitored the field researchers and supported them to ensure effectiveness of data collection and quality of data.

\subsubsection{Analytical framework: variables, hypotheses and model specifications}

I used a multivariate regression model to assess the relationships among collective action drivers and carbon storage in Nepalese forest commons. I constructed a two-stage model. First, I estimated the above ground tree and sapling carbon (AGTSC) for each forest. Second, I constructed a regression model with carbon storage as the continuous dependent variable and collective action drivers as the explanatory variables. I also included some of the critical conditioning variables in the model.

\subsubsection{Variable selection and hypotheses setting}

I carefully selected dependent, explanatory and conditioning variables to accomplish my 
research. Table 5.2 presents these variables and how I operationalized them, and Table 5.3 shows the descriptive statistics of each variable. I collected forest data at tree and plot levels, and social data at community and household levels as appropriate. I transformed all tree and plot data to the forest level, and all household data to the community level so as to match the data at common levels for further analysis. As the forest commons are held in common and are primarily influenced by community-level decisions, I focused my analysis at the forest common level.

Dependent variable: My dependent variable is carbon storage, which is measured in tons per hectare. I used the equations (1) and (2) proposed by Chave et al. (2005) to estimate Above Ground Biomass (AGB), which were prepared by using a large dataset of trees across different climatic conditions of global sites. Equations (1) and (2) were used to estimate AGB in dry (<1500mm average annual rainfall) and moist $(1500-4000 \mathrm{~mm}$ average annual rainfall) forests respectively. These equations were used by several researchers and recommended by the Nepalese government (Ministry of Forest and Soil Conservation [MoFSC], 2010). Approximately 5\% of sample plots in my study were in dry forests.

$$
\begin{aligned}
\operatorname{AGB}(\mathrm{kg}) & =0.112 *\left({ }^{\rho} \mathrm{D}^{2} \mathrm{H}\right)^{0.916} \ldots \ldots \ldots \ldots \ldots \ldots \ldots \ldots \ldots \ldots \ldots \ldots \ldots \ldots \ldots \ldots \ldots \\
\text { AGB }(\mathrm{kg}) & =0.0509^{\rho} \mathrm{D}^{2} \mathrm{H} \ldots \ldots \ldots \ldots \ldots \ldots \\
\text { Where, } \quad \rho & =\text { Specific gravity of wood }\left(\mathrm{g} \mathrm{cm}^{-3}\right) ; \\
\mathrm{D} & =\mathrm{DBH} ; \\
\mathrm{H} & =\text { Tree height }
\end{aligned}
$$


Table 5.2 Descriptions of dependent, explanatory and conditioning variables and their measurement units.

All data collected at household level are aggregated at the community level and data collected at tree and/or forest plot levels are aggregated at the forest level for analysis.

\begin{tabular}{|c|c|c|}
\hline Notation & Variables & Measurement unit \\
\hline \multicolumn{3}{|c|}{ A. Dependent variable } \\
\hline Carbon & Average estimated carbon per hectare of a forest & Metric ton per hectare \\
\hline \multicolumn{3}{|c|}{ B. Explanatory variables } \\
\hline $\begin{array}{l}\text { Conservation } \\
\text { duration }\end{array}$ & $\begin{array}{l}\text { Number of years households in a community have } \\
\text { been engaged in the conservation of forest }\end{array}$ & Number of years \\
\hline $\begin{array}{l}\text { Participating } \\
\text { households }\end{array}$ & $\begin{array}{l}\text { Proportion of households in a community that } \\
\text { participate in forest management activities }\end{array}$ & Proportion \\
\hline $\begin{array}{l}\text { Rules } \\
\text { modification }\end{array}$ & $\begin{array}{l}\text { Community members can modify the rules of forest } \\
\text { management and benefit sharing as per their interest }\end{array}$ & Yes $=1$, No $=0$ \\
\hline $\begin{array}{l}\text { Penalty } \\
\text { system }\end{array}$ & $\begin{array}{l}\text { Forest-managing community has a system of } \\
\text { punishment for forest offenders }\end{array}$ & $\mathrm{Yes}=1, \mathrm{No}=0$ \\
\hline Public audit & $\begin{array}{l}\text { Existence of public audit practice in the forest- } \\
\text { managing community }\end{array}$ & Yes $=1$, No $=0$ \\
\hline Mutual trust & $\begin{array}{l}\text { Average level of mutual trust among forest- } \\
\text { managing community members }\end{array}$ & Yes $=2$, Neutral $=1$, No $=0$ \\
\hline \multicolumn{3}{|c|}{ C. Conditioning variables } \\
\hline Terai & The forest is in the plainland ("Terai") of the country & Yes $=1$, No $=0$ \\
\hline Forest area & The total area of a forest & Hectare \\
\hline NDVI 1989 & $\begin{array}{l}\text { NDVI was calculated for the month of November } \\
1989\end{array}$ & Index \\
\hline $\begin{array}{l}\text { Indigenous } \\
\text { population }\end{array}$ & $\begin{array}{l}\text { Proportion of indigenous peoples and ethnic groups } \\
\text { in a forest-managing community }\end{array}$ & Proportion \\
\hline $\begin{array}{l}\text { Group } \\
\text { household }\end{array}$ & $\begin{array}{l}\text { The total number of households in a forest-managing } \\
\text { community }\end{array}$ & Number \\
\hline Road distance & Time required for two-way travel to the nearest road & $\begin{array}{l}1=<2 \text { hours, } 2=2 \text { hours }-< \\
\text { half-day, } 3=\text { half-day, } 4=> \\
\text { half-day }\end{array}$ \\
\hline Altitude & The average altitude of a forest & Meter \\
\hline Slope & The average slope of a forest & Degree \\
\hline
\end{tabular}


I used species-based wood specific gravity recommended by Jackson (1994) to calculate biomass. Where such information was not available, I used a general value derived from average specific gravity of associated species (same genus and family) within a forest type (Baker et al., 2004; Ngugi et al., 2011). I used Nepal-specific biomass equations developed by Tamrakar (2000) to estimate the green biomass of individual saplings, which was converted into dry biomass by multiplying with species-wise fractions or the average of the associated species as identified in the literature. I used the fractions 0.627 , 0.613, 0.58, 0.57, 0.545, 0.517, 0.5 and 0.45 for Quercus species, Lyonia ovalifolia, Pinus roxburghii, Alnus nepalensis, Schima wallichii, Shorea robusta, Terminalia tomentosa and Pinus wallichiana, respectively (Bhatt \& Tomar, 2002; Jain \& Singh, 1999; Kataki \& Konwer, 2002; Shrestha et al., 2006; Wihersaari, 2005). For unidentified species, or where wood density information was not available for the species, genus or family, I used the overall mean wood density obtained from the database of species compiled for this study (Baker et al., 2004). I converted AGB into carbon stock by multiplying by 0.50 (IPCC, 2006), which I used as a proxy for carbon storage for further analysis. 
Table 5.3 Descriptive statistics of variables.

The total number of observations is 130 .

\begin{tabular}{lrrrr}
\hline Notation & Mean & Standard deviation & Minimum & Maximum \\
\hline Carbon & 92.53 & 76.06 & 0.1685 & 362.09 \\
Conservation duration & 13.63 & 4.98 & 1 & 23 \\
Participating households & 0.74 & 0.33 & 0 & 1 \\
Rules modification & 0.87 & 0.28 & 0 & 1 \\
Penalty system & 0.91 & 0.20 & 0 & 1 \\
Public audit & 0.37 & 0.48 & 0 & 1 \\
Mutual trust & 1.65 & 0.46 & 0.1 & 2 \\
Terai & 0.56 & 0.50 & 0 & 1 \\
Forest area & 129.05 & 161.72 & 1.1 & 1088 \\
NDVI 1989 & 0.4253 & 0.0887 & 0.1216 & 0.5775 \\
Indigenous population & 0.40 & 0.30 & 0 & 1 \\
Group household & 295.82 & 588.09 & 12 & 6081 \\
Road distance & 1.42 & 0.80 & 1 & 4 \\
Altitude & 774.14 & 633.38 & 75 & 2410.6 \\
Slope & 15.79 & 12.63 & 0 & 46.25 \\
\hline
\end{tabular}

Explanatory variables: I selected six critical collective action drivers that constitute critical elements of common property design principles and used them to explain carbon storage. These are the communities' (i) forest conservation history, (ii) engagement in forest management, (iii) ability to modify rules, (iv) ability to enforce sanctions, (v) social capital and (vi) transparency of forestry affairs. I selected these variables on the basis of the existing literature and theoretical expectations in explaining management outcomes of forest commons (e.g., Agrawal \& Chhatre, 2006; Agrawal, 2001, 2000; Anderson \& Agrawal, 2011; Cox et al., 2010; Ostrom, 2009, 2000, 1990; Shyamsundar, 2008). Specially, I considered design principles for better collective action as proposed by Ostrom (1990), which includes (i) clear group boundaries, (ii) match rules governing the forest commons to the local needs and conditions, (iii) ensure the ability of 
communities to modify rules, (iv) ensure monitoring and graduated sanctions, (v) resolve disputes and (vi) strengthen bottom up planning and partnership. Examination of these collective action drivers helps explain variation in forest management outcomes including carbon storage (Agrawal \& Ostrom, 2001; Andersson \& Gibson, 2007; Gibson et al., 2005).

On the basis of the literature, I hypothesized that my explanatory variables are positively associated with carbon storage. For instance, the history of communities' conservation efforts reflects the outcomes of forest commons such as biomass and/or carbon. Generally, more years of conservation result in larger-sized trees and more carbon storage (Luyssaert et al., 2008). For instance, forest carbon stocks in mid-hill Shorea robusta forest proportionally increased with management duration at the rate of $2.6 \mathrm{Mg}$ ha $^{-1} \mathrm{yr}^{-1}$ (Thapa-Magar \& Shrestha, 2015). Researchers have reported that an increased number of households participating in the management of forest resulted in better management outcomes or forest quality. For instance, as the number of households increased in the management of community forests in the hills of Nepal, the quality of forest in terms of cover and area also increased over time (DFRS, 2015). Increases in the proportion of participating households in a community may lead to consolidation of efforts towards better management of forests. Participation of more people may increase the acceptability of decisions at the community level, and also increase the number of community members who embrace a wide variety of traditional knowledge that helps enhance the productivity of forests (Posey, 2008 [1985]). 
The ability of forest-managing communities to modify forest management rules and practices may have positive implications in forest quality. This is particularly true as local communities can effectively use their locally-specific traditional knowledge about forest resource management even during times of unanticipated change (Berkes \& Folke, 1994; Turner et al., 2003). The practice of enforcement of rules including penalties at the community level is a necessary condition for the better management of forests (Gibson et al., 2005). Enforcement increased the probability of regeneration and decreased the chance of degradation of forests (Chhatre \& Agrawal, 2008). Community forest managers have identified transparency as a key element of forest governance that positively contributes to better management of forests. Realizing this, the Nepalese government has been promoting public audit practices at the community level to increase transparency in decisions, activities and financial transactions of forest-managing communities (MoFSC, 2008). It is intuitive that mutual trust among the members of forest-managing communities reduces conflicts in managing forests and thereby may likely improve forest management outcomes.

Conditioning variables: I selected eight conditioning variables that have frequently been cited in the literature as influencing collective actions and forest conditions including carbon (Andersen \& Agrawal, 2011; Beyene et al., 2013; Chaiyo et al., 2011; Chhatre \& Agrawal, 2009). I controlled the effects of these variables so as to address the problem of potential spurious effects on the association between collective action drivers and carbon storage. These conditioning variables primarily characterize the ecological region (e.g., Terai), resource endowment (e.g., forest area, NDVI), community attribute (e.g., total 
number of households and proportion of indigenous population), geographic distance (i.e., time taken to travel to and from the road, a proxy of market pressure), and topographic features (e.g., altitude and slope) in which the forest-managing communities operate.

Nepalese Terai forests are more diverse than those of the hills, and are dominated by one of the most commercially valuable species - Shorea robusta. Due to their accessibility to roads combined with a high demand for timber and a high rate of internal migration, these forests are under high pressures from forest product extraction and land use change. The area and quality of forest commons may have effect on the total as well as the average (i.e., per hectare) carbon in the forest. When all else remain equal, larger and/or better quality forests may have more carbon and fewer livelihood tradeoffs. Altitude and slope also affect the productivity and carbon of the forest. The variations in altitude and slope may affect the availability of temperature, rainfall and nutrients, resulting in varied rate and quantity of increment in tree sizes, densities, cover and species composition (e.g., Chapter 2). As Nepal is a mountainous country with a wide range of altitudes (i.e., 70 - 8848 meters) and slopes (i.e., 0 - 70 degree), Nepalese forest commons are highly affected by such variations.

Time required for two-way travel from a community to the nearest road is a critical measure of remoteness that affects a community's transportation costs and market access. Remoteness of forest may therefore be negatively associated with harvest level of forest products particularly for commercial purposes, leading to greater carbon storage. Due to 
differences in geography and market access, collective actions in remote communities may be different than in those closer to the roads or markets.

Larger numbers of households in a forest-managing community demand a greater quantity of forest products and therefore exert higher pressures on forest resources. Also, more competition for forest products due to high demand makes collective action more challenging, particularly when the resources are limited. Such situations may result in lower levels of carbon stocks in the forest commons. Different groups of indigenous people may have different levels of forest product consumption due to their differential forest-related socio-cultural practices and economic and livelihood strategies. It is evident that certain indigenous groups such as Tamang, Rai and Magar consume more fuelwood than the average community (e.g., Pokharel, 2003). Therefore, it is reasonable to expect that the effect of indigenous populations on carbon storage may be negative.

\subsubsection{Model specification}

The literature considers better collective actions to be crucial for effective, productive management of forest-commons resources such as carbon (e.g., Agrawal \& Chhatre, 2006; Agrawal, 2001; Anderson \& Agrawal, 2011; Ostrom, 1990). I drew my analytical framework from this literature and hypothesized that better collective actions at the community level lead to the development of appropriate, productive forest-management plans, leading to higher levels of carbon storage. As several factors drive collective actions, we can observe some of the critical ones and interpret their relationships to the quality of forest with the support of empirical evidence and literature. Many of the collective action drivers generally do not lend themselves to more robust causal, 
analytical methods such as matching. Therefore, I carried out multiple regression analysis to understand the relationship between collective action drivers and carbon storage.

Collective actions are likely more complex than simply having a unidirectional influence on forest quality measures such as carbon storage. Collective actions in forest commons management constitute the main feature of common property rights, which emerge from endogenous institutional processes (Heltberg, 2001). Such processes are defined, developed and perpetuated by socio-cultural values and traditional practices of forest managing communities through time. Ostrom (1990) highlighted that such processes have been critical to long-term, stable and successful management of forest resources at the local scale. Gautam (1991) also identified that local socio-cultural values and traditional practices have been critical to the emergence and sustenance of Nepalese forest commons including community forestry. Therefore, it is reasonable to assume that a certain level of endogenous institutional process is inevitable in shaping relationships between collective actions and forest resources in Nepal.

Endogenous institutional processes may introduce potential confounders causing problems in the identification of the effects of collective action on carbon storage. Such processes may affect the communities' decisions to opt into forest commons (causing selection bias) and to adopt collective actions considering the condition of forest resources (causing reverse causality). In addition, omission of critical variables in the model may also cause problems in identification. This problem exists particularly when we use cross-sectional, observational data. However, based on the literature and data at hand, my model is almost free from identification problems. 
Selection bias: Different researches such as Alcorn (1981), Barth (2008 [1956]), Posey (2008 [1985]), and Rappaport (2008 [1967]) have shown that the forest management behaviors of local communities are affected by multi-generational evolution of sociocultural, economic, environmental and livelihood values, knowledge and practices. The practice of forest commons management in Nepal has a long history (Gautam, 1991) and therefore is affected by different socio-cultural, economic and environmental values and practices over time. Such values and perspectives are generally developed and refined by the processes occurring at longer temporal and wider spatial scales. Therefore, the current forest management behaviors of communities in Nepal are path dependent and not chosen by the communities themselves. The distribution of forests and collective action features across the communities can be considered as random, as this does not consider outcomes of interest. Such a situation does not allow selection bias taking place in the collective action behavior of local communities.

Omitted variables: My model does not suffer from omission of critical variables. As my sample forest commons are located in human-dominated landscapes, population and institution related variables are important to include in the model (Chhatre \& Agrawal 2009). Therefore, as mentioned in the conditioning variable section (5.2.2.1) I included critical population and institution related variables in my model (Table 5.2). However, I did not include community monitoring, equity, clarity in rule, forest management plan and conflict in my model as they were correlated with the variables included in the model. For instance, communities' ability to change rules is positively correlated with community monitoring practices $(\rho=0.37, p=0.000)$, equity in benefit sharing $(\rho=0.58$, 
$p=0.000)$ and clarity in rules $(\rho=0.46, p=0.000)$. Similarly, the proportion of households engaged in forest management practices is associated with the existence of a forest management plan $(\rho=0.28, p=0.002)$; and mutual trust among households is negatively correlated with conflict in the community $(\rho=-0.29, \mathrm{p}=0.001)$.

Reverse causality: There is a possibility that forest managing communities adopt collective actions through considering the condition of forest resources. Communities' collective actions help them restrict access of outsiders to forest resources through their management as shared private property (McKean \& Ostrom, 1995). Therefore, there is high likelihood that communities take more organized collective actions where higher forest quantity and better forest quality exist where they perceive that benefits from collective actions outweigh the costs of such efforts.

As such a situation has not been prevalent in Nepal, reverse causality is either absent or negligible in my model. The Nepalese government prioritized community forestry, a robust and formal version of forest commons (Table 5.4), in the hill region (Gilmour \& Fisher, 1991; World Bank, 2001). Most of the forests handed over to the communities as community forests were degraded (Kanel \& Shrestha, 2001). The government has maintained its control and has been reluctant to hand over forests to communities in the Terai due to the presence of good quality forests that have high commercial value and revenue potential (Bhattarai, 2006; Gilmour \& Fisher, 1991). Only small to medium sized barren forests in the vicinity of settlements were handed over to communities in the Terai.

My data also show that community forestry status has neither positive nor negative 
association with forest quality matrices such as forest area and NDVI 1989 (Table 5.4). By comparing community and non-community forests, Bluffstone et al. (2015) showed that community forests do not possess a unique path to store more carbon. Chapter 3 of this dissertation provides evidence that community forests, in fact, have less carbon storage than non-community forests. This evidence strongly suggests that better forest quality did not drive more robust formal community forestry that depicts better collective action in Nepal. I also checked the correlation between the independent variables and residual error of my regression model and found that they were not associated $(p=1)$, indicating that there is not endogeneity.

Table 5.4 Regression of community forestry status and collective action drivers and resource variables. Data show that community forestry is statistically, positively associated with five (out of six) collective action drivers under study reflecting the dominant forest commons literature.

\begin{tabular}{ll}
\hline Variables & Coefficient (p-value) \\
\hline Conservation duration & $\mathbf{0 . 0 3}(0.001)$ \\
Participating HH & $\mathbf{0 . 5 3}(0.000)$ \\
Rule change & $\mathbf{0 . 8 3}(0.000)$ \\
Penalty system & $\mathbf{0 . 4 3}(0.053)$ \\
Public audit & $\mathbf{0 . 3 6}(0.000)$ \\
Mutual trust & $0.06(0.590)$ \\
Forest area & $0.0004(0.161)$ \\
NDVI1989 & $-0.77(0.121)$ \\
\hline
\end{tabular}

In recent years, the Nepalese government amended their earlier decision and began handing over large sized, good quality natural forests to the communities throughout the country including Terai. However, as Hyde et al. (1996) demonstrated, reverse causality could be unlikely to be present as the forest-managing communities have no or little incentive to invest in better collective action in case of abundant forest resources. 
Though I cannot exclude all possibilities of endogeneity, I view that the presence of common exogenous factors that affect both collective action drivers and forest carbon storage is unlikely in Nepalese forest commons. Such a logical view is not uncommon and is shared by Beyene et al. (2013) who also used this assumption in an Ethiopian forest commons study. Initiatives for effective collective action and forest commons management are difficult to initiate from the outside but often emerge from complex processes (Ostrom, 2009; Agrawal; 2007), indicating the possibility of no or very low level of effect in both collective actions and forest resources. Agrawal and Yadama (1997) also suggest that collective action mediates the implication of exogenous factors. In fact, it is difficult to even think of a reasonably likely exogenous shock affecting both forest commons and collective action drivers. This finding is applicable to Nepal as Nepalese community forestry policy recognized the community forest user group as an autonomous body for perpetual succession (MoLJ, 1995). Such a legal provision strengthened the role of communities, and constrained the role of external factors, in bringing changes in local level collective actions and forest management outcomes simultaneously.

Model development and diagnostics: I checked Spearman correlations of carbon storage with six explanatory variables to assess the strength of their relationships. I also checked the relationships among the independent variables by using regression. I then built a multiple regression model using equation (3) to assess the significance of explanatory variables i.e., to estimate the unbiased coefficient.

$$
\mathrm{Y}=\beta_{0}+\beta_{\mathrm{i}}\left(\mathrm{X}_{\mathrm{i}}\right)+\varepsilon
$$


Where,

Y Carbon stock in tons

$\beta_{0} \quad$ Value of the function when $X_{i}=0$

$\mathrm{B}_{\mathrm{i}} \quad$ Rate of change in carbon stock for unit change in respective explanatory variables

$\mathrm{X}_{\mathrm{i}} \quad$ Explanatory and conditioning variables used in the model

i $1,2, \ldots \ldots, \mathrm{n}$

$\varepsilon \quad$ Stochastic error not accounted for in the relationship between explanatory and dependent variables assumed to follow a standard normal distribution across observations, and the mean and variance are normalized to zero and one, respectively.

I carried out the diagnostic check of my regression model by looking at both residual plots and statistics. First, I graphically checked residual versus fitted values and carried out the Ramsay Regression Specification Error test to examine for the possibility of nonlinearities of residuals. The p-value $>0.05$ in the Ramsey test indicates the linearity of residuals. Second, I looked at the normal Q-Q plot for the possibility of a non-normal distribution of residuals. Third, I graphically checked the standardized versus fitted values of residuals and carried out the Breusch-Pagan $(\mathrm{BP})$ test (p-value $>0.05)$ to examine the heteroscedasticity, i.e., to test whether the variance of residuals change as the function of observation. The p-value $>0.05$ in the Breusch-Pagan test indicates the homoscedasticity of residuals. Using Cook's Distance, I also examined whether individual observations have a strong influence in the model. Observations having $<1$ Cook's Distance value are considered to not have a strong influence in the model. 
Finally, I calculated Variance Inflation Factors (VIF) for each variable to check for multicollinearity. When a value of VIF is $>4$ for a variable, it is considered as causing multicollinearity.

\subsection{Results and Discussion}

Spearman correlations of explanatory and conditional variables with carbon storage are shown in Table 5.5. The practice of public audit, Terai, forest area, NDVI 1989 and the number of households in forest-managing communities were positively correlated with carbon storage ( $\rho=0.25$ to 0.42 ), indicating moderately strong correlations between these variables and carbon storage. On the contrary, the conservation duration, altitude and slope of forest were negatively correlated with carbon storage. These negative correlations ranged from -0.15 to -0.25 , indicating weak associations between these variables and carbon storage. Six other variables including proportion of household engaged in forest management, communities' ability to modify rules, communities' practice of penalty system, existence of mutual trust among the forest-managing households in a community, proportion of indigenous population in a community and distance of forest from the district headquarters were insignificantly correlated to carbon storage.

My main interest is in the collective action drivers as listed out as exogenous variables in the Table 5.2. My exogenous variables in general are not significantly associated; though there were certain level of association between some of them. 
I developed a multiple regression models to estimate the unbiased coefficients and significance of collective action drivers to explain carbon storage (Table 5.6). Model 1 that uses only collective action drivers represents indicative results, as the effects could be spurious. Therefore, I presented six additional regression models (e.g., Models 2, 3, 4, 5, 6 and 7), which contain all collective action drivers and different sets of conditional variables that dampen spurious effects.

Table 5.5 Spearman correlations of explanatory variables with carbon stocks.

\begin{tabular}{lr}
\hline Variables & Correlation (p-values) \\
\hline Conservation duration & $-0.15(0.081)$ \\
Participating households & $0.14(0.122)$ \\
Rules modification & $-0.02(0.842)$ \\
Penalty system & $-0.08(0.338)$ \\
Public audit & $\mathbf{0 . 2 5}(0.004)$ \\
Mutual trust & $0.06(0.474)$ \\
Terai & $\mathbf{0 . 2 7}(0.002)$ \\
Forest area & $\mathbf{0 . 4 2}(0.000)$ \\
NDVI 1989 & $\mathbf{0 . 3 8}(0.000)$ \\
Indigenous population & $-0.14(0.103)$ \\
Group household & $\mathbf{0 . 3 7}(0.000)$ \\
Headquarter distance & $-0.09(0.330)$ \\
Altitude & $\mathbf{- 0 . 2 2}(0.011)$ \\
Slope & $\mathbf{- 0 . 2 5}(0.004)$ \\
\hline
\end{tabular}

Model 2 adds Terai; Model 3 further adds forest area; Model 4 further adds NDVI 1989; Model 5 further adds number of group households and proportion of indigenous people; Model 6 further adds distance of forest from the district headquarters; and Model 7 finally adds altitude and slope. All models were highly statistically significant $(p=0.000)$ and explain $12-35 \%$ of the variance of carbon storage. My models were well-specified 
as no violation of multiple regression assumptions were reported through residual diagnostic tests. The Ramsay Regression Specification Error test showed that there was no possibility of non-linearity of the residuals ( $\mathrm{p} \geq 0.540)$; the Breusch-Pagan test ruled out the possibility of heteroscedasticity ( $\mathrm{p} \geq 0.309$ ); Cook's Distance indicated the lack of strong influence of any observation (values range from 0.00 to 0.17 ); and the values of VIF range from $1.06-2.53$, which rejects the possibility of multicollinearity.

My models demonstrated mixed results in relation to my hypotheses. Results showed that collective action drivers either positively or negatively explained or did not explain carbon storage in Nepalese forest commons, indicating that better collective action does not store additional carbon in the current setting. This result is in line with other study results using the same data but different methods (e.g., Bluffstone et al. 2015; Chapter 3).

Models 1, 2 and 3 demonstrate that the public audit positively explains carbon storage; change of community's practice of public audit from "no" to "yes" increased carbon storage by 41.54 tons per hectare. However, this result is true in the case of the absence of conditional variables particularly NDVI 1989, which, when included in the model, dampened the significant relationship of public audit and carbon storage.

As hypothesized, the proportion of households engaged in the management of forest commons were consistently and positively correlated with carbon storage in four models only when I included NDVI 1998 (i.e., Models 4, 5, 6 and 7). These models showed an increase in each proportion of households participating in the management of forest commons increased carbon storage by $37.18-41.14$ tons per hectare. 
Table 5.6 Multivariate regression explaining carbon stock.

Coefficients and standard errors are given in the parentheses. Significance codes are - " ***" $=0.01$; “**" $=0.05$ and " $* "=0.1$. I checked the regression results replacing "distance to district headquarter" to "distance to roadhead", but I found that the regression results are still insignificant.

\begin{tabular}{|c|c|c|c|c|c|c|c|}
\hline Variables & Model 1 & Model 2 & Model 3 & Model 4 & Model 5 & Model 6 & Model 7 \\
\hline Conservation duration & $\mathbf{- 3 . 6 3} * * *(1.30)$ & $-3.17 * *(1.28)$ & $-2.97 * * *(1.19)$ & $-2.22 *(1.19)$ & $-\mathbf{2 . 4 3} * *(1.17)$ & $-2.48 * *(1.19)$ & $-2.48 *(1.27)$ \\
\hline Participating households & $41.26(25.28)$ & $37.79(24.58)$ & $37.63(22.87)$ & $\mathbf{3 7 . 1 8}^{*}(22.29)$ & 41.14*(22.27) & $\mathbf{4 0 . 8 9} *(22.38)$ & $\mathbf{4 0 . 4 3 * ( 2 2 . 7 5 )}$ \\
\hline Rules modification & $-28.34(25.50)$ & $-19.03(24.98)$ & $-38.59(23.65)$ & $\mathbf{- 3 6 . 8 9}(23.06)$ & $-38.47 *(22.59)$ & $\mathbf{- 3 8 . 2 0} *(22.71)$ & $\mathbf{- 3 7 . 9 8}(22.89)$ \\
\hline \multirow[t]{2}{*}{ Penalty system } & $-70.52 * *$ & -54.20 & -50.82 & $-71.43 * *$ & $-74.18 * *$ & $-74.61 * *$ & $-74.30 * *$ \\
\hline & $(33.37)$ & $(32.90)$ & $(30.62)$ & $(30.79)$ & $(30.21)$ & $(30.38)$ & $(30.63)$ \\
\hline Public audit & 41.54*** (13.83) & $42.47 * * *(13.43)$ & $22.26 *(13.29)$ & $21.33(12.96)$ & $18.69(13.11)$ & $19.15(13.31)$ & $19.63(13.46)$ \\
\hline Mutual trust & $4.59(15.43)$ & $6.29(15.00)$ & $6.63(13.96)$ & $5.97(13.60)$ & $9.92(13.41)$ & $10.38(13.60)$ & $10.26 \quad(13.72)$ \\
\hline Terai & & 36.53***(12.65) & $17.52(12.52)$ & $9.85(12.52$ & $10.41(12.27)$ & $11.21(12.75)$ & $4.86(19.76)$ \\
\hline Forest area & & & $\mathbf{0 . 1 9} * * *(0.04)$ & $\mathbf{0 . 1 6} * * *(0.04)$ & $\mathbf{0 . 1 7} * * *(0.04)$ & 0. $17 * * *(0.04)$ & $\mathbf{0 . 1 7} * * *(0.04)$ \\
\hline \multirow[t]{2}{*}{ NDVI1990 } & & & & $191.81 * * *$ & $161.68 * *$ & $161.01 * *$ & $160.94 * *$ \\
\hline & & & & $(70.50)$ & $(70.03)$ & (70.37) & $(70.94)$ \\
\hline Indigenous population & & & & & $-47.58 * *(18.34)$ & $-48.16 * *(18.90)$ & $-48.42 * *(19.07)$ \\
\hline Group household & & & & & $0.01(0.01)$ & $0.01(0.01)$ & $0.00(0.01)$ \\
\hline Headquarter distance & & & & & & $1.26(5.24)$ & $1.81(5.63)$ \\
\hline Altitude & & & & & & & $-0.002(0.02)$ \\
\hline \multirow[t]{2}{*}{ Constant } & $177.74 * * *$ & $127.25(12.65)$ & $133.13 * * *$ & 67.45 & 94.08* (48.08) & $91.50 *$ & 99.48* (53.04) \\
\hline & $(43.50)$ & & $(42.57)$ & $(48.00)$ & & $(49.45)$ & \\
\hline Residual standard error & 71.08 & 69.04 & 64.24 & 62.61 & 61.29 & 61.54 & 62.02 \\
\hline Adjusted R-squared & 0.1268 & 0.1759 & 0.2866 & 0.3226 & 0.3506 & 0.3454 & 0.3352 \\
\hline F statistic & 4.121 & 4.935 & 7.479 & 7.822 & 7.332 & 6.672 & 5.645 \\
\hline Degree of freedom & 123 & 122 & 121 & 120 & 118 & 117 & 115 \\
\hline P-value & 0.000 & 0.000 & 0.000 & 0.000 & 0.000 & 0.000 & 0.000 \\
\hline Ramsey test (p-value) & $0.34(0.711)$ & $0.62(0.540)$ & $0.22(0.806)$ & $0.42(0.661)$ & $0.27(0.763)$ & $0.25(0.781)$ & $0.17(0.843)$ \\
\hline BP test (p-value) & $4.71(0.582)$ & $6.90(0.439)$ & $9.07(0.336)$ & $10.06(0.346)$ & $12.29(0.342)$ & $13.21(0.354)$ & $16.07(0.309)$ \\
\hline Cook's D & $0.00-0.13$ & $0.00-0.12$ & $0.00-0.14$ & $0.00-0.17$ & $0.00-0.13$ & $0.00-0.12$ & $0.00-0.11$ \\
\hline VIF & $1.07-1.81$ & $1.07-1.81$ & $1.09-1.81$ & $1.15-1.82$ & $1.06-1.89$ & $1.12-1.90$ & $1.12-3.25$ \\
\hline
\end{tabular}


Surprisingly, in opposition to my hypotheses, the number of years communities managed the forest was negatively correlated with carbon storage both in the case of absence or presence of conditioning variables. My estimates of 2.22 to 3.63 ton carbon per hectare reduction with each year of increase in community engagement in forest conservation was significant $(\mathrm{p}=<0.1,<0.05)$. This result is in line with the finding of Anderson and Agrawal (2011) who showed, by taking cross-country data, a negative association of forest quality with the number of years communities engaged in forest conservation. This result reflects the unique historical context of Nepalese community forestry program in that degraded forests were formally handed over to local communities for management (Kanel \& Shrestha, 2001).

The communities' ability to change the rules did not have significant effect on carbon storage while controlling Terai and forest area. However, when I controlled the NDVI 1989 , unexpectedly the effect became negative (i.e., reduction of 36.89 to 38.47 tons of carbon per hectare for each point increase in NDVI 1989). This indicates the possibility of spurious effects.

The existence of penalty systems in the community was consistently negatively correlated with carbon storage (except Model 2); once a community adopted a penalty system, the quantity of carbon was reduced from 50.82 to 74.18 tons per hectare. The reduction was lower when controlling for the effects of Terai and forest area. The reductions increase either without conditioning variables (i.e., Model 1) or with the presence of more conditioning variables (i.e., Models 4, 5, 6 and 7). The negative association of penalty systems with carbon storage contradicts the findings of Chhatre 
and Agrawal (2008), who demonstrated a positive association between local enforcement and forest quality. This result also indicates the possibility of spurious effects.

Mutual trust among the households within a forest-managing community did not explain the variation in carbon storage. This finding is consistent with and without conditioning variables and probably contradicts the finding of Gibson et al. (1999) and Alcorn \& Toledo (1998) who argued that different measures of social capital explain the condition and management success of local forests. I included mutual trust in the models because of its theoretical significance for future analysis.

Seven out of eight conditioning variables (i.e., Terai, forest area, NDVI1989, proportion of indigenous population, distance from district headquarters, altitude and slope) had the expected sign, confirming the hypothesized direction of relationship between these variables and carbon storage. However, their estimate of unbiased coefficients and level of significance markedly vary. For instance, the estimated coefficients of forest area were significant; it was evident that each additional hectare of forest area increased carbon storage by $0.17-0.19$ tons per hectare. Similarly, the estimated coefficients of NDVI 1989 were significant and evident that each additional number in index increased carbon storage by $160.94-191.81$ tons per hectare. These results of forest area and NDVI reflect that carbon storage is increased as the quality of forest increased. Similar results were reported by Beyene et al. (2013). My results showed that carbon storage was sensitive to the presence of indigenous populations, with each additional proportion of indigenous population decreasing carbon by $47.16-47.58$ tons per hectare. The effects of two-way travel time to district headquarters, altitude and slope were not significant in explaining 
the variation in carbon storage. The total number of households had an unexpected sign, but this variable was also not significant in explaining carbon storage.

Per hectare carbon storage is primarily driven by baseline ecological conditions reflected by forest area and NDVI. Ecological conditions influence the biological potential and physical space for carbon storage. For instance, a higher carbon baseline enhances the biological potential of carbon storage while providing smaller physical space for carbon storage. The larger forest commons could have more undisturbed or less-disturbed forest that potentially saved larger sized trees. Such larger trees are highly correlated with carbon storage.

My models showed that conditioning variables such as Terai, forest area, NDVI and proportion of indigenous population are significantly correlated with carbon (Table 5.5). This indicates that these variables captured the unobserved effects of collective action drivers that explain their relations with carbon storage. In addition, these variables also explain other factors unrelated to collective action such as climate. As I am not interested in analyzing these details, I do not view this issue as a problem. However, I cannot rule out the possibility of empirical effects of the potential confounders that affect my conditioning variables. As I mentioned earlier in the model specification section (5.2.2.2), it is very difficult to envision exogenous factors that strongly affect both collective actions and carbon storage.

While comparing different models, I found that conditioning variables have important implications. It could be because they were associated with both carbon and collective action (Appendix C). This indicates that there are some unobserved aspects of collective 
action captured by conditioning variables that explain these correlations. For instance, all community forest user groups (CFUGs) need to carry out public audits (MoFSC, 2008); the forestry officials closely monitor and ensure that the larger CFUGs comply with the rule. This is also evident in my data that the public audit has positive, significant associations with forest area $(\rho=0.27, p=0.002)$ and number of households in the community $(\rho=0.29, p=0.001)$.

\subsection{Conclusion}

My study contributes to the recently emerging literature on understanding the relationship between collective action drivers and carbon storage (e.g., Beyene et al., 2013; Chazdon 2008; Chhatre \& Agrawal, 2009; Ranganathan et al., 2008) where several aspects are still unknown. As collective action can be contextual and measured in different ways, understanding its relationship with carbon storage may vary considerably. By using the data from nationally representative samples of formal community forests, informal forest commons and their corresponding forest user groups and households, I specifically analyzed the relationships between key collective action drivers and carbon storage both in the absence and presence of conditioning variables.

I found that different collective action drivers of Nepalese forest commons have both favorable and constraining implications for carbon storage. For instance, proportion of household participation in forest management activities and the existence of public audit have positive, and the number of years communities conserved the forest, the ability of communities to modify the rules and the existence of penalty systems have surprisingly 
negative, implications on carbon storage. I also found that the conditioning variables had differential impacts on the coefficient and significance of collective action drivers. They either enhanced or dampened or had a neutral effect on the coefficients and significance of collective action drivers. In aggregate, collective action in Nepalese forest commons is not going to explain or yield carbon. However, my results are indicative and they should be considered preliminary because of potential endogeneity, which was not possible to rule out completely.

My results also indicate the possibility of weak and ineffective implementation and monitoring of collective actions in the management of forest carbon in the Nepalese forest commons. Results also indicate that explicit policies and programs that seek to enhance carbon by steering collective action in a direction that lead to carbon storage are critical. In other words, the Nepalese government may need to pay more attention to strengthen collective action towards enhancing carbon storage so as to make the REDD+ program a success.

My study does not identify specific causal mechanisms although the relationships between collective action drivers and carbon storage were examined. Rather, it clearly points out the urgency of attention for further in-depth research, incorporating other collective action drivers and controlling possible bias due to endogeneity. It also suggests the need to rethink and improve collective action practices in Nepalese forest commons in order to contribute to the global environment through emission reduction and carbon storage. 


\section{Chapter 6: A synthesis of the research}

\subsection{Introduction}

With an aim to inform emerging forest policies that contribute to mitigate climate change, promote biodiversity conservation and support local scale ecosystem services, I draw overall conclusions to my research in this chapter. I specifically highlight the ways that forest commons could ecologically and socio-economically contribute to and/or constrain the contemporary global environmental initiatives such as REDD+. I synthesize the main arguments of my research, demonstrate their linkages with the REDD+ initiatives in Nepal and forest commons literature, and indicate the areas for future inquiry. Specifically, I examined Nepalese forest commons for their contributions to carbon sequestration, biodiversity conservation, equity in benefit sharing, policy provisions and institutional practices. I examined these aspects of forest commons taking an interdisciplinary and multi-scale approach. My research offers important insights into both ongoing policy processes regarding REDD+ in Nepal and the theory and action of forest commons in general.

This chapter is divided into five sections. The next section outlines how the research problem is contextualized within Nepal's forest commons. Section three talks about chapter-wise main findings of the research. Section four highlights the broader relevance, theoretical and methodological contributions, and policy and management implications of findings. Finally, section five signals the future direction of inquiry. 


\subsection{Contextualizing the research}

The global community has put in place agreements to address environmental challenges. For instance, the global community designed and agreed on the United Nations Framework Convention on Climate Change (UNFCCC) and the Convention on Biological Diversity (CBD) to address climate change and biodiversity loss, respectively. These initiatives clearly recognize the importance of tropical forests to sequester carbon and conserve biodiversity (Clark et al., 2001; Mittermeier et al., 2004; Pan et al., 2011; Parmentier et al., 2007; Philips et al., 1998). These agreements need to operate in a context where over a billion local forest users control approximately $15.5 \%$ of global forests for the supply of forest products and local ecosystem services, and the trend of community control is increasing as a result of decentralization reforms, particularly in tropical, developing countries (Charnley \& Poe, 2007; Larson \& Soto, 2008; RRI, 2014; Sunderlin et al., 2008). Scholars have indicated that equity in benefit sharing, appropriate policy provisions and acceptable institutional practices of forest management and carbon sequestration are critical to ensure forest commons contribute to global environmental initiatives.

There is an acute shortage of empirical, evidence-based knowledge that informs practical policies, management plans and incentive mechanisms to support global environmental initiatives at national and local scales. For instance, inadequate empirical knowledge of the relationship between carbon sequestration and biodiversity conservation in tropical forests (Midgley et al., 2010; Szwagrzyk \& Gazda, 2007; Talbot, 2010; Thompson et al., 2011) raised questions about the potential contribution of biodiversity conservation (or 
CBD) to carbon sequestration (or REDD+) and vice versa (Miles \& Dickson, 2010; Secretariat of the Convention on Biological Diversity, 2011). Similarly, potential contributions of formal, more-organized forest commons (i.e., community forestry) to REDD+ and CBD have been unknown due to a lack of robust knowledge on the effectiveness of such forestry on carbon sequestration, biodiversity conservation and equitable benefit sharing. Past studies have identified inconclusive and conflicting results in understanding the relationships between decentralization policies and institutions on local socio-ecological systems, including collective actions and carbon sequestration.

I assessed the ecological, socio-economic and institutional dynamics of Nepalese forest commons to inform contemporary Nepal's international environmental initiatives, particularly REDD+. The Nepalese government has decided to adopt the REDD+ program to contribute to climate change mitigation. It also expects to achieve co-benefits, including biodiversity conservation and socio-economic benefits, from the REDD+ initiative. A range of international non-governmental organizations and donors have been supporting the country's preparations for REDD+ including formulating REDD + strategy, developing institutional mechanisms, and building capacity of grassroots stakeholders and forest-managing communities. Nepalese forest commons provided excellent research sites and offered a unique learning ground to bring wide ranges of ecological and socio-economic issues into the analysis, as Nepal hosts a wide range of geographic locations, climatic patterns, forest types, socio-cultural practices, economic status, and policy and institutional provisions. Also, Nepal provides a long history of forest commons, both formal and informal, where nearly half of the country's population 
is directly engaged in the management of forest commons. Nepalese forest commons are critical components of subsistence livelihoods of local communities and local environmental services. Despite high pressure for land use change and D\&D, they have potential to contribute to the global environmental initiatives in different ways such as sequestering carbon, conserving biodiversity, and accumulating lessons that can be used in similar contexts beyond the country.

\subsection{Main findings}

My research confirmed and expanded upon previous studies within the interdisciplinary arena of human-environment interactions. My findings demonstrated the importance of interdisciplinary (e.g., through an ecological, econometric, social and institutional) and multi-scale (e.g., local, landscape and national) approaches of inquiry in examining and explaining the ecological and socio-economic contributions of forest commons such as carbon storage, biodiversity conservation, equity in benefit sharing and collective action drivers. My findings expanded the current qualitatively-researched knowledge through quantitative research on the (i) relationships of carbon and biodiversity, (ii) effects of formal forestry decentralization on carbon sequestration, biodiversity conservation and benefit sharing, and (iii) relationships between carbon sequestration and drivers of collective action including policy and institution.

My findings clearly indicated that the Nepalese forest commons have potential to contribute to global environmental initiatives including REDD+ and CBD. However, the level of contribution may be different based on the geographic and topographic contexts, management regimes and forest qualities. 


\subsubsection{Relationships between carbon sequestration and biodiversity conservation}

In chapter Two I assessed biodiversity, carbon and their relationships. My assessments bring critical insights for researchers, policy makers and practitioners working at global, national and local levels. My results demonstrated that Nepalese forests have potential to increase carbon storage and biodiversity conservation. As carbon and biodiversity fluctuate across altitude, slope and canopy cover, these are critical factors for planning and implementing forestry projects including REDD+.

My results showed comparable carbon sequestration (98.34 $\pm 4.19 \mathrm{Mg} \mathrm{C} \mathrm{ha}^{-1}$ ) with other field-based regional studies (e.g., Baral et al., 2009; Gurung et al., 2015; Pandey et al., 2014;), which is higher than the IPCC default value (90 $\left.\mathrm{Mg} \mathrm{ha}^{-1}\right)$. Variations in carbon sequestration across geographic and topographic regions reflected differential site quality, climatic factors, topographic conditions and past disturbances. Variations also indicated the possibility of increased carbon sequestration with dedicated forest management interventions in the future. I found that carbon sequestration decreased with increased altitude and slopes. The opposite is true for canopy cover, which has a positive relationship with carbon sequestration. My results showed that biodiversity increased with canopy cover but there was no change across altitudes and slopes. Plot-level biodiversity variations indicated the existence of a wide range of variables simultaneously affecting the distribution of biodiversity.

I found complex and varied relationships of carbon with different indices of biodiversity at the national level and across geographic and topographic regions and in forests with different canopy covers. Such results primarily reflected the existence of a complex 
network of interactions between wide ranges of co-varying abiotic and biotic environmental factors that affect different dimensions of both biodiversity and carbon. However, my study indicated the possibility of synergies between carbon-forestry and biodiversity conservation. It is evident from the fact that species richness and effective number of species were weakly positively correlated with carbon sequestration. This finding reflected earlier findings (e.g., Nadrowski et al., 2010; Potvin et al., 2011; Thompson et al., 2009) and showed the relevance of interspecific complementarity through niche differentiations or moisture conservation between species. However, I found negative or no correlations of carbon with equitability index. I also found skewed carbon sequestration on some species (i.e., $3 \%$ of species contain $84 \%$ of the carbon).

\subsubsection{Effectiveness of formal forest decentralization on carbon sequestration and biodiversity conservation}

In chapter Three I examined the effectiveness of formal forest commons, the CFP, on biodiversity conservation and carbon storage. My results indicated that the CFP has a positive effect on biodiversity at the national level. However, I found mixed and differential - positive, negative and no- effects of CFP on biodiversity conservation across geographic and topographic regions and in forests with different canopy covers. The CF in lower and higher slopes, in Terai districts, and in open canopies had positive effects on biodiversity conservation. However, the CF had a negative effect on the higher altitudes and an insignificant effect in the hills, lower altitudes and closed canopies. My positive biodiversity estimates reflect the contribution of CFP in revitalizing degraded forestlands (Gautam et al., 2002; Luintel et al., 2009), while negative biodiversity 
indicates the communities' preference for valuable species and selective harvesting (Acharya, 2004) and higher pressure in the CFs.

In terms of carbon sequestration, my results indicated that the CFP has a negative effect on carbon at the national level. However, I found mixed and differential - positive, negative and no- effects of CFP on carbon storage across geographic and topographic regions and in forests with different canopy covers. There were significant positive effects of CFP in the open canopies and the lower slopes. On the contrary, there were negative effects of CFP in the higher slopes and the higher altitudes. My carbon estimates were unexpected and complex, both reflecting and contradicting the earlier findings of Bluffstone et al. (2015), which concluded that the CFP effect was not significant. All the results for both biodiversity and carbon were sensitive to the unobserved confounders. However, the level of sensitivity was higher for the negative results.

My results should be viewed in the context of the objectives and management practices in $\mathrm{CF}$, the disturbance regime, the base carbon stock in $\mathrm{CF}$ and $\mathrm{NCF}$, and spillover effect of CFP on NCF, all of which might not have been well captured in the observed confounders. My results demonstrated that the CFP can be an effective forest management strategy to contribute to global ecosystem services including biodiversity conservation and carbon sequestration. They also pointed out the inadequacy of evaluating the effect of CFP at the national scale to identify local effects.

\subsubsection{Effectiveness of formal forest decentralization on equity in benefit sharing}

In chapter Four I examined the effectiveness of formal forest commons, the CFP, on equity in benefit sharing at the household level. My results indicated that the CFP has a 
positive effect on equity at the national level, across social groups (i.e., poor, dalit, women-headed households, indigenous peoples) and hills. However, I found no effect of CFP on equity in Terai. My positive equity estimates reflect the contribution of CFP to better governance and equitable benefits (Luintel et al., 2009, Luintel 2006; McDermott \& Schreckenberg, 2009; Persha \& Anderson, 2014; Pokharel \& Nurse 2004; Pokharel et al., 2007;) and the implementation of community forestry guidelines (Ministry of Forest and Soil Conservation, 2008), while no effect on equity in Terai indicates the lack of effort on the part of communities managing community forests and support agencies in the region in adequately addressing benefit-sharing issues (Bhattarai, 2006; Birendra et al., 2014). All results were moderately to highly sensitive to unobserved confounders. The level of sensitivity to unobserved variables was higher for dalits and lower for indigenous peoples.

My results should be viewed in the context of the socio-cultural practice of resource sharing in Nepalese society and the spillover effect of CFP on NCF. My results strongly demonstrate that the CFP can be an effective forest management strategy to contribute to making REDD+ benefit sharing equitable across the country and social groups such as poor, dalit, indigenous and women-headed households and households in the hills. They also point to the relevance of evaluating the effect of CFP at the national scale as well as across geographic regions and social groups to identify local effects.

\subsubsection{Examination of policy and institutional drivers of carbon sequestration}

In chapter Five I assessed the relationships between collective action drivers and carbon sequestration. My assessments bring critical insight for researchers, policy makers and 
practitioners, and particularly to those who are working at national and local levels. My results demonstrate that collective action drivers may have positive, neutral or negative relationships with carbon sequestration. The conditioning variables may have considerable (either statistically significant or insignificant) effects in shaping those relationships. They either enhance or dampen the relationships between collective action drivers and carbon sequestration to a certain degree.

My results suggest that theoretical expectations and earlier findings of forest commons governance research may not always be true in all cases. My findings also indicate the possibility of weak and ineffective implementation and monitoring of collective action in the management of forest carbon in Nepalese forest commons. My study suggests the need for context-specific in-depth research that considers additional dimensions of collective action to aid in the practical relevance of my research. It also suggests the need for rethinking and improving collective action practices in Nepalese forest commons to contribute to the global environment through emissions reduction and carbon sequestration.

\subsection{Relevance, contributions and implications of findings}

\subsubsection{Broader relevance}

My research findings have broader relevance from both spatial and temporal perspectives. Although my research was based on Nepalese forest commons, results from this work are applicable to other regions, particularly in the tropical, developing countries where formal and/or informal forest commons are in practice. In such countries, the governments are also adopting formal decentralization of forest, and therefore, better 
understanding of the relationships among the driving processes becomes crucial. I suggest careful adaptation of my findings by extracting the idea to suit particular ecological and socio-economic contexts. My aggregated national results and disaggregated results from across the geographic and topographic regions and forests of different canopy covers provide a broad range of lessons for adaptation in different spatial contexts. By providing detailed descriptions of the study regions, future comparisons of my results can also be made. My results will be valuable to others evaluating forest management alternatives in the face of climate change currently and/or in the future.

My research findings suggest the possibility of synergy between two global environmental initiatives, CBD and REDD+. However, care should be taken at the national and local levels while formulating policies, preparing management plans and implementing the plans. Dedicated policy provisions, management plans and actions are critical to achieve synergistic effects of these two global initiatives.

\subsubsection{Theoretical and methodological contributions}

My research is intended to add to the slowly growing interdisciplinary and multi-scale research approaches to socio-ecological systems building on multiple disciplines and scales to examine larger human-environment relationships (e.g., Berkes \& Folke, 1998, 1994). Principally, it adds to the emerging literature and theoretical propositions regarding forest commons management in the context of climate change (Beyene et al., 2013; Chazdon 2008; Chhatre \& Agrawal, 2009; Ranganathan et al., 2008). It specifically demonstrates the use of biophysical, socio-economic, policy and institutional information 
to broaden understanding of human actions on forest resources. My research integrates the biophysical information from the tree, plot, forest and larger spatial scales and socioeconomic and institutional information from the household and community levels. It empirically demonstrates that decentralized forestry and/or communities' engagement in the management of forest could have positive impacts on global environmental outcomes such as biodiversity and carbon sequestration, while fulfilling local forest product needs. It also strengthens the possibility of differential environmental outcomes across space, management regimes and forest qualities, and therefore supports the arguments made for sub-national policies and landscape-level management of forests. In the context of the slowly growing literature on the impact of forestry decentralization, my research brings robust findings and therefore provides strong evidence for policy effectiveness. My research provides novel methods for evaluating the communities' contributions to global environmental initiatives. I employed robust methods to reduce the bias in estimates and strengthened the claim that I have measured the causal effects of formal decentralization of Nepalese forests. My research is one of the pioneer studies in examining the impact of formal forest decentralization. In particular, the evaluation of global environmental outcomes such as biodiversity conservation and carbon storage, instead of socio-economic benefits at the local level, is a novel idea that I brought into the analysis. A mix of data across scales (e.g., tree to landscape level and household to national level) and disciplines (e.g., ecology, socio-economic and policy) brought methodological insights to using multi-scale and interdisciplinary data in examining complex relationships of humans and nature. I demonstrated the complementarities and 
synergy of interdisciplinary, multi-scale and multi-source data of quantitative and qualitative natures. The disaggregated analysis across geographic and topographic regions, management regimes and forest qualities demonstrated the relevance of policy and management of forest commons across spatial scales. It also showed how nationallevel aggregated results can mislead regional or sub-national findings. My research is one of the first studies to examine the impact of formal decentralization of Nepalese forestry by using nationally representative data and robust analytical analysis. Therefore, it contributes by setting the stage for further studies on natural resource policy evaluation in Nepal and beyond.

\subsubsection{Policy and management implications}

My estimates of carbon are conservative (i.e., they include only above ground live tree and sapling) and therefore may be used to guide future research. These estimates may need to be revised for the purpose of incentivizing forest-managing communities under REDD+. The existing biodiversity and possible increase of carbon in the Nepalese forest commons clearly indicates the ability of forest-managing communities to contribute positively to the CBD and REDD+ initiatives. The higher estimates of carbon while using field-based methods than that of the IPCC's biome average indicated the possibilities of more financial incentives for forest-managing communities through REDD+ program if they use field-based methods. Nepalese forest-managing communities could gain more benefits, including local employment opportunities by mobilizing their field-level resource persons to monitor carbon sequestration at the forest level. 
The weak, positive correlations between biodiversity and carbon show the possibility of increasing the number and abundance of species by carbon-forestry, indicating the possibility of synergy between CBD and REDD+. However, my finding of skewed biodiversity in some species and negative associations of carbon with species evenness warns of the possibility of constraining biodiversity conservation and promotion. Therefore, dedicated and appropriate policy provisions and institutional mechanisms and management interventions will be critical to safeguard biodiversity conservation in carbon-forestry. Forest-managing communities may need to adapt their forest management decisions and interventions to make both REDD+ and CBD effective in achieving their goals. Careful and site-specific planning, proper implementation and periodic monitoring of silvicultural activities are critical to ensure synergy between carbon and biodiversity outcomes and thereby promote climate mitigation, biodiversity conservation and other ecosystem services in the long-run. The differential relations of carbon with biodiversity indices indicate that the policy makers and forest-managing communities need to clarify which components of biodiversity (e.g., richness, abundance or evenness) they are prioritizing.

As the formal forest commons is a viable approach towards incentivizing communities (Agrawal, 2007; Agrawal \& Gupta, 2005; Agrawal \& Ostrom, 2008, 2001), policy makers and planners can promote formal decentralization in order to solicit local communities' contributions for promoting biodiversity conservation and carbon sequestration. Disaggregated data would provide useful insights for regional or landscape level planning for community forest management. The forest-managing communities 
may strengthen and/or revise the already tested landscape approach to forest management to promote carbon sequestration without compromising biodiversity conservation potentials.

\subsection{Future areas of inquiry}

There are several unresolved research questions that would increase the scientific understanding of environmental outcomes of forest commons in tropical, developing countries. I suggest some of the critical research areas that stemmed from, but remained outside the scope of, my research. The high variabilities of biodiversity, carbon and their relationships warrant further in-depth research to understand their dynamics (e.g., Day et al., 2013; Thompson et al., 2012). Such research at different spatial and temporal scales would enhance our scientific understanding to a great extent. Use of information about functional and evolutionary diversities, adaptive capacity of forests, impact of forest management modalities and all pools of carbon may help refine understanding of relationships between biodiversity and carbon.

A locally specific approach to explore key drivers of heterogeneity in ecological outcomes of forest commons is crucial to help make policy and management plans of biodiversity- and carbon-focused forestry effective. Landscape level assessments of CFP effectiveness may add value in informing locally suitable planning and management. The examination of the effects of different management interventions and/or silvicultural practices is another prime area for future research. Equally important is to explore the connection of forest resources with livelihood adaptation. Locally specific forest-based adaptation could be helpful to promote resource conservation and livelihoods for which 
study about cross-cultural comparison and traditional ecological knowledge becomes crucial (Spoon, 2013, 2014).

Long-term, ongoing data collection and research may need to be institutionalized to resolve the issues of perplexing changes in biodiversity and carbon. Researchers can continue to test, validate and review the findings of my research over time and with increasing amounts of data. A good mix of biophysical and social surveys, in-depth qualitative interviews, and robust statistical analyses may help elucidate critical relationships between local forest management practices and global environmental initiatives. 


\section{References}

Abadie, A., \& Imbens, G. W. (2006). Large sample properties of matching estimators for average treatment effects. Econometrica, 74(1), 235-267.

Acharya, K. (2004). Does community forests management supports biodiversity conservation? Evidences from two community forests from the mid hills of Nepal. Journal of Forest and Livelihood, 4(1), 44-54.

Adhikari, B. (2005). Poverty, property rights and collective action: Understanding the distributive aspects of common property resource management. Environment and Development Economics, 10, 7-31.

Adhikari, B. \& Lovett, J. C. (2006). Transaction costs and community-based natural resource management in Nepal. Journal of Environmental Management, 78(1), 515.

Adhikari, S., Kingi, T., \& Ganesh, S. (2014). Incentives for community participation in the governance and management of common property resources: The case of community forest management in Nepal. Forest Policy and Economics, 44, 1-9.

Agarwal, B. (2001). Participatory exclusions, community forestry, and gender: An analysis for South Asia and a conceptual framework. World Development, 29(10), $1623-1648$.

Agrawal, A., Nepstad, D., \& Chhatre, A. (2011). Reducing emissions from deforestation and forest degradation. Annual Review of Environment and Resources, 36, 373-396.

Agrawal, A. (2000). Sustainability on the commons. Paper presented at the 8th Biennial Conference of the International Association for the Study of Common Property. Bloomington, IN, USA, May 30-June 4, 2000.

Agrawal, A. (2001). Common property institutions and sustainable governance of resources. World Development, 29(10), 1649-1672.

Agrawal, A. (2007). Forests, governance, and sustainability: Common property theory and its contributions. International Journal of the Commons, 1(1), 111-36.

Agrawal, A., \& Angelsen, A. (2009). Using community forest management to achieve REDD+ goals. In A. Angelsen (Ed.), Realizing REDD+: National strategy and policy options (pp. 201-211). Bogor, Indonesia: Centre for International Forestry Research.

Agrawal, A., \& Chhatre, A. (2006). Explaining success on the commons: Community forest governance in the Indian Himalaya. World Development, 34(1), 149-166.

Agrawal, A., \& Gibson, C. (1999). Enchantment and disenchantment: The role of community in natural resource conservation. World Development, 27(4), 629-650.

Agrawal, A., \& Gupta, K. (2005). Decentralization and participation: The governance of common pool resources in Nepal's Terai. World Development, 33(7), 1101-1114.

Agrawal, A., \& Ostrom, E. (2001). Collective action, property rights, and decentralization 
in resource use in India and Nepal. Politics and Society, 29(4), 485-514.

Agrawal, A., \& Ostrom, E. (2008). Decentralization and community-based forestry: Learning from experience. In L. Webb \& G. P. Shivakoti (Eds.), Decentralization, forests and rural communities: Policy outcomes in South and Southeast Asia (pp, 44-67). New Delhi: SAGE Publications.

Agrawal, A., \& Yadama, G. (1997). How do social institutions mediate market and population pressures on resources? Forest panchayats in Kumaon India. Development and Change, 28, 435-465.

Alcorn, J. B., \& Victor, M. T. (1998). Resilient resource management in Mexico's forest ecosystems: The contribution of property rights. In F. Berkes \& C. Folke (Eds.), Linking social and ecological systems: Management practices and social mechanisms for building resilience (pp. 216-49). Cambridge: Cambridge University Press.

Alcorn, J. B. (1981). Huastec noncrop resource management: Implications for prehistoric rainforest management. Human Ecology, 9(4), 395-417. Retrieved on January 20, 2016 from http://www.springerlink.com.proxy.lib.pdx.edu/content/j7567411nw770284/fulltext .pdf

Andersson, K., \& Agrawal, A. (2011). Inequalities, institutions, and forest commons. Global Environmental Change, 21(3), 866-875.

Andersson, K., \& Gibson, C. C. (2007). Decentralized governance and environmental change: Local institutional moderation of deforestation in Bolivia. Journal of Policy Analysis and Management, 26(1), 99-123.

Angelsen, A., \& Atmadja, A. (2008). What is this book about? In A. Angelsen (Ed.). Moving ahead with REDD: Issues, options and implications (pp. 1-10). Bogor, Indonesia: CIFOR.

Arsel, M. \& Buscher, B. (2012). Nature Inc.: Changes and continuities in neoliberal conservation and market-based environmental policy. Development and Change, 43(1), 53-78. DOI:10.1111/j.1467-7660.2012.01752.x.

Baker, T. R., Phillips, O. L., Malhi, Y., Almeida, S., Arroyo, L., Di Fiore, A., Erwin, T., Killeen, T. J., Laurance, S. G., \& Laurance, W. F. (2004). Variation in wood density determines spatial patterns in Amazonian forest biomass. Global Change Biology, 10(5), 545-562.

Balvanera, P., Pfisterer, A. B., Buchmann, N., He, J. S., Nakashizuka, T., Raffaelli, D., \& Schmid, B. (2006). Quantifying the evidence for biodiversity effects on ecosystem functioning and services. Ecology Letters, 9(10), 1146-1156.

Banjade, M., Paudel, N. S., Karki, R., Sunam, R., \& Paudyal, B. R. (2011). Putting timber in the hot seat: Discourse, policy and contestations over timber in Nepal. Discussion Paper Series 11:2. Kathmandu: ForestAction Nepal. 
Baral, S. K., Malla, R., \& Ranabhat, S. (2009). Above-ground carbon stock assessment in different forest types of Nepal. Banko Janakari, 19(2), 10-14.

Bardhan, P. (2002). Decentralization of governance and development. Journal of Economic Perspectives, 16(4), 185-205.

Barron, P., \& Clark, S. (2006). Decentralizing inequality? Center-Periphery relations, local governance and conflict in Aceh. Washington, DC: The World Bank.

Barth, F. (2008 [1956]). Ecological relationships of ethnic groups in Swat, North Pakistan. In M. R. Dove \& C. Carpenter (Eds.), Environmental anthropology: A historical reader (pp. 181-189). Oxford: Blackwell Publishing.

Batjes. N. H., \& Sombroek, W. G. (1997). Possibilities for carbon sequestration in tropical and subtropical soils. Global Change Biology, 3(2), 161-173.

Beck, J., \& Schwanghart, W. (2010). Comparing measures of species diversity from incomplete inventories: An update. Methods in Ecology and Evolution, 1, 38-44.

Berkes, F., \& Folke, C. (1994). Investing in cultural capital for the sustainable use of natural capital. In A. M. Jansson, M. Hammer, C. Folke \& R Costanza (Eds.), Investing in natural capital: The ecological economics approach to sustainability (pp. 128-149). Washington, DC: Island Press.

Berkes, F., \& Folke, C. (1998). Linking social and ecological systems for resilience and sustainability. In F. Berkes \& C. Folke (Eds.). Linking social and ecological systems: Management practices and social mechanisms for building resilience (pp. 1-26). Cambridge, UK: Cambridge University Press.

Beyene, A. D., Bluffstone, R., \& Mekonnen, A. (2013). Community forests, carbon sequestration and REDD+: Evidence from Ethiopia. Environment and Development Economics, 1-24. Retrieved on December 20, 2015 from http://pdxscholar.library.pdx.edu/cgi/viewcontent.cgi?article=1037\&context=econ $\underline{\mathrm{fac}}$

Bhatt, B. P., \& Tomar, J. M. S. (2002). Firewood properties of some Indian mountain tree and shrub species. Biomass and Bioenergy, 23(4), 257-260.

Bhattarai, B. (2001). Protection of community forests: Options and innovations in the hills of Nepal. Journal of Forestry and Livelihood, 1(1), 14-15.

Bhattarai, B. (2006). Widening the gap between Terai and hill farmers in Nepal? The implications of the new Forest Policy 2000. In S. Mahanty, J. Fox, M. Nurse, P. Stephen \& L. McLees (Eds.), Hanging in the balance: Equity in community based natural resource management in Asia (pp. 143-161). Bangkok: RECOFTC, EastWest Center.

Biermann, F. (2002). Institutions for scientific advice: Global environmental assessments and their influence in developing countries. Global Governance, 8(2), 195-219. 
Birendra, K.C., Mohammod, A. J., \& Inoue, M. (2014). Community forestry in Nepal's Terai region: Local resource dependency and perception on institutional attributes. Environment and Natural Resources Research, 4(4), 142-154.

Bista, D. B. (1991). Fatalism and Development: Nepal's Struggle for Modernization. Calcutta: Orient Longman.

Bluffstone, R., Robinson, E., \& Gulthiga, P. (2013). REDD+ and community-controlled forests in low income countries: Any hope for linkage? Ecological Economics, 87, 43-52.

Bluffstone, R., Somanathan, E., Jha, P., Luintel, H., Bista, R., Paudel, N. S., \& Adhikari, B. (2015). Does collective action sequester carbon? The case of the Nepal community forestry program. Policy Research Working Paper \#7327. World Bank Group. Retrieved on December 10, 2015 from https://openknowledge.worldbank.org/bitstream/handle/10986/22194/Does0collecti v0ity0forestry0program.pdf? sequence $=1 \&$ isAllowed $=\mathrm{y}$

Bosetti, V., Lubowski, R., Golub, A., \& Markandya, A. (2011). Linking reduced deforestation and a global carbon market: Implications for clean energy technology and policy flexibility. Environment and Development Economics, 16(4), 479-505. DOI: $10.1017 / \mathrm{S} 1355770 \mathrm{X} 10000549$

Boyce, J. K., Narain, S., \& Stanton, E. A. (Eds.). (2007). Reclaiming nature: Environmental justice and ecological restoration. London: Athem Press.

Brown, D., Malla, Y., Schreckenberg, K., \& Springate-Baginski, O. (2002). From supervising 'subjects'to supporting citizens: Recent developments in community forestry in Asia and Africa. London: Overseas Development Institute (ODI).

Brown, K., \& Pearce, D. (1994). The economic value of non-market benefits of tropical forests: Carbon storage. In J. Weiss (Ed.), The economics of project appraisal and the environment: New horizon in environment economics (pp. 102-119). London: Edward Elgar.

Brown, S. (I 993). Tropical forests and the global carbon cycle: The need for sustainable land-use patterns. Agriculture, Ecosystems, and Environment, 46(1), 31-44.

Brown, S., Gillespie, A. J. R., \& Lugo, A. E. (1991). Biomass of tropical forests of south and Southeast Asia. Canadian Journal of Forest Research, 21(1), 111-117.

Brown, S., Iverson, L. R., Prasad, A., \& Liu, D. (1993b). Geographical distribution of carbon in biomass and soils of tropical Asian forests. Geocarto International, $8(4), 45-60$.

Busch, J., Godoy, F., Turner, W. R., Harvey, C. A. (2011). Biodiversity co-benefits of reducing emissions from deforestation under alternative reference levels and levels of finance. Conservation Letters, 4, 101-115. 
Cammack, D. (2007). Understanding the political economy of climate change is vital to tackling it: Opinion 92. The UK: Overseas Development Institute.

Campbell, B. M. (2009). Beyond Copenhagen: REDD+, agriculture, adaptation strategies and poverty. Global Environmental Change, 19(4), 397-99.

Campbell, J. G., \& Bhattarai, T. N. (1983). Community forestry private planting survey results. Nepal Forestry Technical Information Bulletin, 8, 20-30.

Caplow, S., Jagger, P., Lawlor, K., \& Sills, E. (2011). Evaluating land use and livelihood impacts of early forest carbon projects: Lessons for learning about REDD+. Environmental Science and Policy, 14(2), 152-167.

Cardinale, B. J., Nelson, K., \& Palmer, M. A. (2000). Linking species diversity to the functioning of ecosystems: On the importance of environmental context. OIKOS, $91,175-183$.

Carter, J., \& Gronow, J. (2005). Recent experience in collaborative forest management: A review paper. CIFOR Occasional Paper No. 43. Bogor, Indonesia: Center for International Forestry Research.

Caspersen, J. P., \& Pacala, S. W. (2001). Successional diversity and forest ecosystem function. Ecological Research. 16(5), 895-903. DOI: 10.1046/j.14401703.2001.00455.x

Cernea, M., \& Schmidt-Soltau, K. (2006). Poverty risks and national parks: Policy issues in conservation and resettlement. World Development, 34(10), 1808-1830.

Chaiyo, U., Garivait, S., \& Wanthongchai, K. (2011). Carbon storage in above-ground biomass of tropical deciduous forest in Ratchaburi province, Thailand. World Academy of Science, Engineering and Technology, 58.

Chapagain, N., \& Banjade, M. R. (2009). Community forestry and local development: Experiences from the Koshi Hills of Nepal, Journal of Forest and Livelihood, 8(2), 78-92.

Charnley, S., \& Poe, M. R. (2007). Community forestry in theory and practice: Where are we now? Annual Review of Anthropology, 36, 301-336.

Chaturvedi, R. K., Raghubanshi, A. S., \& Singh, J. S. (2011). Carbon density and accumulation in woody species of tropical dry forest in India. Forest Ecology and Management, 262(8), 1576-1588.

Chave, J., Andalo, C., \& Brown, C. (2005). Tree allometry and improved estimation of carbon stocks and balance in tropical forests; Oecologia, 145, 87-99. DOI 10.1007/s00442-005-0100-x.

Chazdon, R. (2008). Beyond deforestation: Restoring forests and ecosystem services on degraded lands. Science, 320, 1458-59.

Chhatre, A., \& Agrawal, A. (2009). Tradeoffs and synergies between carbon storage and livelihood benefits from forest commons. Proceedings of the National Academy of Sciences, 106(42), 17667-17670. 
Chhatre, A., \& Agrawal, A. (2008). Forest Commons and local enforcement. Proceedings of the National Academy of Sciences, 105(36), 13286-13291.

Clark, D. A., Brown, S., Kicklighter, D., Chambers, J. Q., Thomlinson, J. R., \& Ni, J. (2001). Measuring net primary production in forest: Concepts and field methods. Ecological Applications, 11, 356-370.

Collatz, G. J., Ball, J. T., Grivet, C., \& Berry, J. A. (1991). Physiological and environmental regulation of stomatal conductance, photosynthesis and transpiration: A model that includes a laminar boundary layer. Agricultural and Forest Meteorology, 54(2-4), 107-136.

Constance, L., McDermott, B. C., \& Kanowski, P. (2010). Global environmental forest policies: An international comparison. Washington DC: Earthscan.

Convention on Biological Diversity. (CBD). (1992). Convention on Biological Diversity. Rio de Janeiro, Argentina. Retrieved on January 15, 2015 from http://www.biodiv.org/convention/

Convention on Biological Diversity. (CBD). (2010). Outcomes of the global expert workshop on biodiversity benefits of reducing emissions from deforestation and forest degradation in developing countries. Convention on Biological Diversity, UNEP/CBD/WS-REDD/1/3, Nairobi, Kenya.

Convention on Biological Diversity. (CBD). (2011). REDD-Plus and biodiversity. Technical Series No. 59. Convention on Biological Diversity, Montreal, Canada.

Coomes, O. T., Grimard, F., Potvin, C., \& Sima, P. (2008). The fate of the tropical forest: Carbon or cattle ?. Ecological Economics, 65(1), 207-12.

Corbera, E., \& Brown, K. (2010). Offsetting benefits? Analyzing access to forest carbon. Environment and Planning, A 42, 1739-61.

Cotula, L., \& Mayers, J. (2009). Tenure in REDD: Start-point or afterthought? Natural Resource Issues No. 15. London: International Institute for Environment and Development.

Cox, M., Arnold, G., \& Tomás, S. V. (2010). A review of design principles for community-based natural resource management. Ecology and Society, 15(4), 38. Retrieved on February 12, 2016 from http://www.ecologyandsociety.org/vol15/iss4/art38/main.html

Crutzen, P. J. \& Andreae, M. O. (1990). Biomass burning in the tropics: Impact on atmospheric chemistry and biogeochemical cycles, Science, 250(4988), 1669-1678.

Dale, V. H., Houghton, R. A., Grainger, A., Lugo, A. E., \& Brown, S. (1993). Emissions of greenhouse gases from tropical deforestation and subsequent use of the land. In Sustainable Agriculture and the Environment in the Humid Tropics: Committee on Sustainable Agriculture and the Environment in the Humid Tropics (pp. 215-262). 
Washington, D C, USA: National Research Council, National Academy Press. Retrieved on April 20, 2016 from http://www.nap.edu/read/1985/chapter/1\#v

Day, M., Baldauf, C., Rutishauser, E., \& Sunderland, T. C. H. (2013). Relationships between tree species diversity and above-ground biomass in central African rainforests: Implications for REDD. Environmental Conservation, 41(1), 64-72. DOI:10.1017/S0376892913000295

Dehejia, R. H., \& Wahba, S. (1999). Causal effects in non-experimental studies: Reevaluating the evaluation of training programs. Journal of the American Statistical Association, 94, 1053-62.

Department of Forest Research and Survey. (DFRS). (1999). Forest and shrub cover of Nepal 1994 (1989-1996) (Publication No. 72), Forest Survey Division, Department of Forest Research and Survey. Kathmandu, Nepal.

Department of Forest Research and Survey. (DFRS). (2015). State of Nepal's forests. Forest resource assessment (FRA) Nepal, Department of Forest Research and Survey (DFRS). Kathmandu, Nepal.

Department of Forest. (DoF). (2015). The community forestry database. Retrieved on August 26, 2015 from http://dof.gov.np/image/data/Community_Forestry/Summary.pdf

Dessler, A. E., \& Parson, E. A. (2006). The science and politics of global climate change: A guide to debate. The UK: The Cambridge University Press.

Diamond, A., \& Sekhon, J. S. (2013). Genetic matching for estimating causal effects: A general multivariate matching method for achieving balance in observational studies. The Review of Economics and Statistics, 95(3), 932-945.

DOI:10.1162/REST_a_00318

Diaz, S., Hector, A., \& Wardle, D. A. (2009). Biodiversity in forest carbon sequestration initiatives: Not just a side benefit. Current Opinion in Environmental Sustainability, 1, 55-60.

Dietz, T., \& Henry, A. D. (2008). Context and the commons. Proceedings of the National Academy of Sciences, 10(36), 13189-13190.

Dixon, R. K., Schroeder, P. E., \& Winjum, J. K. (1991). Assessment of promising forest management practices and technologies for enhancing the conservation and sequestration of atmospheric carbon and their costs at the site level. EPA/600/3911067. Washington, DC, USA: U.S. Environmental protection Agency, Office of Research and Development.

Dixon, R. K., Brown, S., Houghton, R. A., Solomon, A. M., Trexler, M. C., \& Wisniewski, J. (1994). Carbon pools and flux of global forest ecosystems. Science, 263, 185-190. 
Dryzek, J. S., \& Stevenson, H. (2011). Global democracy and earth system governance. Ecological Economics, 70(11), 1865-1874.

Dyer, N. \& Counsel, S. (2010). McREDD: How McKinsey 'cost curves' are distorting REDD. Rainforest Foundation UK Climate and Forests Policy Brief. November 2010.

Eckholm, E. (1975). The deterioration of mountain environments, Science, 189(4205), 764-770. DOI: 10.1126/science.189.4205.764

Eliasch, J. (2008). Climate change: Financing global forests. Eliasch Review. Retrieved on December 30, 2014 from https://www.gov.uk/government/uploads/system/uploads/attachment_data/file/2288 33/9780108507632.pdf

Fairhead, J., Leach, M. \& Scoones, I. (2012). Green grabbing: A new appropriation of nature? Journal of Peasant Studies, 39(2), 237-261.

Fisher, R. J. (1989). Indigenous systems of common property forest management in Nepal. Working Paper No. 18. Honolilu, Hawaii: East West Center,

Flint, E. P., \& Richards, J. F. (1994). Trends in carbon content of vegetation in South and Southeast Asia associated with changes in land use. In V. H. Dale (Ed.), Effects of land use change on atmospheric CO2 concentrations: Southeast Asia as a case study (pp. 201-300). New York, NY, USA: Springer-Verlag.

Folke, C., Holling, C. S., \& Perrings, C. (1996). Biological diversity, ecosystems, and the human scale. Ecological Applications, 6(4), 1018-1024.

Food and Agricultural Organization. (FAO). (1993). Forest resources assessment 1990. Tropical Countries. FAO Forestry Paper 112, Rome, Italy.

Fridley, J. D. (2001). The influence of species diversity on ecosystem productivity: How, where, and why? OIKOS, 93, 514-526.

Gardner, T. A., Barlow, J., Chazdon, R., Ewers, R. M., Harvey, C. A., Peres, C. A., \& Sodhi, N. S. (2009). Prospects for tropical forest biodiversity in a human-modified world. Ecology Letters, 12(6), 561-582.

Gardner, T. A., Burgess, N. D., Aquilar-Amuchastegui, N., Barlow, J., Berenguer, E., Clements, T., Danielsen, F., Ferreira, J., Foden, W., Kapos, V., Khan, S. M., Lees, A. C., Parry, L., Roman-Cuesta, R. M., Schmitt, C. B., Strange, N., Theilade, I., \& Vieira, I. C. G. (2012). A framework for integrating biodiversity concerns into national REDD programmes. Biological Conservation, 154, 61-71.

Gautam, A. P., Edward, L. W., \& Apisit, E. (2002). GIS assessment of land use/land cover changesassociated with community forestry implementation in the middle hills of Nepal. Mountain Research and Development, 22(1), 63-69.

Gautam, K. H. (1991). Indigenous forest management systems in the hills of Nepal. (Doctoral Dissertation). Retrieved from Australian National University, Australia on April 22, 2016 from http://lib.icimod.org/record/9809/files/217.pdf 
Geist, H. J. \& Lambin E. F. (2002). Proximate causes and underlying driving forces of tropical deforestation, BioScience, 52(2), 143-150.

Gibson, C. C., Williams, J. T., \& Ostrom, E. (2005). Local enforcement and better forests. World Development, 33(2), 273-284.

Gibson, C., Williams, J., and Ostrom, E. (1999). Social capital and the governance of forest resources. Workshop in political theory and policy analysis. Indiana University, Bloomington, IN. Retrieved on April 22, 2016 from http://dlc.dlib.indiana.edu/dlc/handle/10535/4454

Gibson, L., Lee, T. M., Koh, L. P., Brook, B. W., Gardner, T. A., Barlow, J., Peres, C. A., Bradshaw, C. J. A., Laurance, W. F., Lovejoy, T. E., \& Sodhi, N. S. (2011). Primary forests are irreplaceable for sustaining tropical biodiversity. Nature, 478, 378-381.

Giddens, A. (2008). The politics of climate change: The national response to the challenge of global warming. Policy network paper. The UK: Policy Network.

Gilmour, D. A., \& Fisher, R. J. (1991). Villagers, forests and forester: The philosophy, process and practice of community forestry in Nepal. Kathmandu, Nepal: Sahayogi Press.

Gilmour, D. A., King, G. C., Applegate, G. B, \& Mohns, B. (1990). Silviculture of plantation forest in central Nepal to maximize community benefits. Forest Ecology and Management, 32(2-4), 173-186.

Goldammer, J. G. (Ed.). (1990). Fire in the tropical biota: Ecosystem processes and global challenges. Ecological Studies 84. Berlin, Germany: Springer Verlag.

Grainger, A. (1988). Estimating areas of degraded tropical lands requiring replenishment of forest cover. International Tree Crops Journal, 5(1/2), 31-61.

Gross, C. (2007). Community perspectives of wind energy in Australia: The application of a justice and community fairness framework to increase social acceptance. Energy Policy, 35(5), 2727-2736.

Gupta, J. (2009). Climate change and development cooperation: Trends and questions. Current Opinion in Environmental Sustainability, 1(2), 207-213.

Gurung, M. B., Bigsby, H., Cullen, R., \& Manandhar, U. (2015). Estimation of carbon stock under different management regimes of tropical forest in the terai arc landscape, Nepal, Forest Ecology and Management, 356, 144-152.

Hansen, B. B., (2004). Full matching in an observational study of coaching for the SAT. Journal of the American Statistical Association, 99(467), 609-618.

Hardin, G. (1968). The tragedy of the commons. Science, 168(3859), 1243-1248. DOI:10.1126/science.162.3859.1243

Haripriya, G. S. (2000). Estimates of biomass in Indian forests. Biomass Bioenergy, $19(4), 245-258$.

Harmon, M. E. (2001). Carbon sequestration in forests: Addressing the scale question. Journal of Forestry, 99(4), 24-29. 
Harrison, M. E, Paoli, GaD. (2012). Managing the risk of biodiversity leakage from prioritising REDD+ in the most carbon-rich forests: the case study of peat-swamp forests in Kalimantan, Indonesia. Tropical Conservation Science, 5, 426-433.

Harvey, C. A., Dickson, B., \& Kormos, C. (2010). Opportunities for achieving biodiversity conservation through REDD. Conservation Letters, 3, 53-61.

Hassan, R., Scholes, R., \& Ash, N. (Eds.). (2005). Ecosystems and human well-being: Current state and trends (Vol. 1). New York, NY: Island Press.

Healy, C., Gotelli, N. J., \& Potvin, C. (2008). Partitioning the effects of biodiversity and environmental heterogeneity for productivity and mortality in a tropical tree plantation. Journal of Ecology, 96, 903-913. DOI: 10.1111/j.13652745.2008.01419.x

Heckman, J., Ichimura, H., Smith, J., \& Todd, P. (1998). Characterizing selection bias using experimental data. Econometrica, 66(5), 1017-1098.

Heinrich, C., Maffioli, A., \& Vázquez, G. (2010). A primer for applying propensity-score matching impact-evaluation guidelines. Technical Note, Inter-American

Development Bank. Retrieved on August 172015 from http://idbdocs.iadb.org/wsdocs/getdocument.aspx?docnum=35320229

Heltberg, R. (2001). Determinants and impacts of local institutions for common resource management. Environment and Development Economics, 6(2), 183-208.

Hendrickson, N. (2008). Counterfactual reasoning: A basic guide for analysts, strategists, and decision makers, The Proteus Monograph Series, 2(5). Retrieved on 20 September 2015 from http://www.au.af.mil/au/awc/awcgate/armyusawc/csl_counterfactual_reasoning.pdf

Hiraldo, R., \& Tanner, T. (2011). Forest voices: Competing narratives over REDD. Institute of Development Studies (IDS) Bulletin, 42(3), 42-51.

Ho, D. E., Imai, K., King., G., \& Stuart, E. A. (2007). Matching as nonparametric preprocessing for reducing model dependence in parametric causal inference. Political Analysis, 15, 199-236. DOI:10.1093/pan/mpl013

Hobley, M. (2007). Where in the world is there pro-poor forestry and tenure reform? Washington, DC: Rights and Resources Initiative.

Hooper, D. U., Chapin, F. S., Ewel, J. J., Hector, A., Inchausti, P., Lavorel, S., Lawton, J. H., Lodge, D. M., Loreau, M., Naeem, S., Schmid, B., Setala, H., Symstad, A. J., Vandermeer, J., \& Wardle, D. A. (2005). Effects of biodiversity on ecosystem functioning: A consensus of current knowledge. Ecological Monographs, 75(1), 335. DOI: $10.1890 / 04-0922$

Houghton, J. T., Callander, B. A., \& Varney, S. K. (Eds.). (1992). Climate Change 1992: The supplementary report to the IPCC scientific assessment. Cambridge: Cambridge University Press. 
Houghton, R. A. (2005). Aboveground forest biomass and the global carbon balance. Global Change Biology, 11(6), 945-958. Retrieved on July 25, 2015 from http://dx.doi.org/10.1111/j.1365-2486.2005.00955.x.

Houghton, R. A., \& Hackler. J. L. (2000). Changes in terrestrial carbon storage in the United States. 1.: The roles of agriculture and forestry. Global Ecology and Biogeography, 9(2), 125-144.

Huettner, M. (2012). Risks and opportunities of REDD+ implementation for environmental integrity and socio- economic compatibility. Environmental Science and Policy, 15(1), 4-12.

Hujer, R., Caliendo, M., \& Thomsen, S. L. (2004). New evidence on the effects of job creation schemes in Germany: A matching approach with threefold heterogeneity. Research in Economics, 58, 257-302.

Hyde, W., Amacher , G., \& Magrath, W. (1996). Deforestation and forest land use: Theory, evidence and policy implications. The World Bank Research Observer, 11.

Imai, K., King, G., \& Stuart, E. A. (2008). Misunderstandings between experimentalists and observationalists about causal inference. Journal of the Royal Statistical Society, 171, 481-502. DOI:10.1111/j.1467-985X.2007.00527.x. Series A

Imbens, G. W. (2004). Nonparametric estimation of average treatment effects under exogeneity: A review. Review of Economics and Statistics, 86(1), 4-29.

Intergovernmental Panel of Climate Change. (IPCC). (1992). Climate change: The IPCC response strategies. WMO/UNEP Island Press, Covelo, CA, USA, p. 273.

Intergovernmental Panel of Climate Change. (IPCC). (2007). Climate change 2007: The physical science basis. Summary for policymakers. Retrieved on February 12, 2014 from http://www.ipcc.ch/pdf/assessment-report/ar4/wg1/ar4-wg1-spm.pdf

Intergovernmental Panel on Climate Change. (IPCC). (2006). Good practice guidelines for national greenhouse gas inventories, Switzerland: Intergovernmental panel on climate change.

International Panel on Climate Change. (IPCC). (2007). Climate change 2007: The physical science basis. Contribution of working group I to the fourth assessment report of the intergovernmental panel on climate change. New York, NY: Cambridge University Press.

Iversen, V., Chhetry, B., Francis, P., Gurung, M., Kafle, G., Pain, A. \& Seeley, J. (2006). High value forests, hidden economies and elite capture: Evidence from forest user groups in Nepal's Terai. Ecological Economics, 58, 93-107.

Jackson, J. K. (1994). Manual of afforestation in Nepal. (Vol. 2), Forest Research and Survey Centre, Kathmandu, Nepal.

Jain, R. K., \& Singh, B. (1999). Fuelwood characteristics of selected indigenous tree species from central India. Bioresource Technology, 68(3), 305-308. 
Jasanoff, S., \& Martello, M. L. (Eds.). (2004). Earthly politics: Local and global in environmental governance. Cambridge, MA: The MIT Press.

Jodha, N. S. (2008). Some places again: A restricted revisit to dry regions of India. In R. Ghate, N. S. Jodha, \& P. Mukhopadhyay (Eds.) Promise, trust, and evolution: Managing the commons of South Asia (pp. 51-69), Oxford: Oxford University Press.

Johannes, R. E. (2002). The renaissance of community-based marine resource management in Oceania. Annual Review of Ecology and Systematics, 33(1), 317340.

Johnson, C., \& Forsyth, T. (2002). In the eyes of the state: Negotiating a 'rights based approach' to forest conservation in Thailand. World Development, 30(9), 15911605.

Jolliffe, I. T. (2002). Principal component analysis ( $2^{\text {nd }}$ Ed.). New York, NY: Springer.

Jost, L. (2006). Entropy and diversity. OIKOS, 113(2), 363-375.

Kakonen, M., Lebel, L., Karhunmaa, K., Dany, V., \& Try, T. (2014). Rendering climate change governable in the least-developed countries: Policy narratives and expert technologies in Cambodia. Forum for Development Studies, 41(3), 351-376. http://dx.doi.org/10.1080/08039410.2014.962599

Kanel, K. R. (2004). Twenty-five years of community forestry: Contribution to millennium development goals. In K.R. Kanel, P. Mathema, B. R. Kandel, D. R. Niraula, A. Sharma \& M. Gautam (Eds.), Twenty five years of community forestry: Proceedings of the fourth national community forestry workshop, (pp. 4-18). Nepal: Community Forestry Division, Department of Forest.

Kanel, K., \& Shreshtha, K. (2001). Tropical secondary forests in Nepal and their importance to local people. Journal of Tropical Forest Science, 13(4), 691-704.

Kanowski, P. J., McDermott, C. L., Cashore, B. W. (2011). Implementing REDD+: lessons from analysis of forest governance. Environmental Science \& Policy, 14(2), 111-117.

Karlsson, S., Srebotnjak, T., \& Gonzales, P. (2007). Understanding the north-south knowledge divide and its implications for policy: A quantitative analysis of the generation of scientific knowledge in the environmental sciences. Environmental Science and Policy, 10(7-8), 668-684.

Karsenty, A., \& Ongolo, S. (2012). Can "fragile states" decide to reduce their deforestation? The inappropriate use of the theory of incentives with respect to the REDD mechanism. Forest Policy and Economics, 18, 38-45.

Kataki, R., \& Konwer, D. (2002). Fuelwood characteristics of indigenous tree species of north-east India. Biomass and Bioenergy, 22(6), 433-437.

Ketterings, Q. M.; Coe, R.; Van Noordwijk, M.; Ambagau, Y., \& Palm, C. A. (2001). Reducing uncertainty in the use of allometric biomass equations for predicting 
above ground tree biomass in mixed secondary forest. Forest Ecology and Management, 146, 199-209.

Khanal Chhetri, B. B., Asante, P., \& Yoshimoto, A. (2016). Forest dependence and inequality: An empirical study from community forests in Kaski, Nepal. Forest Resources \& Mathematical Modeling, 15, 33-43. DOI:10.15684/formath.15.004

Khatri, D. (2012). Is REDD+ redefining forest governance in Nepal? The Journal of Forest and Livelihoods, 10(1), 74-87.

Kindermann, G., Obersteiner, M., Sohngen, B., Sathaye, J., Andrasko, K., Rametsteiner, E., Schlamadinger, B., Wunder, S., \& Beach, R. (2008). Global cost estimates of reducing carbon emissions through avoided deforestation. Proceedings of the National Academy Sciences, 105(30), 10302-307.

Kirschbaum, M. U. F. (1996). The carbon sequestration potential of tree plantations in Australia. In K. G. Eldridge, M. P. Crowe \& K. M. Old (Eds.), Environmental management: The role of eucalyptus and other fast growing species (pp. 77-89). CSIRO Forestry and Forest Products.

Kunwar, S. C, Ansari, A. S., \& Luintel, H. (2009). Non-timber forest products enterprise development: Regulatory challenges experienced in the Koshi Hills of Nepal. Journal of Forest and Livelihood, 8(2), 39-50.

Lahsen, M. (2004). Transnational locals: Brazilian experience of the climate regime. In S. Janasoff \& M. L. Martello (Eds.), Earthly politics. Local and global in environmental governance (pp. 151-171). Cambridge, MA: The MIT Press.

Lamichhane, D., \& Parajuli, R. (2014). How good is the governance status in community forestry? A case study from midhills in Nepal. Journal of Ecosystems. Retrieved on January 2, 2016 from http://dx.doi.org/10.1155/2014/541374

Larson, A. M. \& Soto, F. (2008). Decentralization of natural resource governance regimes. Annual Review of Environment and Resources, 33, 213-239. Retrieved on February 24, 2016 from http://dx.doi.org/10.1146/annurev.environ.33.020607.095522

Larson, A. M., Barry, D., Dahal, G. R., \& Colfer, C. J. P. (Eds.). (2010). Forests for people: Community rights and forest tenure reform. London: Earthscan.

Lauer, M. (2012). Oral traditions or situated practices? Understanding how indigenous communities respond to environmental disasters. Human Organization, 71(2), 176187.

Leach, M., Mearns, R., \& Scoones, I. (1999). Environmental entitlements: Dynamics and institutions in collaborative natural resource management. World Development, 27(2), 225-247.

Lee, K. (1993). Compass and gyroscope. Washington, DC: Island Press. 
Lewis, S. L., Lopez-Gonzalez, G., Sonké, B., Affum-Baffoe, K., Baker, T. R., Ojo, L. O., Philips, O. L., Reitsma, J. M., White, L., Comiskey, J. A., Djuikouo, M. N., Ewango, C. E. N., Feldpausch, T. R., Hamilton, A .C., Gloor, M., Hart, T., Hladik, A., Lloyd, J., Lovett, J. C., Makana, J. R., Malhi, Y.,Mbago, F. M., Ndangalasi, H. J., Peacock, J., Peh, K. S .H., Sheil, D., Sunderland, T., Swaine, M. D.,Taplin, J., Taylor, D., Thomas, S. C., Votere, R., \& Wöll, H. (2009). Increasing carbon storage in intact African tropical forests. Nature, 457, 1003-1007.

Li, T. M. (1996). Images of community: Discourse and strategy in property relations. Development and Change, 27, 501-527.

Lise, W. (2007). An econometric and game theoretic model of common pool resource management: People's participation in forest management in India. New York, NY: Nova Science Publishers Inc.

Loreau, M., \& Hector, A. (2001). Partitioning selection and complementarity in biodiversity experiments. Nature, 412, 72-76.

Lovbrand, E. (2014). Knowledge and the environment. In M. M. Bitsill, K. Hochstetler \& D. Stevis (Eds.) Advances in international environmental politics (pp. 161-184). New York, NY: Palgrave Macmillan.

Lovbrand, E., \& Stripple, J. (2011). Making climate change governable: Accounting for carbon as sinks, credits and personal budgets. Critical Policy Studies, 5(2), 187200.

Lovera, S. (2009). REDD Realities. In U. Brand, N. Bullard, E. Lander \& T. Mueller (Eds.), Contours of climate justice: Ideas for shaping new climate and energy policy. Critical Currents-6, 46-53. Uppsala: Dag Hammarskjöld Foundation.

Luintel, H. (2006). Do civil society organizations promote equity in community forestry? A reflection from Nepal's experience. In S. Mahanth, J. Fox, M. Nurse and L. Mclees (Eds.), Hanging in the balance: Equity in community-based natural resource management in Asia (pp. 122-142). Bangkok: RECOFTC \& East-West Centre.

Luintel, H., \& Chhetri, R. B. (2008). Understanding tenure security in community forestry. Journal of Forest and Livelihood, 7(1), 1-5.

Luintel, H., \& Timsina, N. (2008). How effective is the community forestry in recognizing women as empowered agencies? A research report. Nepal: ForestAction Nepal.

Luintel, H., Ojha, H., Rana, B., Subedi, R. \& Dhungana, H. (2009). Community forestry in Nepal: Promoting livelihoods, community development and the environment. ForestAction and Livelihoods and Forestry Programme.

Luintel, H., Silori, C. S., Frick, S., \& Poudyal, B. H. (2013). Grassroots capacity building for REDD+: Lessons from Nepal. Journal of Forest and Livelihood, 11(2), 1-13. 
Lung, M. \& Espira, A. (2015). The influence of stand variables and human use on biomass and carbon stocks of a transitional African forest: Implications for forest carbon projects, Forest Ecology and Management, 351, 36-46.

Luyssaert, S., Schulze, E. D., Borner, A., Knohl, A., Hessenmoller, D., Law, B. E., Ciais, P., \& Grace, J. (2008). Old-growth forests as global carbon sinks. Nature, 455, 213215.

MacDicken, K. G. (1997). A guide to monitoring carbon storage in forestry and agroforestry projects. Arlington, USA: Winrock International.

Mahalanobis, P. C. (1936). On the generalized distance in statistics. In the proceedings of the national institute of sciences of India, 2(1), 49-55.

Mahanty, S., Fox, J., Nurse, M., Stephen, P., \& McLees, L. (2006). Introduction: Equity in community - based resource management. In S. Mahanty, J. Fox, M. Nurse, P. Stephen, \& M. Leslie. (Eds.), Hanging in the balance: Equity in community-based natural resource management in Asia (pp. 1-14). RECOFTC and East West Center.

Mahanty, S., Guernier, J., \& Yami, Y. (2009). A fair share? Sharing the benefits and costs of collaborative forest management. International Forestry Review, 11(2), 268-280. Retrieved on January 12, 2016 from http://www.bioone.org/doi/full/10.1505/ifor.11.2.268

Malla, Y. B., Neupane, H. R., \& Branney, P. J. (2003). Why aren't poor people benefiting more from community forestry? The Journal of Forest and Livelihood, 3(1), 78-90.

Maniatis, D., Malhi, Y., Saint Andre, L., Mollicone, D., Barbier, N., Saatchi, S., Henry,M., Tellier, L., Schwartzenberg, M., \& White, L. (2011). Evaluating the potential of commercial forest inventory data to report on the forest carbon stock and forest carbon stock changes for REDD under the UNFCCC. International Journal of Forestry Research. DOI:10.1155/2011/134526

Manly, B. F. J. (2005). Multivariate statistical methods: A primer. (3rd ed.). Boca Raton, Florida: Chapman \& Hall/CRC Press.

Mansuri, G., \& Rao, V. (2004). Community-based and driven development: A critical review. The World Bank Research Observer, 19(1), 1-39.

McAfee, K. (2012). The contradictory logic of global ecosystem services markets. Development and Change, 43(1), 105-131.

McDermott, M., \& Schreckenberg, K. (2009). Equity in community forestry: Insights from North and South. International Forestry Review, 11(2), 157-170.

McDermott, M., Mahanty, S., \& Schreckenberg, K. (2013). Examining equity: A multidimensional framework for assessing equity in payments for ecosystem services. Environmental Science and Policy, 33, 416 - 427.

McDowell, N. (2002). Developing countries to gain from carbon-trading fund. Nature, 420(6911), 4. 
McKean, M., \& Ostrom, E. (1995). Common property regimes in the forest: Just a relic from the past? Unasylva, 46(180), 3-15.

McKinsey \& Company. (2009). Pathways to a low-carbon economy: Version 2 of the global greenhouse gas abatement cost curve. McKinsey \& Company.

McNaughton, S. J., Oesterheld, M., Frank, D. A., \& Williams, K. J. (1989). Ecosystemlevel patterns of primary production and herbivory in terrestrial habitats. Nature, 341, 142-144.

Mein-shausen, M., Meinshausen, N., Hare, W., Raper, S. C. B., Frieler, K., Knutti, R., Frame, D. J., \& Allen, M. R. (2009). Greenhouse-gas emission targets for limiting global warming to $20 \mathrm{C}$. Nature, 458, 1158-1162.

Metz, B., Davidson, O. R., Bosch, P. R., Dave, R., \& Meyer, L.A. (Eds.). (2007). Climate change 2007 - mitigation of climate change: Working group III contribution to the fourth assessment report of the IPCC. UK: Cambridge: Cambridge University Press.

Meynen, N., \& Dornboos, M. (2005). Decentralising natural resource management: A recipe for sustainability and equity? In J. C. \& A. M. Larson. (Eds.), Democratic decentralisation through a natural resource lens. (pp. 235-254), New York, NY: Routledge. DOI:10.1080/09578810410001688824

Midgley, G. F., Bond, W. J., Kapos, V. K., Ravilious, C., Scharlemann, J. P. W., \& Woodward, F .I. (2010). Terrestrial carbon stocks and biodiversity: Key knowledge gaps and some policy implications. Current Opinion on Environmental Sustainability, 2(4), 264-270.

Miles, L., \& Dickson, B. (2010). REDD-plus and biodiversity: Opportunities and challenges. Unasylsva, 61, 56-63

Miles, L., \& Kapos, V. (2008). Reducing greenhouse gas emissions from deforestation and forest degradation: Global land-use implications. Science, 320, 1454-1455.

Millennium Ecosystem Assessment. (MEA). (2005). Ecosystems and human well-being: Current state and trends. (Vol. 1). New York: Island Press.

Ministry of Forests and Soil Conservation. (MoFSC). (1988). Master plan for forestry sector. Kathmandu, Nepal

Ministry of Forests and Soil Conservation. (MoFSC). (2000). Forest policy of Nepal 2000. Kathmandu, Nepal

Ministry of Forest and Soil Conservation. (MoFSC). (2008). Community forestry development programme guidelines (2nd ed.). Kathmandu, Nepal.

Ministry of Forest and Soil Conservation. (MoFSC). (2010a). Carbon measurement guidelines. Kathmandu, Nepal.

Ministry of Forests and Soil Conservation. (MoFSC). (2010b). Nepal's REDD+ readiness preparation proposal $(2010-2013)$. Kathmandu, Nepal. 
Ministry of Forests and Soil Conservation. (MoFSC). (2014). Nepal national biodiversity strategy and action plan 2014 - 2020. Kathmandu. Government of Nepal,

Ministry of Law and Justice. (MoLJ). (1993). Forest act of Nepal 1993. Kathmandu, Nepal.

Ministry of Law and Justice. (MoLJ). (1995). Forest regulation of Nepal 1995. Kathmandu, Nepal.

Mittermeier, R. A., Robles-Gil, P., Hoffman, M., Pilgrim, J. D., Brooks, T., Mittermeier, C. G., \& Da Fonseca, G. A. B. (2004). Hotspots revisited: Earth's biologically richest and most endangered terrestrial ecoregions. Mexico City, Mexico: Conservation International in association with CEMEX.

Mohan, S., Nair, P. K. R., \& Long, A. J. (2007). An assessment of ecological diversity in homegardens: A case study from Kerala State, India. Journal of Sustainable Agriculture, 29, 135-153

Myneni, R. B., Hall, F. G., Sellers, P. J., \& Marshak, A. L. (1995). The interpretation of spectral vegetation indexes. IEEE Transactions on Geoscience and Remote Sensing, 33(2), 481-486.

Nadrowski, K., Wirth, C., \& Scherer-Lorenzen, M. (2010). Is forest diversity driving ecosystem function and service? Current Opinion on Environmental Sustainability, 2(1-2), 75-79.

Naidu, S. C. (2009). Heterogeneity and collective management: Evidence from common forests in Himachal Pradesh, India. World Development, 37(3), 676-686.

Naidu, S. C. (2011). Access to benefits from forest commons in the western Himalayas. Ecological Economics, 71, 202-210.

Ngugi, M. R., Johnson, R. W., \& McDonald, W. J. F. (2011). Restoration of ecosystems for biodiversity and carbon sequestration: Simulating growth dynamics of brigalow vegetation communities in Australia. Ecological Modelling, 222(3), 785-794.

Nilsson, S., \& Schophauser, W. (1995). The carbon-sequestration potential of a global afforestation program. Climatic Change, 30(3), 267-293.

Nurse, M., \& Malla, Y. (2006). Advances in community forestry in Asia. In P. Gyamtsho, B.K. Singh \& G. Rasul (Eds.). Capitalisation and sharing of experiences on the interaction between forest policies and land use patterns in Asia: Link people with resources. Proceedings of a Workshop, Godavari, Nepal, 26-28 January 2005, Technical Papers, 2, 25-31.

Oli, B. N., \& Shrestha, K. (2009). Carbon status in forests of Nepal: An overview. Journal of Forest and Livelihood, 8(1), 63-66.

Organization for the Economic Cooperation and Development. (2008). Handbook on constructing composite indicators: Methodology and user guide. Organization for the Economic Cooperation and Development, European Commission (Joint 
Research Center). Retrieved on October 27, 2015 from

http://www.oecd.org/std/42495745.pdf

Ostrom, E. (1990). Governing the commons: The evolution of institutions for collective action. Cambridge, UK: Cambridge University Press,

Ostrom, E. (2000). Collective action and the evolution of social norms. Journal of Economic Perspectives, 14(3),137 - 158.

Ostrom, E. (2009). A general framework for analyzing sustainability of social-ecological systems. Science, 325(5939), 419-422.

Ostrom, E. (2010). Keynote speech. The South Asian network of development and environmental economists. December 2010.

Paavola, J., \& Adger, W. N. (2005). Institutional ecological economics. Ecological Economics, 53(3), 353-368.

Pachauri, R. K. (2007). Climate change: Synthesis report. Contribution of working groups I, II and III to the fourth assessment report of the Intergovernmental Panel on Climate Change. Geneva, Switzerland: IPCC.

Pagiola, S., Rios, A. R., \& Arcenas, A. (2008). Can the poor participate in payments for environmental services? Lessons from the Silvopastoral Project in Nicaragua. Environmental Development Economics, 13(3), 299-325.

Pan, Y., Birdsey, R. A., Fang, J., Houghton, R., Kauppi, P. E., Kurz, W. A., Philips, O. L., Schivdenko, A., Lewis, S. L., Canadell, J. G., Ciasis, P., Jackson, R. B., Pacala, S. W., McGuire, A. D., Piao, S., Rautiainen, A., Sitch, S., \& Hayes, D. (2011). A large and persistent carbon sink in the world's forests. Science, 333, 988-993.

Pandey, S. S., Cockfield, G., \& Maraseni, T. N. (2014). Dynamics of carbon and biodiversity under REDD+ regime: A case from Nepal. Environmental Science and Policy, 38, 272-281. Retrieved on August 1, 2015 from http://dx.doi.org/10.1016/j.envsci.2014.01.005

Paquette, A., \& Messier, C. (2011). The effect of biodiversity on tree productivity: From temperate to boreal forests. Global Ecology Biogeography, 20, 170-180.

Parmentier, I., Malhi, Y., Senterre, B., Whittaker, R. J., Alonso, M. P. B., Balinga, A., Bakayoko, A., Bongers, F., Chatelain, C., Comiskey, J. A., Cortay, R., Djuikouo Kamdem, M. N., Doucet, J. L., Gautier, L., Hawthorne, W. D., Issembe, Y. A., Kouamé, F. N., Kouka, L. A., Leal, M. E., Lejoly, J., Lewis, S. L., Nusbaumer, L., Parren, M. P. E, Peh, K. S. H., Philips, O. L., Sheil, D., Sonké, B., Sosef, M. S. M., Sunderland, T. C. H., Stropp, J., Steege, H. T., Swaine, M. D., Tchouto, M. G. P., Van Gemerden, S., Van Valkenburn, J. L. C. H., \& Wöll, H. (2007). The oddman out? Might climate explain the lower tree alpha-diversity of African rain forests relative to Amazonian rain forests? Journal of Ecology, 95, 1058-1071.

Parton, W. J., Scurlock, J. M. 0., Ojima, D. S., Gilmanov, T. G., Scholes, R. J., Schimel, D. S., Kirchner, T., Menaut, J. C., Seastedt, T., Moya, G. E., Kamnalrut, 
A., \& Kiny-amario. J. I. (1993). Observations and modeling of biomass and soil organic matter dynamics for the grassland biome worldwide. Global Biogeochemical Cycles, 7(4), 785-809.

Patel, T., Dhiaulhaq, A., Gritten, D., Yasmi, Y., Bruyn, T. D., Paudel, N. S., Luintel, H., Khatri, D. B., Silori, C., \& Suzuki, R. (2013). Predicting future conflict under REDD+ implementation. Forests, 4, 343-363. DOI:10.3390/f4020343

Pattanayak, S. K. (2009). Rough guide to impact evaluation of environmental and development programs. SANDEE. Retrieved on September 15, 2015 from http://www.sandeeonline.org/uploads/documents/publication/847_PUB_Working_P aper_40.pdf.

Paudel, D., Keeling, S. J., \& Khanal, D. (2006). Forest products verification in Nepal and the work of the commission to investigate the abuse of authority. Country case study No. 10. VERIFOR. The World Bank, ODI, RECOFTC, CIFOR and CATIE.

Paudel, N.S., Khatri, D.B., Karki, R., \& Paudel, G. (2014). Understanding drivers and causes of deforestation and forest degradation in Nepal: Potential policies and measures for REDD+. Ministry of Forest and Soil Conservation Nepal, UN-REDD Programme and ForestAction Nepal. Retrieved on October 15, 2015 from www.tinyurl.com/nepal-drivers-redd

Paudel, N. S., Luintel, H., Khatri, D., Karanjit, S. (2011). REDD+ and conflict: A case of REDD + project in Nepal. Phase II Study Report. ForestAction and RECOFTC.

Pellow, D. N., \& Brulle, R. J. (2005). Power, justice, and the environment: Toward critical environmental justice studies. MIT Press, 1-19.

Persha, L., \& Andersson, K. (2014). Elite capture risk and mitigation in decentralized forest governance regimes. Global Environmental Change, 24, 265-276.

Peskett, L., Schreckenberg, K., \& Brown, B. (2011). Institutional approaches for carbon financing in the forest sector: Learning lessons for REDD? From forest carbon projects in Uganda. Environmental Science and Policy, 14(2), 216-229.

Phelps, J., Guerrera, M. C., Dalabajan, D. A., Young, B., \& Webb, E. L. (2010a). What makes a REDD country? Global Environmental Change, 20, 322-332.

Phelps, J., Webb, E., \& Agrawal, A. (2010b). Does REDD threaten to recentralize forest governance? Science, 328, 312-313.

Phillips, O. L., Malhi, Y., Higuchi, N., Laurance, W. F., Nunez, P. V., Vasquez, R. M., Laurance, S. G., Ferreira, L. V., Stern, M., Brown, S., \& Grace, J. (1998). Changes in the carbon balance of tropical forest: Evidence from long-term plots. Science, 282, 439-442.

Pokharel, B. (2003). Changing pattern of forest consumption: a case study from and eastern hill village in Nepal, Occasional paper in Sociology and Anthropology, 8, 41-58. Retrieved on August 1, 2015 from http://www.dspace.cam.ac.uk/handle/1810/229104 
Pokharel, B. K., \& Mahat, A. (2009). Kathmandu to Jiri: A photo journey (1968 - 2005). Nepal Swiss Community Forestry Project, SDC, Inter-cooperation, Nepal.

Pokharel, B. K., \& Nurse, M. (2004). Forests and people's livelihoods: Benefiting the poor from community forestry. Journal of Forests and Livelihoods, 4(1), 19-29.

Pokharel, B. K., Branney, P., Nurse, M., \& Malla, Y. B. (2007). Community forestry: Conserving forests, sustaining livelihoods and strengthening democracy. The Journal of Forest and Livelihood, 6(2), 8-19.

Pokharel, B. K., Paudel, D., \& Gurung, B. D. (2006). Forests, community-based governance and livelihoods: Insights from the Nepal Swiss Community Forestry Project in capitalisation and sharing of experiences on the interaction between forest policies and land use patterns in Asia. Linking people with resources. Volume 2: Technical papers. pp 53-60. SDC and ICIMOD.

Polack, E. (2008). A right to Adaptation: Securing the participation of marginalized groups. In T. Tanner \& T. Mitchell (Eds.). Poverty in a changing climate. Institute of Development Studies (IDS) Bulletin, 39(4), 16-23.

Polasky, S., \& Segerson, K. (2009). Integrating ecology and economics in the study of ecosystem services: Some lessons learned. The Annual Review of Resource Economics, 1, 409-434.

Posey, D. A. (2008 [1985]). Indigenous management of tropical forest ecosystems: The case of the Kayapo Indians of the Brazilian Amazon. In M. R. Dove \& C. Carpenter (Eds.). Environmental anthropology: A historical reader (pp. 89-101). Oxford: Blackwell Publishing.

Potvin, C., Mancilla, L., Buchmann, N., Monteza, J., Moore, T., Murphy, M., Oelmann, Y., Scherer-Lorenzen, M., Turner, B. L., Wilcke, W., Zeugin, F., \& Wolf, S. (2011). An ecosystem approach to biodiversity effects: Carbon pools in a tropical tree plantation. Forest Ecology and Management, 261(10), 1614-1624.

Poudel, M., Thwaites, R., Race, D. \& Dahal, G. R. (2015). Social equity and livelihood implications of REDD+ in rural communities - a case study from Nepal. International Journal of the Commons, 9(1), 177-208. DOI: http://doi.org/10.18352/ijc.444

Prost, M., \& Camprubi, A. T. (2012). Against fairness? International environmental law, disciplinary bias, and pareto justice. Leiden Journal of International Law, 25(2), 379-396.

Putz, F. E., \& Redford, K. H. (2009). Dangers of carbon-based conservation. Global Environmental Change, 19, 400-401.

Ranganathan, J., Raudsepp-Hearne, C., Lucas, N., Irwin, F., Zurek, M., Bennett, K., Ash, N., \& West, P. (2008). Ecosystem services: A guide for decision makers.

Washington, DC: World Resources Institute. http://www.wri.org/publication/ecosystem-services-a-guidefor-decision-makers 
Rappaport, R. A. (2008 [1967]). Ritual regulation of environmental relations among a New Guinea people. In M.R. Dove \& C. Carpenter (Eds.) Environmental anthropology: A historical reader (pp. 254-264). Oxford: Blackwell Publishing.

Ratsimbazafy, L. C., Harada, K., \& Yamamura, M. (2011). Forest conservation and livelihood conflict in REDD: A case study from the corridor Ankeniheny Zahamena REDD project, Madagaskar. International Journal of Biodiversity and Conservation, 3(12), 618-630.

Rawls, J. (1971). A theory of justice. Cambridge, MA: Harvard University Press.

Ribot, J., \& Peluso, N. (2003). A theory of access. Rural Sociology, 68(2), 153-181.

Rights and Resources Initiative. (2014). What future for reform? Progress and slowdown in forest tenure reform since 2002. Washington DC.

Rosenbaum, P. R. (2002). Observational Studies ( $2^{\text {nd }}$ Ed.). New York, NY: Springer Verlag.

Rosenbaum, P. R., \& Rubin, D. B. (1983). The central role of the propensity score in observational studies for causal effects. Biometrika, 70(1), 41-55.

Rosenbaum, P. R., \& Rubin, D. B. (1985). Constructing a control group using multivariate matched sampling methods that incorporate the propensity score. The American Statistician, 39(1), 33-38.

Rubin, D. B. (1980). Bias reduction using Mahalanobis-metric matching. Biometrics, 36, 293-98.

Rubin, D. B. (2001). Using propensity scores to help design observational studies: Application to the tobacco litigation. Health Services and Outcomes Research Methodology, 2(3), 169-188.

Rubin, D. B., \& Thomas, N. (1996). Matching using estimated propensity scores: Relating theory to practice. Biometrics, 52, 249-264. DOI:10.2307/2533160. [PubMed: 8934595]

Ryan, M. G. (1991). Effects of climate change on plant respiration. Ecological Applications, 1, 157-167.

Saatchi, S. S., Harris, N. L., Brown, S., Lefsky, M., Mitchard, E. T. A., Salas, W., Zutta, B. R., Buermann, W., Lewis, S. L., Hagen, S., Petrova, S., White, L., Silman, M. \& Morel, A. (2011). Benchmark map of forest carbon stocks in tropical regions across three continents. Proceedings of the National Academy of Sciences USA, 108, 9899-9904.

Sapkota, I., Tigabu, M., \& Christer Ode'n, P. (2009). Species diversity and regeneration of old-growth seasonally dry Shorea robusta forests following gap formation. Journal of Forestry Research, 20(1), 7-14.

Saxena, A. K., \& Singh, J. S. (1987). A phytosociological analysis of woody species: Forest communities of a part of Kumaon Himalaya. Vegetation, 3-22. 
Scheller, R. M., \& Mladenoff, D. J. (2008). Simulated effects of climate change, tree species migrations, and forest fragmentation on aboveground carbon storage on a forested landscape. Climate Research, 36(3), 191-202.

Scherr, S. J., White, A., \& Kaimowitz, D. (2004). A new agenda for forest conservation and poverty reduction: Making markets work for low income producers. Washington DC: Forest Trends.

Schlapfer, F., Schmid, B., \& Seidl, I. (1999). Expert estimates about effects of biodiversity on ecosystem processes and services. OIKOS, 84, 346-352.

Schlarger, E., \& Ostrom, E. (1992). Property rights regimes and natural resources: A conceptual analysis. Land Economics, 68(3), 249-263.

Schroeder, D., \& Pisupati, B. (2010). Ethics, justice and the convention on biological diversity. United Nations Environment Program and University of Central Lancashire, UK. Retrieved on August 30, 2015 fromhttp://www.unep.org/delc/Portals/119/UNEP_Justice_Final_V2a.pdf

Schwartz, M. W., Brigham, C. A., Hoeksema, J. D., Lyons, K. G., Mills, M. H., van Mantgem, P. J. (2000). Linking biodiversity to ecosystem function: Implications for conservation ecology. Oecologia, 122, 297-305.

Secretariat of the Convention on Biological Diversity. (SCBD). (2011). Connecting biodiversity and climate change mitigation and adaptation: Report of the second ad hoc technical expert group on biodiversity and climate change. Technical Series No. 41, Secretariat of the Convention on Biological Diversity, Montreal, Canada.

Secretariat of the Convention on Biological Diversity. (SCBD). (2009). REDD-plus and biodiversity. Technical Series No. 59. Secretariat of the Convention on Biological Diversity, Montreal, Canada.

Sekhon, J. S. (2011). Multivariate and propensity score matching software with automated balance optimization: The matching package for R. Journal of Statistical Software, 42(7), 1-52. Retrieved on August 28, 2015 from http://sekhon.berkeley.edu/papers/MatchingJSS.pdf.

Sellers, P. J. (1985). Canopy reflectance, photosynthesis, and transpiration. International Journal of Remote Sensing, 6, 1335-1372.

Sen, A. (1992). Inequality re-examined. Oxford: Oxford University Press.

Seymour, F. (2011). A presentation given by the director of CIFOR on the overview of $R E D D+$ research. Retrieved on January 13, 2014 from http://blog.cifor.org/3408/cifor-director-general-gives-overview-of-reddresearch/\#.ULExpEKTxbw

Sharma, C. M., Baduni, N. P., Gairola, S., Ghildiyal, S. K., \& Suyal, S. (2010). Tree diversity and carbon stocks of some major forest types of Garhwal Himalaya, India. Forest Ecology and Management, 260, 2170-2179. 
Shrestha, B. B., Uprety, Y., \& Jha, P. K. (2006). Wood properties in relation to foliar phenology of some planted tree species at Kirtipur, central Nepal. Tropical Ecology, 47(2), 201-209.

Shrestha, U. B., Shrestha, B. B., \& Shrestha, S. (2010). Biodiversity conservation in community forests of Nepal: Rhetoric and reality. International Journal of Biodiversity and Conservation, 2(5), 98-104.

Shyamsundar, P. (2008). Decentralization, devolution, and collective action: A review of international. In R. Ghate, N. S. Jodha \& P. Mukhopadhyay (Eds.). Experience, promise, trust, and evolution: Managing the commons of South Asia. Oxford: Oxford University Press.

Smith, P. D. \& McDonough, M. H. (2001). Beyond public participation: Fairness in natural resource decision making. Society and Natural Resources, 14, 239-249.

Sombroek. W. G., Nachtergaele, F. O., \& Hebel. A. (1993). Amounts, dynamics and sequestering of carbon in tropical and subtropical soils. Ambio, 22(7), 417-426.

Spoon, J. (2011). The heterogeneity of Khumbu Sherpa ecological knowledge and understanding in Sagarmatha (Mount Everest) national park and buffer zone, Nepal. Human Ecology, 39(5): 657-672.

Spoon, J. (2014). Everyday Buddhism and environmental decisions in the world's highest ecosystem. Journal for the Study of Religion, Nature and Culture, 8(4), 429-459.

Spoon, J. (2013). From yaks to tourists: Sherpa livelihood adaptations in Sagarmatha (Mount Everest) national park and buffer zone, Nepal. In L. Lozny (Ed.), Continuity and change in cultural mountain adaptations: From prehistory to contemporary threats (pp. 319-340). New York, NY: Springer.

Stadelmann, M., Roberts, J. T., \& Michaelowa, A. (2010). Keeping a big promise: Options for baselines to assess "new and additional" climate finance. CIS Working Paper no. 66. Zurich: ETH Zurich and University of Zurich.

Stainton, J. D. A. (1972). Forests of Nepal. London: John Murray.

Stallard, R. F. (1998). Terrestrial sedimentation and the carbon cycle: Coupling weathering and erosion to carbon burial. Global Biogeochemical Cycles, 12(2), 231-257.

Stern, S. N. (2006). Stern review: The economics of climate change. Cambridge, UK: Cambridge University Press.

Stickler, C., Nepstad, D. C., Coe, M. T., Mcgrath, D. G., Rodrigues, H. O., Walker, W. S., Soares-Filho, B., \& Davidson, E. A. (2009). The potential ecological costs and cobenefits of REDD: A critical review and case study from the Amazon region. Global Change Biology, 15(12), 2803-2824.

Strassburg, B. B. N., Kelly, A., Balmford, A., Davies, R. G., Gibbs, H. K, Lovett, A., Miles, L., Orme, C. D. L., Price, J., Turner, R.K., \& Rodrigues, A. S. L. (2010). 
Global congruence of carbon storage and biodiversity in terrestrial ecosystems. Conservation Letters, 3(2), 98-105.

Strassburg, B., Turner, R. K., Fisher, B., Schaeffer, R., \& Lovett, A. (2009). Reducing emissions from deforestation - the "combined incentives" mechanism and empirical simulations. Global Environmental Change - Human and Policy Dimensions, 19, 265-278.

Sunam, R. K. \& McCarthy, J. F. (2010). Advancing equity in community forestry: Recognition of the poor matters. International Forestry Review, 12(4), 370-382.

Sunderlin, W., Hatcher, J., \& Liddle, M. (2008). From exclusion to ownership? Challenges and opportunities in advancing forest tenure reforms. Washington, DC: Rights and Resources Initiative.

Swamy, P., Sundarapandian, S. M., Chandrasekar, P., Chandrasekaran, S. (2000). Plant species diversity and tree population structure of a humid tropical forest in Tamil Nadu, India. Biodiversity and Conservation, 9(12), 1643-1669.

Szwagrzyk, J., \& Gazda, A. (2007). Above-ground standing biomass and tree species diversity in natural stands of Central Europe. Journal of Vegetation Science, 18, $555-562$.

Tachibana, T., Upadhyaya, H. K., Pokharel, R., Rayamajhi, S., \& Otsuka, K. (2001). Common property forest management in the hill region of Nepal, In K. Otsuka \& F. Place (Eds.), Land tenure and natural resource management: A comparative study of agrarian communities in Asia and Africa (pp. 273-314). The International Food Policy Research Institute and the Johns Hopkins University Press.

Talbot, J. D. (2010). Carbon and biodiversity relationships in tropical forests. Multiple Benefits Series 4. Report prepared on behalf of the UN-REDD Programme. School of Geography, University of Leeds, Leeds / UNEP World Conservation Monitoring Centre. Cambridge, UK.

Tamrakar, P. R. (2000). Biomass and volume tables with species description for community forest Management. Kathmandu: Ministry of Forest and Soil Conservation (MoFSC), NARMSAP-TISC.

Tanner, T., \& Allouche, J. (2011). Towards a new political economy of climate change and development. Institute of Developmental Studies (IDS) Bulletin, 42(3), 1-14.

Tanner, T., \& Harvey, B. (2013). Social justice and low carbon development. In F. Urban \& J. Nordensvard (Eds.). Low carbon development: Key issues (pp. 55-65). London: Earthscan.

Taylor, D., Hamilton, A. C., Lewis, S. L., \& Nantale, G. (2008). Thirty-eight years of change in a tropical forest: Plot data from Mpanga forest reserve, Uganda. African Journal of Ecology, 46, 655-667. 
Thapa-Magar, K. B., \& Shrestha, B. B. (2015). Carbon stock in community managed hill Sal (Shorea robusta) forests of central Nepal. Journal of Sustainable forestry, 34, 384-501. DOI: 10.1080/10549811.2015.1031251.

Thoemmes, F. J., \& Kim, E. S. (2011). A systematic review of propensity score methods in the social sciences. Multivariate Behavioral Research, 46(1), 90-118.

Thomas, C. D., Anderson, B. J., Moilanen, A., Eigenbrod, F, Heinemeyer, A., Quaife, T., Roy, D. B., Gillings, S., Armsworth, P. R. \& Gaston. K. J. (2013). Reconciling biodiversity and carbon conservation. Ecology Letters, 16, 39-47.

Thompson, I. D., Ferreira, J., Gardner, T., Guariguata, M., Koh, L. P., Okabe, K., Pan, Y., Schmitt, C. B., Tylianakis, J., Barlow, J., Kapos, V., Kurz, W. A., Parrotta, J. A., Spalding, M. D., \& van Vliet, N. 2012. Forest biodiversity, carbon and other ecosystem services: relationships and impacts of deforestation and forest degradation (Chapter 2). In J. A. Parrotta, C, Wildburger \& S. Mansourian (Eds.), Understanding relationships between biodiversity, carbon, forests and people: The key to achieving REDD + objectives. A global assessment report prepared by the Global Forest Expert Panel on Biodiversity, Forest Management, and REDD+. IUFRO World Series Volume 31. Vienna. $161 \mathrm{p}$.

Thompson, I., Mackey, B., McNulty, S., \& Mosseler, A. (2009). Forest resilience, biodiversity and climate change. A synthesis of the biodiversity/resilience/stability relationship in forest ecosystems. Technical Series Secretariat of the Convention on Biological Diversity, 43, Montreal 67. Secretariat of the Convention on Biological Diversity, UNEP, Montreal, Canada [www document]. URL http://www.cbd.int/doc/publications/cbd-ts-43-en.pdf

Thompson, M. C., Baruah, M., \& Carr, E. R. (2011). Seeing REDD? As a project of environmental governance. Environment Science Policy, 14(2), 100-110.

DOI:10.1016/j.envsci.2010.11.006

Thoms, C. A. (2008). Community control of resources and the challenge of improving local livelihoods: A critical examination of community forestry in Nepal. Geoforum, $39,1452-1465$.

Tilman, D. (2001). Functional diversity. In S. A. Levin. (Ed.). Encyclopedia of biodiversity. (pp. 109-120) (Vol. 3). San Diego: Academic Press.

Toni, F. (2011). Decentralization and REDD+ in Brazil. Forests, 2, 66-85.

Trexler, M. C., \& Haugen, C. (1995). Keeping it green: Evaluating tropical forestry strategies to mitigate global warming. Washington DC, USA: World Resources Institute.

Turner, N., Davidson-Hunt, I. J., O'Flaherty, M. (2003). Living on the edge: Ecological and cultural edges as sources of diversity for social-ecological resilience. Human Ecology, 31(3), 439-461. 
United Nations Framework on Climate Change (UNFCCC). (2007a). Climate change 2007: Synthesis report. Contribution of working groups I, II and III to the fourth assessment report of the intergovernmental panel on climate change.

United Nations Framework on Climate Change (UNFCCC). (2007b). Reducing emissions from deforestation in developing countries: Approaches to stimulate action, Conference of the Parties, Bali, 3 December to 14 December 2007. United Nations Framework Convention on Climate Change (UNFCCC), Bonn, Germany. Retrieved on January 15, 2014 from http://unfccc.int/resource/ United Nations Framework on Climate Change (UNFCCC). (2009). Report of the conference of the parties on its fifteenth session, held in Copenhagen from 7 to 19 December 2009. Retrieved on January 15, 2015 from http://unfccc.int/resource/ docs/2009/cop15/eng/11a01.pdf

United Nations Framework on Climate Change. (UNFCCC). (2011). Fact sheet:

Reducing emissions from deforestation in developing countries: approaches to stimulate action. Retrieved on January 15, 2015 from https://unfccc.int/files/press/backgrounders/application/pdf/fact_sheet_reducing_em issions from deforestation.pdf

United Nations Framework on Climate Change. (UNFCCC). (2015). Draft decision: Adoption of the Paris agreement, Conference of the parties: Twenty-first session, Paris. Retrieved on April 15, 2016 from http://unfccc.int/resource/docs/2015/cop21/eng/109r01.pdf

Upreti, D. R., Luintel, H., \& Bhandari, K. (2011). REDD+ and conflict: A case of $R E D D+$ project in Nepal. Phase I study report. ForestAction and RECOFTC.

Venter, O., Laurance, W. F., Iwamura, T., Wilson, K. A., Fuller, R. A., \& Possingham, H. P. (2009). Harnessing carbon payments to protect biodiversity. Science, 326(5958), 1368.

Warren, J., Topping, C. J., \& James, P. (2009). A unifying evolutionary theory for the biomass-diversity-fertility relationship. Theoretical Ecology, 2(2), 119-126.

Water and Energy Commission Secretariat. (2010). Energy sector synopsis report. Water and Energy Commission Secretariat, Kathmandu. Retrieved on January 15, 2015 from http://dib.dk/wpcontent/uploads/file/Low\%20carbon\%20Nepal\%20Case\%20Study.pdf

Webb, J. (2011). Making climate change governable: The case of the UK climate change risk assessment and adaptation planning. Science and Public Policy, 38(4), 279292.

Whitehead, M. (1991). The concepts and principles of equity and health. Health Promotion International, 6(3), 217-228.

Wihersaari, M. (2005). Greenhouse gas emissions from final harvest fuel chip production in Finland. Biomass and Bioenergy, 28(5) 435-443. 
Wilson, E. O. (1992). The diversity of life. Harvard University Press.

Winjum, J. K., Dixon, R. K., \& Schroeder, P. E. (1992a). Estimating the global potential of forest and agroforest management practices to sequester carbon. Water, Air, and Soil Pollution, 64(1), 213-227.

Winjum, J. K., Meganck, R. A., \& Dixon, R. K. (1992b). Expanding global forest management: An easy first approach. Journal of Forestry, 9l(4), 38-42.

Wollenberg, E., \& Springate-Baginski, O. (Eds.) (2010). REDD, forest governance and rural livelihood: The emerging agenda. Bogor, Indonesia: CIFOR.

Woodall, C. W., D’Amato, A. W., Bradford, J. B., \& Finley, A. O. (2011). Effects of stand and inter-specific stocking on maximizing standing tree carbon stocks in the eastern United States. Forest Science, 57, 365-378.

World Bank. (2001). Community forestry in Nepal. Precis. World Bank operation evaluation department, 217, 1-4. Retrieved on October 27, 2015 from http://ieg.worldbank.org/Data/reports/217_nepal_forestry.pdf

World Bank. (2004). Sustaining forests: A development strategy. Washington DC: World Bank.

World Bank. (2009). Forests sourcebook: Practical guide for sustaining forests in international cooperation. World Bank: Washington, D.C.

Wunder, S. (2008). Payments for environmental services and the poor: Concepts and preliminary evidence. Environmental Development Economics, 13(3), 279-297.

Yadav, N. P., Dev, O. P., Springate-Baginski, O., \& Soussan, J. (2003). Forest management and utilization under community forestry. The Journal of Forest and Livelihood, 3(1), 37-50. 
Appendix A. Covariate wise before and after matching standardized difference of mean

\begin{tabular}{|c|c|c|c|c|c|c|c|c|c|c|c|c|c|c|c|c|c|c|}
\hline \multirow[t]{2}{*}{ Covariates } & \multicolumn{2}{|c|}{$\begin{array}{l}\text { Overall } \\
\text { forest }\end{array}$} & \multicolumn{2}{|c|}{$\begin{array}{l}\text { Lower } \\
\text { altitude }\end{array}$} & \multicolumn{2}{|c|}{$\begin{array}{l}\text { Higher } \\
\text { altitude }\end{array}$} & \multicolumn{2}{|c|}{ Lower slope } & \multicolumn{2}{|c|}{$\begin{array}{l}\text { Higher } \\
\text { slope }\end{array}$} & \multicolumn{2}{|l|}{ Terai } & \multicolumn{2}{|l|}{ Hill } & \multicolumn{2}{|c|}{$\begin{array}{l}\text { Open } \\
\text { canopy }\end{array}$} & \multicolumn{2}{|c|}{$\begin{array}{l}\text { Closed } \\
\text { canopy }\end{array}$} \\
\hline & $\begin{array}{l}\text { BM } \\
\text { SD } \\
\text { M }\end{array}$ & $\begin{array}{l}\text { AM } \\
\text { SD } \\
\text { M }\end{array}$ & $\begin{array}{l}\text { BM } \\
\text { SDM }\end{array}$ & $\begin{array}{l}\text { AM } \\
\text { SD } \\
\text { M }\end{array}$ & $\begin{array}{l}\text { BM } \\
\text { SD } \\
\text { M }\end{array}$ & $\begin{array}{l}\text { AM } \\
\text { SD } \\
\text { M }\end{array}$ & $\begin{array}{l}\text { BM } \\
\text { SD } \\
\text { M }\end{array}$ & $\begin{array}{l}\text { AM } \\
\text { SD } \\
\text { M }\end{array}$ & $\begin{array}{l}\text { BM } \\
\text { SD } \\
\text { M }\end{array}$ & $\begin{array}{l}\text { AM } \\
\text { SD } \\
\text { M }\end{array}$ & $\begin{array}{l}\text { BM } \\
\text { SD } \\
\text { M }\end{array}$ & $\begin{array}{l}\mathbf{A M} \\
\text { SD } \\
\mathbf{M}\end{array}$ & $\begin{array}{l}\text { BM } \\
\text { SD } \\
\text { M }\end{array}$ & $\begin{array}{l}\text { AM } \\
\text { SD } \\
\text { M }\end{array}$ & $\begin{array}{l}\text { BM } \\
\text { SD } \\
\text { M }\end{array}$ & $\begin{array}{l}\text { AM } \\
\text { SD } \\
\text { M }\end{array}$ & $\begin{array}{l}\text { BM } \\
\text { SDM }\end{array}$ & $\begin{array}{l}\text { AM } \\
\text { SD } \\
\text { M }\end{array}$ \\
\hline Forest size & 0.31 & 0.12 & 0.52 & 0.28 & $\ldots$ & $\ldots$ & 0.48 & 0.21 & 49 & 0.20 & 0.52 & 0.16 & $\ldots$ & $\ldots$ & $\ldots$ & $\ldots$ & 0.37 & 0.19 \\
\hline $\begin{array}{l}\text { Forest per } \\
\text { household }\end{array}$ & $\ldots$ & $\ldots$ & $\ldots$ & $\ldots$ & 0.04 & 0.08 & $\ldots$ & $\ldots$ & $\ldots$ & $\ldots$ & $\ldots$ & $\ldots$ & 0.31 & 0.26 & 0.14 & 0.15 & $\ldots$ & $\ldots$ \\
\hline $\begin{array}{l}\text { Travel time } \\
\text { to nearest } \\
\text { road }\end{array}$ & 0.17 & 0.25 & $\ldots$ & $\ldots$ & -0.08 & 0.13 & 0.28 & 0.12 & $\ldots$ & $\ldots$ & 0.12 & -0.24 & $\ldots$ & $\ldots$ & 0.20 & 0.10 & 0.16 & 0.16 \\
\hline $\begin{array}{l}\text { Travel time } \\
\text { to district } \\
\text { headquarter }\end{array}$ & $\ldots$ & $\ldots$ & 0.37 & 0.14 & $\ldots$ & $\ldots$ & $\ldots$ & $\ldots$ & -0.07 & 0.28 & $\ldots$ & $\ldots$ & 0.06 & -0.04 & $\ldots$ & $\ldots$ & $\ldots$ & $\ldots$ \\
\hline Slope & 0.86 & 0.18 & 0.72 & 0.23 & -0.09 & 0.01 & 0.70 & 0.01 & 0.24 & 0.14 & 0.56 & 0.15 & -0.1 & -0.00 & 0.85 & -0.03 & 0.89 & 0.17 \\
\hline Altitude & 0.82 & 0.23 & 0.85 & 0.30 & -0.01 & 0.01 & 0.63 & 0.20 & 0.35 & 0.25 & 0.68 & 0.15 & -0.23 & -0.18 & 0.88 & 0.16 & 0.77 & 0.11 \\
\hline $\begin{array}{l}\text { Moisture } \\
\text { gradient }\end{array}$ & -0.41 & 0.04 & -0.55 & -0.06 & 0.5 & 0.12 & -0.53 & 0.16 & 0.24 & 0.12 & -0.38 & 0.02 & 0.24 & 0.03 & -0.23 & 0.24 & -0.56 & $\begin{array}{l}- \\
0.03\end{array}$ \\
\hline $\begin{array}{l}\text { Broadleaved } \\
\text {-conifer } \\
\text { gradient }\end{array}$ & 0.54 & 0.19 & $\ldots$ & $\ldots$ & -0.23 & -0.02 & $\ldots$ & $\ldots$ & 0.15 & 0.11 & $\ldots$ & $\ldots$ & -0.21 & -0.06 & 0.51 & -0.03 & 0.56 & 0.25 \\
\hline Sal & -0.42 & 0.05 & -0.14 & -0.13 & $\ldots$ & $\ldots$ & -0.43 & 0.00 & -0.09 & 0.11 & -0.20 & -0.04 & 0.22 & 0.21 & -0.39 & -0.05 & -0.43 & -0.02 \\
\hline Soil erosion & -0.07 & 0.03 & 0.09 & 0.09 & $\ldots$ & $\ldots$ & -0.03 & 0.06 & -0.34 & 0.04 & -0.15 & 0.11 & -0.20 & 0.11 & 0.26 & 0.03 & -0.32 & 0.09 \\
\hline NDVI 1990 & -0.32 & -0.09 & -0.25 & -0.18 & 0.14 & 0.04 & -0.27 & -0.03 & -0.14 & -0.12 & -0.12 & 0.03 & 0.11 & 0.04 & -0.37 & -0.09 & -0.27 & -0.14 \\
\hline
\end{tabular}




\begin{tabular}{|c|c|c|c|c|c|c|c|c|c|c|c|c|c|c|c|c|c|c|}
\hline \multirow[t]{2}{*}{ Covariates } & \multicolumn{2}{|c|}{$\begin{array}{l}\text { Overall } \\
\text { forest }\end{array}$} & \multicolumn{2}{|c|}{$\begin{array}{l}\text { Lower } \\
\text { altitude }\end{array}$} & \multicolumn{2}{|c|}{$\begin{array}{l}\text { Higher } \\
\text { altitude }\end{array}$} & \multicolumn{2}{|c|}{ Lower slope } & \multicolumn{2}{|c|}{$\begin{array}{l}\text { Higher } \\
\text { slope }\end{array}$} & \multicolumn{2}{|c|}{ Terai } & \multicolumn{2}{|l|}{ Hill } & \multicolumn{2}{|c|}{$\begin{array}{l}\text { Open } \\
\text { canopy }\end{array}$} & \multicolumn{2}{|c|}{$\begin{array}{l}\text { Closed } \\
\text { canopy }\end{array}$} \\
\hline & $\begin{array}{l}\text { BM } \\
\text { SD } \\
\text { M }\end{array}$ & $\begin{array}{l}\text { AM } \\
\text { SD } \\
\text { M }\end{array}$ & $\begin{array}{l}\text { BM } \\
\text { SDM }\end{array}$ & $\begin{array}{l}\mathbf{A M} \\
\mathbf{S D} \\
\mathbf{M}\end{array}$ & $\begin{array}{l}\text { BM } \\
\text { SD } \\
\text { M }\end{array}$ & $\begin{array}{l}\mathbf{A M} \\
\mathbf{S D} \\
\mathbf{M}\end{array}$ & $\begin{array}{l}\text { BM } \\
\text { SD } \\
\text { M }\end{array}$ & $\begin{array}{l}\mathbf{A M} \\
\mathbf{S D} \\
\mathbf{M}\end{array}$ & $\begin{array}{l}\text { BM } \\
\text { SD } \\
\text { M }\end{array}$ & $\begin{array}{l}\text { AM } \\
\text { SD } \\
\text { M }\end{array}$ & $\begin{array}{l}\text { BM } \\
\text { SD } \\
\text { M }\end{array}$ & $\begin{array}{l}\text { AM } \\
\text { SD } \\
\text { M }\end{array}$ & $\begin{array}{l}\text { BM } \\
\text { SD } \\
\text { M }\end{array}$ & $\begin{array}{l}\text { AM } \\
\text { SD } \\
\text { M }\end{array}$ & $\begin{array}{l}\text { BM } \\
\text { SD } \\
\text { M }\end{array}$ & $\begin{array}{l}\mathbf{A M} \\
\mathbf{S D} \\
\mathbf{M}\end{array}$ & $\begin{array}{l}\text { BM } \\
\text { SDM }\end{array}$ & $\begin{array}{l}\mathbf{A M} \\
\text { SD } \\
\mathbf{M}\end{array}$ \\
\hline $\begin{array}{l}\text { Community } \\
\text { conserving } \\
\text { forest }\end{array}$ & 0.92 & 0.02 & 0.54 & 0.18 & $\ldots$ & $\ldots$ & 0.65 & 0.25 & 1.01 & 0.48 & 0.58 & 0.25 & $\ldots$ & $\ldots$ & $\ldots$ & $\ldots$ & $\ldots$ & $\ldots$ \\
\hline $\begin{array}{l}\text { Forest users } \\
\text { households }\end{array}$ & 0.01 & 0.10 & 0.10 & 0.14 & $\ldots$ & $\ldots$ & 0.18 & 0.25 & 0.34 & 0.07 & 0.17 & 0.20 & $\ldots$ & $\ldots$ & $\ldots$ & $\ldots$ & 0.03 & 0.14 \\
\hline $\begin{array}{l}\text { Ancestral } \\
\text { home }\end{array}$ & 0.60 & 0.11 & 0.27 & -0.11 & 0.65 & 0.12 & 0.30 & -0.04 & 0.15 & 0.08 & 0.32 & -0.08 & 0.01 & 0.08 & 0.76 & -0.10 & 0.48 & 0.15 \\
\hline $\begin{array}{l}\text { Ethnic } \\
\text { population }\end{array}$ & 0.13 & 0.10 & 0.38 & -0.03 & -0.28 & -0.05 & 0.23 & -0.01 & -0.01 & 0.10 & 0.35 & 0.14 & $\ldots$ & $\ldots$ & 0.19 & 0.02 & 0.06 & 0.02 \\
\hline $\begin{array}{l}\text { Poor } \\
\text { population }\end{array}$ & -0.05 & 0.06 & -0.01 & 0.05 & -0.39 & 0.22 & $\ldots$ & $\ldots$ & -0.02 & 0.23 & -0.57 & -0.11 & 0.09 & 0.04 & -0.25 & 0.02 & 0.11 & 0.23 \\
\hline
\end{tabular}


Appendix B. Covariate wise before and after matching standardized difference of mean

\begin{tabular}{|c|c|c|c|c|c|c|c|c|c|c|c|c|c|c|}
\hline \multirow[t]{2}{*}{ Covariates } & \multicolumn{2}{|c|}{ Overall } & \multicolumn{2}{|l|}{ Poor } & \multicolumn{2}{|l|}{ Dalit } & \multicolumn{2}{|c|}{$\begin{array}{l}\text { Indigenous } \\
\text { peoples }\end{array}$} & \multicolumn{2}{|c|}{$\begin{array}{l}\text { Women- } \\
\text { headed } \\
\text { household }\end{array}$} & \multicolumn{2}{|l|}{ Hill } & \multicolumn{2}{|l|}{ Terai } \\
\hline & $\begin{array}{l}\text { BM } \\
\text { SDM }\end{array}$ & $\begin{array}{l}\text { AM } \\
\text { SDM }\end{array}$ & $\begin{array}{l}\text { BM } \\
\text { SDM }\end{array}$ & $\begin{array}{l}\text { AM } \\
\text { SDM }\end{array}$ & $\begin{array}{l}\text { BM } \\
\text { SDM }\end{array}$ & $\begin{array}{l}\text { AM } \\
\text { SDM }\end{array}$ & $\begin{array}{l}\text { BM } \\
\text { SDM }\end{array}$ & $\begin{array}{l}\text { AM } \\
\text { SDM }\end{array}$ & $\begin{array}{l}\text { BM } \\
\text { SDM }\end{array}$ & $\begin{array}{l}\text { AM } \\
\text { SDM }\end{array}$ & $\begin{array}{l}\text { BM } \\
\text { SDM }\end{array}$ & $\begin{array}{l}\text { AM } \\
\text { SDM }\end{array}$ & $\begin{array}{l}\text { BM } \\
\text { SDM }\end{array}$ & $\begin{array}{l}\text { AM } \\
\text { SDM }\end{array}$ \\
\hline Forest size & 0.25 & 0.17 & 0.09 & 0.15 & -0.17 & 0.13 & 0.34 & 0.15 & 0.48 & 0.19 & $\ldots$ & $\ldots$ & 0.50 & 0.17 \\
\hline $\begin{array}{l}\text { Forest users } \\
\text { households }\end{array}$ & -0.00 & 0.09 & 0.03 & 0.11 & -0.68 & 0.20 & 0.05 & 0.12 & 0.04 & 0.06 & 0.57 & 0.11 & 0.14 & 0.10 \\
\hline $\begin{array}{l}\text { Travel time to } \\
\text { nearest road }\end{array}$ & 0.14 & 0.23 & 0.06 & 0.31 & 0.21 & 0.20 & 0.01 & 0.17 & 0.10 & 0.26 & -0.09 & 0.19 & 0.22 & 0.25 \\
\hline Altitude & 0.88 & 0.14 & 0.86 & 0.12 & 1.42 & -0.00 & 0.57 & 0.24 & 1.00 & 0.20 & 0.07 & 0.05 & 0.72 & 0.24 \\
\hline Slope & 1.01 & 0.17 & 1.09 & 0.21 & 1.72 & -0.13 & 0.83 & 0.24 & 1.15 & 0.08 & 0.01 & 0.07 & 0.74 & 0.21 \\
\hline $\begin{array}{l}\text { Community } \\
\text { conserving forest }\end{array}$ & 0.48 & 0.04 & 0.42 & 0.11 & $\ldots$ & $\ldots$ & 0.61 & 0.06 & 0.78 & 0.17 & 0.60 & -0.03 & 0.26 & 0.04 \\
\hline Moisture gradient & -0.53 & 0.05 & -0.45 & 0.20 & $\ldots$ & $\ldots$ & -0.41 & 0.11 & -0.62 & 0.09 & 0.28 & 0.13 & -0.61 & 0.02 \\
\hline $\begin{array}{l}\text { Broadleaved- } \\
\text { conifer gradient }\end{array}$ & 0.48 & 0.05 & 0.43 & 0.16 & 0.73 & 0.19 & 0.29 & 0.03 & 0.41 & 0.15 & -0.08 & 0.00 & $\ldots$ & $\ldots$ \\
\hline Sal & -0.53 & -0.07 & -0.56 & -0.14 & -0.80 & 0.17 & -0.34 & -0.01 & -0.59 & -0.02 & -0.03 & 0.04 & -0.24 & -0.26 \\
\hline Soil erosion & -0.10 & 0.05 & 0.07 & 0.04 & 0.38 & -0.18 & -0.15 & -0.14 & -0.07 & -0.05 & -0.24 & 0.09 & -0.13 & 0.19 \\
\hline NDVI 1989 & -0.29 & -0.24 & -0.22 & -0.22 & -0.63 & -0.25 & -0.20 & 0.12 & -0.22 & -0.14 & 0.04 & -0.21 & -0.18 & -0.22 \\
\hline $\begin{array}{l}\text { Proportion of } \\
\text { ancestral house }\end{array}$ & 0.77 & 0.06 & 0.84 & 0.09 & 1.46 & 0.07 & 0.51 & 0.18 & 0.78 & 0.02 & 0.21 & -0.01 & 0.58 & 0.16 \\
\hline $\begin{array}{l}\text { Proportion of } \\
\text { ethnic population }\end{array}$ & 0.14 & 0.09 & 0.19 & 0.16 & 0.00 & 0.03 & 0.30 & 0.22 & 0.18 & 0.05 & 0.12 & 0.14 & 0.29 & 0.08 \\
\hline $\begin{array}{l}\text { Proportion of } \\
\text { poor population }\end{array}$ & 0.05 & 0.12 & $\ldots$ & $\ldots$ & -0.16 & 0.09 & -0.03 & 0.20 & -0.10 & 0.23 & 0.28 & 0.22 & -0.56 & 0.04 \\
\hline
\end{tabular}


Appendix C. Exploratory regression of independent variables.

Variables in the top row were considered as dependent (Y) and in the first column as independent (X). Coefficient (p- values) are reported.

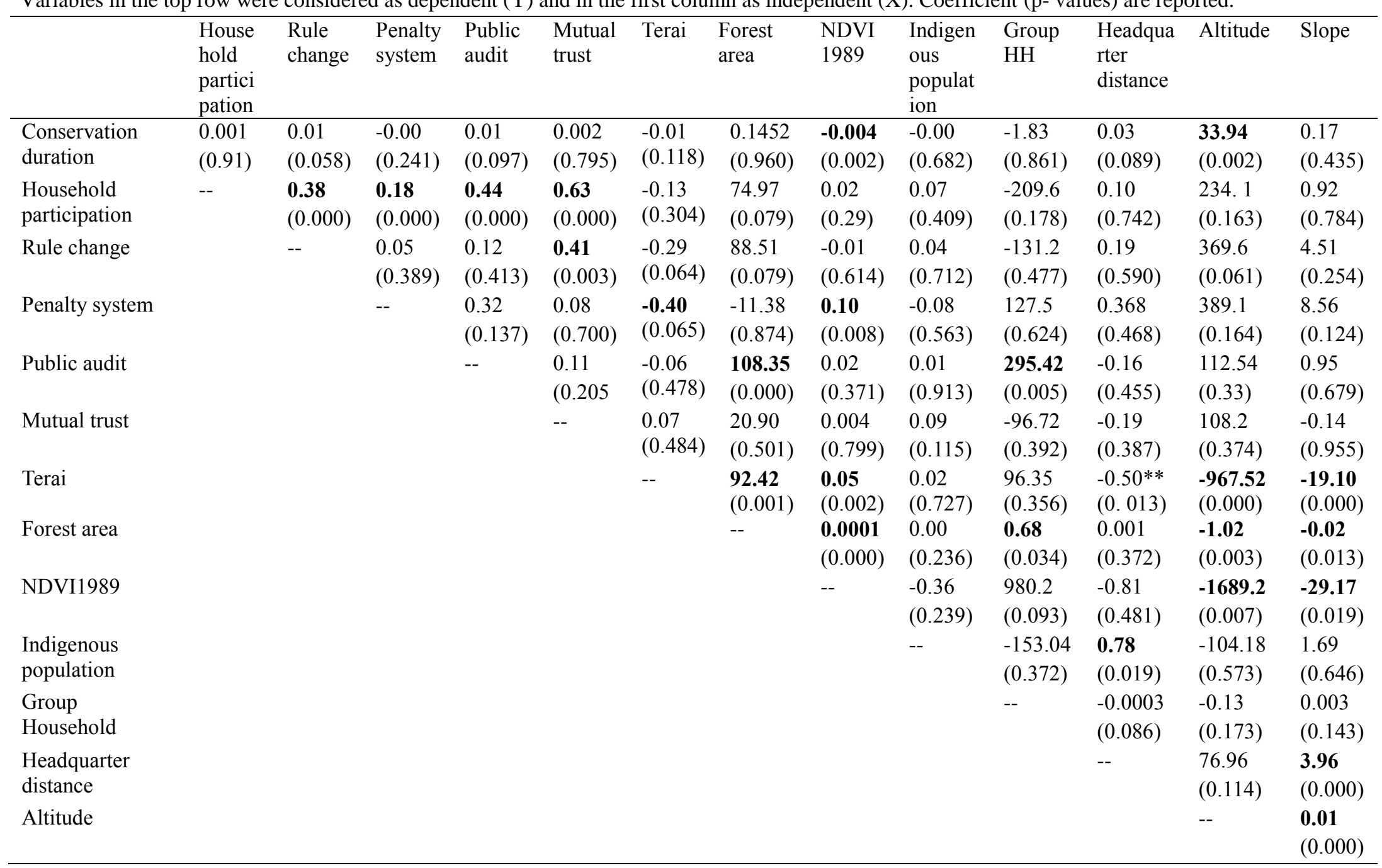

